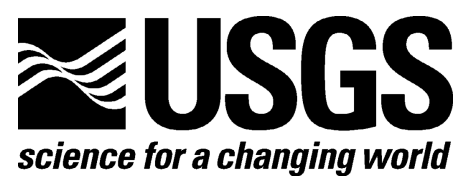

WOVOdat Design Document: The Schema, Table Descriptions, and Create Table Statements for the Database of Worldwide Volcanic Unrest (WOVOdat Version 1.0)

By Dina Y. Venezky and Christopher G. Newhall

2007

Open File Report 2007-1117

U.S. Department of the Interior

U.S. Geological Survey 


\section{U.S. Department of the Interior DIRK KEMPTHORNE, Secretary}

\section{U.S. Geological Survey \\ Mark D. Myers, Director}

U.S. Geological Survey, Reston, Virginia: 2007

For product and ordering information:

World Wide Web: http://www.usgs.gov/pubprod

Telephone: 1-888-ASK-USGS

For more information on the USGS - the Federal source for science about the Earth, its natural and living resources, natural hazards, and the environment:

World Wide Web: http://www.usgs.gov

Telephone: 1-888-ASK-USGS

Suggested citation

Venezky, D. Y, and Newhall, C.G., 2007, WOVOdat design document; the schema, table descriptions, and create table statements for the database of w orldwide volcanic unrest (WOVOdat Version 1.0): U.S. Geological Survey Open File Report 2007-1117, 184 p. [http://pubs.usgs.gov/of/2007/1117/].

Any use of trade, product, or firm names is for descriptive purposes only and does not imply endorsement by the U.S. Government.

Although this report is in the public domain, permission must be secured from the individual copyright owners to reproduce any copyrighted material contained within this report. 


\section{Contents}

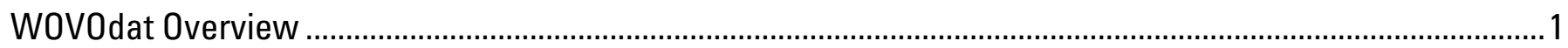

WOVOdat Framework

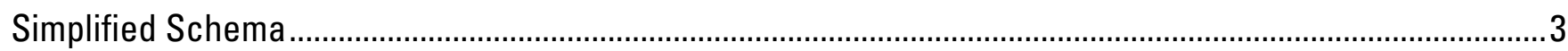

Prototype Hardware and Software .......................................................................................................

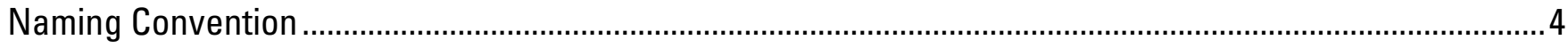

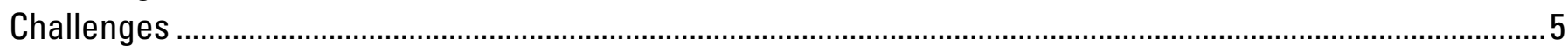

Time

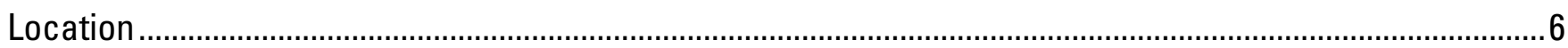

Data Collection from Permanent and Non-Permanent Instruments................................................................6

Data Ownership and Availability............................................................................................................

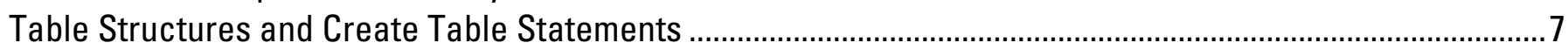

Volcano

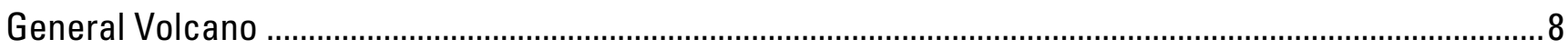

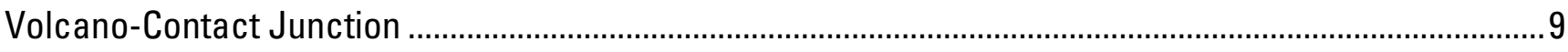

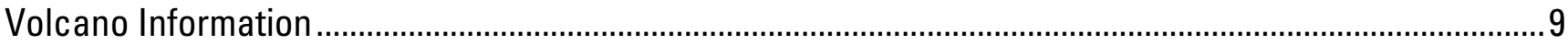

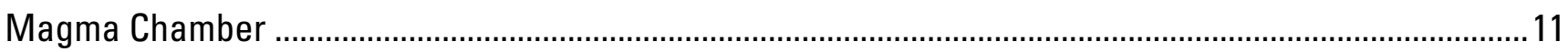

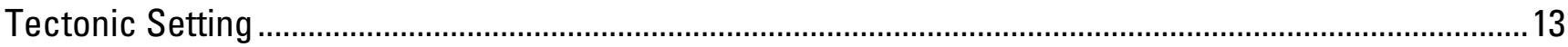

Create table statements for Volcano tables........................................................................................... 14

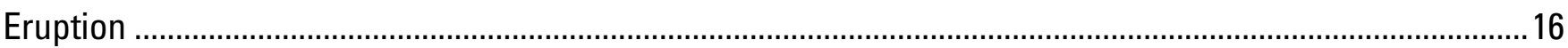

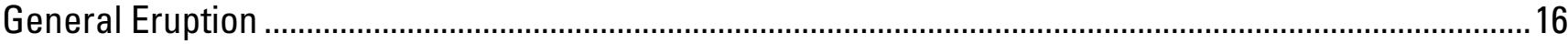

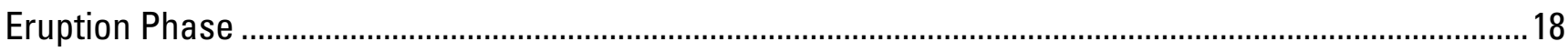

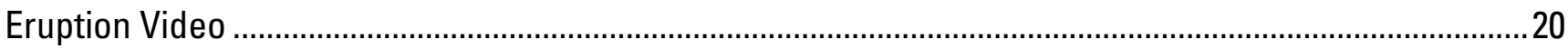

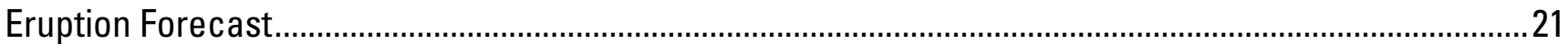

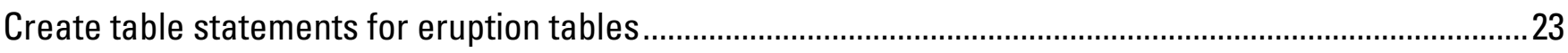

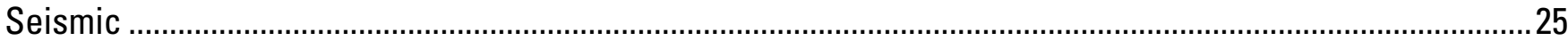

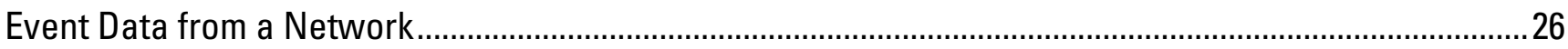

Event Data from a Single Station ...........................................................................................................

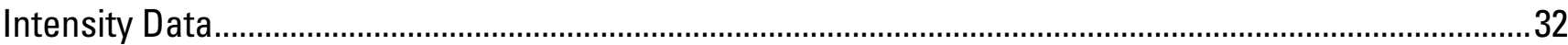

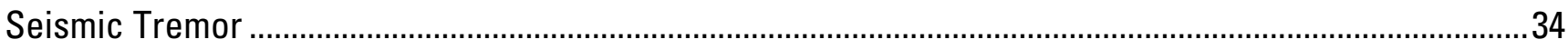

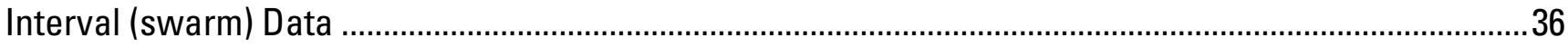

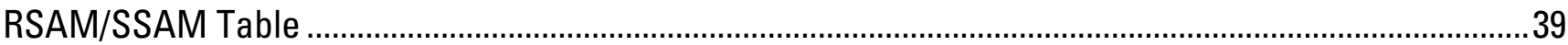

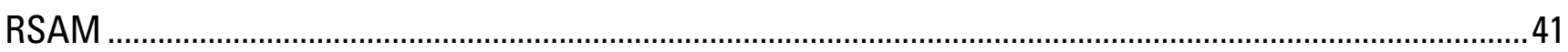

SSAM

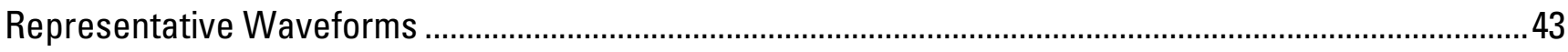

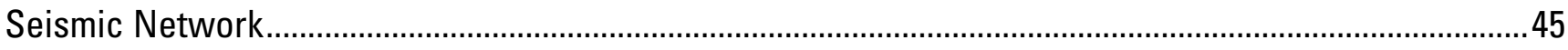

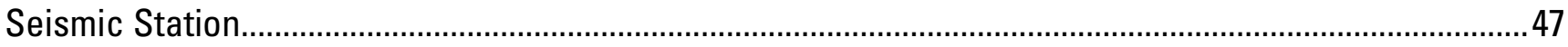

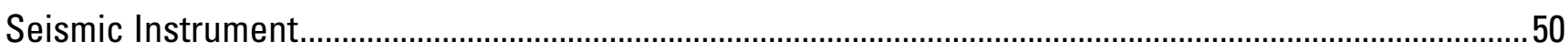

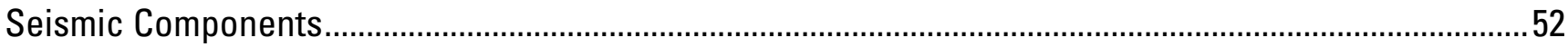

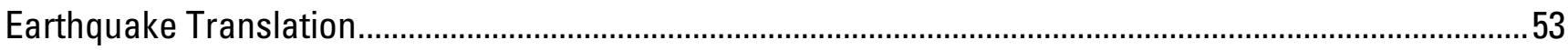

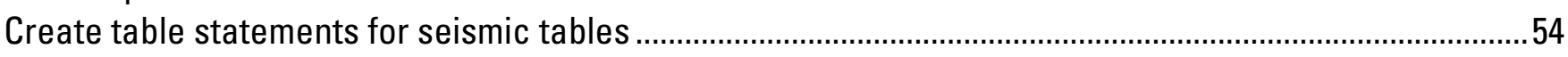

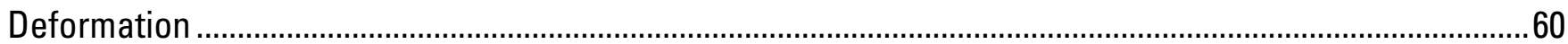




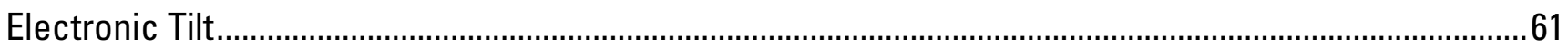

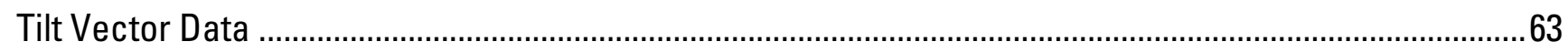

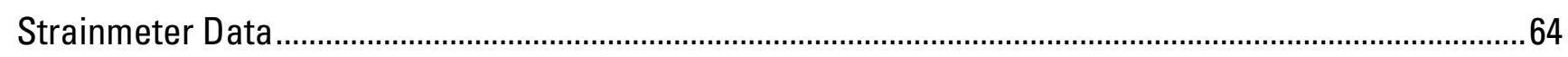

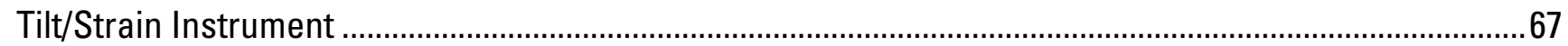

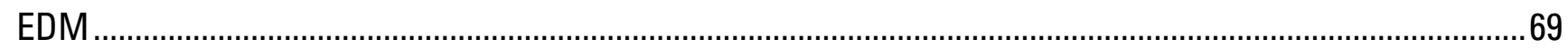

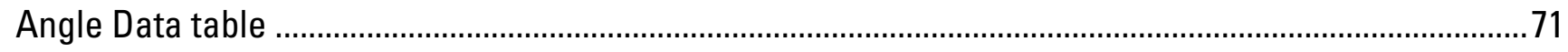

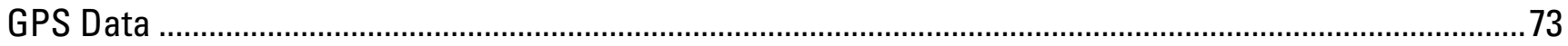

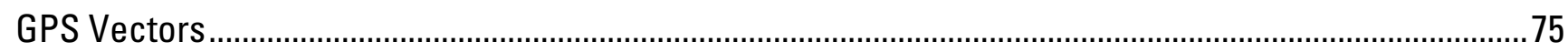

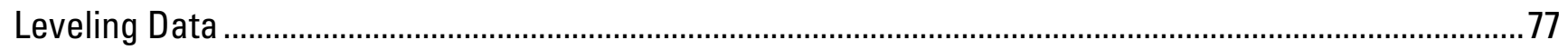

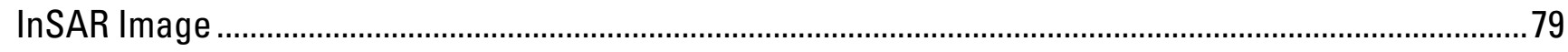

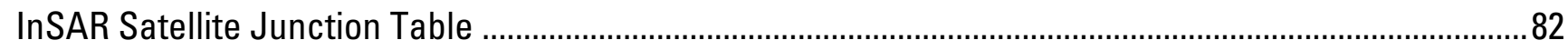

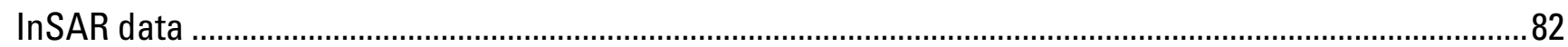

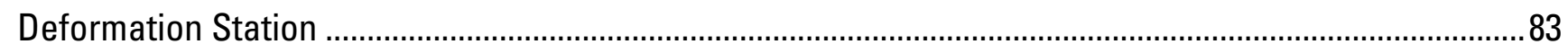

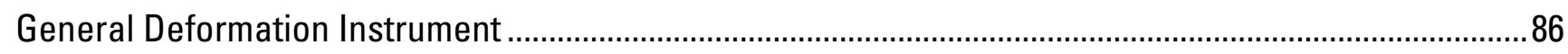

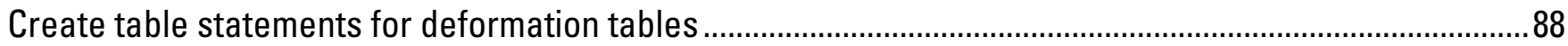

Gas

Directly Sampled Gas ........................................................................................................................... 94

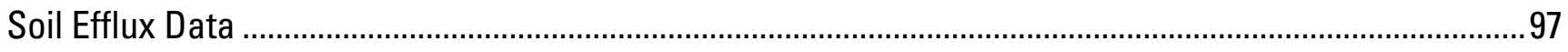

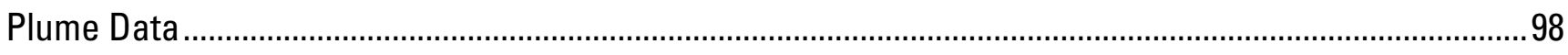

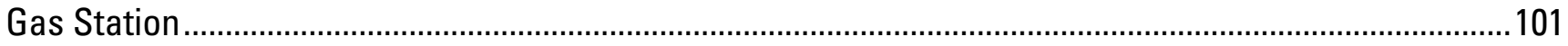

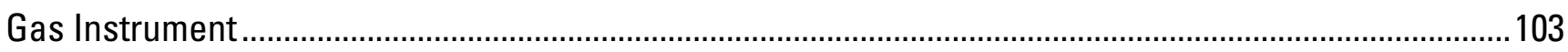

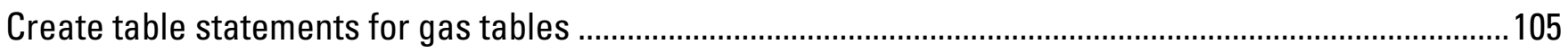

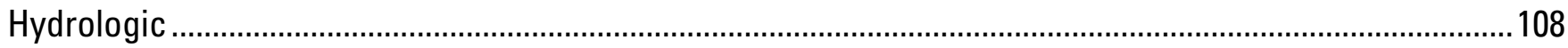

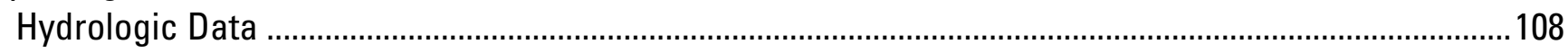

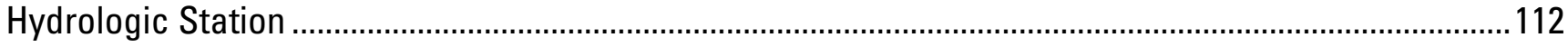

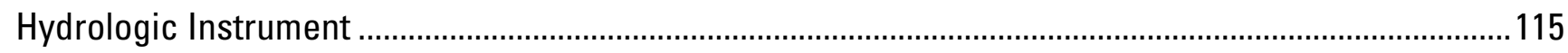

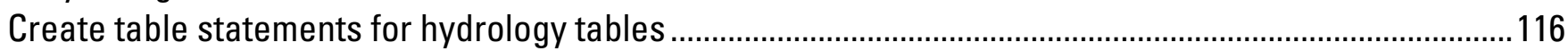

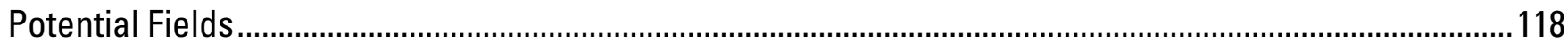

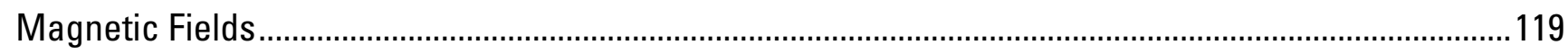

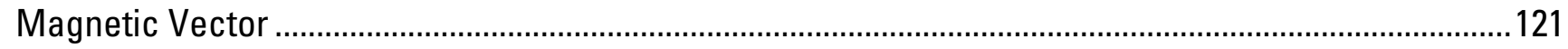

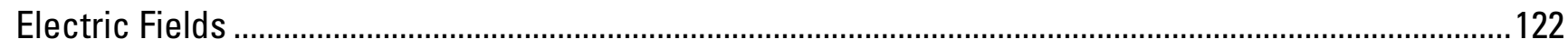

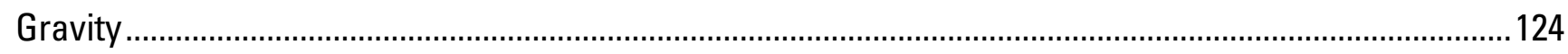

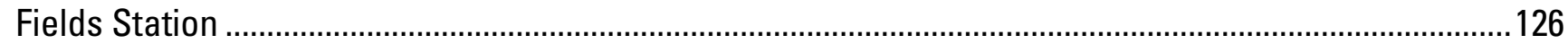

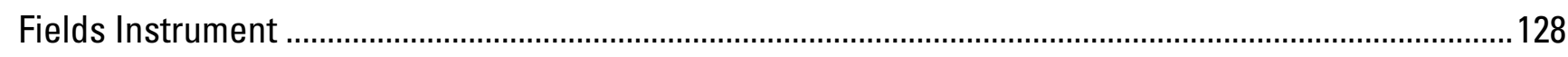

Create Table Statements for potential fields tables ........................................................................... 130

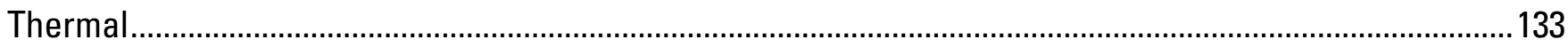

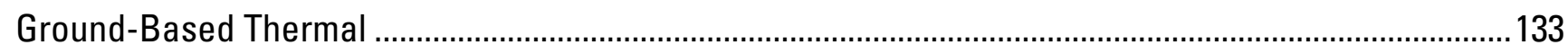

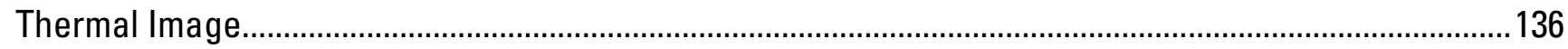

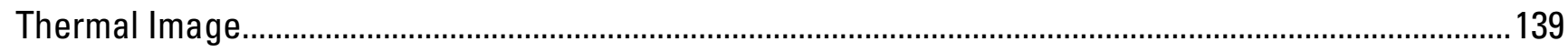

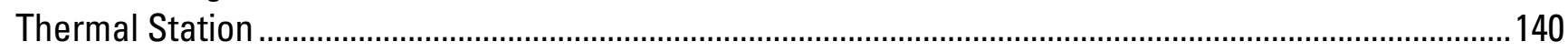

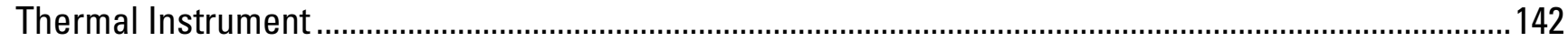

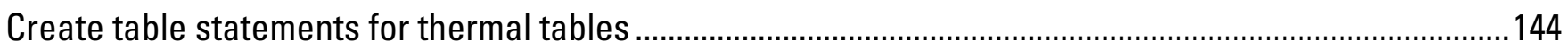

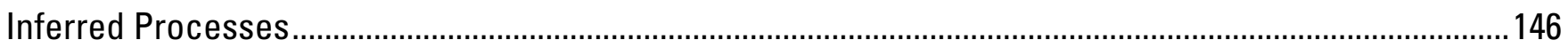




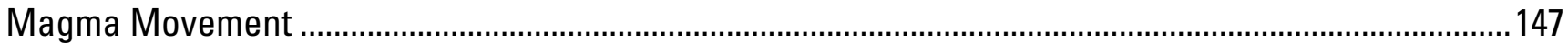

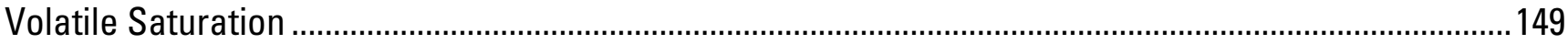

Buildup of Magma Pressure ............................................................................................................ 151

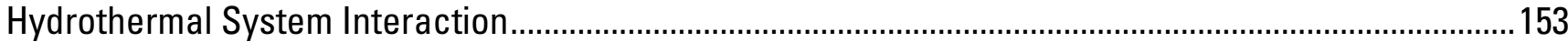

Regional Tectonics Interactions .................................................................................................... 155

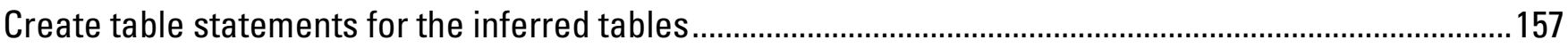

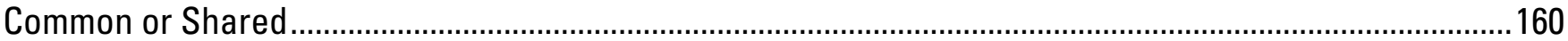

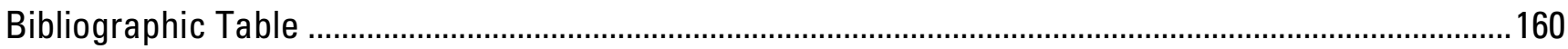

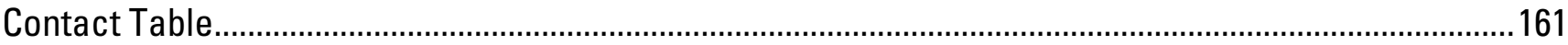

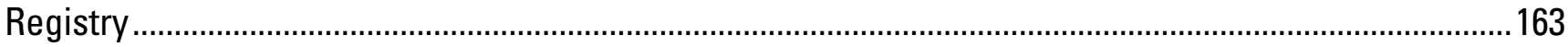

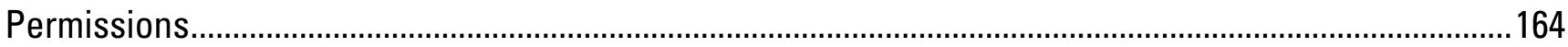

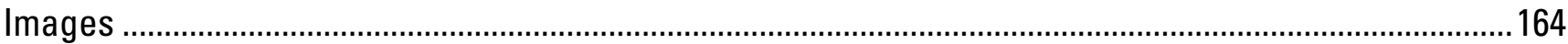

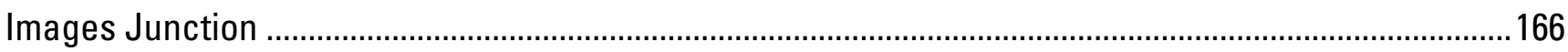

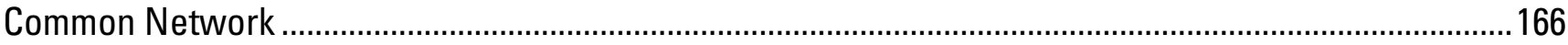

Satellite Table

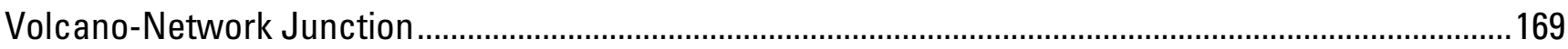

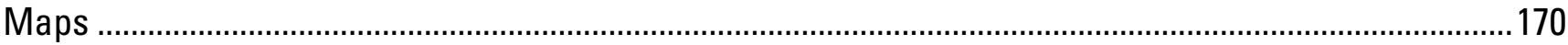

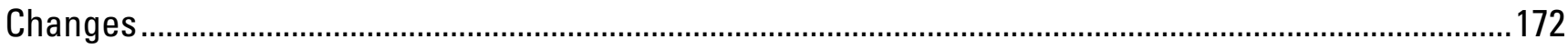

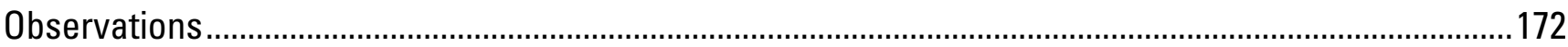

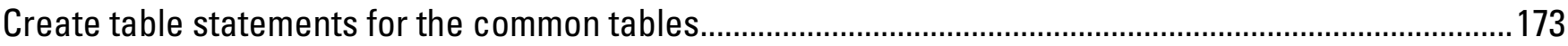

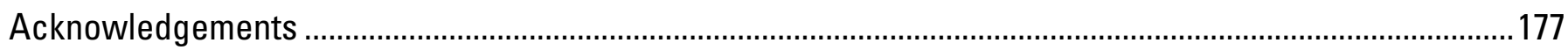

Comments and Conclusions ...................................................................................................................... 177

\section{Figure}

Figure 1. Simplified WOVOdat Schema .......................................................................................................

\section{Tables}

Table N1. The WOVOdat naming convention............................................................................................

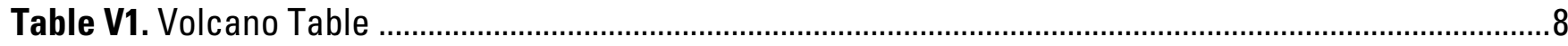

Table V2. Volcano-Contact Junction Table .......................................................................................

Table V3. Volcano Information Table .................................................................................................

Table V4. Magma Chamber Table .....................................................................................................11

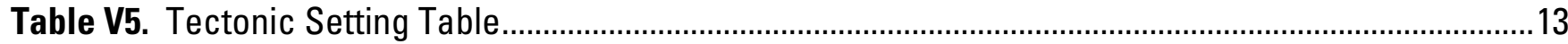

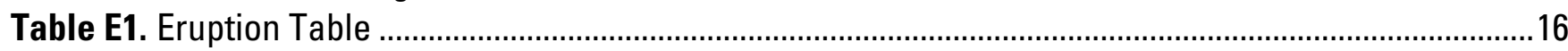

Table E2. Eruption Phase Table .......................................................................................................18

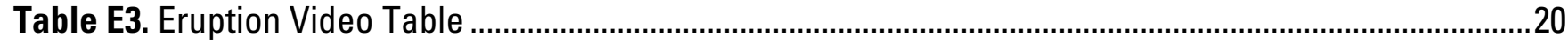

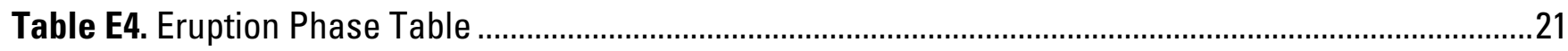

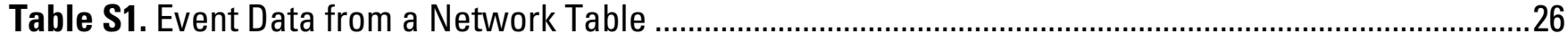

Table S2. Event Data from a Single Station Table …………......................................................................

Table S3. Intensity Date Table ...........................................................................................................

Table S4. Seismic Tremor Table ............................................................................................................ 


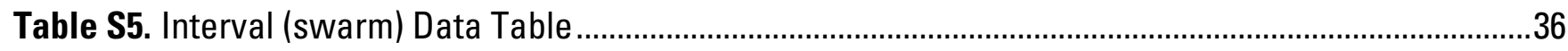

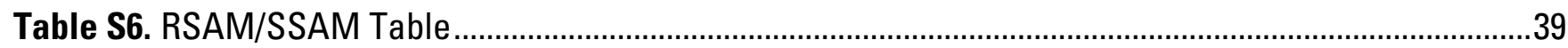

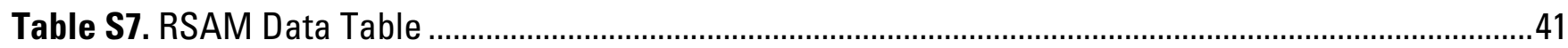

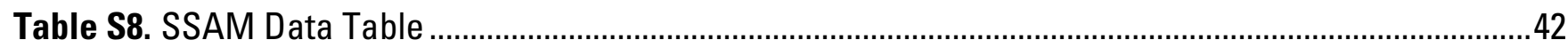

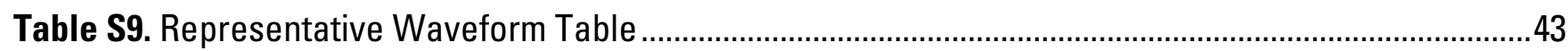

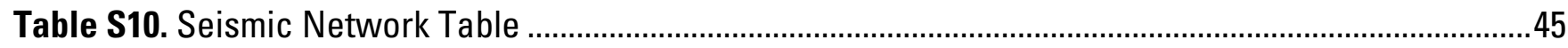

Table S11. Seismic Station Table .......................................................................................................

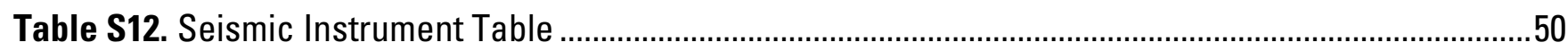

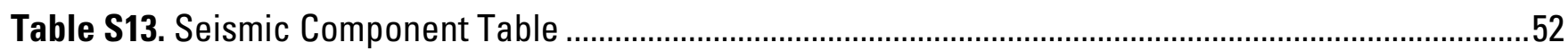

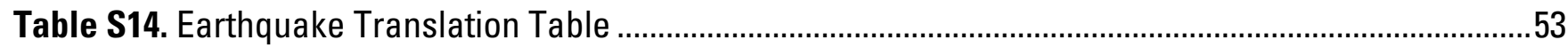

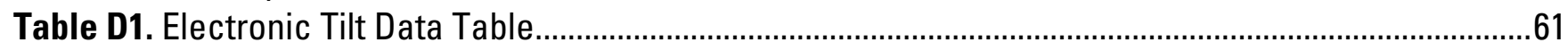

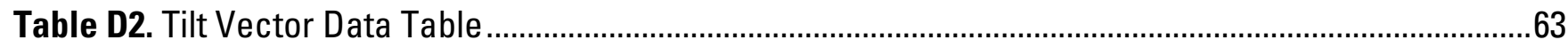

Table D4. Tilt/Strain Instrument Table ..................................................................................................67

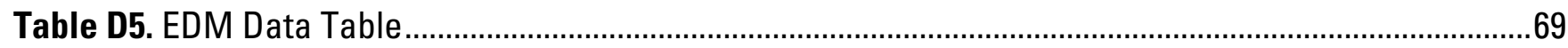

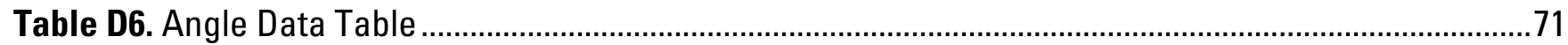

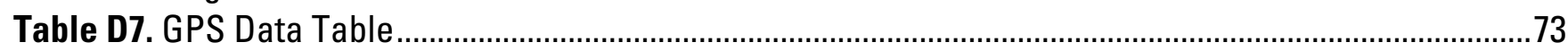

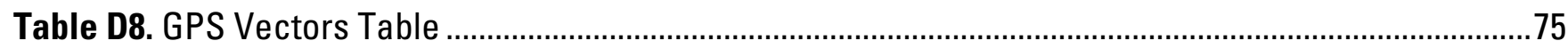

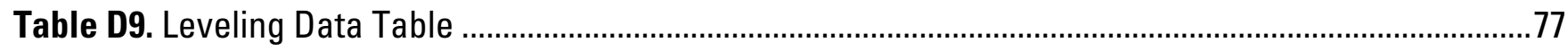

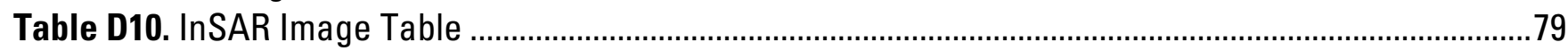

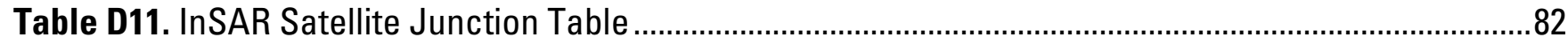

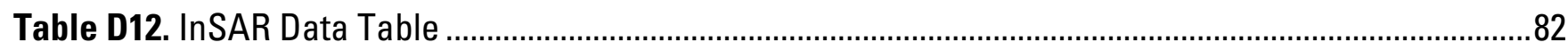

Table D13. Deformation Station Table ...................................................................................................

Table D14. General Deformation Instrument Table ................................................................................... 86

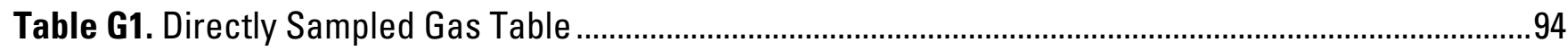

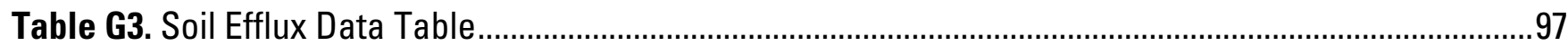

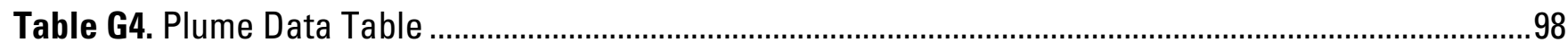

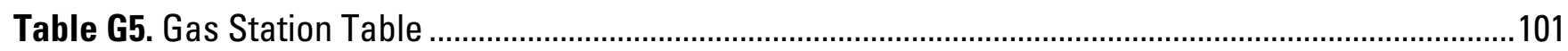

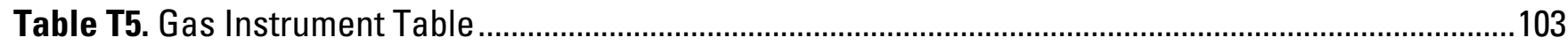

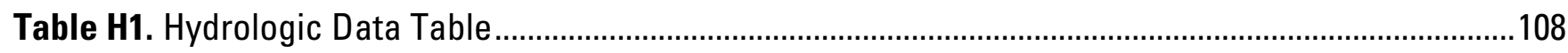

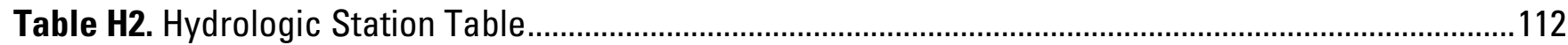

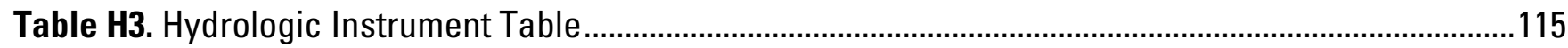

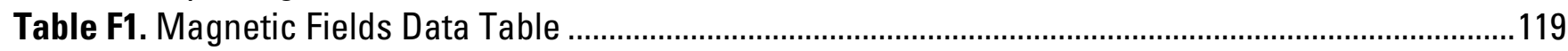

Table F2. Magnetic Vector Data Table .............................................................................................121

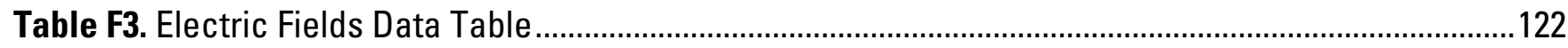

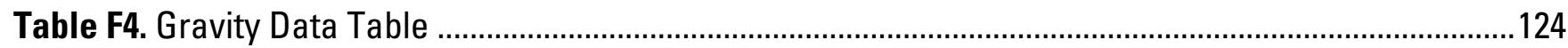

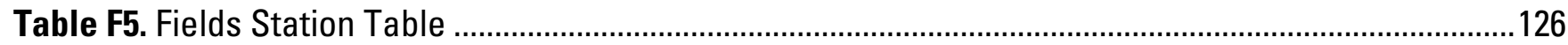

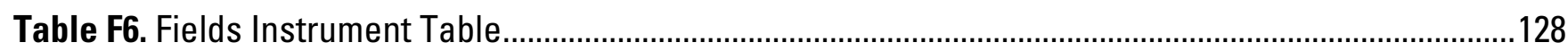

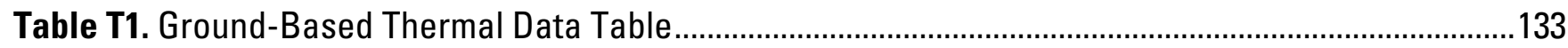

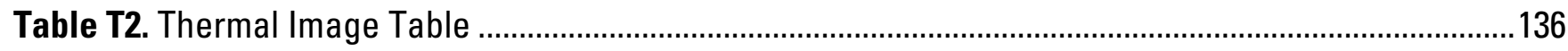

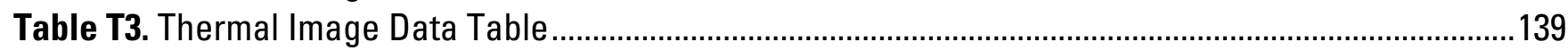

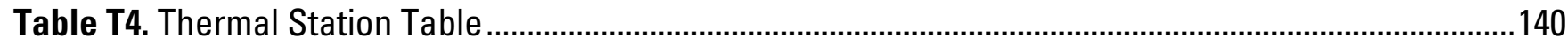

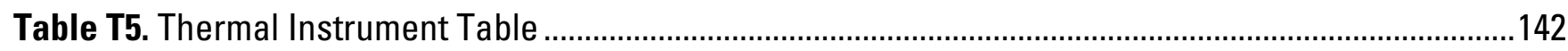

Table IP1. Magma Movement Table ...................................................................................................... 147 


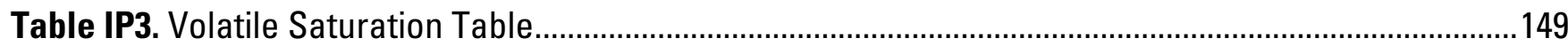

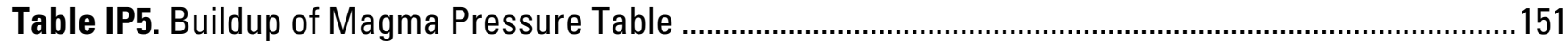

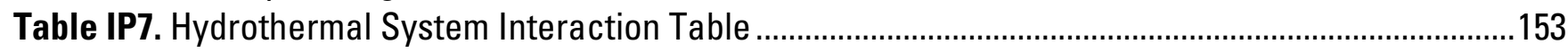

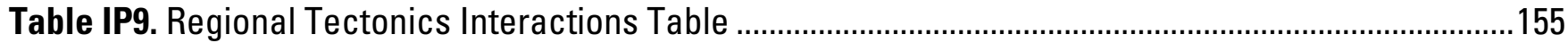

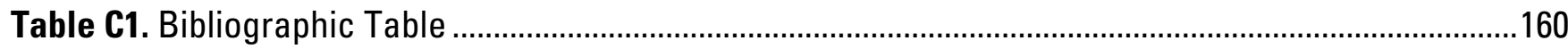

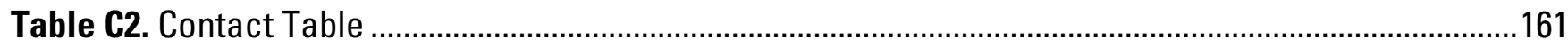

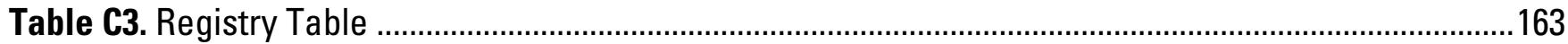

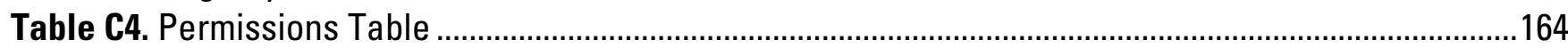

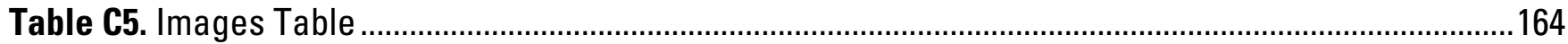

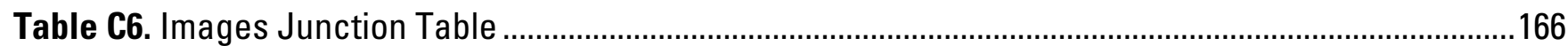

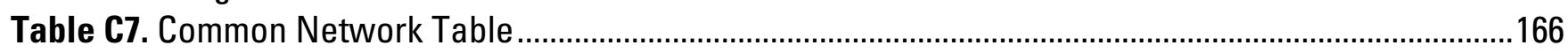

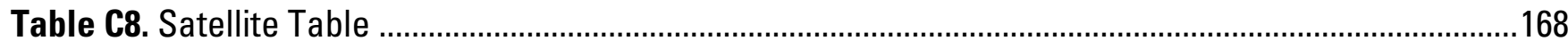

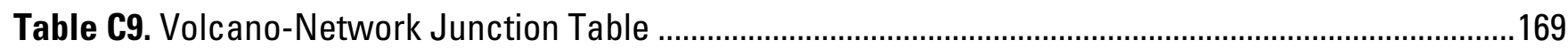

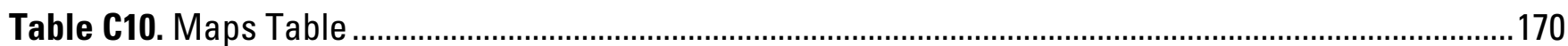

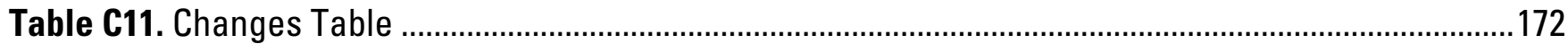

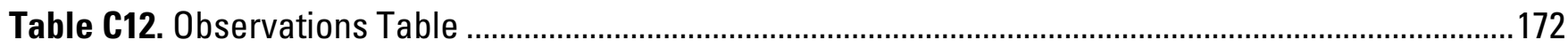




\title{
WOVOdat Design Document: The Schema, Table Descriptions, and Create Table Statements for the Database of Worldwide Volcanic Unrest (WOVOdat Version 1.0)
}

\author{
By Dina Y. Venezky' and Christopher G. Newhall
}

\section{WOVOdat Overview}

During periods of volcanic unrest, the ability to forecast near future activity has been a primary concern for human populations living near volcanoes. Our ability to forecast future activity and mitigate hazards is based on knowledge of previous activity at the volcano exhibiting unrest and knowledge of previous activity at similar volcanoes. A small set of experts with past experience are often involved in forecasting. We need to both preserve the knowledge the experts use and continue to investigate volcanic data to make better forecasts. Advances in instrumentation, networking, and data storage technologies have greatly increased our ability to collect volcanic data and share observations with our colleagues. The wealth of data creates numerous opportunities for gaining a better understanding of magmatic conditions and processes, if the data can be easily accessed for comparison. To allow for comparison of volcanic unrest data, we are creating a central database called WOVOdat. WOVOdat will contain a subset of time-series and geo-referenced data from each WOVO observatory in common and easily accessible formats.

WOVOdat is being created for volcano experts in charge of forecasting volcanic activity, scientists investigating volcanic processes, and the public. The types of queries each of these groups might ask range from, "What volcanoes were active in November of 2002?" and "What are the relationships between tectonic earthquakes and volcanic processes?" to complex analyses of volcanic unrest to determine what future activity might occur.

A new structure for storing and accessing our data was needed to examine processes across a wide range of volcanologic conditions. WOVOdat provides this new structure using relationships to connect the data parameters such that searches can be created for analogs of unrest. The subset of data that will fill WOVOdat will continue to be collected by the observatories, who will remain the primary archives of raw and detailed data on individual episodes of unrest. MySQL, an Open Source database, was chosen as the WOVOdat database for its integration with common web languages.

The question of where the data will be stored and how the disparate data sets will be integrated will not be discussed in detail here. The focus of this document is to explain the data types, formats, and table organization chosen for WOVOdat 1.0. It was written for database administrators, data loaders,

\footnotetext{
${ }^{1}$ Menlo Park, Calif.

${ }^{2}$ Albay, Philippines. (Emeritus)
} 
query writers, and anyone who monitors volcanoes. We begin with an overview of several challenges faced and solutions used in creating the WOVOdat schema. Specifics are then given for the parameters and table organization. After each table organization section, basic create table statements are included for viewing the database field formats.

In the next stage of the project, scripts will be needed for data conversion, entry, and cleansing. Views will also need to be created once the data have been loaded and the basic queries are better known. Many questions and opportunities remain. We look forward to the growth and continual improvement in efficiency of the system. We hope WOVOdat will improve our understanding of magmatic systems and help mitigate future volcanic hazards.

\section{WOVOdat Framework}

A relational database was chosen as the model for storing and accessing the large amounts of data of volcanic unrest. A relational database is a collection of tables that are related by common fields. Each table contains a collection of records, which can be thought of as rows. The records contain fields or attributes, which can be thought of as columns. Each table contains a unique key, called the primary ID, for linking with other tables. If the primary ID of table A is placed in table B then table B would contain its own primary ID plus the primary ID from A. The primary ID from table A is referred to as a foreign key or foreign ID when found in other tables. Whether the primary ID from table A is placed into table $\mathrm{B}$ or the primary ID from table $\mathrm{B}$ is placed in table $\mathrm{A}$ is a function of the types of relationships the data have to each other.

There are three relationships between data; one-to-one (1:1), one-to-many $(1: \mathrm{m})$, and many-to-many (m:n). In a one-to-one relationship, only one instance exists in table B for each instance of table A and vice-versa. For example, each U.S. scientist in table A is associated with one Social Security Number (SSN) in table B and each SSN in table B is associated with one scientist in table A. In a one-to-many relationship, there are multiple instances of table B for each instance of table A but for each instance of table B, only one instance of table A exists. For example, a volcano can have multiple installed instruments on it. When each instrument, in the example, is examined, it is found to be associated with only one volcano. For each instance of table A in a many-to-many relationship, there are multiple instances of table B and for each instance of table B, there are multiple instances of table A. For example, a volcano can be monitored by many non-permanent instruments, such as a thermometer carried into the field. And each non-permanent instrument can be used to monitor multiple volcanoes.

When tables are created for data with one-to-many relationships, the foreign key of the one part of the relationship is placed in the table of the many part of the relationship. For example, a table with installed instruments at a volcano would include the volcano ID as a foreign key to link the instruments back to the volcano. If the instruments were put in the volcano table then multiple attributes would be needed to link all of the instruments. Additionally, new instruments would require new fields in the volcano table. By adding the volcano ID to the instruments table instead, no additional fields are needed if a new instrument is added.

The language used to access data in a relational database is called Structured Query Language (SQL). Using SQL, a query could be written to return all instruments installed at a particular volcano. A join or join operation would be used in the query to connect the data from both tables. The query would select the volcano name and instrument name from the volcano table and instrument table where the volcano ID in the instrument table was equal to the volcano ID in the volcano table and the volcano ID in the volcano table was the ID for the name of the volcano of interest. Queries to search for patterns of volcanic unrest are much more complicated and require a structured database organization or normalization to make them more efficient. The first step towards a structured organization is a logical 
model that represents the entities and their relationships. The logical model can then be normalized to reduce data redundancies, data anomalies, and various inefficiencies that would otherwise increase the number of joins and increase the potential for data errors.

\section{Simplified Schema}

WOVOdat was created by developing a list of common queries for examining patterns of volcanic unrest. A list of parameters was created to cover the types of volcanic unrest data of interest. A logical model was created to give a graphical representation of each set of attributes, primary keys, and foreign keys. The graphical representation of the logical model was presented at the Fall American Geophysical Union meeting in December 2003 to communicate the data requirements and relationships. Tables were created after normalizing the logical model. Additional foreign keys were then added based on expected common queries. As a relational database, links between tables in WOVOdat have been declared, but other links can be made in queries that were not predetermined.

A block diagram of the overall structure is given below. The Volcano table is the center point of the data structure from which all other data can be linked. Monitoring data are generally linked from the data to the station where the data were collected to the network of stations to the volcano. In the cases where the data are collected by satellite, the data is linked to the satellite and then directly to the volcano. Eruption data are linked from the eruption phase to the eruption to the volcano.

Bibliographic information are stored in a bibliographic table along with basic keywords for linking to information from all other tables. The contact information for data collectors, stations, and data loaders is linked directly to the Contact table.

\section{Simplified WOVOdat schema}

Instrument, Bibliographic, and Contact information included for all data.

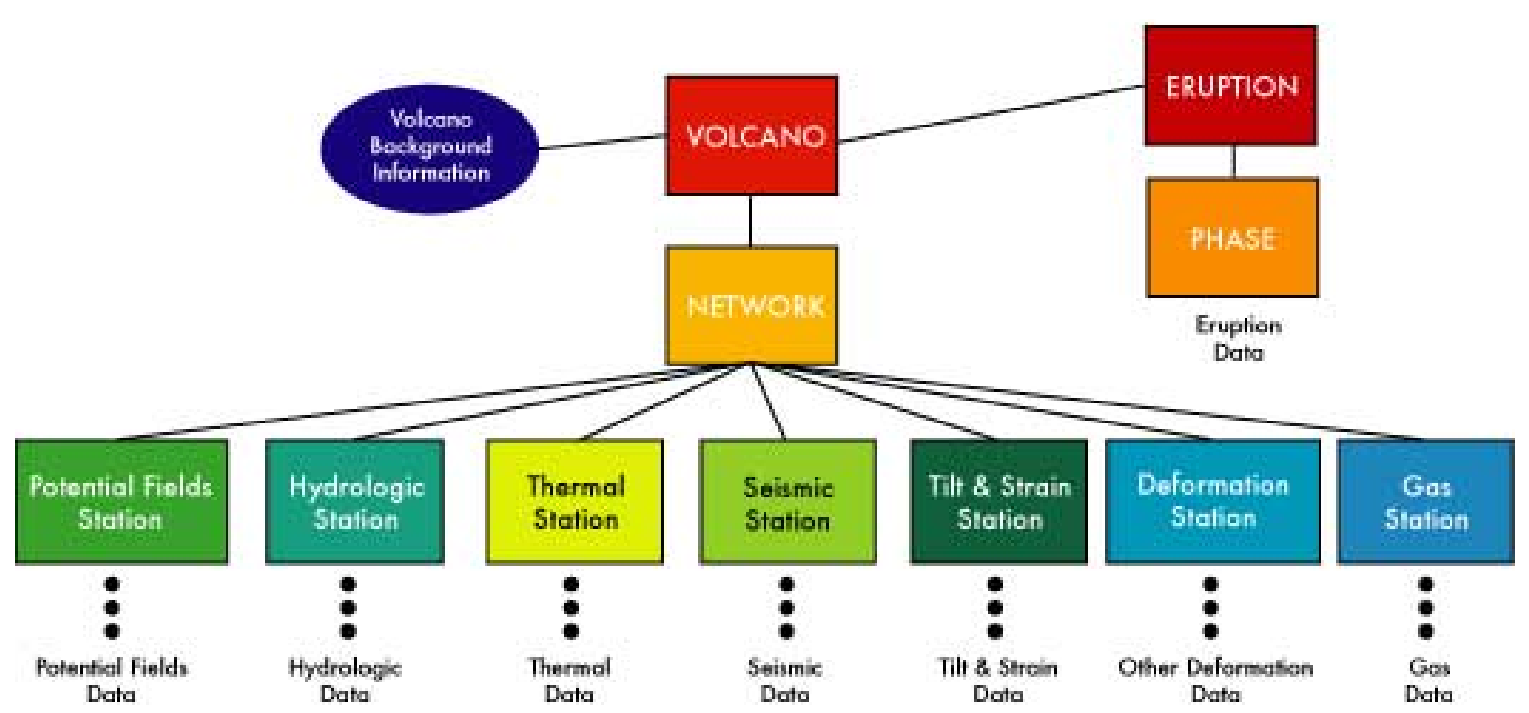

Figure 1. Simplified WOVOdat Schema 


\section{Prototype Hardware and Software}

WOVOdat 1.0 was designed using MySQL version 4.0.14. for Mac OS X in early 2004. The database ran on Mac OS X version 10.3.3 running an Apache web server version 1.3.29 and PHP version 4.3.2. Several web scripts were written in HTML, PHP, and XML to pull data from a preliminary database called wovotest.

\section{Naming Convention}

WOVOdat was designed to be a scalable database for global use by a range of end-users. Most end-users will utilize previously created web-based applications or will request queries from a WOVOdat team, however, some users may prefer to write their own queries. Future attributes and tables may also need to be added by people unfamiliar with the original design. To address these needs, a naming convention was created to provide enough information about the attribute and the table to which it belongs without being too lengthy and cumbersome. The WOVOdat naming convention was based on a large retail corporate database naming convention where disparate groups of people were involved with changes throughout the project lifecycle and attribute names needed to indicate what they were and the table from which they originated. The unique attribute names are used in a few junction tables to associate images and data changes with fields in other tables.

Table N1. The WOVOdat naming convention

\begin{tabular}{|c|c|}
\hline $\mathrm{a}$ & $\begin{array}{l}\text { Category - seismic (s), deformation (d), gas (g), thermal (t), hydrologic } \\
\text { (h), volcano (v), inferred processes (I), potential fields (f), common } \\
\text { (c), junction (j) }\end{array}$ \\
\hline $\mathrm{b}$ & $\begin{array}{l}\text { Table type - data (d), station information (s), instrument (i), network } \\
\text { (n), bibliographic (b), contact (c ) }\end{array}$ \\
\hline cde & $\begin{array}{l}\text { Subcategory, if necessary - gps (gps), tilt (tlt), tremor, (trm), gravity } \\
\text { (gra). } \mathrm{CO}_{2} \text { flux (co2), etc.. }\end{array}$ \\
\hline fgh* & $\begin{array}{l}\text { Attribute - latitude (lat), end point or final benchmark (fbm), } \\
\text { description (desc), etc. }\end{array}$ \\
\hline
\end{tabular}

The WOVOdat naming convention follows the format of ab_cde_fgh, where the category and table type can be quickly discerned from the first two letters $(\mathrm{ab})$ of the attribute. The first letter of the attribute (a) is the category to which the attribute belongs. These categories include selections of data such as seismic or geodetic as well as broader categories such as common tables and junction tables. The second letter of the attribute (b) gives the table type to which the attribute belongs. The table type gives information about the type of data in the tables such as data, station information, instrument information, network information, bibliographic information, and contact information. Junction tables start with a single letter ( $\mathrm{j}$ ). The second set of descriptive acronyms (cde) describes a subcategory, if appropriate. The subcategories describe the categories in more detail such as distinguishing between electronic tilt data, vector tilt data, and gps data in the geodetic category. The subcategory for Junction tables is four letters in length and combines two letters from each of the tables it is joining. The final set of attributes (fgh*), further describe the attribute and include shorthand for such terms as location, time, resolution, etc. 


\section{Challenges}

There were several challenges that spanned multiple tables warranting a separate discussion. Below is an overview of the challenges faced and solutions used for formatting time and location data along with the table organization selected for data collected by both permanent and non-permanent instruments. Having data in standard formats greatly increases the ease at which data can be compared. Unfortunately, there are no standards that cover volcano monitoring data and multiple formats for the same type of data can be found within an observatory. Therefore, a collection of global data will contain a wide variety of formats.

The formats chosen for WOVOdat will most likely be questioned throughout the project's lifecycle and we hope WOVOdat will create opportunities for designing volcano monitoring data standards. Because of the large range in formats used, we tried to include as many experts in data format discussions as possible. Parameters were discussed at the WOVOdat meeting in Bali in 2000 and again in Menlo Park, CA in 2002. Emails were sent to all WOVO observatories with hyperlinks to the parameters and formats posted on the WOVOdat website for feedback. Additional group discussions, email discussions, and phone conversations were held in 2003 to try to finalize the parameter list and formats. This documentation was developed in early 2004 to provide more detailed information about the choices made. In late 2006, a WOVOdat steering committee was established that met at the Fall American Geophysical Union meeting. A follow-up technical design workshop was held in February 2007 where this schema was discussed for possible use by teams at INGV (Bologna, Italy) and NIED (Japan).

\section{Time}

Recording time-stamped global data such that it can be used for future comparisons presents two main challenges. The first is determining when to convert data from one time zone to another and the second is agreeing on a standard for handling differences in level of detail between data that was recorded by an instrument for that second and data where less detail is known. Simple scripts can perform conversions to a different time zone as long as the difference between the UTC zone and the Universal Time Code (UTC) is known. However, the conversions can reduce the speed at which data is returned from complex queries. Because WOVOdat will be used mainly for accessing data, it is better to increase the data input effort than to slow down the query process. To make the query process as easy and fast as possible, all times should be converted to the Universal Time Code (UTC) prior to entry into WOVOdat, except for the load dates, which will be automatically entered in UTC. The decision for UTC was made based the ease of loading the local data and assumption that queries needing the load date information would be orders of magnitude less frequent than queries comparing the other data. Standard data loading scripts to convert time should be made available for consistency. The conversion from local time to UTC will be stored in the station tables and network tables to make the conversion to UTC faster when necessary. We found having the UTC conversion in only the Volcano table made the conversion queries more complicated and time consuming.

The standards chosen for the time formats are the MySQL data type, DATETIME (YYYY-MMDD hh:mm:ss), for all time data and TIMESTAMP (YYYYMMDDhhmmss), for all load dates. The load dates are entered automatically every time data is loaded into WOVOdat. Special scripts will be needed to load less detailed time data and flag it with the known level of detail. Because MySQL does not validate dates like other databases, it requires the months range from 0 to 12 and the dates from 0 to 31, we originally discussed a zero date for months where the exact day is unknown and a zero month years where the exact month is unknown. A standard day, such as the $15^{\text {th }}$, should be used when the 
exact day is not known, and a standard month, such as January, should be used when the month is not known. Information about the known level of detail should be included in the comments field.

\section{Location}

The ability to compare geospatial data is important to the success of WOVOdat, which means a common reference frame or datum is a necessity. A datum is a global reference model that is used to compute horizontal and vertical positions. Early datums were surface oriented and local. In North America one such early datum was NAD27. As models for calculating the surface of the Earth and the tools used to measure the distance between two points have become more sophisticated, local datums have undergone revisions. The more recent datums are now earth-centered and created using GPS (Global Positioning System) technology. Unfortunately, it is often difficult to convert data from one datum to another. The difference between older datums and more recent datums can be significant because the datums are based on different moel reference ellipsoids and changes vary with location (the shift from NAD27 to NAD83 is as large as 100 meters [325 feet] in portions of California). To solve several datum issues, WGS 84 (World Geodetic System of 1984) was created using advancements in GPS technology to be a standard global datum. Although NAD83 is based on similar technology, it was created using different ellipsoids and therefore small differences have been found.

To make comparisons easier, WGS 84 has been chosen as the standard for WOVOdat. As such, all data should be converted to WGS 84 prior to entry. Although new datums may be introduced in the future, is likely that conversions from WGS 84 to the new standards will be common.

\section{Data Collection from Permanent and Non-Permanent Instruments}

The comparisons of data collected from instruments that are either carried into the field or installed permanently at a station, present data organization challenges. Access to instrument information is required for data comparisons to ensure similar collection methods. Therefore, a database-wide organization was needed to simplify queries where data collection frequencies could change. Multiple junction tables were examined to allow for the many-to-many instrument-to-station relationships, however, this method was found to require more data entry and potentially more difficult queries than other solutions. Our solution involves linking instrument information directly from the data tables for the temporary instruments whereas data collected from permanently installed instruments would be linked to the instrument information through the station tables. The station tables link to contact information for the data collector so tables that contain data collected using temporary instruments need to include a link to the contact information for the collector. Tables that hold data from both temporary and permanently installed instruments include a flag to indicate if the data were collected periodically $(\mathrm{P})$ or continuously $(\mathrm{C})$. There were discussions about limiting the amount of continuous data in WOVOdat, such as every 10 minutes instead of every 10 seconds. A decision was made to let the observatories submit their preferred data frequency instead of imposing calculations to limit the amount of data.

Image data that can be collected from an instrument on a moving object or from a fixed point such as a caldera rim or observatory roof also present a data organization challenge. A similar solution to that used for periodic data is used for data collection for instruments without a fixed location. The image data collected by instruments on moving objects include the location of the instrument during data collection in the data table. The image data collected from a stationary location do not include the location in the data tables because the location can be found using a link to the station table. The station tables include fields for indicating if the station is collecting data at that point in space or remotely, as is 
the case for image data. The data tables allow for the collection of both types of data and scripts are needed to load the data properly for each case.

\section{Data Ownership and Availability}

One common concern about storing data in a global database is loss of data ownership. To alleviate these concerns, we've added access to the data owner's contact information and a method for the data owner to set when the data can become public. Each WOVOdat table contains an ID for the data collector or data owner, an ID for the person who put the data into WOVOdat, and a date after which the data can become public. The data owner fields link to the contact table for contact or reference information. The publish date sets a time after which the data will be made public in the database. The publish date can be set up to two years in advance giving the data owner time to analyze and publish their data. Data that has been entered in advance would be available to the owner for comparisons with other global data. It would also be available to the database administrator and a select WOVOdat volcanology experts for use during times of volcanic hazards.

\section{Table Structures and Create Table Statements}

Throughout this document, italics are used to provide additional information about choices made in the schema organization. The additional information gives a more complete summary of the discussions that led to this version of the schema. Table names are capitalized and all attributes are in lowercase. SI units (Le Système international d'unités or International System of Units) were chosen for all parameters.

In creating tables, the number of joins for currently known queries were reduced whenever possible.

\section{Volcano}

The volcano section of WOVOdat contains not only information about the volcano but also the necessary links between the monitoring data and the eruption data. Data from the Smithsonian Global Volcanism Program will fill most of these tables, however, some data will need to be entered by hand through a web form.

- The data in the volcano tables ranges from location and tectonic environment information to inferred dimensions of the magma storage system. There are four volcano tables:

- The Volcano table, vd, contains only the attributes that are unlikely to change for linking to all other tables. We include only the attributes that are unlikely to change.

- The Volcano Information table, vd_inf, contains more specific information about the volcano that could possibly change over time such as the volcano height and description.

- The Magma Chamber table contains information that could be used to define the magma storage system such as the depth of a low velocity zone and volume of the largest eruption.

- The Tectonic Setting table stores information about the tectonic environment. 


\section{General Volcano}

Table V1. Volcano Table

\begin{tabular}{|l|l|l|}
\hline vd_id & Volcano ID & An identifier for linking with other tables \\
\hline vd_name & Volcano name & $\begin{array}{l}\text { The name of the volcano stored in the } \\
\text { CAVW as the primary name. }\end{array}$ \\
\hline vd_tzone & & $\begin{array}{l}\text { The time zone relative to UTC. Please enter } \\
\text { the number of hours from GMT, using a } \\
\text { negative sign (-) for hours before GMT and } \\
\text { no sign for positive numbers (sxx.x). }\end{array}$ \\
\hline vd_mcont & Time zone & $\begin{array}{l}\text { A flag (please enter M for multiple contacts) } \\
\text { to indicate that there are multiple contacts } \\
\text { for this volcano and the Volcano-Contact } \\
\text { Junction table should be queried to access } \\
\text { all of the contact information. }\end{array}$ \\
\hline cc_id & Contact flag & $\begin{array}{l}\text { An identifier for linking to contact } \\
\text { information about the person or observatory } \\
\text { who monitors the volcano. }\end{array}$ \\
\hline vd_loaddate & Contact ID & The date this row was entered in UTC. \\
\hline vd_pubdate & Publish date & $\begin{array}{l}\text { The date this row can become public. This } \\
\text { date can be set up to two years in advance. }\end{array}$ \\
\hline cc_id_load & & $\begin{array}{l}\text { An identifier for linking to contact } \\
\text { information for the person who entered this } \\
\text { row of data. }\end{array}$ \\
\hline
\end{tabular}

The Volcano table is one of the fundamental tables of WOVOdat in that it links to almost every other table. Our original design included one volcano table instead of volcano and volcano information tables. Certain queries, however, were found to be too cumbersome if information in the volcano table were to change, because the time of data collection would need to be matched to the valid time for the volcano information for each query. A simple change in the design was made to create two volcano tables, which should prevent a substantial amount of work in the future.

The Volcano table (vd for volcano data) stores two pieces of data that are unlikely to change, the volcano name and the time zone. There may be instances where one of these attributes changes and a solution based on when the change occurs in WOVOdat's lifecycle will be needed. The primary ID, vd_id, is stored in multiple other tables for linking from the monitoring or eruption data to the volcano data. The time zone, vd_tzone, provides the information necessary to convert from local time to UTC. The contact ID (cc_id) links to contact information for the primary observatory that manages this volcano. In some cases there are multiple observatories monitoring one volcano so a flag, vd_mcont, has been included to indicate the Volcano Contact Junction table should be queried for additional contact information. The letter M should be entered in the vd_mcont field if there are multiple contacts. The data loader ID, cc_id_load, links to the Contact table for more information about the person who loaded the data into WOVOdat. The load date, vd_loaddate, is a TIMESTAMP and entered automatically in UTC and the date the data can become public is stored in vd_pubdate. 
Volcano-Contact Junction

Table V2. Volcano-Contact Junction Table

\begin{tabular}{|c|c|c|}
\hline jj_volcon_id & Volcano Contact junction ID & An identifier for linking with other tables. \\
\hline vd_id & Volcano ID & $\begin{array}{l}\text { The identifier for linking to the volcano } \\
\text { table. The volcano table stores the volcano } \\
\text { name and time zone. It is used to connect to } \\
\text { all other data. }\end{array}$ \\
\hline cc_id & Contact ID & $\begin{array}{l}\text { An identifier for linking to contact } \\
\text { information about the person or observatory } \\
\text { who monitors the volcano. }\end{array}$ \\
\hline jj_volcon_loaddate & Load date & The date this row was entered in UTC. \\
\hline 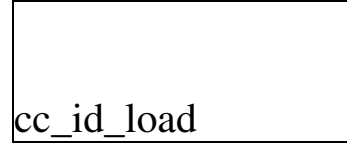 & Data loader ID & $\begin{array}{l}\text { An identifier for linking to contact } \\
\text { information for the person who entered this } \\
\text { row of data. }\end{array}$ \\
\hline
\end{tabular}

The Volcano Contact Junction table, jj_volcon, is the junction table for the many-to-many relationship between the volcano and the observatories that monitor the volcano. The table contains a primary ID, jj_volcon_id, for joining with other tables in separate databases if needed, the volcano ID, vd_id, the contact ID, cc_id, a load date, jj_volcon_loaddate, and a data loader ID, cc_id_load for linking with contact information about the person who loaded the information.

Volcano Information

Table V3. Volcano Information Table

\begin{tabular}{|l|l|l|}
\hline vd_inf_id & Volcano information ID & An identifier for linking with other tables \\
\hline vd_id & Volcano ID & $\begin{array}{l}\text { The identifier for linking to the volcano } \\
\text { table. The volcano table stores the volcano } \\
\text { name and time zone. It is used to connect to } \\
\text { all other data. }\end{array}$ \\
\hline vd_inf_cavw & CAVW Number & $\begin{array}{l}\text { The Catalog of Active Volcanoes of the } \\
\text { World (CAVW) number from the } \\
\text { Smithsonian (nn-nn-nnn). }\end{array}$ \\
\hline vd_inf_desc & Short narrative & $\begin{array}{l}\text { A short narrative about the volcano and its } \\
\text { history. }\end{array}$ \\
\hline vd_inf_slat & & $\begin{array}{l}\text { The summit latitude in decimal degrees } \\
\text { from the Smithsonian (positive is to the N) } \\
\text { (sxx.xxxxxxx). }\end{array}$ \\
\hline vd_inf_slon & Summit Latitude & $\begin{array}{l}\text { The summit longitude in decimal degrees } \\
\text { from the Smithsonian (positive is to the E) } \\
\text { (sxxx.xxxxxxx). }\end{array}$ \\
\hline vd_inf_datum & Summit Longitude & $\begin{array}{l}\text { The datum used for the longitude and } \\
\text { latitude. WGS 84 is the official datum for } \\
\text { WOVOdat. Please include the original }\end{array}$ \\
\hline
\end{tabular}




\begin{tabular}{|c|c|c|}
\hline & & datum as well. \\
\hline vd_inf_selev & Elevation of summit & $\begin{array}{l}\text { The summit elevation in meters from the } \\
\text { Smithsonian where positive values are } \\
\text { above sea level (sxxxx). }\end{array}$ \\
\hline vd_inf_type & Volcano type & $\begin{array}{l}\text { The type of volcano from the Smithsonian. } \\
\text { This field will list all types in order from } \\
\text { primary through secondary. }\end{array}$ \\
\hline vd_inf_evol & Volume of edifice & The volume of the edifice (xx.x). \\
\hline vd_inf_numcald & Number of calderas present & The number of calderas present (xx). \\
\hline vd_inf_lcald_dia & Diameter of largest caldera & $\begin{array}{l}\text { The diameter of the largest caldera or crater } \\
\text { (xxx.x). }\end{array}$ \\
\hline vd_inf_ycald_lat & Latitude of youngest caldera & $\begin{array}{l}\text { The latitude of youngest caldera in decimal } \\
\text { degrees (sxx.xxxxxxx). }\end{array}$ \\
\hline vd_inf_ycald_lon & $\begin{array}{l}\text { Longitude of youngest } \\
\text { caldera }\end{array}$ & $\begin{array}{l}\text { The longitude of youngest caldera in } \\
\text { decimal degrees (sxxx.xxxxxxx). }\end{array}$ \\
\hline vd_inf_ycald_datum & Datum & $\begin{array}{l}\text { The datum used for the longitude and } \\
\text { latitude. WGS } 84 \text { is the official WOVOdat } \\
\text { datum and locations should be converted } \\
\text { wherever possible. }\end{array}$ \\
\hline vd_inf_stime & Start time & $\begin{array}{l}\text { The time the data became valid or was } \\
\text { measured in UTC stored as DATETIME } \\
\text { (YYYY-MM-DD hh:mm:ss). If the data } \\
\text { needs to be updated then this field will help } \\
\text { find information about the volcano for the } \\
\text { time period requested. }\end{array}$ \\
\hline vd_inf_stime_unc & Start time uncertainty & $\begin{array}{l}\text { The uncertainty in time the data became } \\
\text { valid or was measured in UTC stored as } \\
\text { DATETIME (YYYY-MM-DD hh:mm:ss). }\end{array}$ \\
\hline vd_inf_etime & End time & $\begin{array}{l}\text { The time the data changed in UTC stored as } \\
\text { DATETIME (YYYY-MM-DD hh:mm:ss). } \\
\text { This field will be null if the data are still } \\
\text { valid. }\end{array}$ \\
\hline vd_inf_etime_unc & End time uncertainty & $\begin{array}{l}\text { The uncertainty in time the data changed in } \\
\text { UTC stored as DATETIME (YYYY-MM- } \\
\text { DD hh:mm:ss). This field will be null if the } \\
\text { data are still valid. }\end{array}$ \\
\hline cc_id & Contact ID & $\begin{array}{l}\text { An identifier for linking to contact } \\
\text { information. }\end{array}$ \\
\hline vd_inf_loaddate & Load date & The date this row was entered in UTC. \\
\hline vd_inf_pubdate & Publish date & $\begin{array}{l}\text { The date this row can become public. This } \\
\text { date can be set up to two years in advance. }\end{array}$ \\
\hline cc_id_load & Data loader ID & $\begin{array}{l}\text { An identifier for linking to contact } \\
\text { information for the person who entered this } \\
\text { row of data. }\end{array}$ \\
\hline
\end{tabular}


The Volcano Information table (vd_inf for volcano data - information) contains information about the volcano that could possibly change over the life of the database, such as the CAVW number, the location of the summit, and other descriptive information (please see the Volcano table for additional discussion). Much of this information will be loaded from the Smithsonian Global Volcanism Program' Volcano Reference File (VRF). The primary key is vd_inf_id, which will be entered automatically and is set up as a medium integer. The Volcano ID, vd_id, is the primary key from the volcano table and will be used to link the volcano information to eruption information and monitoring data. The contact ID (cc_id) links to contact information for the primary observatory that manages this volcano. In some cases there are multiple observatories monitoring one volcano. Information about the multiple observatories can be found using the flag in the Volcano table and the Volcano Contact Junction table. A flag similar to the one in the Volcano Table may make it easier to find this additional information. The data loader ID, cc_id_load, links to the Contact table for more information about the person who loaded the data into WOVOdat. The load date, vd_inf_loaddate, is a TIMESTAMP and entered automatically in UTC and the date the data can become public is stored in vd_pubdate. The Volcano Information Table includes the Catalog of Active Volcanoes of the World (CAVW) number, vd_inf_cavw, from the Smithsonian along with a short narrative of the volcano, vd_inf_desc, also from the Smithsonian. The CAVW numbers are based on geographic regions and there have been cases where a volcano has been added to the CAVW and the CAVW numbers of previously known volcanoes have been changed to "make room" for the new volcano. The location information for the summit of the volcano includes the latitude, vd_inf_lat, longitude, vd_inf_lon, elevation, vd_inf_elev, and datum, vd_inf_datum. All data should be converted to WGS 84 prior to entering WOVOdat. If conversion is not possible during data loading, the original datum must be entered into the datum field, vd_inf_datum. When a volcano erupts, there is the potential for changes in the summit latitude, longitude, elevation, edifice volume, diameter of primary caldera, latitude and longitude of primary caldera, number of calderas, the volcano type, and the description of the volcano. For example, when Mt. St. Helens erupted on May $18^{\text {th }}, 1980$ the summit elevation went from about $3900 \mathrm{~m}$ to $2400 \mathrm{~m}$.

The volcano type, vd_inf_type, is a list of volcano types from the Smithsonian starting with the primary volcano type. The volume of the edifice, vd_inf_evol, number of calderas present, vd_inf_numcald, diameter of largest caldera, vd_inf_lcald_dia, and locations of the youngest caldera, vd_inf_ycald_lat and vd_inf_ycald_lon will also be based on data in the Smithsonian database. If the information in the Volcano Information table has been changed, the vd_inf_stime and vd_inf_etime, will be used for linking to information for the appropriate time period. The vd_inf_stime attribute is the time the data became valid or was measured. The vd_inf_etime is the time the data changed. If the data in the Volcano Information table have not changed, the vd_inf_etime attribute will be null and the table can be easily queried to return this information. The uncertainties for the start and end times are stored in vd_inf_stime_unc and vd_inf_etime_unc.

Magma Chamber

Table V4. Magma Chamber Table

\begin{tabular}{|l|l|l|}
\hline vd_mag_id & Magma chamber ID & An identifier for linking with other tables. \\
\hline vd_id & Volcano ID & $\begin{array}{l}\text { The identifier for linking to the volcano } \\
\text { table. The volcano table stores the volcano } \\
\text { name and time zone. It is used to connect to }\end{array}$ \\
\hline
\end{tabular}




\begin{tabular}{|c|c|c|}
\hline & & all other data. \\
\hline vd_mag_lvz_dia & $\begin{array}{l}\text { The diameter of low velocity } \\
\text { zone }\end{array}$ & $\begin{array}{l}\text { The diameter of low velocity zone in } \\
\text { kilometers (xxx). }\end{array}$ \\
\hline vd_mag_lvz_vol & Volume of low velocity zone & $\begin{array}{l}\text { The volume of low velocity zone in cubic } \\
\text { kilometers }(\mathrm{x} x \mathrm{xx})\end{array}$ \\
\hline vd_mag_tlvz & Top of low velocity zone & $\begin{array}{l}\text { The depth to top of low velocity zone in } \\
\text { kilometers (xx) }\end{array}$ \\
\hline vd_mag_lerup_vol & Volume of largest eruption & $\begin{array}{l}\text { The volume, expressed as dense rock } \\
\text { equivalent or DRE, of the largest historic or } \\
\left.\text { prehistoric eruption (in } \mathrm{km}^{3}\right)(\mathrm{xxxx} . \mathrm{xxx}) \text {. }\end{array}$ \\
\hline vd_mag_drock & Dominant rock type & $\begin{array}{l}\text { The dominant rock type, for example, } \\
\text { andesite. }\end{array}$ \\
\hline vd_mag_orock & Outlier rock type & The outlier rock type, for example, basalt. \\
\hline vd_mag_orock2 & Outlier rock type 2 & A second outlier rock type, if applicable. \\
\hline vd_mag_orock3 & Outlier rock type 3 & A third outlier rock type, if applicable. \\
\hline vd_mag_minsio2 & Minimum $\mathrm{SiO}_{2}$ & $\begin{array}{l}\text { The minimum } \mathrm{SiO}_{2} \text { content of whole rocks } \\
\text { erupted (xx.xx). }\end{array}$ \\
\hline vd_mag_maxsio2 & Maximum $\mathrm{SiO}_{2}$ & $\begin{array}{l}\text { The maximum } \mathrm{SiO}_{2} \text { content of whole rocks } \\
\text { erupted (xx.xx). }\end{array}$ \\
\hline vd_mag_com & Comments & $\begin{array}{l}\text { Comments or a description of the magma } \\
\text { chamber. }\end{array}$ \\
\hline cc_id & Collector ID & $\begin{array}{l}\text { An identifier for linking to contact } \\
\text { information about the person who collected } \\
\text { this data. }\end{array}$ \\
\hline vd_mag_loaddate & Load date & The date this row was entered in UTC. \\
\hline vd_mag_pubdate & Publish date & $\begin{array}{l}\text { The date this row can become public. This } \\
\text { date can be set up to two years in advance. }\end{array}$ \\
\hline cc_id_load & Data loader ID & $\begin{array}{l}\text { An identifier for linking to contact } \\
\text { information for the person who entered this } \\
\text { row of data. }\end{array}$ \\
\hline
\end{tabular}

The Magma Chamber table (vd_mag for volcano data - magma chamber) contains information about the magma chamber such as its composition(s) and minimum size (based on the largest eruption volume). The primary key is vd_mag_id, which will be entered automatically and is set up as a medium integer. The Volcano ID, vd_id, is the primary key from the volcano table and will be used to link to volcano information, eruption information, and monitoring data. The collector ID (cc_id) links to contact information for the primary observatory in charge of the volcano. There will also be a junction table for connecting this table with reference data, which will provide access to the people who collected the data in this table. The data loader ID, cc_id_load, links to the Contact table for more information about the person who loaded the data into WOVOdat. The load date, vd_mag_loaddate, is a TIMESTAMP and entered automatically in UTC and the date the data can become public is stored in vd_mag_pubdate. 
One method for determining information about the magma chamber is through geophysical surveys of the low velocity zone (a zone that could potentially contain magma). The diameter of the low velocity zone is stored in kilometers in vd_mag_lvz_dia, the volume of the low velocity zone is stored in cubic kilometers in vd_mag_lvz_vol, and the top of the low velocity zone is stored in kilometers in vd_mag_tlvz. Another method of estimating the size of the magma chamber is from the size of an eruption. We store the volume (dense rock equivalent) of the largest eruption in cubic kilometers in vd_mag_lerup_vol. Additional information about the magma chamber can be gained from the types of eruptive products. We store the dominant rock type, vd_mag_drock, and three outlier types, vd_mag_orock, vd_mag_orock2, and vd_mag_orock3. The range in $\mathrm{SiO}_{2}$ contents of the whole rock eruptive products is stored as a minimum $\mathrm{SiO}_{2}$, vd_mag_minsio2, and maximum $\mathrm{SiO}_{2}$, vd_mag_maxsio2. The final attribute is a comments field, vd_mag_com, for any additional comments about the magma chamber.

\section{Tectonic Setting}

Table V5. Tectonic Setting Table

\begin{tabular}{|l|l|l|}
\hline vd_tec_id & Tectonic setting ID & An identifier for linking with other tables \\
\hline vd_id & Volcano ID & $\begin{array}{l}\text { The identifier for linking to the volcano } \\
\text { table. The volcano table stores the volcano } \\
\text { name and time zone. It is used to connect to } \\
\text { all other data. }\end{array}$ \\
\hline vd_tec_desc & Local tectonic setting & $\begin{array}{l}\text { A 255-character field for a description of } \\
\text { the local tectonic setting. }\end{array}$ \\
\hline vd_tec_strslip & Rate of strike-slip & $\begin{array}{l}\text { The rate of arc- or ridge- parallel strike-slip } \\
\text { in centimeters per year (xx.x). }\end{array}$ \\
\hline vd_tec_ext & Rate of extension & $\begin{array}{l}\text { The rate of extension in centimeters per year } \\
\text { (xx.x). }\end{array}$ \\
\hline vd_tec_conv & Rate of convergence & $\begin{array}{l}\text { The rate of convergence in centimeters per } \\
\text { year (xx.x). }\end{array}$ \\
\hline vd_tec_travhs & Travel rate across hotspot & $\begin{array}{l}\text { The rate of travel across a hotspot in } \\
\text { centimeters per year (xx.x). }\end{array}$ \\
\hline vd_tec_com & Comments & $\begin{array}{l}\text { A 255-character text field for added } \\
\text { comments about the tectonic setting. }\end{array}$ \\
\hline & & $\begin{array}{l}\text { An identifier for linking to contact } \\
\text { information about the person who collected } \\
\text { this data. }\end{array}$ \\
\hline cc_id & Collector ID & The date this row was entered in UTC. \\
\hline vd_tec_loaddate & Load date & $\begin{array}{l}\text { The date this row can become public. This } \\
\text { date can be set up to two years in advance. }\end{array}$ \\
\hline vd_tec_pubdate & Publish date & $\begin{array}{l}\text { An identifier for linking to contact } \\
\text { information for the person who entered this } \\
\text { row of data. }\end{array}$ \\
\hline cc_id_load & Data loader ID & \\
\hline
\end{tabular}

The Tectonic Setting table (vd_tec for volcano data - tectonic setting) contains information about the local tectonic setting such as rates of movement either along a plate or over a hotspot. This 
information will all need to be entered by hand from a variety of sources. The primary key is vd_tec_id, which will be entered automatically and is set up as a medium integer. The Volcano ID, vd_id, is the primary key from the volcano table and will be used to link to volcano information, eruption information, and monitoring data. The collector ID (cc_id) links to contact information for the primary observatory in charge of the volcano. There will also be a junction table for connecting this table with reference data, which will provide access to the people who collected the data in this table. The data loader ID, cc_id_load, links to the same contact table and provides the same information about the person who loaded the data into WOVOdat. The load date, vd_tec_loaddate, is a TIMESTAMP and entered automatically in UTC and the date the data can become public is stored in vd_tec_pubdate.

Information about the local tectonic setting can be stored in the description attribute, vd_tec_desc. The rates of arc- or ridge-parallel strike slip, rate of extension, and rate of convergence are stored in vd_tec_strslip, vd_tec_ext, and vd_tec_conv all as centimeters per year. The rate of movement over a hotspot is stored in vd_travhs, also in centimeters per year. We also include an added comments field, vd_tec_com, for additional comments about the tectonic setting that are not covered in vd_tec_desc.

\section{Create table statements for Volcano tables.}

DROP TABLE IF EXISTS vd;

create table vd (

vd_id mediumint not null auto_increment,

vd_name varchar(255),

vd_tzone float,

vd_mcont char(1),

cc_id mediumint,

vd_loaddate datetime,

cc_id_load mediumint,

primary key (vd_id));

DROP TABLE IF EXISTS jj_volcon;

create table jj_volcon (

jj_volcon_id mediumint not null auto_increment,

vd_id mediumint,

cc_id mediumint,

jj_volcon_loaddate datetime,

cc_id_load mediumint,

primary key (jj_volcon_id));

DROP TABLE IF EXISTS vd_inf;

create table vd_inf (

vd_inf_id mediumint not null auto_increment,

vd_id mediumint,

vd_inf_cavw varchar(15),

vd_inf_desc varchar(255),

vd_inf_slat float,

vd_inf_slon float,

vd_inf_datum varchar(30),

vd_inf_selev float,

vd_inf_type varchar(255),

vd_inf_evol float,

vd_inf_numcald float, 
vd_inf_lcald_dia float, vd_inf_ycald_lat float, vd_inf_ycald_lon float, vd_inf_ycald_datum varchar(30), vd_inf_stime datetime, vd_inf_stime_unc datetime, vd_inf_etime datetime, vd_inf_etime_unc datetime, cc_id mediumint, vd_inf_loaddate datetime, vd_inf_pubdate datetime, cc_id_load mediumint, primary key (vd_inf_id));

DROP TABLE IF EXISTS vd_mag;

create table vd_mag (

vd_mag_id mediumint not null auto_increment, vd_id mediumint, vd_mag_lvz_dia float, vd_mag_lvz_vol float, vd_mag_tlvz float, vd_mag_lerup_vol float, vd_mag_drock varchar(60), vd_mag_orock varchar(60), vd_mag_orock2 varchar(60), vd_mag_orock3 varchar(60), vd_mag_minsio2 float, vd_mag_maxsio2 float, vd_mag_com varchar(255), cc_id mediumint, vd_mag_loaddate datetime, vd_mag_pubdate datetime, cc_id_load mediumint, primary key (vd_mag_id));

DROP TABLE IF EXISTS vd_tec;

create table vd_tec (

vd_tec_id mediumint not null auto_increment, vd_id mediumint, vd_tec_desc varchar(255),

vd_tec_strslip float,

vd_tec_ext float,

vd_tec_convfloat,

vd_tec_travhs float, vd_tec_com varchar(255),

cc_id mediumint,

vd_tec_loaddate datetime, vd_tec_pubdate datetime, cc_id_load mediumint, primary key (vd_tec_id)); 


\section{Eruption}

Volcanic eruptions can be classified in multiple ways based on the style of eruption, composition, duration, and location. The eruption section of WOVOdat contains general information about each volcanic eruption including parameters used to describe the type of eruption, video of the eruption, and forecasts made about the eruption. The tables are linked to the Volcano table for volcano information and for access to the monitoring data. The Smithsonian Global Volcanism Program will be a source for most of the data in the eruption tables. All other data will need to be entered by hand through a web form. The eruption tables store information about each volcanic eruption, the individual eruption phases, sample video footage, and forecasts made prior to the eruptions. There are five eruption tables:

- The Eruption table, ed, contains summary information about an eruption such as a narrative and time period.

- The Eruption Phase table, ed_phs, contains more specific information about individual eruption phases such as the size of the phase and composition of magma.

- The Eruption Phase table links to the Eruption table. Some of the eruption phase data will come from the Smithsonian but the rest will need to be entered by hand.

- The Eruption Video table, ed_vid, stores information about a video clip of the eruption including the location of the clip and a summary of the clip contents.

- The Eruption Forecast table, ed_for, stores information about forecasts made for a phase of the eruption such as an overview of the forecast and the eruption times forecasted.

General Eruption

Table E1. Eruption Table

\begin{tabular}{|l|l|l|}
\hline ed_id & Eruption data ID & An identifier for linking with other tables \\
\hline vd_id & Volcano ID & $\begin{array}{l}\text { The identifier for linking to the volcano } \\
\text { table. The volcano table stores the volcano } \\
\text { name and time zone. It is used to connect to } \\
\text { all other data. }\end{array}$ \\
\hline ed_name & $\begin{array}{l}\text { The name (other than eruption year) that is } \\
\text { often used to refer to the eruption (e.g., the } \\
\text { Hoei eruption of Fuji or the VTTS eruption } \\
\text { of Novarupta/Katmai). }\end{array}$ \\
\hline ed_nar & Name of the eruption & $\begin{array}{l}\text { A narrative of eruption (if any) from the } \\
\text { Smithsonian. This field is currently 255 } \\
\text { characters. }\end{array}$ \\
\hline ed_stime & Narrative of eruption (if any & $\begin{array}{l}\text { The eruption start time in UTC stored as } \\
\text { DATETIME (YYYY-MM-DD hh:mm:ss). }\end{array}$ \\
\hline ed_stime_unc & Start time of eruption & $\begin{array}{l}\text { The uncertainty in the eruption start time in } \\
\text { STC stored as DATETIME (YYYY-MM- } \\
\text { DD hh:mm:ss). }\end{array}$ \\
\hline
\end{tabular}




\begin{tabular}{|l|l|l|}
\hline ed_etime & End time of eruption & $\begin{array}{l}\text { The eruption end time in UTC stored as } \\
\text { DATETIME (YYYY-MM-DD hh:mm:ss). }\end{array}$ \\
\hline ed_etime_unc & $\begin{array}{l}\text { End time of eruption } \\
\text { uncertainty }\end{array}$ & $\begin{array}{l}\text { The uncertainty in the eruption end time in } \\
\text { UTC stored as DATETIME (YYYY-MM- } \\
\text { DD hh:mm:ss). }\end{array}$ \\
\hline ed_climax & Onset of eruption climax & $\begin{array}{l}\text { The onset of eruption climax in UTC stored } \\
\text { as DATETIME (YYYY-MM-DD } \\
\text { hh:mm:ss). }\end{array}$ \\
\hline ed_climax_unc & $\begin{array}{l}\text { Onset of eruption climax } \\
\text { uncertainty }\end{array}$ & $\begin{array}{l}\text { The uncertainty in the time of the onset of } \\
\text { eruption climax in UTC stored as } \\
\text { DATETIME (YYYY-MM-DD hh:mm:ss). }\end{array}$ \\
\hline ed_com & Comments & $\begin{array}{l}\text { A text field for storing comments and } \\
\text { additional information about the eruption. }\end{array}$ \\
\hline cc_id & Contact ID & $\begin{array}{l}\text { An identifier for linking to contact } \\
\text { information for this row of eruption data. }\end{array}$ \\
\hline ed_loaddate & Load date & The date this row was entered in UTC. \\
\hline ed_pubdate & Publish date & $\begin{array}{l}\text { The date this row can become public. This } \\
\text { date can be set up to two years in advance. }\end{array}$ \\
\hline cc_id_load & Data loader ID & $\begin{array}{l}\text { An identifier for linking to contact } \\
\text { information for the person who entered this } \\
\text { row of data. }\end{array}$ \\
\hline
\end{tabular}

The Eruption table (ed for eruption data) stores general information about an eruption such as a narrative and time span. More specific information about the eruption is stored in the Eruption Phase table, which links to the Eruption table. The primary ID is ed_id and the main foreign key is the volcano ID, vd_id for linking to the volcano and monitoring information. The contact ID, cc_id, links to contact information for the primary person responsible for the eruption data. Multiple people can enter eruption data as long as each entry is kept separate and includes the appropriate contact ID. The data loader ID, cc_id_load, links to the Contact table for more information about the person who loaded the data into WOVOdat. The data loader is not necessarily the person responsible for the eruption data. The load date, ed_loaddate, is a TIMESTAMP and entered automatically in UTC and the date the data can become public is stored in ed_pubdate.

The name by which the eruption is most often referred to is stored in ed_name. A narrative of the eruption from the Smithsonian database or entered by hand is stored in ed_nar. This field is currently a 255-character text field and we may need to increase its size if the narratives are longer. The time span of the eruption is stored as ed_stime and ed_etime, both in UTC DATETIME. The onset of the eruption climax is also stored in UTC DATETIME in the field ed_climax. Uncertainties for the time span and eruption climax are stored in ed_stime_unc, ed_etime_unc, and ed_climax_unc. Additional comments about the eruption can be stored in ed_com. 
Eruption Phase

Table E2. Eruption Phase Table

\begin{tabular}{|c|c|c|}
\hline ed_phs_id & Eruption phase ID & An identifier for linking with other tables \\
\hline ed_id & Eruption ID & $\begin{array}{l}\text { An identifier for linking with information in } \\
\text { the Eruption table. The Eruption table } \\
\text { contains general information about an } \\
\text { eruption including a narrative and time } \\
\text { span. The Eruption table also links to the } \\
\text { Volcano table. }\end{array}$ \\
\hline d_phs_phsnum & Phase number & $\begin{array}{l}\text { The observatory defined phase number } \\
\text { starting with number } 1 \text { for the first phase of } \\
\text { the eruption. }\end{array}$ \\
\hline ed_phs_stime & Start time & $\begin{array}{l}\text { The start time of this phase in UTC stored } \\
\text { as DATETIME (YYYY-MM-DD } \\
\text { hh:mm:ss). }\end{array}$ \\
\hline ed_phs_stime_unc & Start time uncertainty & $\begin{array}{l}\text { The uncertainty in the start time of this } \\
\text { phase in UTC stored as DATETIME } \\
\text { (YYYY-MM-DD hh:mm:ss). }\end{array}$ \\
\hline ed_phs_etime & End time & $\begin{array}{l}\text { The end time of this phase in UTC stored as } \\
\text { DATETIME (YYYY-MM-DD hh:mm:ss). }\end{array}$ \\
\hline ed_phs_etime_unc & End time uncertainty & $\begin{array}{l}\text { The uncertainty in the end time of this phase } \\
\text { in UTC stored as DATETIME (YYYY- } \\
\text { MM-DD hh:mm:ss). }\end{array}$ \\
\hline ed_phs_desc & Description & $\begin{array}{l}\text { A description of the eruption characteristics } \\
\text { for this phase (please include the word } \\
\text { climax for the climax of the eruption for } \\
\text { search purposes). }\end{array}$ \\
\hline ed_phs_vei & VEI, this phase & $\begin{array}{l}\text { The volcanic explosivity index (VEI) for } \\
\text { this phase taken from the Smithsonian. }\end{array}$ \\
\hline ed_phs_max_lext & xtrusion rate & The maximum lava extrusion rate in $\mathrm{m} 3 / \mathrm{s}$. \\
\hline ed_phs_max_expdis & $\begin{array}{l}\text { Max explosive mass } \\
\text { discharge rate }\end{array}$ & $\begin{array}{l}\text { The maximum explosive mass discharge } \\
\text { rate in } \mathrm{kg} / \mathrm{s} \times 10^{6} \text {. }\end{array}$ \\
\hline ed_phs_dre & DRE & $\begin{array}{l}\text { The volume of material erupted or DRE in } \\
\mathrm{m}^{3} \times 10^{6} \text {. }\end{array}$ \\
\hline ed_phs_mix & Magma mixing & $\begin{array}{l}\text { A text field to indicate if there is evidence } \\
\text { of magma mixing. Use Y for detected, } \mathrm{N} \text { for } \\
\text { not seen, or U for unknown. You can also } \\
\text { give a short description of the evidence for } \\
\text { magma mixing. }\end{array}$ \\
\hline ed_phs_col & Column height & $\begin{array}{l}\text { The maximum height of the eruption } \\
\text { column in kilometers above sea level. }\end{array}$ \\
\hline ed_phs_coldet & Column height determination & $\begin{array}{l}\text { The method used to determine the } \\
\text { maximum height of the eruption column. }\end{array}$ \\
\hline & & $\begin{array}{l}\text { The minimum } \mathrm{SiO}_{2} \text { of the matrix glass as a } \\
\text { s/weight percent }(\mathrm{xx} . \mathrm{xx} \%) \text {. }\end{array}$ \\
\hline
\end{tabular}




\begin{tabular}{|c|c|c|}
\hline ed_phs_maxsio2_mg & $\begin{array}{l}\text { Maximum } \mathrm{SiO}_{2} \text { of matrix } \\
\text { glass }\end{array}$ & $\begin{array}{l}\text { The maximum } \mathrm{SiO}_{2} \text { of the matrix glass as a } \\
\text { weight percent }(\mathrm{xx} \cdot \mathrm{xx} \%) \text {. }\end{array}$ \\
\hline ed_phs_minsio2_wr & Minimum $\mathrm{SiO}_{2}$ of whole rock & $\begin{array}{l}\text { The minimum } \mathrm{SiO}_{2} \text { of the whole rock as a } \\
\text { weight percent (xx.xx\%). }\end{array}$ \\
\hline ed_phs_maxsio2_wr & Maximum $\mathrm{SiO}_{2}$ of whole rock & $\begin{array}{l}\text { The maximum } \mathrm{SiO}_{2} \text { of the whole rock as a } \\
\text { weight percent }(\mathrm{xx} . \mathrm{xx} \%) \text {. }\end{array}$ \\
\hline ed_phs_totxtl & Total crystallinity & $\begin{array}{l}\text { The total crystallinity of the dominant rock } \\
\text { type in volume } \%(x x \%) \text {. }\end{array}$ \\
\hline ed_phs_phenc & Phenocryst content & $\begin{array}{l}\text { The percentage of phenocrysts in the } \\
\text { dominant rock type }(\mathrm{xx} \%) \text {. }\end{array}$ \\
\hline ed_phs_phena & Phenocryst assemblage & $\begin{array}{l}\text { The phenocryst assemblage listed in order } \\
\text { of most abundant to least abundant. }\end{array}$ \\
\hline ed_phs_h2o & Pre-eruption water content & $\begin{array}{l}\text { Pre-eruption water content in melt, as } \\
\text { analyzed in melt inclusions in phenocrysts. }\end{array}$ \\
\hline ed_phs_h2o_xtl & $\begin{array}{l}\text { Phenocryst with melt } \\
\text { inclusion }\end{array}$ & $\begin{array}{l}\text { A description of the phenocryst and the melt } \\
\text { inclusion that was analyzed to determine the } \\
\text { pre-eruption water content along with the } \\
\text { method used. }\end{array}$ \\
\hline ed_phs_com & Comments & $\begin{array}{l}\text { Additional information about this eruptive } \\
\text { phase including descriptions of the rocks, } \\
\text { phenocrysts, and inclusions. }\end{array}$ \\
\hline cc_id & Contact ID & $\begin{array}{l}\text { An identifier for linking to contact } \\
\text { information for these data. }\end{array}$ \\
\hline ed_phs_loaddate & Load date & The date this row was entered in UTC. \\
\hline ed_phs_pubdate & Publish date & $\begin{array}{l}\text { The date this row can become public. This } \\
\text { date can be set up to two years in advance. }\end{array}$ \\
\hline cc_id_load & Data loader ID & $\begin{array}{l}\text { An identifier for linking to contact } \\
\text { information for the person who entered this } \\
\text { row of data. }\end{array}$ \\
\hline
\end{tabular}

The Eruption Phase table (ed_phs for eruption data - phase) stores specific information about the eruption such as the size of the phase and composition of magma. The primary ID is ed_phs_id and the phase information is linked to the main Eruption table by the Eruption table ID, ed_id. The contact ID, cc_id, links to contact information for the person responsible for the data. If there are multiple viewpoints, Use separate entries into the Eruption Phase table along with the appropriate contact ID. The data loader ID, cc_id_load, links to the Contact table for more information about the person who loaded the data into WOVOdat. The load date, ed_phs_loaddate, is a TIMESTAMP and entered automatically in UTC and the date the data can become public is stored in ed_phs_pubdate.

The eruption phase number, ed_phs_num, is a number assigned by the observatory for the particular eruption phase. If the available information is not subdivided by phase, use "phase 1" to show details of the entire eruption. The time span of the eruption phase is stored in ed_phs_stime and ed_phs_etime, along with the uncertainties in the times ed_phs_stime_unc and ed_phs_etime_unc, all in UTC DATETIME. A description of the phase is stored in ed_phs_desc. The description field is currently limited to 255-characters, if more space is required we will need to change the data type. The VEI (volcano explosivity index) for the phase is stored in ed_phs_vei. The VEI should come from the Smithsonian database. The maximum lava extrusion rate, ed_phs_maxlext, is stored in cubic meters per 
second and the maximum explosive discharge rate, ed_phs_maxexpdis, is stored in kilograms per second $\times 10^{6}$. The volume of erupted magma or dense rock equivalent, ed_phs_dre, is stored in cubic meters $\times 10^{6}$.

The Eruption Phase table also contains information about magma mixing for the observed phase. The field, ed_phs_mix, should include a single character, Y for evidence of magma mixing detected, $\mathrm{N}$ for not seen, and $U$ for unknown. In addition, brief comments about the observed magma mixing can be entered such as large quantities of banded pumice. Information about the column height for this phase should be stored in ed_phs_col as kilometers. The method used to determine the column height should be stored in the text field ed_phs_coldet. The composition of the rock types from the phase are stored as maximum and minimum $\mathrm{SiO}_{2}$ content of the matrix glass, ed_phs_minsio2_mg and ed_phs_maxsio2_mg, and of the whole rock, ed_phs_minsio2_wr and ed_phs_maxsio2_wr. The compositions are stored as weight percents with two decimal places of precision. In addition to the composition, we also request information about the total crystallinity, ed_phs_totxtl, and the phenocryst content, ed_phs_phenc, and both as volume percents. The phenocryst assemblage should be included in ed_phs_phena in order of most abundant to least abundant. The pre-eruption water content in the melt, as analyzed in melt inclusions in phenocrysts, is stored in ed_phs_h2o. A description of the phenocryst and the melt inclusion that was analyzed to determine the pre-eruption water content should be stored in ed_phs_h2o_xtl along with the analysis method used. The final field is the comments field, ed_phs_com, for any additional information about the eruption phase.

\section{Eruption Video}

Table E3. Eruption Video Table

\begin{tabular}{|c|c|c|}
\hline ed_vid_id & Video ID & An identifier for linking with other tables \\
\hline vd_id & Volcano ID & $\begin{array}{l}\text { The identifier for linking to the Volcano } \\
\text { table. The Volcano table stores the volcano } \\
\text { name and time zone. It is used to connect to } \\
\text { all other data. }\end{array}$ \\
\hline ed_id & Eruption ID & $\begin{array}{l}\text { An identifier for linking with information in } \\
\text { the Eruption table. The Eruption table } \\
\text { contains general information about an } \\
\text { eruption including a narrative and time } \\
\text { span. }\end{array}$ \\
\hline ed_phs_id & Eruption phase ID & $\begin{array}{l}\text { The identifier for linking to the Eruption } \\
\text { Phase table. The Eruption Phase table stores } \\
\text { specific information about the eruption } \\
\text { phase such as the time span and } \\
\text { composition. }\end{array}$ \\
\hline ed_vid_link & Video clip link & $\begin{array}{l}\text { A link to the video clip or information about } \\
\text { where to find the video clip. }\end{array}$ \\
\hline ed_vid_stime & Start time & $\begin{array}{l}\text { The start time of the video clip in UTC } \\
\text { stored as DATETIME (YYYY-MM-DD } \\
\text { hh:mm:ss). }\end{array}$ \\
\hline
\end{tabular}




\begin{tabular}{|c|c|c|}
\hline ed_vid_stime_unc & Start time uncertainty & $\begin{array}{l}\text { The uncertainty in the start time of the video } \\
\text { clip in UTC stored as DATETIME (YYYY- } \\
\text { MM-DD hh:mm:ss). }\end{array}$ \\
\hline ed_vid_length & Length of video clip & $\begin{array}{l}\text { The length of the video clip stored in TIME } \\
\text { (hh:mm:ss). }\end{array}$ \\
\hline ed_vid_desc & Description & $\begin{array}{l}\text { A text field for a short description of the } \\
\text { video, e.g., strombolian eruption footage } \\
\text { taken from northwest of the vent at a } \\
\text { distance of } 5 \mathrm{~km} \text {. This field should contain } \\
\text { enough information to allow the user to } \\
\text { determine if the video will be useful to } \\
\text { them. }\end{array}$ \\
\hline ed_vid_com & Comments & $\begin{array}{l}\text { A text field for additional information about } \\
\text { the video including copyright information. }\end{array}$ \\
\hline cc_id & Contact ID & $\begin{array}{l}\text { An identifier for linking to contact } \\
\text { information for the video clip. }\end{array}$ \\
\hline ed_vid_loaddate & Load date & The date this row was entered in UTC. \\
\hline ed_vid_pubdate & Publish date & $\begin{array}{l}\text { The date this row can become public. This } \\
\text { date can be set up to two years in advance. }\end{array}$ \\
\hline cc_id_load & Data loader ID & $\begin{array}{l}\text { An identifier for linking to contact } \\
\text { information for the person who entered this } \\
\text { row of data. }\end{array}$ \\
\hline
\end{tabular}

The Eruption Video table (ed_vid for eruption data - video) stores information about a video clip of the eruption. The primary ID is ed_vid_id and the video information is linked to several foreign keys. At the most general level, we include the volcano ID, vd_id, in case the video covers several eruptions. The eruption ID, ed_id, is included for cases where the video contains scenes from multiple phases of an eruption and the eruption phase ID, ed_phs_id, is included for the most specific case where the video is of a single eruptive phase. The contact ID (cc_id) links to contact information for the person who created the video. The data loader ID, cc_id_load, links to the Contact table for more information about the person who loaded the data into WOVOdat. The load date, ed_vid_loaddate, is a TIMESTAMP and entered automatically in UTC and the date the data can become public is stored in ed_phs_pubdate.

The video link, ed_vid_link, contains a link or information on how to access the video footage. The start time of the video, ed_vid_stime, stores the time the video starts in UTC as DATETIME and the length of the video, ed_vid_length, is stored as TIME (hh:mm:ss). The description field, ed_vid_desc, is a text field for a short description of the video such as "strombolian eruption footage taken $5 \mathrm{~km}$ northwest of the vent." The description field should contain enough information for the user so a decision can be made about the usefulness of the video prior to downloading it. The comments field, ed_vid_com, should include copyright information and any additional comments.

\section{Eruption Forecast}

Table E4. Eruption Phase Table

\begin{tabular}{|l|l|l|}
\hline ed_for_id & Forecast ID & An identifier for linking with other tables \\
\hline
\end{tabular}




\begin{tabular}{|c|c|c|}
\hline vd_id & Volcano ID & $\begin{array}{l}\text { The identifier for linking to the Volcano } \\
\text { table. The Volcano table stores the volcano } \\
\text { name and time zone. It is used to connect to } \\
\text { all other data. }\end{array}$ \\
\hline ed_phs_id & Eruption phase ID & $\begin{array}{l}\text { The identifier for linking to the Eruption } \\
\text { Phase table. The Eruption Phase table stores } \\
\text { specific information about the eruption } \\
\text { phase such as the time span and } \\
\text { composition. }\end{array}$ \\
\hline ed_for_desc & Description & $\begin{array}{l}\text { A short description of the forecast for this } \\
\text { phase. Please include the forecast type and } \\
\text { magnitude ( } 255 \text { character text field). }\end{array}$ \\
\hline ed_for_open & Forecast window opens & $\begin{array}{l}\text { The earliest expected start time of the } \\
\text { eruption,in UTC stored as DATETIME } \\
\text { (YYYY-MM-DD hh:mm:ss). }\end{array}$ \\
\hline ed_for_open_unc & $\begin{array}{l}\text { Forecast window opens } \\
\text { uncertainty }\end{array}$ & $\begin{array}{l}\text { The uncertainty in the earliest expected start } \\
\text { time of the eruption,in UTC stored as } \\
\text { DATETIME (YYYY-MM-DD hh:mm:ss). }\end{array}$ \\
\hline ed_for_close & Forecast window closes & $\begin{array}{l}\text { The latest expected start time of the } \\
\text { eruption, in UTC stored as DATETIME } \\
\text { (YYYY-MM-DD hh:mm:ss). }\end{array}$ \\
\hline ed_for_close_unc & $\begin{array}{l}\text { Forecast window closes } \\
\text { uncertainty }\end{array}$ & $\begin{array}{l}\text { The uncertainty in the latest expected start } \\
\text { time of the eruption, in UTC stored as } \\
\text { DATETIME (YYYY-MM-DD hh:mm:ss). }\end{array}$ \\
\hline ed_for_time & Forecast issue date & $\begin{array}{l}\text { The time the forecast was issued in UTC } \\
\text { stored as DATETIME (YYYY-MM-DD } \\
\text { hh:mm:ss). }\end{array}$ \\
\hline ed_for_time_unc & $\begin{array}{l}\text { Forecast issue date } \\
\text { unceratinty }\end{array}$ & $\begin{array}{l}\text { The uncertainty in the time the forecast was } \\
\text { issued in UTC stored as DATETIME } \\
\text { (YYYY-MM-DD hh:mm:ss). }\end{array}$ \\
\hline ed_for_tsucc & $\begin{array}{l}\text { Success of forecast time flag } \\
\text { success }\end{array}$ & $\begin{array}{l}\text { A flag and comments on the success of the } \\
\text { forecasted time of the eruption. Use the } \\
\text { letters } Y \text { for yes, } \mathrm{N} \text { for no, or } \mathrm{P} \text { for Partly. }\end{array}$ \\
\hline ed_for_msucc & $\begin{array}{l}\text { Success of forecast } \\
\text { magnitude flag }\end{array}$ & $\begin{array}{l}\text { A flag and cmments on the success of the } \\
\text { forecasted type and magnitude of the } \\
\text { eruption. Use the letters Y for yes, } \mathrm{N} \text { for no, } \\
\text { or P for Partly. }\end{array}$ \\
\hline ed_for_com & Forecast comments & $\begin{array}{l}\text { Any comments or additional information } \\
\text { about the forecast, including what aspects } \\
\text { were or were not successful. }\end{array}$ \\
\hline cc_id & Contact ID & $\begin{array}{l}\text { An identifier for linking to contact } \\
\text { information about the forecast. }\end{array}$ \\
\hline ed_for_loaddate & Load date & The date this row was entered in UTC. \\
\hline
\end{tabular}




\begin{tabular}{|l|l|l|}
\hline ed_for_pubdate & Publish date & $\begin{array}{l}\text { The date this row can become public. This } \\
\text { date can be set up to two years in advance. }\end{array}$ \\
\hline cc_id_load & Data loader ID & $\begin{array}{l}\text { An identifier for linking to contact } \\
\text { information for the person who entered this } \\
\text { row of data. }\end{array}$ \\
\hline
\end{tabular}

The Eruption Forecast table (ed_for for eruption data - forecast) stores information about forecasts made for a phase of the eruption, such as an overview of the forecast and the times forecasted. The forecasts give an insight into what was thought would occur at specific times during unrest. WOVOdat should provide the opportunity to analyze forecasts with monitoring data and event outcomes for future crisis situations.

The primary ID is ed_for_id and links to the Volcano table, vd_id, and the Eruption Phase table, ed_phs_id, are included to provide access to additional information about the volcanic activity. Originally, we wanted to only include the eruption phase ID, however, we also want information about forecasts where an eruption did not occur prior to the issuing of another forecast. Additional information about forecasts for events that did not lead to an eruption can be found using the link to the Volcano table. The contact ID, cc_id, links to contact information for the person who created the forecast. The data loader ID, cc_id_load, links to the Contact table for more information about the person who loaded the data into WOVOdat. The load date, ed_for_loaddate, is a TIMESTAMP and entered automatically in UTC and the date the data can become public is stored in ed_phs_pubdate.

The forecast description, ed_for_desc, is a 255-character text field for describing the forecast made. Additional space may be required in the future. We store three separate forecast times: the earliest forecast start of the eruption, ed_for_open; the latest forecast start of the eruption, ed_for_close; and the time the forecast was made, ed_for_time. There are two fields that will store flags and comments on the success of the forecast, ed_for_tsuccess for evaluating the timing of the eruption and ed_for_msucc for evaluating the success of the type and magnitude of the forecast. We request the use of the letters $\mathrm{Y}$ (successful, correct), N (unsuccessful, incorrect), or P (partly successful) for both of the success evaluation fields. The comments field, ed_for_com, is a 255-character text field for any additional information about the forecast. If there are multiple comments for a particular forecast, then we may want a separate table for people to be able to provide additional comments.

\section{Create table statements for eruption tables}

DROP TABLE IF EXISTS ed;

create table ed (

ed_id mediumint not null auto_increment,

vd_id mediumint,

ed_name varchar(60),

ed_nar varchar(255),

ed_stime datetime,

ed_stime_unc datetime,

ed_etime datetime,

ed_etime_unc datetime,

ed_climax datetime,

ed_climax_unc datetime,

ed_com varchar(255),

cc_id mediumint,

ed_loaddate datetime,

ed_pubdate datetime, 
cc_id_load mediumint,

primary key (ed_id));

DROP TABLE IF EXISTS ed_phs;

create table ed_phs (

ed_phs_id mediumint not null auto_increment, ed_id mediumint,

ed_phs_phsnum float,

ed_phs_stime datetime,

ed_phs_stime_unc datetime,

ed_phs_etime datetime,

ed_phs_etime_unc datetime,

ed_phs_desc varchar(255),

ed_phs_vei mediumint,

ed_phs_max_lext float,

ed_phs_max_expdis float,

ed_phs_dre float,

ed_phs_mix char(1),

ed_phs_col float,

ed_phs_coldet varchar(255),

ed_phs_minsio2_mg float,

ed_phs_maxsio2_mg float,

ed_phs_minsio2_wr float,

ed_phs_maxsio2_wr float,

ed_phs_totxtl float,

ed_phs_phenc float,

ed_phs_phena varchar(255),

ed_phs_h2o float,

ed_phs_h2o_xtl varchar(255),

ed_phs_com varchar(255),

cc_id mediumint,

ed_phs_loaddate datetime,

ed_phs_pubdate datetime,

cc_id_load mediumint,

primary key (ed_phs_id));

DROP TABLE IF EXISTS ed_vid;

create table ed_vid (

ed_vid_id mediumint not null auto_increment, vd_id mediumint,

ed_id mediumint,

ed_phs_id mediumint,

ed_vid_link varchar(255),

ed_vid_stime datetime,

ed_vid_stime_unc datetime,

ed_vid_length time,

ed_vid_desc varchar(255),

ed_vid_com varchar(255),

cc_id mediumint,

ed_vid_loaddate datetime,

ed_vid_pubdate datetime,

cc_id_load mediumint,

primary key (ed_vid_id)); 
DROP TABLE IF EXISTS ed_for;

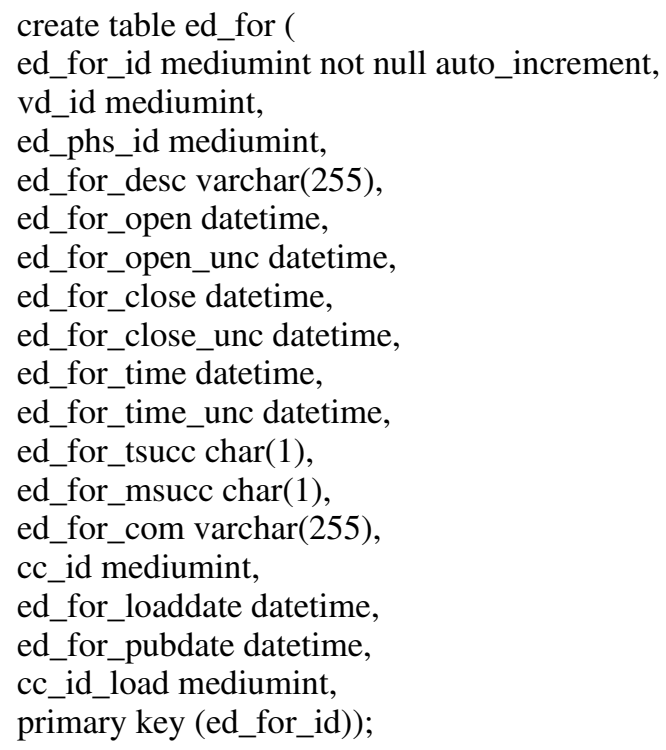

\section{Seismic}

One of the most useful types of information about volcanic unrest is seismic data. Almost all volcanoes exhibit some type of seismic activity prior to eruption. Our ability to collect the seismic data, however, is limited by the number and types of instruments at a volcano. The seismic tables were created to store earthquake and volcanic tremor data as recorded by both seismic networks and individual seismic stations. At this time, only a few volcanoes have networks with more than 50 stations; many more have less than five. Additionally, many of the seismometers of interest are shortperiod instruments although use of broadband instruments is increasing. Originally, only the processed data was going to be included in these tables but many of the seismic experts who reviewed the parameter list have requested more background information to provide the details needed to understand the processed data. We have added more background information and included qualitative attributes to more fully describe the instrument response for those who would like the additional information. We would also like to store some waveforms as digital data but a table has not been created for the storage. Once the storage formats are known, a table named Waveform Data (sd_wvd) should be created that links to the Waveform table.

- Multiple seismic tables were created to accommodate the large variation in seismic data that have been and are currently being collected.

- The Event Data from a Network table stores the magnitudes, locations, and additional information about earthquakes recorded at multiple stations in a network.

- The Event Data from a Single Station stores the maximum amplitude of the trace, the coda duration, and a felt intensity for events recorded at single stations. The latter data cannot be used to find a location of the event.

- The Intensity table stores information about felt earthquakes. Although the data are not recorded by an instrument, we provide links to the Seismic Station or Seismic Network tables for the cases where the intensity reports can be linked to recorded data about the event.

- The Tremor table stores the duration of the tremor, amplitudes, and dominant frequencies for periods of tremor. The tremor envelope will be picked by the observatory and can be linked to a waveform in the waveform table. 
- The Interval (Swarm) Data table stores the number of felt earthquakes, total seismic release, and migration of hypocenters for specified periods of time.

- The next three tables store Real-time Seismic-Amplitude Measurements (RSAM) and Seismic Spectral-Amplitude Measurements (SSAM), which integrate seismic activity in real-time during volcanic crises using the amplitudes and frequencies of seismic signals rather than the locations and magnitudes of the earthquakes.

- The Waveforms table stores representative waveforms and links to archives of additional waveforms.

- The Seismic Network table stores information about the seismic network such as the velocity model and instrument type.

- The Seismic Station table stores information about the individual stations such as their location, instrument type, and system gain.

- The Seismic Instrument table provides information about the instruments such as model, manufacturer, number of components, dynamic range, and instrument gain.

- The information about how the individual components attach to the instrument is stored in the Seismic Component table.

- The Earthquake Translation table links earthquake types used by individual observatories to the WOVOdat earthquake type.

Event Data from a Network

Table S1. Event Data from a Network Table

\begin{tabular}{|c|c|c|}
\hline sd_evn_id & Seismic data ID & An identifier for linking with other tables. \\
\hline sn_id & Seismic network ID & $\begin{array}{l}\text { An identifier for linking with the seismic } \\
\text { network information. The Seismic Network } \\
\text { table provides information on the velocity } \\
\text { model used and a link to the volcano } \\
\text { information. }\end{array}$ \\
\hline sd_evn_eventid & Event identifier & The event identifier used by observatory. \\
\hline sd_evn_arch & Seismogram archive & $\begin{array}{l}\text { Location of the seismogram archive, if } \\
\text { available. The network ID and collector ID } \\
\text { also link to additional contact information. }\end{array}$ \\
\hline sd_evn_time & Origin time & $\begin{array}{l}\text { The time of the beginning of the event in } \\
\text { UTC stored as DATETIME (YYYY-MM- } \\
\text { DD hh:mm:ss). }\end{array}$ \\
\hline sd_evn_time_unc & Origin time uncertainty & $\begin{array}{l}\text { The uncertainty in the time of the beginning } \\
\text { of the event in UTC stored as DATETIME } \\
\text { (YYYY-MM-DD hh:mm:ss). }\end{array}$ \\
\hline sd_evn_dur & Duration (coda length) & $\begin{array}{l}\text { Average duration of the earthquake as } \\
\text { recorded at stations }<15 \mathrm{~km} \text { from the } \\
\text { volcano (in } \mathrm{sec} \text { ) }\end{array}$ \\
\hline sd_evn_dur_unc & $\begin{array}{l}\text { Duration (coda length) } \\
\text { uncertainty }\end{array}$ & $\begin{array}{l}\text { The uncertainty in the average duration of } \\
\text { the earthquake as recorded at stations }<15 \\
\mathrm{~km} \text { from the volcano (in sec) }\end{array}$ \\
\hline sd_evn_tech & Location technique & The technique used to locate the event. \\
\hline
\end{tabular}




\begin{tabular}{|c|c|c|}
\hline & & $\begin{array}{l}\text { Please include information about each } \\
\text { recalculation such as "initial Hypo71, those } \\
\text { locations recalculated using double } \\
\text { difference". There is a } 255 \text {-character limit } \\
\text { on this field. }\end{array}$ \\
\hline sd_evn_picks & Picks & $\begin{array}{l}\text { A description of how the picks were } \\
\text { determined. Use A for an automatic picker, } \\
\mathrm{R} \text { for hand-picked with a ruler, } \mathrm{H} \text { for a } \\
\text { human using a computer-based picker, or U } \\
\text { for unknown. }\end{array}$ \\
\hline sd_evn_elat & Estimated latitude & $\begin{array}{l}\text { Estimated latitude of the seismic event } \\
\text { (positive = N) (sxx.xxxxxxx). }\end{array}$ \\
\hline sd_evn_elon & Estimated longitude & $\begin{array}{l}\text { Estimated longitude of the seismic event } \\
\text { (positive = E) (sxxx.xxxxxxx). }\end{array}$ \\
\hline sd_evn_datum & Datum & $\begin{array}{l}\text { The datum used for the longitude and } \\
\text { latitude. WGS } 84 \text { is the official WOVOdat } \\
\text { datum and locations should be converted } \\
\text { wherever possible. }\end{array}$ \\
\hline sd_evn_edep & Estimated depth & $\begin{array}{l}\text { Estimated depth of the seismic event in } \\
\text { kilometers (xxx.x). }\end{array}$ \\
\hline sd_evn_fixdep & Fixed depth flag & $\begin{array}{l}\text { A flag to indicate that the depth was held } \\
\text { fixed by the location algorithm. Use Y for } \\
\text { fixed, } \mathrm{N} \text { for not fixed, and U for unknown. } \\
\text { If the depth was fixed, information about } \\
\text { how the depths are fixed should be available } \\
\text { in the Seismic Network table. }\end{array}$ \\
\hline sd_evn_nst & Total number of stations & $\begin{array}{l}\text { The total number of seismic stations that } \\
\text { reported arrival times for this earthquake. }\end{array}$ \\
\hline sd_evn_nph & Number of phases & $\begin{array}{l}\text { The total number of } \mathrm{P} \text { and } \mathrm{S} \text { arrival-time } \\
\text { observations used to compute the } \\
\text { hypocenter location }\end{array}$ \\
\hline sd_evn_gp & Azimuthal gap & $\begin{array}{l}\text { The largest azimuthal gap between } \\
\text { azimuthally adjacent stations (in degrees, } 0 \text { - } \\
\text { 360) (xxx). }\end{array}$ \\
\hline sd_evn_dcs & Distance to closest station & $\begin{array}{l}\text { Horizontal distance from the epicenter to } \\
\text { the nearest station in } \mathrm{km}(\mathrm{xx} . \mathrm{x}) \text {. }\end{array}$ \\
\hline sd_evn_rms & Rms & $\begin{array}{l}\text { The weighted root-mean-square (RMS) } \\
\text { travel time residual, in sec. This parameter } \\
\text { provides a measure of the fit of the observed } \\
\text { arrival times to the predicted arrival times } \\
\text { for this location (xx.xx) }\end{array}$ \\
\hline sd_evn_herr & Horizontal error & $\begin{array}{l}\text { The horizontal location error, in km, defined } \\
\text { as the length of the largest projection of the } \\
\text { three principal errors on a horizontal plane. } \\
\text { The principal errors are the major axes of } \\
\text { the error ellipsoid, and are mutually } \\
\text { perpendicular (xx.xxx). }\end{array}$ \\
\hline
\end{tabular}




\begin{tabular}{|c|c|c|}
\hline sd_evn_xerr & X error & $\begin{array}{l}\text { The maximum } x \text { (longitude) error, in } \mathrm{km} \text {, } \\
\text { for cases where the horizontal error is not } \\
\text { given. }\end{array}$ \\
\hline sd_evn_yerr & Y error & $\begin{array}{l}\text { The maximum y (latitude) error, in } \mathrm{km} \text {, for } \\
\text { cases where the horizontal error is not } \\
\text { given. }\end{array}$ \\
\hline sd_evn_derr & Depth error & $\begin{array}{l}\text { The depth error, in km, defined as the } \\
\text { largest projection of the three principal } \\
\text { errors on a vertical line (xx.xxx). }\end{array}$ \\
\hline sd_evn_locqual & Location quality & $\begin{array}{l}\text { The quality of the calculated location. The } \\
\text { quality marker will be defined by } \\
\text { WOVOdat and added at a later date. }\end{array}$ \\
\hline sd_evn_pmag & Primary Magnitude & The primary Magnitude stored as X.X. \\
\hline sd_evn_pmag_type & Primary Magnitude type & $\begin{array}{l}\text { The primary Magnitude type, e.g., } M_{s}, M_{b} \text {, } \\
M_{w}, M_{d} \text { (the last, duration or "coda" } \\
\text { magnitude). }\end{array}$ \\
\hline sd_evn_smag & Secondary Magnitude & $\begin{array}{l}\text { A secondary Magnitude, where given, } \\
\text { stored as x.x. }\end{array}$ \\
\hline sd_evn_smag_type & Secondary Magnitude type & A secondary Magnitude type. \\
\hline sd_evn_eqtype & $\begin{array}{l}\text { Earthquake type (WOVOdat } \\
\text { terminology) }\end{array}$ & $\begin{array}{l}\text { The WOVOdat terminology for the } \\
\text { earthquake type. Please see the Earthquake } \\
\text { Translation table (sr_eqtr) for information } \\
\text { on the translation from the original } \\
\text { terminology to the WOVOdat terminology. }\end{array}$ \\
\hline sd_evn_eqtype_org & $\begin{array}{l}\text { Earthquake type (original } \\
\text { terminology) }\end{array}$ & $\begin{array}{l}\text { The original terminology for the earthquake } \\
\text { type given by the observatory. (for example, } \\
\text { VT, LP; A,B,C; HF, LF; other) }\end{array}$ \\
\hline sd_evn_mtscale & Moment tensor scale & $\begin{array}{l}\text { The scale of the following moment tensor } \\
\text { data. Please store as a multiplier for the } \\
\text { moment tensor data. }\end{array}$ \\
\hline sd_evn_mxx & Moment tensor $\mathrm{m} \_\mathrm{xx}$ & Moment tensor $\mathrm{m} \_\mathrm{xx}$ stored as $+/-\mathrm{x} . \mathrm{xx}$. \\
\hline sd_evn_mxy & Moment tensor $\mathrm{m} \_\mathrm{xy}$ & Moment tensor $\mathrm{m} \_\mathrm{xy}$ stored as $+/$ - $\mathrm{x} . \mathrm{xx}$. \\
\hline sd_evn_mxz & Moment tensor $\mathrm{m} \_\mathrm{xz}$ & Moment tensor $\mathrm{m} \_\mathrm{xz}$ stored as +/- $\mathrm{x} . \mathrm{xx}$. \\
\hline sd_evn_myy & or $\mathrm{m} \_\mathrm{yy}$ & Moment tensor m_yy stored as +/- x.xx. \\
\hline sd_evn_myz & Moment t & Moment tensor m_yz stored as +/- x.xx. \\
\hline sd_evn_mzz & Moment tensor $\mathrm{m} \_z z$ & Moment tensor $\mathrm{m} \_z z$ stored as $+/$ - $\mathrm{x} . \mathrm{xx}$. \\
\hline sd_evn_strk1 & Strike 1 & $\begin{array}{l}\text { Strike } 1 \text { of best double couple }(0-360 \\
\text { degrees) (xxx). }\end{array}$ \\
\hline sd_evn_strk1_err & Strike 1 Error & The uncertainty in the value of strike $1(\mathrm{x})$. \\
\hline sd_evn_dip1 & Dip 1 & $\begin{array}{l}\text { Dip } 1 \text { of best double couple (0-90 degrees) } \\
\text { (xx). }\end{array}$ \\
\hline sd_evn_dip1_err & Dip 1 Error & The uncertainty in the value of dip 1 (x). \\
\hline sd_evn_rak1 & & $\begin{array}{l}\text { Rake } 1 \text { of best double couple (0-90 degrees) } \\
(\mathrm{xx}) \text {. }\end{array}$ \\
\hline sd_evn_rak1_err & Rake 1 Error & The uncertainty in the value of rake 1 (x). \\
\hline sd_evn_strk2 & Strike 2 & $\begin{array}{l}\text { Strike } 2 \text { of best double couple, if available } \\
(0-360 \text { degrees })(\mathrm{xx}) \text {. }\end{array}$ \\
\hline
\end{tabular}




\begin{tabular}{|l|l|l|}
\hline sd_evn_strk2_err & Strike 2 Error & The uncertainty in the value of strike 2 (x). \\
\hline sd_evn_dip2 & Dip 2 & $\begin{array}{l}\text { Dip 2 of best double couple, if available (0- } \\
\text { 90 degrees) (xx). }\end{array}$ \\
\hline sd_evn_dip2_err & Dip 2 error & The uncertainty in the value of dip 2 (x). \\
\hline sd_evn_rak2 & Rake 2 & $\begin{array}{l}\text { Rake 2 of best double couple, if available } \\
\text { (0-90 degrees) (xx). }\end{array}$ \\
\hline sd_evn_rak2_err & Rake 2 error & The uncertainty in the value of rake 2 (x). \\
\hline sd_evn_foc & Focal plane solution & $\begin{array}{l}\text { The focal plane solution (beachball, w/ } \\
\text { arrivals) stored as a .gif for well defined } \\
\text { events. }\end{array}$ \\
\hline sd_evn_samp & Sampling rate & The sampling rate in Hz. \\
\hline cc_id_owner & Data owner ID & $\begin{array}{l}\text { The link to the contact information for the } \\
\text { owner of this set of data. }\end{array}$ \\
\hline sd_evn_loaddate & Load date & The date this row was entered in UTC. \\
\hline sd_evn_pubdate & Publish date & $\begin{array}{l}\text { The date this row can become public. This } \\
\text { date can be set up to two years in advance. }\end{array}$ \\
\hline & & $\begin{array}{l}\text { An identifier for linking to contact } \\
\text { information for the person who entered this } \\
\text { row of data. }\end{array}$ \\
\hline cc_id_load & Data loader ID &
\end{tabular}

The Event Data from a Network table (sd_evn for seismic data - event from a network) contains seismic data that were collected from several stations in a network and then processed to give a location. Most of these data are in an electronic format and will be loaded by scripts from either the observatories or from a central seismic database like IRIS. The primary ID is sd_evn_id and there are several foreign IDs for linking to other tables. The Seismic Network table is linked by sn_id and provides the velocity model, a conversion from local time to UTC, information about the type of instruments used (for instrument details you would need to link to the station tables associated with the network and then from there to the instrument table), a link to the volcano information, and a link to the contact information for the person responsible for the network. The data loader ID, cc_id_load, links contact information about the person who loaded the data (ran the script or is in charge of running the script) into WOVOdat and the data owner ID, cc_id_owner, links to the contact information for the person who owns the data. The load date, sd_evn_loaddate, is a TIMESTAMP and entered automatically in UTC. The date the data can become public is stored in sd_evn_pubdate.

The event identifier used by the observatory that collected the data is stored as sd_evn_eventid and the location of the seismogram archive is stored as sd_evn_arch. The archive contact information may be the same as the network contact information and the collector information, if the data are not stored in a central repository. Additional information about the waveform data, if available, including a link to the waveform, can be found in the Waveform table (sd_wav). The technique used to locate the event is stored as, sd_evn_tech. We added this field to the data table to store not only the original technique used to locate the event but also any subsequent recalculations. An example entry into this text field would be "initial Hypo71, those locations recalculated using double difference".

The origin time of the seismic event, sd_evn_time, and the uncertainty, sd_evn_time_unc, are stored as DATETIME in UTC (see time discussion under challenges). The average length of earthquake codas are stored in sd_evn_dur to simplify the estimation of coda magnitudes. The uncertainty for the average length of the earthquake codes are stored in sd_evn_dur_unc. A description of how the picks were determined is stored in sd_evn_picks. Use A for an automatic picker, $\mathrm{R}$ for hand-picked with a ruler, $\mathrm{H}$ for a human using a computer-based picker, or $\mathrm{U}$ for unknown. The estimated latitude and 
longitude of the epicenter are stored as sd_evn_elat and sd_evn_elon and the estimated depth of the hypocenter is stored as sd_evn_edep. A flag, sd_evn_fixdep, is included to indicate fixed depths where $\mathrm{Y}$ is for depths that are fixed, $\mathrm{N}$ is for depths that are not fixed, and $\mathrm{U}$ is for unknown. If the depths have been held fixed in the location algorithm then the Seismic Network table, linked by sn_id, should indicate this. The datum for the latitudes and longitudes are stored as sd_evn_datum. Most of the seismic community uses WGS 84 as their datum, which is the preferred datum for WOVOdat.

The U.S. Geological Survey Earthquake Program web pages (http://earthquake.usgs.gov/recenteqsww/glossary.htm) provided information for the next set of attributes. The total number of stations and phases used to determine the location of the event are stored as integers in sd_evn_nst and sd_evn_nph. The azimuthal gap, sd_evn_gp, is the largest azimuthal gap between azimuthally adjacent stations in degrees (0-360). The horizontal distance from the epicenter to the nearest station is stored in sd_evn_dcs (dcs is for distance to the closest station) in $\mathrm{km}$. The rootmean-square (RMS) travel time residual is stored in seconds in the attribute sd_evn_rms. This parameter provides a measure of the fit of the observed arrival times to the predicted arrival times for this location. The value is dependent on the accuracy of the velocity model used to compute the earthquake location, the quality weights assigned to the arrival time data, and the procedure used to locate the earthquake (the velocity model can be found in the network table). The horizontal location error, sd_evn_herr, is defined as the length of the largest projection of the three principal errors on a horizontal plane and is stored in $\mathrm{km}$. Alternatively, we include fields for the $\mathrm{x}$ and $\mathrm{y}$ error, sd_evn_xerr and sd_evn_yerr, if the uncertainties are stored by $\mathrm{x}$ and $\mathrm{y}$ errors instead of the error on the xy plane. The depth error, sd_evn_derr, is defined as the largest projection of the three principal errors on a vertical line and is also stored in $\mathrm{km}$. The quality of the calculation location is given in sd_evn_locqual. This quality marker is based on a WOVOdat quality scale that has not yet been created.

The earthquake magnitude is a logarithmic measure of size that is computed by different methods depending on the range of the magnitude and type of seismometer used in the measurement. Because there are different methods for measuring magnitude, we are providing fields to store a primary magnitude and type and a secondary magnitude and type. In many cases a secondary magnitude will not be available. The primary and secondary magnitudes are stored as sd_evn_pmag and sd_evn_smag. The identifying factor for the magnitudes is the magnitude type, sd_evn_pmag_type and sd_evn_smag_type. The magnitude types are limited to the following: duration (Md), local (ML), surface wave $(\mathrm{Ms})$, moment $(\mathrm{Mw})$ and body $(\mathrm{Mb})$. The duration magnitude $(\mathrm{Md})$ is based on the duration of shaking as measured by the time decay of the amplitude of the seismogram. This magnitude (also known as coda magnitude) is often used to compute magnitude from seismograms with "clipped" waveforms due to limited dynamic recording range of analog instrumentation. The local magnitude (ML) is the original magnitude relationship defined by Richter and Gutenberg for local earthquakes and is based on the maximum amplitude of a seismogram recorded on a Wood-Anderson torsion seismograph (appropriate adjustments are made for modern instrumentation). The surface wave magnitude (Ms) is used for distant earthquakes based on the amplitude of Rayleigh surface waves measured at a period near $20 \mathrm{sec}$. The moment magnitude (Mw) is based on the moment of the earthquake, which is equal to the rigidity of the earth times the average amount of slip on the fault times the amount of fault area that slipped. The body magnitude $(\mathrm{Mb})$ is based on the amplitude of $\mathrm{P}$ bodywaves and is most appropriate for deep-focus earthquakes.

The earthquake type as defined by WOVOdat is stored as sd_evn_eqtype. The earthquake translation table (sr_eqtr for seimic reference table - earthquake translations) will be used to map original terminologies into standard WOVOdat earthquake terminology. At present, different scientists refer to earthquakes using several different terminologies and we hope that including a standard WOVOdat terminology along with the original earthquake type, sd_evn_eqtype_org, will facilitate systematic searches and correlations between data. 
We store the six moment tensors $\mathrm{m} \_x x, \mathrm{~m} \_x y, \mathrm{~m} \_\mathrm{xz}, \mathrm{m} \_\mathrm{yy}, \mathrm{m} \_\mathrm{yz}$, and $\mathrm{m} \_z z$ with the format $+/$ x.xx as sd_evn_mxx, sd_evn_mxy, sd_evn_mxz, sd_evn_yy, sd_evn_yz,sd_evn_zz. The scale for the moment tensors is stored as a multiplier in sd_evn_mtscale.We also store two strikes, dips, and rakes for the best double couple, if available, as sd_evn_strk1, sd_evn_dip1, sd_evn_rake1, sd_evn_strk2, sd_evn_dip2, and sd_evn_rake2. The strikes are stored in degrees from 0-360 and the dips and rakes are stored in degrees from 0-90. The uncertainties in the strikes, dips, and rakes are stored in sd_evn_strk1_err, sd_evn_dip1_err, sd_evn_rake1_err, sd_evn_strk2_err, sd_evn_dip2_err, and sd_evn_rake2_err. An image (the beach ball arrivals) of the focal plane solution, sd_evn_foc, is requested for well-defined events to show the solution graphically and to show any non-double couple component. The sample rate of stored event data is given in sd_evn_samp.

\section{Event Data from a Single Station}

Table S2. Event Data from a Single Station Table

\begin{tabular}{|c|c|c|}
\hline sd_evs_id & Event data ID & An identifier for linking with other tables \\
\hline ss_id & Seismic station ID & $\begin{array}{l}\text { An identifier for linking with the seismic } \\
\text { station information. The Seismic Station } \\
\text { table provides the station location, } \\
\text { instrument information, and a conversion } \\
\text { from local time to UTC. }\end{array}$ \\
\hline sd_evs_time & Event start time & $\begin{array}{l}\text { The event start time (P phase) in UTC } \\
\text { stored as DATETIME (YYYY-MM-DD } \\
\text { hh:mm:ss). }\end{array}$ \\
\hline sd_evs_time_unc & Event start time uncertainty & $\begin{array}{l}\text { The uncertainty in the event start time (P } \\
\text { phase) in UTC stored as DATETIME } \\
\text { (YYYY-MM-DD hh:mm:ss). }\end{array}$ \\
\hline sd_evs_picks & Picks & $\begin{array}{l}\text { A description of how the picks were } \\
\text { determined. Use A for an automatic picker, } \\
\mathrm{R} \text { for hand-picked with a ruler, } \mathrm{H} \text { for a } \\
\text { human using a computer-based picker, or U } \\
\text { for unknown. }\end{array}$ \\
\hline sd_evs_spint & S-P Interval & $\begin{array}{l}\text { The interval between the } \mathrm{S} \text { and } \mathrm{P} \text { start times } \\
\text { in seconds. }\end{array}$ \\
\hline sd_evs_dur & Coda duration & $\begin{array}{l}\text { The length or duration of the event in } \\
\text { seconds from the start time until a } \\
\text { background level has returned. }\end{array}$ \\
\hline sd_evs_dur_unc & Coda duration uncertainty & $\begin{array}{l}\text { The uncertainty in the length or duration of } \\
\text { the event in seconds from the start time until } \\
\text { a background level has returned. }\end{array}$ \\
\hline sd_evs_dist_actven & Distance from active vent & $\begin{array}{l}\text { The approximate distance from where the } \\
\text { event was recorded to the active vent. }\end{array}$ \\
\hline sd_evs_maxamptrac & Max amplitude of trace & $\begin{array}{l}\text { The maximum amplitude of trace. Please } \\
\text { enter this information only if whole system } \\
\text { magnification is listed in Seismic Station } \\
\text { table. }\end{array}$ \\
\hline
\end{tabular}




\begin{tabular}{|l|l|l|}
\hline sd_evs_samp & Sampling rate & $\begin{array}{l}\text { The sampling rate in Hz of the stored } \\
\text { single-station data. }\end{array}$ \\
\hline cc_id & Collector ID & $\begin{array}{l}\text { An identifier for linking to contact } \\
\text { information for the data collector. }\end{array}$ \\
\hline sd_evs_loaddate & Load date & The date this row was entered in UTC. \\
\hline sd_evs_pubdate & Publish date & $\begin{array}{l}\text { The date this row can become public. This } \\
\text { date can be set up to two years in advance. }\end{array}$ \\
\hline cc_id_load & $\begin{array}{l}\text { An identifier for linking to contact } \\
\text { information for the person who entered this } \\
\text { row of data. }\end{array}$ \\
\hline
\end{tabular}

The Event Data from a Single Station table (sd_evs for seismic data - event from a single station) contains seismic data that were collected from a single station and therefore no location can be calculated. The event data from a single station primary ID is sd_evs_id. The Seismic Station table is linked by ss_id and provides the location of the station, a conversion from local time to UTC, a link to the instrument table, and a link to the Seismic Network table, if the station is part of a network. The Event Data from a Single Station table was originally created to store data from stations that are not linked to a network, however, we understand that there is valuable information from single stations that are part of a network, for example, event counts from a single station that might be more complete than an event count based only on located events. The collector ID, cc_id, and data loader ID, cc_id_load, both link to contact information in the Contact table. The load date, sd_evn_loaddate, is a TIMESTAMP and entered automatically in UTC. The date the data can become public is stored in sd_evs_pubdate.

The event start time and uncertainty, recorded as the beginning of the P phase, sd_evs_time and sd_evs_time_unc, is stored in UTC as DATETIME and the duration of the event or coda duration and its uncertainty is stored in seconds as sd_evs_dur and sd_evs_dur_unc. The time interval between the $S$ and $\mathrm{P}$ arrivals is stored as sd_evs_spint in seconds. The distance from the active vent to where the event was recorded can be stored in sd_evs_dist_actven. We originally wanted to calculate this distance from other data in WOVOdat but at this time we do not store the location of the active vent. We store the location of the summit and of the youngest caldera in the Volcano Information table and the times and compositions of the eruptions in the Eruption and Eruption Phase tables. We will need to add an active vent location to the Eruption Phase table to make this calculation or make the sd_evs_dis_actven a text field and request that the vent location is entered, if known, as well as the distance. The maximum amplitude of the trace, sd_evs_maxamptrac, should be stored only if the whole system magnification is listed in the Seismic Station table. The Event Data from a Single Station also includes a reported intensity of the event as sd_evs_fint. If additional intensity information is available, it will be stored in the Intensity table along with a link to the event ID. The sampling rate of the data is stored in sd_evs_samp. Note: The sampling rate in the Seismic Component table refers to the collection rate for the data.

Intensity Data

Table S3. Intensity Date Table

\begin{tabular}{|l|l|l|}
\hline sd_int_id & Intensity ID & An identifier for linking with other tables \\
\hline vd_id & Volcano ID & $\begin{array}{l}\text { An identifier for linking to the volcano } \\
\text { information. }\end{array}$ \\
\hline
\end{tabular}




\begin{tabular}{|l|l|l|}
\hline sd_evn_id & Probable network event ID & $\begin{array}{l}\text { This is the probable event identifier for } \\
\text { linking with event information from the } \\
\text { Network table, if available. }\end{array}$ \\
\hline sd_evs_id & $\begin{array}{l}\text { Probable single station event } \\
\text { ID }\end{array}$ & $\begin{array}{l}\text { This is the probable event identifier for } \\
\text { linking with event information from the } \\
\text { single Station table, if available. }\end{array}$ \\
\hline sd_int_time & Time & $\begin{array}{l}\text { Approximate time of event (UTC) stored as } \\
\text { DATETIME (YYYY-MM-DD hh:mm:ss). }\end{array}$ \\
\hline sd_int_time_unc & Time uncertainty & $\begin{array}{l}\text { Uncertainty in the approximate time of } \\
\text { event (UTC) stored as DATETIME } \\
\text { (YYYY-MM-DD hh:mm:ss). }\end{array}$ \\
\hline sd_int_city & City & $\begin{array}{l}\text { The name of the city or town where the } \\
\text { event was felt. }\end{array}$ \\
\hline sd_int_maxdist & Max distance, felt & $\begin{array}{l}\text { The maximum distance at which the } \\
\text { earthquake was felt, measured from the } \\
\text { volcano summit in km (xxx). }\end{array}$ \\
\hline sd_int_maxrint & Maximum reported intensity & $\begin{array}{l}\text { The maximum reported intensity (modified } \\
\text { mercalli intensity) (x). }\end{array}$ \\
\hline sd_int_maxrint_dist & $\begin{array}{l}\text { Distance at max reported } \\
\text { intensity }\end{array}$ & $\begin{array}{l}\text { The distance from the volcano's summit to } \\
\text { where the maximum intensity was reported } \\
\text { in km (xxx) }\end{array}$ \\
\hline cc_id & Collector ID & $\begin{array}{l}\text { An identifier for linking to contact } \\
\text { information for the data collector. }\end{array}$ \\
\hline sd_int_loaddate & Load date & The date this row was entered in UTC. \\
\hline sd_int_pubdate & Publish date & $\begin{array}{l}\text { The date this row can become public. This } \\
\text { date can be set up to two years in advance. }\end{array}$ \\
\hline cc_id_load & Data loader ID & $\begin{array}{l}\text { An identifier for linking to contact } \\
\text { information for the person who entered this } \\
\text { row of data. }\end{array}$ \\
\hline
\end{tabular}

The Intensity Data table (sd_int for seismic data - intensity) was created to store information about the intensities of events that may or may not have been recorded by a station. The intensity data will most likely not be in an electronic format and we may need to create a web form for inserting the data into the table. The primary ID for the Intensity table is sd_int_id and there are several foreign IDs for linking to other tables. The volcano ID, vd_id, is the primary link for location and will also give the conversion from local time to UTC (see below). The links to additional event information are sd_evs_id or sd_evn_id depending on whether the event can be linked to an event recorded at a single station or an event recorded by a network. The event may not be able to be linked to a station if the nearby station was not functioning for any reason or if there were no nearby instruments. Much of the data in this table will be approximate but may cover episodes of unrest for which we have no other information.

The collector ID, cc_id, links to contact information about the person or observatory that collected the data and the data loader ID, cc_id_load, links to the Contact table for more information about the person who entered the data into WOVOdat. The load date, sd_evn_loaddate, is a TIMESTAMP and entered automatically in UTC. The date the data can become public is stored in sd_int_pubdate.

The approximate time of the event along with the uncertainty is stored in sd_int_time and sd_int_time_unc in UTC DATETIME. The conversion factor for converting local time to UTC can be 
found in the Volcano table (vd_vol), which is linked to the Intensity table by the volcano ID. The city or town where the event was felt is stored in sd_int_city. The three other defining attributes for the intensity are the maximum distance felt, the maximum reported intensity, and the distance at maximum reported intensity. The maximum distance felt, sd_int_maxdist, is the maximum distance at which the earthquake was felt in $\mathrm{km}$, measured from the volcano's summit. The maximum reported intensity, sd_int_maxrint, is the maximum reported modified mercalli intensity. The distance of the maximum reported intensity from the volcano's summit, sd_int_maxrint_dist, is stored in km.

\section{Seismic Tremor}

Table S4. Seismic Tremor Table

\begin{tabular}{|c|c|c|}
\hline sd_trm_id & Tremor data ID & An identifier for linking with other tables \\
\hline sn_id & Seismic network ID & $\begin{array}{l}\text { An identifier for linking with the seismic } \\
\text { network information. The Seismic Network } \\
\text { table provides information on the velocity } \\
\text { model used and a link to the volcano } \\
\text { information. }\end{array}$ \\
\hline ss_id & Seismic station ID & $\begin{array}{l}\text { An identifier for linking with the seismic } \\
\text { station information. The Seismic Station } \\
\text { table provides the station location, } \\
\text { instrument information, and a conversion } \\
\text { from local time to UTC. Enter this field } \\
\text { only if the reports are from a single station. }\end{array}$ \\
\hline sd_trm_stime & Start time of tremor envelope & $\begin{array}{l}\text { The start time (UTC) stored as DATETIME } \\
\text { (YYYY-MM-DD hh:mm:ss) for individual } \\
\text { envelope. The start and end times are } \\
\text { defined by the observatories. }\end{array}$ \\
\hline sd_trm_stime_unc & $\begin{array}{l}\text { Start time of tremor envelope } \\
\text { uncertainty }\end{array}$ & $\begin{array}{l}\text { The uncertainty in the start time (UTC) } \\
\text { stored as DATETIME (YYYY-MM-DD } \\
\text { hh:mm:ss) for individual envelope. The start } \\
\text { and end times are defined by the } \\
\text { observatories. }\end{array}$ \\
\hline sd_trm_etime & End time of tremor envelope & $\begin{array}{l}\text { The end time (UTC) stored as DATETIME } \\
\text { (YYYY-MM-DD hh:mm:ss) for individual } \\
\text { envelope. The start and end times are } \\
\text { defined by the observatories. }\end{array}$ \\
\hline sd_trm_etime_unc & $\begin{array}{l}\text { End time of tremor envelope } \\
\text { uncertainty }\end{array}$ & $\begin{array}{l}\text { The uncertainty in the end time (UTC) } \\
\text { stored as DATETIME (YYYY-MM-DD } \\
\text { hh:mm:ss) for individual envelope. The start } \\
\text { and end times are defined by the } \\
\text { observatories. }\end{array}$ \\
\hline sd_trm_dur_day & Tremor duration per day & $\begin{array}{l}\text { The total duration of tremor for each day in } \\
\text { minutes (xxxx). }\end{array}$ \\
\hline
\end{tabular}




\begin{tabular}{|c|c|c|}
\hline sd_trm_dur_day_unc & $\begin{array}{l}\text { Tremor duration per day } \\
\text { uncertainty }\end{array}$ & $\begin{array}{l}\text { The uncertainty in the total duration of } \\
\text { tremor for each day in minutes (xxxx). }\end{array}$ \\
\hline sd_trm_type & Type of tremor & $\begin{array}{l}\text { The type and a description of the tremor, } \\
\text { e.g., any temporal pattern such as banding, } \\
\text { spasmodic bursts, etc. Use } \mathrm{N} \text { for narrow } \\
\text { band or B for broadband and include the } \\
\text { frequency range. Broadband includes } \\
\text { spasmodic bursts and should span a } \\
\text { frequency range greater than } 3 \mathrm{~Hz} \text {. }\end{array}$ \\
\hline sd_trm_qdepth & Qualitative depth & $\begin{array}{l}\text { The qualitative depth of the tremor. Use D } \\
\text { for deep }(>10 \mathrm{~km}), \text { I for intermediate }(4-10 \\
\mathrm{km}), \mathrm{S} \text { for shallow }(\mathrm{S}=0-4 \mathrm{~km}) \text {, or } \mathrm{U} \text { for } \\
\text { unknown. }\end{array}$ \\
\hline sd_trm_domfreq1 & Dominant frequency 1 & The dominant frequency (in Hz) (xx.xx). \\
\hline sd_trm_domfreq2 & $\begin{array}{l}\text { Dominant frequency } 2 \text { (if } \\
\text { any) }\end{array}$ & $\begin{array}{l}\text { The second dominant frequency (if any, in } \\
\text { Hz) (xx.xx). }\end{array}$ \\
\hline sd_trm_maxamp & $\begin{array}{l}\text { Maximum amplitude of } \\
\text { tremor }\end{array}$ & $\begin{array}{l}\text { The maximum amplitude of tremor (refer to } \\
\text { the Seismic Station table for system gain } \\
\text { information) (xx). }\end{array}$ \\
\hline sd_trm_noise & Background noise & The background noise level (xx). \\
\hline sd_trm_reddis & RD & $\begin{array}{l}\text { The reduced displacement (as estimated } \\
\text { using a station }>5 \mathrm{~km} \text { from source to } \\
\text { minimize the effects of geometrical } \\
\text { spreading (xx). }\end{array}$ \\
\hline sd_trm_rderr & RD Error & The reduced displacement error (xx). \\
\hline sd_trm_visact & Associated visible activity & $\begin{array}{l}\text { A description of any associated visible } \\
\text { activity. }\end{array}$ \\
\hline cc_id & Collector ID & $\begin{array}{l}\text { An identifier for linking to contact } \\
\text { information for the data collector. }\end{array}$ \\
\hline sd_trm_loaddate & Load date & The date this row was entered in UTC. \\
\hline sd_trm_pubdate & Publish date & $\begin{array}{l}\text { The date this row can become public. This } \\
\text { date can be set up to two years in advance. }\end{array}$ \\
\hline cc_id_load & Data loader ID & $\begin{array}{l}\text { An identifier for linking to contact } \\
\text { information for the person who entered this } \\
\text { row of data. }\end{array}$ \\
\hline
\end{tabular}

The Seismic Tremor table (sd_trm for seismic data - tremor) contains information about tremor such as the time interval, qualitative depth, dominant frequency, amplitude range, and reduced displacement. The information in this table will most likely need to be entered by hand into a web form. The seismic tremor primary ID is sd_trm_id and we include two foreign keys for linking to the seismic network or seismic station information depending on where the data were collected. If the tremor data were collected by stations in a network, then the seismic network ID, sn_id, should be used for linking to location and instrument information. If the tremor data were collected by a single station that is not part of a network, then the seismic station ID, ss_id, should be used for linking to the location and instrument information. The collector ID, cc_id, links to contact information about the person or observatory that collected the data and should be used to request any additional information about the tremor. The data loader ID, cc_id_load, links to the Contact table for more information about the person 
who loaded the data into WOVOdat. The load date, sd_trm_loaddate, is a TIMESTAMP and entered automatically in UTC. The date the data can become public is stored in sd_trm_pubdate.

The seismic tremor is defined in time by a start, stop, and a duration/day. The start time of the tremor envelope, sd_trm_stime, should be the time chosen by the observatory as the beginning of the tremor event described in the row of data in UTC DATETIME. The end time of the tremor envelope, sd_trm_etime, is the time chosen by the observatory as the end of the tremor event described in the row of data in UTC DATETIME. The duration of tremor per day, sd_trm_dur_day, should give a total amount of time each day that tremor is felt; for example, if there are three episodes of tremor, each of approximately 20 minutes in length, then sd_trm_dur_day would be 60 minutes. Each time has an associated uncertainty, sd_trm_stime_unc,sd_trm_etime_unc, and sd_trm_dur_day_unc, in the same units as the measured time.

The type and description of tremor field, sd_trm_type, indicates if the tremor is narrowband (N) or broadband (B) where broadband is defined as a frequency range greater than $3 \mathrm{~Hz}$. The tremor description should include any temporal patterns such as banding, spasmodic bursts, etc. The qualitative depth of the origin of the tremor, sd_trm_qdepth, is a single letter code, D for deep or $>10 \mathrm{~km}$, I for intermediate or $4-10 \mathrm{~km}, \mathrm{~S}$ for shallow or $0-4 \mathrm{~km}$, and $\mathrm{U}$ for unknown. The dominant frequency, sd_trm_domfreq1, is the dominant frequency of the tremor in Hz. The second dominant frequency, sd_trm_domfreq2, also in $\mathrm{Hz}$, covers cases where a second frequency peak is recorded. The maximum amplitude of the tremor is stored as a range in $\mathrm{mm}$ in the fields maximum amplitude of tremor, sd_trm_maxamp, and background noise, sd_trm_noise. The system gain information should be available in the Seismic Station table. The reduced displacement, sd_trm_reddis, has units of $\mathrm{cm}^{2}$ and the associated error, sd_trm_rderr, is also in $\mathrm{cm}^{2}$.

The associated visible activity field, sd_trm_visact, should be used to provide additional information about any associated activity that was seen during the tremor envelope. This field has a 255 character limit.

Interval (swarm) Data

Table S5. Interval (swarm) Data Table

\begin{tabular}{|l|l|l|}
\hline sd_ivl_id & Interval data ID & An identifier for linking with other tables \\
\hline sn_id & Seismic network ID & $\begin{array}{l}\text { An identifier for linking with the seismic } \\
\text { network information. The Seismic Network } \\
\text { table provides information on the velocity } \\
\text { model used and a link to the volcano } \\
\text { information. }\end{array}$ \\
\hline ss_id & $\begin{array}{l}\text { An identifier for linking with the seismic } \\
\text { station information. The Seismic Station } \\
\text { table provides the station location, } \\
\text { instrument information, and a conversion } \\
\text { from local time to UTC. Enter this field } \\
\text { only if a single station was used for counts. }\end{array}$ \\
\hline sd_ivl_stime & Seismic station ID & $\begin{array}{l}\text { The start time (UTC) of this interval based } \\
\text { on instrument recordings stored as } \\
\text { DATETIME (YYYY-MM-DD hh:mm:ss). }\end{array}$ \\
\hline
\end{tabular}




\begin{tabular}{|c|c|c|}
\hline sd_ivl_stime_unc & Interval start time uncertainty & $\begin{array}{l}\text { The uncertainty in the start time (UTC) of } \\
\text { this interval based on instrument recordings } \\
\text { stored as DATETIME (YYYY-MM-DD } \\
\text { hh:mm:ss). }\end{array}$ \\
\hline sd_ivl_etime & Interval end time & $\begin{array}{l}\text { The end time (UTC) of this interval based } \\
\text { on instrument recordings stored as } \\
\text { DATETIME (YYYY-MM-DD hh:mm:ss). }\end{array}$ \\
\hline sd_ivl_etime_unc & Interval end time uncertainty & $\begin{array}{l}\text { The uncertainty in the end time (UTC) of } \\
\text { this interval based on instrument recordings } \\
\text { stored as DATETIME (YYYY-MM-DD } \\
\text { hh:mm:ss). }\end{array}$ \\
\hline sd_ivl_hdist & Horizontal distance & $\begin{array}{l}\text { The horizontal distance from the summit to } \\
\text { the swarm center in } \mathrm{km}(\mathrm{xx} . \mathrm{x}) \text {. }\end{array}$ \\
\hline sd_ivl_avgdepth & Mean depth of swarm & Mean depth of the swarm earthquakes in $\mathrm{m}$ ) \\
\hline sd_ivl_vdispers & Vertical dispersion & $\begin{array}{l}\text { Range (dispersion) of depths over which } \\
\text { these swarm earthquakes occurred }\end{array}$ \\
\hline sd_ivl_hmigr_hyp & $\begin{array}{l}\text { Horizontal migration of } \\
\text { hypocenters }\end{array}$ & $\begin{array}{l}\text { Any horizontal migration of hypocenters } \\
\text { from/to the summit in km (Use positive } \\
\text { numbers for outward and negative numbers } \\
\text { for inward ) (sxx.x). }\end{array}$ \\
\hline sd_ivl_vmigr_hyp & $\begin{array}{l}\text { Vertical migration of } \\
\text { hypocenters }\end{array}$ & $\begin{array}{l}\text { Any vertical migration of hypocenters in } \mathrm{km} \\
\text { (Use positive numbers for up and negative } \\
\text { numbers for down) (sxx.x). }\end{array}$ \\
\hline sd_ivl_patt & Temporal pattern of swarm & $\begin{array}{l}\text { The temporal pattern of the swarm (using } \\
\text { one of the WOVOdat defined patterns). The } \\
\text { WOVOdat defined patterns need to be } \\
\text { added. }\end{array}$ \\
\hline sd_ivl_data & Types of data & $\begin{array}{l}\text { A description of the types of data included } \\
\text { in the earthquake counts. Use } \mathrm{L} \text { for } \\
\text { earthquakes that have been located, } \mathrm{C} \text { for } \\
\text { those detected by a computer trigger } \\
\text { algorithm, } \mathrm{H} \text { for hand counted, U for } \\
\text { unknown or any combination of the above. }\end{array}$ \\
\hline sd_ivl_picks & Picks & $\begin{array}{l}\text { A description of how the picks were } \\
\text { determined. Use A for an automatic picker, } \\
\mathrm{R} \text { for hand-picked with a ruler, } \mathrm{H} \text { for a } \\
\text { human using a computer-based picker, or } \mathrm{U} \\
\text { for unknown. }\end{array}$ \\
\hline sd_ivl_felt_stime & $\begin{array}{l}\text { Earthquake counts felt start } \\
\text { time }\end{array}$ & $\begin{array}{l}\text { The felt earthquake counts measurement } \\
\text { start time (UTC) stored as DATETIME } \\
\text { (YYYY-MM-DD hh:mm:ss). }\end{array}$ \\
\hline sd_ivl_felt_sti & $\begin{array}{l}\text { Earthquake counts felt start } \\
\text { time uncertainty }\end{array}$ & $\begin{array}{l}\text { The uncertainty in the felt earthquake } \\
\text { counts measurement start time (UTC) stored } \\
\text { as DATETIME (YYYY-MM-DD } \\
\text { hh:mm:ss). }\end{array}$ \\
\hline
\end{tabular}




\begin{tabular}{|c|c|c|}
\hline sd_ivl_felt_etime & $\begin{array}{l}\text { Earthquake counts felt stop } \\
\text { time }\end{array}$ & $\begin{array}{l}\text { The felt earthquake counts measurement } \\
\text { stop time (UTC) stored as DATETIME } \\
\text { (YYYY-MM-DD hh:mm:ss). }\end{array}$ \\
\hline sd_ivl_felt_etime_unc & $\begin{array}{l}\text { Earthquake counts felt end } \\
\text { time uncertainty }\end{array}$ & $\begin{array}{l}\text { The uncertainty in the felt earthquake } \\
\text { counts measurement end time (UTC) stored } \\
\text { as DATETIME (YYYY-MM-DD } \\
\text { hh:mm:ss). }\end{array}$ \\
\hline sd_ivl_nrec & $\begin{array}{l}\text { Number of recorded } \\
\text { earthquakes }\end{array}$ & $\begin{array}{l}\text { The recorded earthquake count during the } \\
\text { specified time interval (xxxxxx). }\end{array}$ \\
\hline sd_ivl_nfelt & Number of felt earthquakes & $\begin{array}{l}\text { The number of felt earthquakes for this } \\
\text { interval (xxxx). }\end{array}$ \\
\hline sd_ivl_etot_stime & Seismic E window opens & $\begin{array}{l}\text { The total seismic energy release (seismic } \\
\text { moment) measurement start time (UTC) } \\
\text { stored as DATETIME (YYYY-MM-DD } \\
\text { hh:mm:ss). }\end{array}$ \\
\hline sd_ivl_etot_stime_unc & $\begin{array}{l}\text { Seismic E window opens } \\
\text { uncertainty }\end{array}$ & $\begin{array}{l}\text { The uncertainty in the total seismic energy } \\
\text { release (seismic moment) measurement start } \\
\text { time (UTC) stored as DATETIME (YYYY- } \\
\text { MM-DD hh:mm:ss). }\end{array}$ \\
\hline sd_ivl_etot_etime & Seismic E window closes & $\begin{array}{l}\text { The total seismic energy release (seismic } \\
\text { moment) measurement stop time (UTC) } \\
\text { stored as DATETIME (YYYY-MM-DD } \\
\text { hh:mm:ss). }\end{array}$ \\
\hline sd_ivl_etot_etime_u & $\begin{array}{l}\text { Seismic E window closes } \\
\text { cuncertainty }\end{array}$ & $\begin{array}{l}\text { The uncertainty in the total seismic energy } \\
\text { release (seismic moment) measurement end } \\
\text { time (UTC) stored as DATETIME (YYYY- } \\
\text { MM-DD hh:mm:ss). }\end{array}$ \\
\hline sd_ivl_etot & $\begin{array}{l}\text { Total seismic E release } \\
\text { (seismic moment) }\end{array}$ & $\begin{array}{l}\text { The total seismic energy release (seismic } \\
\text { moment) for this swarm interval in erg }{ }^{-0.5}\end{array}$ \\
\hline sd_ivl_desc & Desc & $\begin{array}{l}\text { A field for describing the swarms or interval } \\
\text { data and any uncertainties in the data such } \\
\text { as location. }\end{array}$ \\
\hline cc_id & Colles & $\begin{array}{l}\text { An identifier for linking to contact } \\
\text { information for the data collector. }\end{array}$ \\
\hline sd_ivl_loaddate & & The date this row was entered in UTC. \\
\hline sd_ivl_pubdate & Publish date & $\begin{array}{l}\text { The date this row can become public. This } \\
\text { date can be set up to two years in advance. }\end{array}$ \\
\hline cc_id_load & Data loader ID & $\begin{array}{l}\text { An identifier for linking to contact } \\
\text { information for the person who entered this } \\
\text { row of data. }\end{array}$ \\
\hline
\end{tabular}

The Seismic Interval (swarm) data table (sd_ivl for seismic data - intervals) contains data about earthquakes that occur in specified time intervals, e.g., as seismic swarms. The seismic interval primary ID is sd_ivl_id and we include two foreign keys for linking to the network or station information depending on where the data were collected. If the interval data were collected by a network, then the seismic network ID, sn_id, should be used for linking to location and instrument information. If the interval data were collected by a single station that is not part of a network, then the seismic station ID, 
ss_id, should be used for linking to the location and instrument information. The collector ID, cc_id, links to contact information about the person or observatory that collected the data and should be used to request any additional information about the data. The data loader ID, cc_id_load, links to the Contact table for more information about the person who loaded the data into WOVOdat. The load date, sd_ivl_loaddate, is a TIMESTAMP and entered automatically in UTC. The date the data can become public is stored in sd_ivl_pubdate.

The Seismic Interval data table describes swarms in three ways: spatial distribution, temporal pattern, and energy release. Ideally, all of this information would be from the same time period, however, in many cases the time periods may not be exact so additional time fields are included to handle these cases. The interval start and end times are given by sd_ivl_stime and sd_ivl_etime along with their uncertainties, sd_ivl_stime_unc and sd_ivl_etime_unc. All are stored in UTC as DATETIME. The distance from the swarm to the summit is stored in kilometers as sd_ivl_hdist, for horizontal distance. This field should be entered, if known, instead of calculated because we do not store the average location of the swarm. An average depth of the swarm is stored in sd_ivl_avgdepth and the vertical range of swarm events is stored in sd_ivl_vdispers. Any horizontal migration of the hypocenters, sd_ivl_hmigr, is stored in kilometers with a positive value moving towards the summit and a negative value moving away from the summit. Any vertical migration of the hypocenters, sd_ivl_vmigr, is also stored in kilometers with a positive value moving upwards and a negative value moving downwards. We request the inclusion of location uncertainties in the description field, sd_ivl_desc (see below), if location data are entered.

The temporal pattern of a swarm, sd_ivl_patt, will be input from a small set of generic WOVOdat-defined temporal patterns. Counts of recorded and felt earthquakes during the interval are stored as sd_ivl_nrec and sd_ivl_nfelt, respectively. The interval start and end times for the counts are given by sd_ivl_felt_stime and sd_ivl_felt_etime along with their uncertainties, sd_ivl_felt_stime_unc and sd_ivl_felt_etime_unc. All are stored in UTC as DATETIME. Because counts depend heavily on how they are made, we include an attributesd_ivl_data to note whether the instrumental counts (sd_ivl_nrec) are based on earthquakes that have been located (L), those detected and automatically counted by a computer trigger algorithm $(\mathrm{C})$, hand counted $(\mathrm{H})$, or counted in some unknown or combination way (U). If the earthquake counts include earthquakes that have been located, those located events should be included in the Event Data from a Network Table. The field, sd_ivl_picks, stores a description of how the picks were determined (A for an automatic picker, $\mathrm{R}$ for hand-picked with a ruler, $\mathrm{H}$ for a human using a computer-based picker, or $\mathrm{U}$ for unknown).

The total seismic energy release or seismic moment of an interval or swarm is stored as sd_ivl_etot. The interval start and end times for the total seismic energy release are given by sd_ivl_etot_stime and sd_ivl_etot_etime along with their uncertainties, sd_ivl_etot_stime_unc and sd_ivl_etot_etime_unc. All are stored in UTC as DATETIME. The description field, sd_ivl_desc, provides a place to store additional information about the data such as the uncertainties in locations.

\section{RSAM/SSAM Table}

Table S6. RSAM/SSAM Table

\begin{tabular}{|l|l|l|}
\hline sd_sam_id & RSAM/SSAM ID & An identifier for linking with other tables \\
\hline ss_id & & $\begin{array}{l}\text { An identifier for linking with the seismic } \\
\text { station information. The Seismic Station } \\
\text { table provides the station location, } \\
\text { instrument information, and a conversion }\end{array}$ \\
\hline
\end{tabular}




\begin{tabular}{|c|c|c|}
\hline & & from local time to UTC \\
\hline sd_sam_stime & Start time & $\begin{array}{l}\text { The measurement start time (UTC) of } \\
\text { RSAM or SSAM measurements (stored as } \\
\text { DATETIME (YYYY-MM-DD hh:mm:ss)). }\end{array}$ \\
\hline sd_sam_stime_unc & Start time uncertainty & $\begin{array}{l}\text { The uncertainty in the measurement start } \\
\text { time (UTC) of RSAM or SSAM } \\
\text { measurements (stored as DATETIME } \\
\text { (YYYY-MM-DD hh:mm:ss)). }\end{array}$ \\
\hline sd_sam_etime & End time & $\begin{array}{l}\text { The measurement eend time (UTC) of a } \\
\text { continuous string of RSAM or SSAM } \\
\text { measurements (UTC) stored as DATETIME } \\
\text { (YYYY-MM-DD hh:mm:s)). }\end{array}$ \\
\hline sd_sam_etime_unc & End time uncertainty & $\begin{array}{l}\text { The uncertainty in the measurement end } \\
\text { time (UTC) of RSAM or SSAM } \\
\text { measurements (stored as DATETIME } \\
\text { (YYYY-MM-DD hh:mm:ss)). }\end{array}$ \\
\hline sd_sam_int & Counting interval & $\begin{array}{l}\text { The time interval in seconds for each } \\
\text { measurement bin in the associated RSAM } \\
\text { and SSAM data tables. }\end{array}$ \\
\hline sd_sam_int_unc & Counting interval uncertainty & $\begin{array}{l}\text { The uncertainty in the time interval in } \\
\text { seconds for each measurement bin in the } \\
\text { associated RSAM and SSAM data tables. }\end{array}$ \\
\hline cc_id & Collector ID & $\begin{array}{l}\text { An identifier for linking to contact } \\
\text { information for the data collector. }\end{array}$ \\
\hline sd_sam_loaddate & Load date & The date this row was entered in UTC. \\
\hline sd_sam_pubdate & Publish date & $\begin{array}{l}\text { The date this row can become public. This } \\
\text { date can be set up to two years in advance. }\end{array}$ \\
\hline cc_id_load & Data loader ID & $\begin{array}{l}\text { An identifier for linking to contact } \\
\text { information for the person who entered this } \\
\text { row of data. }\end{array}$ \\
\hline
\end{tabular}

The Real-time Seismic-Amplitude Measurements (RSAM) and Seismic Spectral-Amplitude Measurements (SSAM) table store information needed to create RSAM and SSAM images. These techniques were developed by the USGS to summarize seismic activity in real-time during volcanic crises. The techniques use the amplitudes and frequencies of seismic signals instead of the locations and magnitudes of the earthquakes, which makes them an ideal tool for rapid analysis during periods of time when seismicity has reached a level at which individual seismic events are difficult to distinguish. The RSAM/SSAM table (sd_sam for seismic data - RSAM/SSAM) stores the information needed to define the boundaries of RSAM and SSAM images. The data needed to create these images are stored in the individual RSAM and SSAM data tables.

The primary ID for the RSAM/SSAM table is sd_sam_id. The information in the RSAM/SSAM table is linked to the station tables by ss_id to provide background information on the stations collecting the data such as their location and types of instruments. The collector ID, cc_id, links to contact information about the person or observatory that collected the data and should be used to request any additional information about the seismic activity. The data loader ID, cc_id_load, links to the Contact table for more information about the person who loaded the data into WOVOdat. The load date, 
sd_sam_loaddate, is a TIMESTAMP and entered automatically in UTC. The date the data can become public is stored in sd_sam_pubdate.

There are six data fields in the RSAM/SSAM table; start time, end time, and interval time along with each uncertainty. The start time, sd_sam_stime, gives the beginning of the entire time interval for the image and the end time, sd_sam_etime, gives the end time for all of the data collected for the image. The interval, sd_sam_int, gives the amount of time for each interval or bin of data (see the RSAM and SSAM data tables for more information). The uncertainties for each time, sd_sam_stime_unc, sd_sam_etime_unc, and sd_sam_int_unc are given the same format as the measurements.

\section{RSAM}

Table S7. RSAM Data Table

\begin{tabular}{|l|l|l|}
\hline sd_rsm_id & RSAM ID & An identifier for linking with other tables. \\
\hline sd_sam_id & & $\begin{array}{l}\text { An identifier for linking with the main } \\
\text { RSAM/SSAM table. The RSAM/SSAM } \\
\text { table stores the entire time period and the } \\
\text { interval time for the RSAM image. }\end{array}$ \\
\hline sd_rsm_stime & RSAM/SSAM ID & The starting time for the given interval. \\
\hline sd_rsm_stime_unc & Start time uncertainty & $\begin{array}{l}\text { The uncertainty in the starting time for the } \\
\text { given interval. }\end{array}$ \\
\hline sd_rsm_count & RSAM count & $\begin{array}{l}\text { The RSAM count during this interval } \\
\text { (xxxx). }\end{array}$ \\
\hline sd_rsm_calib & RSAM Calibration (if any) & $\begin{array}{l}\text { The reduced displacement per 100 RSAM } \\
\text { counts. }\end{array}$ \\
\hline sd_rsm_loaddate & Load date & The date this row was entered in UTC. \\
\hline sd_rsm_pubdate & Publish date & $\begin{array}{l}\text { The date this row can become public. This } \\
\text { date can be set up to two years in advance. }\end{array}$ \\
\hline & & $\begin{array}{l}\text { An identifier for linking to contact } \\
\text { information for the person who entered this } \\
\text { row of data. }\end{array}$ \\
\hline cc_id_load & Data loader ID &
\end{tabular}

RSAM gives a measure of the overall level of seismic activity because it combines the average amplitude of ground shaking caused by earthquakes and volcanic tremor over successive short (often 10 minute) intervals of time. The RSAM Data table (sd_rsm for seismic data - RSAM) stores the data needed to create an RSAM image. The RSAM primary ID is sd_rsm_id and the data table is linked to the main RSAM/SSAM table by sd_sam_id for information about the period of time for the entire RSAM, the intervals of time for each data point (bin), and the data collector. The data loader ID, cc_id_load, links to the contact table and provides information about the person who loaded the data into WOVOdat. The load date, sd_rsm_loaddate, is a TIMESTAMP and entered automatically in UTC. The date the data can become public is stored in sd_rsm_pubdate.

There are three fundamental variables in the RSAM Data table, start time, RSAM count, and RSAM calibration. The start time, sd_rsm_stime, gives the beginning of each individual time interval. The uncertainty in the start time is recorded in sd_rsm_stime_unc. The RSAM count, sd_rsm_count, is the average amplitude of tremor, earthquakes, and noise combined, over each successive short time increment (bin). The RSAM calibration, sd_rsm_calib, gives the reduced displacement per 100 RSAM 
counts. It was unclear where the calibration information should be stored and we decided the data table would give the most accurate information for both RSAM and SSAM. Originally the calibrations were included in the Seismic Station table but we were concerned the calibration would change more frequently than other data in that table. We also considered putting it into the main RSAM/SSAM table but we wanted the RSAM and SSAM calibrations to be stored at the same level in the table hierarchy and putting the SSAM calibration in the SSAM data table requires the least number of additional attributes (please see the SSAM Data table for more information).

SSAM

Table S8. SSAM Data Table

\begin{tabular}{|c|c|c|}
\hline sd_ssm_id & SSAM ID & An identifier for linking with other tables \\
\hline sd_sam_id & RSAM/SSAM ID & $\begin{array}{l}\text { An identifier for linking with the main } \\
\text { RSAM/SSAM table. The RSAM/SSAM } \\
\text { table stores the entire time period and the } \\
\text { interval time for the RSAM image. }\end{array}$ \\
\hline sd_ssm_stime & Start time & The start time for the given interval. \\
\hline sd_ssm_stime_unc & Start time uncertainty & $\begin{array}{l}\text { The uncertainty in the starting time for the } \\
\text { given interval. }\end{array}$ \\
\hline sd_ssm_lowf & Low frequency & $\begin{array}{l}\text { The low frequency limit in } \mathrm{Hz} \text { for this } \\
\text { frequency range (xx.xxx). }\end{array}$ \\
\hline sd_ssm_highf & High frequency & $\begin{array}{l}\text { The high frequency limit in } \mathrm{Hz} \text { for this } \\
\text { frequency range (xx.xxx). }\end{array}$ \\
\hline sd_ssm_count & SSAM count & $\begin{array}{l}\text { The SSAM count for this time and } \\
\text { frequency interval }(\mathrm{xxxxx}) \text {. }\end{array}$ \\
\hline sd_ssm_calib & SSAM Calibration (if any) & $\begin{array}{l}\text { The reduced displacement per } 100 \text { SSAM } \\
\text { counts for the specified frequency range. }\end{array}$ \\
\hline sd_ssm_loaddate & Load date & The date this row was entered in UTC. \\
\hline sd_ssm_pubdate & Publish date & $\begin{array}{l}\text { The date this row can become public. This } \\
\text { date can be set up to two years in advance. }\end{array}$ \\
\hline cc_id_load & Data loader ID & $\begin{array}{l}\text { An identifier for linking to contact } \\
\text { information for the person who entered this } \\
\text { row of data. }\end{array}$ \\
\hline
\end{tabular}

The Seismic Spectral-Amplitude Measurement (SSAM) system computes in real-time the average amplitude of the seismic signals in specific frequency bands. This type of measurement provides additional information about the nature of seismicity in a simple graphical format that helps to highlight subtle shifts in frequency that can be related to changing dynamics of magma movement. The SSAM Data table (sd_ssm for seismic data - SSAM) stores the data needed to create an SSAM image. The primary ID is sd_ssm_id. The SSAM Data table is linked to the main RSAM/SSAM table by sd_sam_id for information about the period of time for the entire SSAM, the intervals of time for each data point (bin), and the data collector. The data loader ID, cc_id_load, links to the contact table and provides information about the person who loaded the data into WOVOdat. The load date, sd_ssm_loaddate, is a TIMESTAMP and entered automatically in UTC. The date the data can become public is stored in sd_ssm_pubdate. 
There are five data fields in the SSAM Data table: start time, low frequency value, high frequency value, SSAM count, and SSAM calibration. The start time, sd_ssm_stime, gives the beginning of the individual time interval. The uncertainty for the starting time is recorded in sd_ssm_stime_unc. The amount of time in the interval is given in the RSAM/SSAM table. The frequency range for the given interval is defined by a low value, sd_ssm_lowf, and a high value, sd_ssm_highf, both in Hz. The SSAM count, sd_rsm_count, is the average amplitude of the seismic signals in the specific frequency band for the given time interval. The SSAM calibration, sd_ssm_calib, gives the reduced displacement per 100 SSAM counts for each frequency band.

Representative Waveforms

Table S9. Representative Waveform Table

\begin{tabular}{|c|c|c|}
\hline sd_wav_id & Waveform ID & $\begin{array}{l}\text { An identifier for linking with other } \\
\text { tables }\end{array}$ \\
\hline sd_evn_id & Network event data ID & $\begin{array}{l}\text { An identifier for linking with the event } \\
\text { information for events from a network. }\end{array}$ \\
\hline sd_evs_id & $\begin{array}{l}\text { Single station event data } \\
\text { ID }\end{array}$ & $\begin{array}{l}\text { An identifier for linking with the event } \\
\text { information for events from a single } \\
\text { station. }\end{array}$ \\
\hline sd trm id & Tremor data ID & $\begin{array}{l}\text { An identifier for linking with tremor } \\
\text { information for waveforms recorded } \\
\text { during a tremor envelope. }\end{array}$ \\
\hline sd_wav_arch & Waveform archive & $\begin{array}{l}\text { Location of seismogram archive. This } \\
\text { information should be used to find } \\
\text { additional waveforms beyond the } \\
\text { representative waveforms stored here.. }\end{array}$ \\
\hline sd_wav_link & Waveform link & $\begin{array}{l}\text { A link to the archive where the } \\
\text { waveform is stored. This link should } \\
\text { bring up an image of the waveform. If } \\
\text { the link is unavailable, please see the } \\
\text { waveform archive for more } \\
\text { information. }\end{array}$ \\
\hline sd_wav_dist & Distance from the summit & $\begin{array}{l}\text { The distance that the waveform was } \\
\text { recorded from the summit. . Use P for } \\
\text { proximal }(<2 \mathrm{~km}) \text {, I for intermediate }(2- \\
5 \mathrm{~km}) \text {, D for distal }(>5 \mathrm{~km}) \text {, and U for } \\
\text { unknown if the distance is unknown. }\end{array}$ \\
\hline sd_wav_img & Waveform & The waveform stored as an image \\
\hline sd_wav_info & $\begin{array}{l}\text { Information about the } \\
\text { waveform }\end{array}$ & $\begin{array}{l}\text { Background information to include the } \\
\text { event type in WOVOdat terminology, } \\
\text { the volcano or approximate location } \\
\text { where the event occurred, and a time. }\end{array}$ \\
\hline sd_wav_desc & Description & $\begin{array}{l}\text { Added description of the waveform. } \\
\text { Include how often and when this kind } \\
\text { of waveform occurs, , and any }\end{array}$ \\
\hline
\end{tabular}




\begin{tabular}{|l|l|l|}
\hline & & interpretations. \\
\hline cc_id & Collector ID & $\begin{array}{l}\text { An identifier for linking to contact } \\
\text { information for the data collector. }\end{array}$ \\
\hline sd_wav_loaddate & Load date & The date this row was entered in UTC. \\
\hline sd_wav_pubdate & Publish date & $\begin{array}{l}\text { The date this row can become public. } \\
\text { This date can be set up to two years in } \\
\text { advance. }\end{array}$ \\
\hline cc_id_load & $\begin{array}{l}\text { An identifier for linking to contact } \\
\text { information for the person who entered } \\
\text { this row of data. }\end{array}$ \\
\hline
\end{tabular}

The Waveform table (sd_wav for seismic data - waveforms) contains sample waveforms to highlight common and uncommon events at different volcanoes and links to the event information. Some of these waveforms will be stored elsewhere in a digital format whereas others will need to be scanned. This table was created to store images of the waveforms and we will need a separate waveform data table to store the actual data. The waveform primary ID is sd_wav_id and we include two foreign keys for linking the waveform to the event data. The links to the event data provide access to details about the event such as the specific time and location. It was decided not to duplicate the time and location information in this table and instead to request more general information about the location and time in a text field called information. Time and location data can be added in the future, if necessary.

Additional digital waveforms will be stored in archives that are web accessible. Instead of storing the digital data for all of these waveforms, we will provide links to the waveform data archives via sd_wav_arch. This information should be used to find the waveform if a waveform link is not available or no longer active. The link to the archive where the waveform can be found is stored in sd_wav_link. This link should bring up an image of the waveform. The collector ID, cc_id, links to contact information about the person or observatory that collected the data and should be used to request any additional information about the waveform. The data loader ID, cc_id_load, links to the Contact table for more information about the person who loaded the data into WOVOdat. The load date, sd_wav_loaddate, is a TIMESTAMP and entered automatically in UTC. The date the data can become public is stored in sd_wav_pubdate.

There are four data attributes in the waveform table: the distance from the vent, the waveform image, waveform information, and a waveform description. As a proxy for distance to the hypocenters, distance to the summit should be used. The language for this field should be proximal for $<2 \mathrm{~km}$, intermediate for $2-5 \mathrm{~km}$, distal for $>5 \mathrm{~km}$, and unknown if the distance is unknown.

The waveform image, sd_wav_img, will store images of representative waveforms in a standard format such as .jpg. This field and the following descriptive fields were created to store example waveforms that will need to be scanned. The background information, sd_wav_info, should include the event type in WOVOdat terminology, the volcano or approximate location where the event occurred, and a time. The background information will be used to search for sample waveforms of a particular type of event or a particular volcano. The description of the waveform, sd_wav_desc, should include how often and when this type of event occurs, and any interpretations. The description should provide additional information about common or not-so-common waveforms for comparison with those seen at other volcanoes. 


\section{Seismic Network}

Table S10. Seismic Network Table

\begin{tabular}{|c|c|c|}
\hline sn_id & Seismic network ID & An identifier for linking with other tables. \\
\hline $\mathrm{vd}$ id & Volcano ID & $\begin{array}{l}\text { An identifier for linking to the Volcano } \\
\text { table. The Volcano table is used to link with } \\
\text { eruption information and other monitoring } \\
\text { data. }\end{array}$ \\
\hline sn_name & Network name & $\begin{array}{l}\text { The name of the network given by the } \\
\text { observatory. }\end{array}$ \\
\hline sn_vmodel & Velocity model & $\begin{array}{l}\text { A description the velocity model if it is a } \\
\text { simple 2D model. For more complex } \\
\text { models, Use the sn_vmodel_detail field. }\end{array}$ \\
\hline sn_vmodel_detail & Velocity model detail & $\begin{array}{l}\text { A link to a file containing additional details } \\
\text { about the velocity model, including } \\
\text { graphical descriptions of a 3-D model. This } \\
\text { may be stored in the database as a blob. }\end{array}$ \\
\hline sn_zerokm & Zero km & $\begin{array}{l}\text { The elevation of the zero km "depth", in } \\
\text { meters above sea level. For some networks } \\
\text { the zero km value will be sea level whereas } \\
\text { other networks use a local base level or } \\
\text { average elevation of stations in the network. } \\
\text { Please also describe what negative depths } \\
\text { mean, if applicable. }\end{array}$ \\
\hline sn_fdepth & Fixed Depth Description & $\begin{array}{l}\text { A description of whether and how depths in } \\
\text { the data tables are held fixed by the location } \\
\text { algorithm }\end{array}$ \\
\hline sn_stime & Start date & $\begin{array}{l}\text { The date (UTC) the network was set up and } \\
\text { activated or the time new information in this } \\
\text { table became valid. The date is stored in } \\
\text { DATETIME (YYYY-MM-DD hh:mm:ss). }\end{array}$ \\
\hline sn_stime_unc & Start date uncertainty & $\begin{array}{l}\text { The uncertainty in the date (UTC) the } \\
\text { network was set up and activated. The date } \\
\text { is stored in DATETIME (YYYY-MM-DD } \\
\text { hh:mm:ss). }\end{array}$ \\
\hline sn_etime & End date & $\begin{array}{l}\text { The date (UTC) the network was } \\
\text { permanently decommissioned or the time } \\
\text { the information in this table became invalid. } \\
\text { The date is stored in DATETIME (YYYY- } \\
\text { MM-DD hh:mm:ss). See observatory for } \\
\text { station and network operation history. }\end{array}$ \\
\hline
\end{tabular}




\begin{tabular}{|c|c|c|}
\hline sn_etime_unc & End date uncertainty & $\begin{array}{l}\text { The uncertainty in the date (UTC) the } \\
\text { network was was permanently } \\
\text { decommissioned or the time the information } \\
\text { in this table became invalid. The date is } \\
\text { stored in DATETIME (YYYY-MM-DD } \\
\text { hh:mm:ss). }\end{array}$ \\
\hline sn_tot & $\begin{array}{l}\text { Total number of } \\
\text { seismometers }\end{array}$ & $\begin{array}{l}\text { The number of permanent seismometers in } \\
\text { the network. }\end{array}$ \\
\hline sn_bb & $\begin{array}{l}\text { Number of broadband } \\
\text { seismometers }\end{array}$ & $\begin{array}{l}\text { The number of broadband seismometers in } \\
\text { network (corner period }>10 \mathrm{~s} \text { ) }\end{array}$ \\
\hline sn_smp & $\begin{array}{l}\text { Number of short- and mid- } \\
\text { period seismometers }\end{array}$ & $\begin{array}{l}\text { The number of short- and mid-period } \\
\text { seismometers in network (corner period }<10 \\
\text { s) }\end{array}$ \\
\hline sn_digital & $\begin{array}{l}\text { Number of digital } \\
\text { seismometers }\end{array}$ & $\begin{array}{l}\text { The number of digital seismometers in the } \\
\text { network (not including analog seismometers } \\
\text { whose signal is later converted to digital }\end{array}$ \\
\hline sn_analog & $\begin{array}{l}\text { Number of analog } \\
\text { seismometers }\end{array}$ & $\begin{array}{l}\text { The number of analog seismometers } \\
\text { including those whose signal is later } \\
\text { converted to digital }\end{array}$ \\
\hline sn_tcomp & $\begin{array}{l}\text { Number of } 3 \text { component } \\
\text { seismometers }\end{array}$ & $\begin{array}{l}\text { The number of 3-component seismometers } \\
\text { in network }\end{array}$ \\
\hline sn_micro & Number of microphones & $\begin{array}{l}\text { The number of microphones in the network } \\
\text { (for recording air waves, acoustic signals) }\end{array}$ \\
\hline sn_desc & Description & $\begin{array}{l}\text { Additional description of the network that } \\
\text { should include azimuthal coverage, how the } \\
\text { data are relayed, status information and any } \\
\text { other descriptive information that could be } \\
\text { helpful. }\end{array}$ \\
\hline sn_utc & Difference from UTC & $\begin{array}{l}\text { Time zone relative to UTC. Please enter the } \\
\text { number of hours from GMT, using a } \\
\text { negative sign (-) for hours before GMT and } \\
\text { no sign for positive numbers. }\end{array}$ \\
\hline cc_id & Contact ID & $\begin{array}{l}\text { An identifier for linking to contact } \\
\text { information about the observatory or person } \\
\text { who installed the network. }\end{array}$ \\
\hline sn_loaddate & Load date & The date this row was entered in UTC. \\
\hline sn_pubdate & Publish date & $\begin{array}{l}\text { The date this row can become public. This } \\
\text { date can be set up to two years in advance. }\end{array}$ \\
\hline cc_id_load & Data loader ID & $\begin{array}{l}\text { An identifier for linking to contact } \\
\text { information for the person who entered this } \\
\text { row of data. }\end{array}$ \\
\hline
\end{tabular}

The Seismic Network table (sn for seismic network) contains information about the seismic network such as the velocity model used for computing the event locations and a general overview of the types of instruments used. The individual stations in the network are linked to the Seismic Network 
table by a link in the Seismic Station table, which contains more information about the individual stations. The seismic network primary ID is sn_id and the table is linked to the Volcano table by the volcano ID, vd_id. The contact ID (cc_id) links to contact information about the person or observatory that installed and/or maintains the network and should be used to request additional information. The data loader ID, cc_id_load, links to the Contact table for more information about the person who loaded the data into WOVOdat. The load date, sn _loaddate, is a TIMESTAMP and entered automatically in UTC. The date the data can become public is stored in sn_pubdate.

The name of the seismic network used by the observatories is stored in sn_name. The velocity model, sn_vmodel, should be used to describe simple, 2D, velocity models. The velocity model detail attribute, sn_vmodel_detail, should be used for more complex models and includes a link to a file or a blob that contains a full description of the model. We recommend that this additional information is included if a description of the velocity model cannot be given in the 255 character limit sn_vmodel. If greater detail is needed, the contact person or observatory (cc_id) responsible for the network can be contacted. A start and end date for the validity of the Seismic Network table may need to be added in the future in case the velocity model changes.

The zero km attribute, sn_zerokm, stores the value of the zero $\mathrm{km}$ mark in meters above sea level for earthquake depths in the associated data tables. For some networks the zero km value will be sea level whereas other networks pick a local baselevel, e.g., the foot of a volcano or the average elevation of seismometers in the network. This field should also describe what negative depths mean, if applicable. The fixed depth description attribute, sn_fdepth, stores a description of how the flagged depths in the data tables are fixed, if applicable.

The Seismic Network table also includes start and end dates, sn_stime and sn_etime, along with uncertainties, sn_stime_unc and sn_etime_unc, in DATETIME UTC. These dates provide information on when the network is active or when the information in the table is valid. There are several fields to indicate the types and numbers of instruments in the network including the total number of permanent seismometers, sn_tot, the number of broadband seismometers, sn_bb, the number of short- and midperiod seismometers, sn_smp, the number of digital seismometers, sn_digital, the number of analog seismometers, sn_analog, the number of three component seismometers, sn_tcomp, and the number of microphones, sn_micro.

The description of the network, sn_desc, should include how well the stations are spaced around the volcano (azimuthal coverage), how the data are relayed, network status information, and any other descriptive information that could be helpful. The Seismic Network table also stores the difference from local time to UTC as sn_utc. This information allows for the conversion back to UTC for data that links to the Seismic Network table and not the Seismic Station table as discussed in the Time Section.

\section{Seismic Station}

Table S11. Seismic Station Table

\begin{tabular}{|l|l|l|}
\hline ss_id & Seismic station table ID & An identifier for linking with other tables. \\
\hline sn_id & $\begin{array}{l}\text { An identifier for linking with the seismic } \\
\text { network information. The Seismic Network } \\
\text { table provides information on the velocity } \\
\text { model used and a link to the volcano } \\
\text { information. }\end{array}$ \\
\hline ss_name & Sesimic network ID & The name of the station given by the \\
\hline
\end{tabular}




\begin{tabular}{|c|c|c|}
\hline & & observatory. \\
\hline ss_lat & Latitude & $\begin{array}{l}\text { The latitude of the station in degrees } \\
\text { (sxx.xxxxxxx). }\end{array}$ \\
\hline ss_lon & Longitude & $\begin{array}{l}\text { The longitude of the station in degrees } \\
\text { (sxxx.xxxxxxx) }\end{array}$ \\
\hline SS_datum & Datum & $\begin{array}{l}\text { The datum used for the longitude and } \\
\text { latitude. WGS } 84 \text { is the official WOVOdat } \\
\text { datum }\end{array}$ \\
\hline Ss_elev & Elevation & $\begin{array}{l}\text { The nominal elevation of the ground where } \\
\text { the station is located. All elevations are } \\
\text { assumed to be above sea level unless a } \\
\text { negative sign is used (indicating an } \\
\text { elevation below sea level) (sxxxx). }\end{array}$ \\
\hline Ss_depth & Depth of Instrument & $\begin{array}{l}\text { The depth of the instrument in meters below } \\
\text { the elevation given in ss_elev. If there are } \\
\text { multiple components at different depths, } \\
\text { please give a list of depths. }\end{array}$ \\
\hline ss_stime & Start date & $\begin{array}{l}\text { The date (UTC) the station was set up and } \\
\text { activated or the time new information in this } \\
\text { table became valid. The date is stored in } \\
\text { DATETIME (YYYY-MM-DD hh:mm:ss). }\end{array}$ \\
\hline ss_stime_unc & Start date uncertainty & $\begin{array}{l}\text { The uncertainty in the date (UTC) the } \\
\text { station was set up and activated. The date is } \\
\text { stored in DATETIME (YYYY-MM-DD } \\
\text { hh:mm:ss). }\end{array}$ \\
\hline ss_etime & End date & $\begin{array}{l}\text { The date (UTC) the station was permanently } \\
\text { decommissioned or the time the information } \\
\text { in this table became invalid. The date is } \\
\text { stored in DATETIME (YYYY-MM-DD } \\
\text { hh:mm:ss). See observatory for details of } \\
\text { station operation history. }\end{array}$ \\
\hline ss_etime_unc & End date uncertainty & $\begin{array}{l}\text { The uncertainty in the date (UTC) the } \\
\text { station was was permanently } \\
\text { decommissioned or the time the information } \\
\text { in this table became invalid. The date is } \\
\text { stored in DATETIME (YYYY-MM-DD } \\
\text { hh:mm:ss). }\end{array}$ \\
\hline ss_utc & Difference from UTC & $\begin{array}{l}\text { Time zone relative to UTC. Please enter the } \\
\text { number of hours from GMT, using a } \\
\text { negative sign (-) for hours before GMT and } \\
\text { no sign for positive numbers (sxx.x). }\end{array}$ \\
\hline ss_instr_type & Instrument type(s) & $\begin{array}{l}\text { The type(s) of instruments installed at this } \\
\text { station. For more detailed information, } \\
\text { please see the Seismic Instrument table. }\end{array}$ \\
\hline
\end{tabular}




\begin{tabular}{|c|c|c|}
\hline Ss_sgain & System gain & $\begin{array}{l}\text { Total gain from seismometer, telemetry, and } \\
\text { recorder. The instrument gain can also be } \\
\text { found in the instrument table. Please refer to } \\
\text { the observatory for information on gain } \\
\text { updates. }\end{array}$ \\
\hline Ss_desc & Station description & $\begin{array}{l}\text { A description of the station including the } \\
\text { type of material it is set in, any issues with } \\
\text { the installation and/or function, how the } \\
\text { data are relayed, and any additional } \\
\text { descriptive information. }\end{array}$ \\
\hline SS_com & Comments & $\begin{array}{l}\text { Comments about the station including } \\
\text { information about status. }\end{array}$ \\
\hline CC_id & Contact ID & $\begin{array}{l}\text { An identifier for linking to contact } \\
\text { information. }\end{array}$ \\
\hline Ss_loaddate & Load date & The date this row was entered in UTC. \\
\hline ss_pubdate & Publish date & $\begin{array}{l}\text { The date this row can become public. This } \\
\text { date can be set up to two years in advance. }\end{array}$ \\
\hline CC_id_load & Data loader ID & $\begin{array}{l}\text { An identifier for linking to contact } \\
\text { information for the person who entered this } \\
\text { row of data. }\end{array}$ \\
\hline
\end{tabular}

The Seismic Station table (ss - for seismic station) stores information such as a location, name, system gain, and comments about the stations where the data are collected. The primary ID is ss_id and there are several foreign IDs for linking to other tables. The Seismic Station table links to the Seismic Network table by the seismic network ID, sn_id. It is through the Network table that the data can be linked to the volcano. The contact ID (cc_id) links to contact information about the person or observatory that manages the station and the data loader ID, cc_id_load, links to the Contact table for more information about the person who loaded the data into WOVOdat. The load date, ss_loaddate, is a TIMESTAMP and entered automatically in UTC. The date the data can become public is stored in ss_pubdate.

The station name, ss_name, is given by the observatories and will be visible to users on the web interface to search for information about the station. The Seismic Station table stores all of the location information for the station including the latitude, ss_lat, longitude, ss_lon, elevation, ss_elev, and datum, ss_datum. All data should be converted to WGS 84 prior to entering WOVOdat. If conversion is not possible during data loading, the original datum must be entered into the datum field, ss_datum field. The elevation, ss_elev, should be of the ground where the station is located and not the elevation of the instrument. The depth of the instrument, ss_depth, should be the depth in meters below the ground elevation. We also store the depth of the component in the Seismic Component table. In the case where there are multiple sensors at different depths, please give a list of depths. The Seismic Station table also includes start and end dates, ss_stime and ss_etime, along with uncertainties, ss_stime_unc and ss_etime_unc, in DATETIME UTC. These dates provide information on when the station is active or when the information in the table is valid. For example, we would like to store when the system gain changes. The Seismic Station table also stores the difference from local time to UTC as ss_utc. This information allows for the conversion back to UTC whenever needed as discussed in the Time Section. We are requesting general information about the instrument, such as the number of components, in the instrument type field, ss_instr_type. The instrument specifics are stored in the Seismic Instrument table and can be linked from that table using the seismic station ID. The system gain attribute in the Seismic 
Station table, ss_sgain, is the total gain from the seismometer, the telemetry, and the recorder. We have also added an instrument gain attribute into the Seismic Instrument table for storing this information when available.

The station description, ss_desc, contains information about the station including the type of material the instrument is set in, any issues with the installation and/or function, how the data are relayed, and any additional descriptive information. The Seismic Station Comments attribute, ss_com, was created to include information about the status of the station and any other applicable comments. Originally we were going to have a separate status table but we've decided to include the status in the station table along with the valid start and stop dates. It may become necessary to include a status table once we starting working with seismic data from multiple observatories.

\section{Seismic Instrument}

Table S12. Seismic Instrument Table

\begin{tabular}{|l|l|l|}
\hline si_id & Seismic Instrument ID & An identifier for linking with other tables \\
\hline ss_id & Seismic station ID & $\begin{array}{l}\text { An identifier for linking with the seismic } \\
\text { station information. The Seismic Station } \\
\text { table provides the station location, } \\
\text { instrument information, and a conversion } \\
\text { from local time to UTC }\end{array}$ \\
\hline si_name & Name & $\begin{array}{l}\text { The name, model, and manufacturer of the } \\
\text { instrument (recorder). }\end{array}$ \\
\hline si_type & Type & $\begin{array}{l}\text { The type of instrument. This field should } \\
\text { include if the instrument is analog or digital. }\end{array}$ \\
\hline si_range & Dynamic range & $\begin{array}{l}\text { The dynamic range of the instrument, please } \\
\text { provide the units. }\end{array}$ \\
\hline si_igain & Instrument gain & The instrument gain. \\
\hline si_filter & Filters & $\begin{array}{l}\text { Information about filters if they have been } \\
\text { applied. }\end{array}$ \\
\hline si_ncomp & Number of components & The number of components. \\
\hline si_resp & Response overview & $\begin{array}{l}\text { An overview of the response for the } \\
\text { instrument (poles and zeros). }\end{array}$ \\
\hline si_stime_unc & Start date uncertainty & $\begin{array}{l}\text { A pointer to the file that contains the } \\
\text { instrument response (poles and zeros) in } \\
\text { more detail, if available. }\end{array}$ \\
\hline si_resp_file & Response in detail & $\begin{array}{l}\text { The time the instrument information in this } \\
\text { table became valid in UTC stored as } \\
\text { DATETIME (YYYY-MM-DD hh:mm:ss). }\end{array}$ \\
\hline si_stime & Start time & $\begin{array}{l}\text { The uncertainty in the time the instrument } \\
\text { information in this table became valid in } \\
\text { UTC stored as DATETIME (YYYY-MM- } \\
\text { DD hh:mm:ss) }\end{array}$ \\
\hline & & \\
& &
\end{tabular}




\begin{tabular}{|l|l|l|}
\hline & & $\begin{array}{l}\text { The time the instrument information in this } \\
\text { table changed in UTC stored as DATETIME } \\
\text { (YYYY-MM-DD hh:mm:ss). This field will } \\
\text { be null if the original information is still } \\
\text { valid. }\end{array}$ \\
\hline si_etime & End time & $\begin{array}{l}\text { The uncertainty in the time the instrument } \\
\text { information in this table changed in UTC } \\
\text { stored as DATETIME (YYYY-MM-DD } \\
\text { hh:mm:ss). This field will be null if the } \\
\text { original information is still valid. }\end{array}$ \\
\hline si_etime_unc & End time uncertainty & Comments on the instrument. \\
\hline si_com & Comments & $\begin{array}{l}\text { An identifier for linking with the person or } \\
\text { group of people who use this instrument. }\end{array}$ \\
\hline cc_id & Contact ID & The date this row was entered in UTC. \\
\hline si_loaddate & Load date & $\begin{array}{l}\text { The date this row can become public. This } \\
\text { date can be set up to two years in advance. }\end{array}$ \\
\hline si_pubdate & Publish date & $\begin{array}{l}\text { An identifier for linking to contact } \\
\text { information for the person who entered this } \\
\text { row of data. }\end{array}$ \\
\hline cc_id_load & Data loader ID &
\end{tabular}

The Seismic Instrument table (si_) stores information such as the instrument name, model, number of components and response time. The primary ID is si_id and the Seismic Station ID, ss_id, is included to link to information about the location of station where the instrument is installed. We put the Seismic Station ID in the Seismic Instrument table in case there were multiple instruments at a station. The Seismic Component Table includes a link to the Seismic Instrument table for cases where an instrument has multiple components. The Seismic Component table, si_cmp, defines the channels and location of the components. The contact ID (cc_id) links to contact information about the person or observatory that manages the station and the data loader ID, cc_id_load, links to the Contact table for more information about the person who loaded the data into WOVOdat. The load date, si_loaddate, is a TIMESTAMP and entered automatically in UTC. The date the data can become public is stored in si_pubdate.

The basic information in the Instrument table includes the instrument name, model and manufacturer in si_name and the instrument type in si_type. We request that the instrument type include if the instrument is digital or analog. The flexible instrument parameters include dynamic range, gain, and filters. The dynamic range is stored as text in si_range, the instrument gain is stored as si_igain, and any information about filters should be stored as text in si_filters. The number of components that link to the instrument should be stored in si_ncomp. The details about these components such as their type, orientation, and band are stored in the Seismic Component table, si_cmp. The instrument response is stored in two fields, response overview, and response details. The response overview, si_resp, is a descriptive text field and should include a brief overview of the poles and zeros. The response detail, si_resp_det, is a pointer to a file that is either stored on the database server or is web accessible. The response detail file, if available, should include the details of the poles and zeros. We will probably include this information as a blob in the database to keep all of the information together. The instrument information can change so we include valid from, si_stime, and valid to, si_etime, times (UTC DATETIME) for capturing each time frame when the data are valid. The start and end times also have associated uncertainties, si_stime_unc and si_etime_unc. A comments field, si_com, is included to store additional information. 


\section{Seismic Components}

Table S13. Seismic Component Table

\begin{tabular}{|c|c|c|}
\hline si_cmp_id & $\begin{array}{l}\text { Seismic Component } \\
\text { (geophone) ID }\end{array}$ & An identifier for linking with other tables \\
\hline si_cmp_name & Name & $\begin{array}{l}\text { The name, manufacturer, and model of the } \\
\text { geophone. }\end{array}$ \\
\hline si_cmp_cname & Component Name & $\begin{array}{l}\text { The name of the component given by the } \\
\text { observatory, if applicable. }\end{array}$ \\
\hline si_cmp_type & Type & The type of geophone. \\
\hline si_cmp_resp & Response function & $\begin{array}{l}\text { A description of the response of the } \\
\text { component. }\end{array}$ \\
\hline si_cmp_band & Band Type & $\begin{array}{l}\text { The band type for this component. Please } \\
\text { follow the SEED convention for Band Code } \\
\text { (S, B, V, etc). }\end{array}$ \\
\hline si_cmp_samp & Sampling rate & The sample rate for the component, in $\mathrm{Hz}$ \\
\hline si_cmp_icode & Instrument Code component & $\begin{array}{l}\text { The instrument code for this component. } \\
\text { Please follow the SEED convention for } \\
\text { Instrument Code. }\end{array}$ \\
\hline si_cmp_orient & Orientation & $\begin{array}{l}\text { The orientation code for this component. } \\
\text { Please follow the SEED convention for } \\
\text { Instrument Code (Z, N, E, A, B C, etc). }\end{array}$ \\
\hline si_cmp_sens & Sensitivity of component & $\begin{array}{l}\text { The sensitivity of the component, please } \\
\text { include the units. }\end{array}$ \\
\hline si_cmp_depth & Depth of component & $\begin{array}{l}\text { The depth of the component in meters. This } \\
\text { field is used to differentiate (make unique) } \\
\text { similar components in a borehole (xxxx). }\end{array}$ \\
\hline si_cmp_com & Comments & Comments on the component. \\
\hline cc_id & Contact ID & $\begin{array}{l}\text { An identifier for linking with the person or } \\
\text { group of people who use this instrument. }\end{array}$ \\
\hline si_cmp_loaddate & Load date & The date this row was entered in UTC. \\
\hline si_cmp_pubdate & Publish date & $\begin{array}{l}\text { The date this row can become public. This } \\
\text { date can be set up to two years in advance. }\end{array}$ \\
\hline cc_id_load & Data loader ID & $\begin{array}{l}\text { An identifier for linking to contact } \\
\text { information for the person who entered this } \\
\text { row of data. }\end{array}$ \\
\hline
\end{tabular}

The Seismic Component table (si_cmp, for Seismic Instrument - Component) stores information about an individual component (geophone) that sends data to the instrument or recorder such as the component name, model, orientation, band type, and sampling rate. The primary ID is si_cmp_id. The primary identifiers for seismic data include network information, station information, channel information, and location information. The Component table, si_cmp, links to the Instrument table, which provides details about the recorder. The Seismic Instrument table links to the Seismic Station table, which links to the Network table. The contact ID (cc_id) links to contact information about the 
person or observatory that manages the station and the data loader ID, cc_id_load, links to the Contact table for more information about the person who loaded the data into WOVOdat. The load date, si_cmp_loaddate, is a TIMESTAMP and entered automatically in UTC. The date the data can become public is stored in si_cmp_pubdate.

The basic information in the Component table includes the component name, model, and manufacturer in si_cmp_name and the component type in si_type. Include these here only if there is more detail than could be shown in the Instrument table. If the observatory has given the component a name, then it can be stored in si_cmp_cname. We request that the instrument type include if the instrument is digital or analog. The response function, si_cmp_resp, is a descriptive text field for storing information about the component response. The band type, si_cmp_band, should store a single letter code for the band type based on the SEED list of band codes. The SEED codes were chosen because they are used by many members of the seismological community and having a code will help cut down on spelling errors that will need to be cleansed. We will include a table that defines the SEED codes used in WOVOdat. The sampling rate, si_cmp_samp is currently a text field for storing the sampling rate or range in Hz. By using a text field we can handle single sampling rates or ranges of rates. The instrument code, si_cmp_icode, is also a one letter code following the SEED convention that gives information about the type of instrument such as a high or low gain seismometer. The orientation, si_cmp_orient, should be used to store the orientation of the component following SEED convention. Examples of the orientation are Z, N, or E for the traditional Vertical, North-South, East-West orientations; A, B, or C for a triaxial orientation (edges of a cube turned up on a corner); $\mathrm{T}$ or $\mathrm{R}$ for formed beams; 1, 2, or 3 for orthogonal components with non-traditional orientations, etc. The sensitivity of the component should be stored in si_cmp_sens. The final attribute needed to define the component is the depth, si_smp_depth, or location of the component in a borehole. This attribute is necessary for instances where there are several similar components in the same borehole. We also include a comments field, si_cmp_com, for storing comments about the component.

\section{Earthquake Translation}

Table S14. Earthquake Translation Table

\begin{tabular}{|l|l|l|}
\hline st_eqt_id & Earthquake translation ID & An identifier for linking with other tables. \\
\hline st_eqt_org & Original terminology & $\begin{array}{l}\text { The original terminology used by the } \\
\text { observatory. An observatory link, through } \\
\text { the contact ID, is needed to differentiate } \\
\text { who is using the original terminology. }\end{array}$ \\
\hline st_eqt_wovo & $\begin{array}{l}\text { The WOVOdat earthquake terminology. } \\
\text { This standard name will be used to describe } \\
\text { the earthquakes and to find similar } \\
\text { earthquakes that had different original } \\
\text { terminology. }\end{array}$ \\
\hline st_eqt_desc & WOVOdat terminology & $\begin{array}{l}\text { A description of the WOVOdat } \\
\text { terminology. }\end{array}$ \\
\hline
\end{tabular}




\begin{tabular}{|l|l|l|}
\hline & & $\begin{array}{l}\text { An identifier for linking to contact } \\
\text { information for the observatory. This link is } \\
\text { needed to link the observatory to the } \\
\text { original term since multiple observatories } \\
\text { use the same term to mean different things. }\end{array}$ \\
\hline cc_id & Contact ID & The date this row was entered in UTC. \\
\hline st_eqt_loaddate & Load date & $\begin{array}{l}\text { The date this row can become public. This } \\
\text { date can be set up to two years in advance. }\end{array}$ \\
\hline st_eqt_pubdate & Publish date & $\begin{array}{l}\text { An identifier for linking to contact } \\
\text { information for the person who entered this } \\
\text { row of data. }\end{array}$ \\
\hline cc_id_load & Data loader ID &
\end{tabular}

The Earthquake Translation table (st_eqt, for Seismic Translation - Earthquake Types) allows users to translate an earthquake type defined by one observatory to the WOVOdat earthquake type. Some observatories refer to different earthquake types by the same name or similar earthquake types by different names. The WOVOdat earthquake type will allow for queries by a similar earthquake type. The primary ID is st_eqt_id. The original terminology provided by the observatory is stored in st_eqt_org and the WOVOdat terminology is stored in st_eqt_wovo; both fields are text fields. A description of the WOVOdat terminology is given in st_eqt_desc. The contact ID (cc_id) links to contact information about the person or observatory that uses the original terminology. This field is needed because multiple observatories use the same term to mean different things. The data loader ID, cc_id_load, links to the same contact table and provides contact information about the person who loaded the data into WOVOdat. The load date, st_eqt_loaddate, is a TIMESTAMP and entered automatically in UTC. The date the data can become public is stored in st_eqt_pubdate.

\section{Create table statements for seismic tables}

\section{DROP TABLE IF EXISTS sd_evn;}

create table sd_evn (

sd_evn_id mediumint not null auto_increment,

sn_id mediumint,

sd_evn_eventid varchar(30),

sd_evn_arch varchar(255),

sd_evn_time datetime,

sd_evn_time_unc datetime,

sd_evn_dur float,

sd_evn_tech varchar(255),

sd_evn_picks char(1),

sd_evn_elat float,

sd_evn_elon float,

sd_evn_datum varchar(30),

sd_evn_edep float,

sd_evn_fixdep char(1),

sd_evn_nst float,

sd_evn_nph float,

sd_evn_gp float,

sd_evn_des float,

sd_evn_rms float,

sd_evn_herr float,

sd_evn_xerr float, 
sd_evn_yerr float,

sd_evn_derr float,

sd_evn_locqual varchar(255),

sd_evn_pmag float,

sd_evn_pmag_type varchar(30),

sd_evn_smag float,

sd_evn_smag_type varchar(30),

sd_evn_eqtype varchar(255),

sd_evn_eqtype_org varchar(255),

sd_evn_mtscale float,

sd_evn_mxx float,

sd_evn_mxy float,

sd_evn_mxz float,

sd_evn_myy float,

sd_evn_myz float,

sd_evn_mzz float,

sd_evn_strk1 float,

sd_evn_strk1_err float,

sd_evn_dip1 float,

sd_evn_dip1_err float,

sd_evn_rak1 float,

sd_evn_rak1_err float,

sd_evn_strk2 float,

sd_evn_strk2_err float,

sd_evn_dip2 float,

sd_evn_dip2_err float,

sd_evn_rak2 float,

sd_evn_rak2_err float,

sd_evn_foc varchar(255),

sd_evn_samp float,

sd_evn_loaddate datetime,

sd_evn_pubdate datetime,

cc_id_owner mediumint,

cc_id_load mediumint,

primary key (sd_evn_id));

DROP TABLE IF EXISTS sd_evs;

create table sd_evs (

sd_evs_id mediumint not null auto_increment,

ss_id mediumint,

sd_evs_time datetime,

sd_evs_time_unc datetime,

sd_evs_picks char(1),

sd_evs_spint float,

sd_evs_dur float,

sd_evs_dist_actven float,

sd_evs_maxamptrac float,

sd_evs_samp float,

cc_id mediumint,

sd_evs_loaddate datetime,

sd_evs_pubdate datetime,

cc_id_load mediumint,

primary key (sd_evs_id));

DROP TABLE IF EXISTS sd_int;

create table sd_int ( 
sd_int_id mediumint not null auto_increment, vd_id mediumint,

sd_evn_id mediumint, sd_evs_id mediumint, sd_int_time datetime,

sd_int_time_unc datetime, sd_int_city varchar(30),

sd_int_maxdist float,

sd_int_maxrint float,

sd_int_maxrint_dist float,

cc_id mediumint,

sd_int_loaddate datetime,

sd_int_pubdate datetime,

cc_id_load mediumint,

primary key (sd_int_id));

DROP TABLE IF EXISTS sd_trm;

create table sd_trm (

sd_trm_id mediumint not null auto_increment,

sn_id mediumint,

ss_id mediumint,

sd_trm_stime datetime,

sd_trm_stime_unc datetime,

sd_trm_etime datetime,

sd_trm_etime_unc datetime,

sd_trm_dur_day float,

sd_trm_dur_day_unc float,

sd_trm_type varchar(255),

sd_trm_qdepth varchar(30),

sd_trm_domfreq1 float,

sd_trm_domfreq2 float,

sd_trm_maxamp float,

sd_trm_noise float,

sd_trm_reddis float,

sd_trm_rderr float,

sd_trm_visact varchar(255),

cc_id mediumint,

sd_trm_loaddate datetime,

sd_trm_pubdate datetime,

cc_id_load mediumint,

primary key (sd_trm_id));

DROP TABLE IF EXISTS sd_ivl;

create table sd_ivl (

sd_ivl_id mediumint not null auto_increment,

sn_id mediumint,

ss_id mediumint,

sd_ivl_stime datetime,

sd_ivl_stime_unc datetime,

sd_ivl_etime datetime,

sd_ivl_etime_unc datetime,

sd_ivl_hdist float,

sd_ivl_avgdepth float,

sd_ivl_vdispers float,

sd_ivl_hmigr_hyp float, 
sd_ivl_vmigr_hyp float,

sd_ivl_patt varchar(30),

sd_ivl_data char(1),

sd_ivl_picks char(1),

sd_ivl_felt_stime datetime,

sd_ivl_felt_stime_unc datetime,

sd_ivl_felt_etime datetime,

sd_ivl_felt_etime_unc datetime,

sd_ivl_nrec float,

sd_ivl_nfelt float,

sd_ivl_etot_stime datetime,

sd_ivl_etot_stime_unc datetime,

sd_ivl_etot_etime datetime,

sd_ivl_etot_etime_unc datetime,

sd_ivl_etot float,

sd_ivl_desc varchar(255),

cc_id mediumint,

sd_ivl_loaddate datetime,

sd_ivl_pubdate datetime,

cc_id_load mediumint,

primary key (sd_ivl_id));

DROP TABLE IF EXISTS sd_sam;

create table sd_sam (

sd_sam_id mediumint not null auto_increment, ss_id mediumint,

sd_sam_stime datetime,

sd_sam_stime_unc datetime,

sd_sam_etime datetime,

sd_sam_etime_unc datetime,

sd_sam_int float,

sd_sam_int_unc float,

cc_id mediumint,

sd_sam_loaddate datetime,

sd_sam_pubdate datetime,

cc_id_load mediumint,

primary key (sd_sam_id));

DROP TABLE IF EXISTS sd_rsm;

create table sd_rsm (

sd_rsm_id mediumint not null auto_increment,

sd_sam_id mediumint,

sd_rsm_stime datetime,

sd_rsm_stime_unc datetime,

sd_rsm_count float,

sd_rsm_calib float,

sd_rsm_loaddate datetime,

sd_rsm_pubdate datetime,

cc_id_load mediumint,

primary key (sd_rsm_id));

DROP TABLE IF EXISTS sd_ssm;

create table sd_ssm (

sd_ssm_id mediumint not null auto_increment,

sd_sam_id mediumint, 
sd_ssm_stime datetime,

sd_ssm_stime_unc datetime,

sd_ssm_lowf float,

sd_ssm_highf float,

sd_ssm_count float,

sd_ssm_calib float,

sd_ssm_loaddate datetime,

sd_rsm_pubdate datetime,

cc_id_load mediumint,

primary key (sd_ssm_id));

DROP TABLE IF EXISTS sd_wav;

create table sd_wav (

sd_wav_id mediumint not null auto_increment,

sd_evn_id mediumint,

sd_evs_id mediumint,

sd_trm_id mediumint,

sd_wav_arch varchar(255),

sd_wav_link varchar(255),

sd_wav_dist varchar(30),

sd_wav_img varchar(255),

sd_wav_info varchar(255),

sd_wav_desc varchar(255),

cc_id mediumint,

sd_wav_loaddate datetime,

sd_wav_pubdate datetime,

cc_id_load mediumint,

primary key (sd_wav_id));

DROP TABLE IF EXISTS sn;

create table sn (

sn_id mediumint not null auto_increment,

vd_id mediumint,

sn_name varchar(30),

sn_vmodel varchar(255),

sn_vmodel_detail varchar(255),

sn_zerokm varchar(255),

sn_fdepth varchar(255),

sn_stime datetime,

sn_stime_unc datetime,

sn_etime datetime,

sn_etime_unc datetime,

sn_tot float,

sn_bb float,

sn_smp float,

sn_digital float,

sn_analog float,

sn_tcomp float,

sn_micro varchar(255),

sn_desc varchar(255),

sn_utc float,

cc_id mediumint,

sn_loaddate datetime,

sn _pubdate datetime,

cc_id_load mediumint,

primary key (sn _id)); 
DROP TABLE IF EXISTS ss;

create table ss (

ss_id mediumint not null auto_increment,

sn_id mediumint,

ss_name varchar(30),

ss_lat float,

ss_lon float,

ss_datum varchar(30),

ss_elev float,

ss_depth varchar(255),

ss_stime datetime,

ss_stime_unc datetime,

ss_etime datetime,

ss_etime_unc datetime,

ss_utc float,

ss_instr_type varchar(255),

ss_sgain float,

ss_desc varchar(255),

ss_com varchar(255),

cc_id mediumint,

ss_loaddate datetime,

ss_pubdate datetime,

cc_id_load mediumint,

primary key (ss_id));

\section{DROP TABLE IF EXISTS si;}

create table si (

si_id mediumint not null auto_increment,

ss_id mediumint,

si_name varchar(255),

si_type varchar(255),

si_range varchar(255),

si_igain float,

si_filter varchar(255),

si_ncomp float,

si_resp varchar(255),

si_resp_file varchar(255),

si_stime datetime,

si_stime_unc datetime,

si_etime datetime,

si_etime_unc datetime,

si_com varchar(255),

cc_id mediumint,

si_loaddate datetime,

si_pubdate datetime,

cc_id_load mediumint,

primary key (si_id));

DROP TABLE IF EXISTS si_cmp;

create table si_cmp (

si_cmp_id mediumint not null auto_increment,

si_cmp_name varchar(255),

si_cmp_cname varchar(30),

si_cmp_type varchar(255), 
si_cmp_resp varchar(255),

si_cmp_band varchar(30),

si_cmp_samp float,

si_cmp_icode varchar(30),

si_cmp_orient varchar(30),

si_cmp_sens varchar(255),

si_cmp_depth float,

si_cmp_com varchar(255),

cc_id mediumint,

si_cmp_loaddate datetime,

si_cmp_pubdate datetime,

cc_id_load mediumint,

primary key (si_cmp_id));

DROP TABLE IF EXISTS st_eqt;

create table st_eqt (

st_eqt_id mediumint not null auto_increment,

st_eqt_org varchar(255),

st_eqt_wovo varchar(255),

st_eqt_desc varchar(255),

cc_id mediumint,

st_eqt_loaddate datetime,

st_eqt_pubdate datetime,

cc_id_load mediumint,

primary key (st_eqt_id));

\section{Deformation}

The Deformation tables store data of a variety of geodetic methods, from precise leveling and tiltmeters to GPS and radar interferometry. Multiple Deformation tables were created for the different types of data:

- The Electronic Tilt table stores tilt data in either processed or raw form. Most modern tilt data are collected electronically and continuously.

- The Tilt Vector table stores the values of tilt vectors where the original data are no longer available. The vector data may need to be entered by hand.

- The Strainmeter table stores both strain data and processed information such as the maximum and minimum principle strains. The strain data are collected electronically and continuously.

- The Tilt/Strain Instrument table stores information about the individual components of tiltmeters and strainmeters. This instrument table gives general tilt/strain instrument information and the information that is needed for processing raw (electronic tilt) data.

- The EDM table stores the line lengths measured between two stations along with measurement errors and links to the station information. Most EDM data are not continuous.

- The Angle Data table stores legacy and a small amount of recent theodolite data are.

- The GPS table stores GPS data, errors, and information about the orbits and processing method. The GPS data can be continuous or periodic.

- The GPS vectors table stores vector information where the original GPS position data are unavailable.

- The Leveling table contains the elevation changes along lines of benchmarks. These data are collected in campaign mode. 
- The InSAR image table stores information about selected radar interferograms, including the area, location, pixel size, and processing method.

- The InSAR Satellite Junction table contains the necessary IDs for linking the InSAR data to the satellite from which it was collected.

- The InSAR data table is linked to the InSAR image table and contains the pixel-by-pixel data of interferograms.

- The Deformation Station table stores location information including the datum, a list of any installed instruments, and a conversion from local time to UTC. A new row should be created in the Deformation Station table every time the information about the station changes.

- The General Deformation Instrument table contains general information about non tilt/strain instruments, their resolution, and links to the Deformation Station table for installed instruments and the non tilt/strain data tables.

One of the challenges in creating tables for the deformation parameters is that stations or benchmarks can be used for multiple types of measurements; they can contain permanent instruments or be used with different types of instruments periodically as part of a campaign; and there are some stations that contain both a benchmark for leveling and GPS studies plus an installed instrument within a few feet. Our solution was to create one general station table to store location information and two instrument tables to store instrument specifics for both installed and campaign instruments. The first instrument table is for Tilt and Strain and the other instrument table covers all other deformation monitoring. We then put links to both the station and instrument tables into most of the data tables.

Electronic Tilt

Table D1. Electronic Tilt Data Table

\begin{tabular}{|c|c|c|}
\hline dd_tlt_id & Tilt data ID & An identifier for linking with other tables. \\
\hline ds_id & Deformation Station ID & $\begin{array}{l}\text { An identifier for linking to the Deformation } \\
\text { Station information. The Deformation } \\
\text { Station table stores location information } \\
\text { including the datum, a list of any installed } \\
\text { instruments, and a conversion from local } \\
\text { time to UTC. }\end{array}$ \\
\hline di_tlt_id & Tilt/Strain Instrument ID & $\begin{array}{l}\text { An identifier for linking with the tilt/strain } \\
\text { instrument table. This table gives } \\
\text { conversion information for processing raw } \\
\text { data and general instrument information. }\end{array}$ \\
\hline dd_tlt_time & Time & $\begin{array}{l}\text { The measurement time in UTC stored as } \\
\text { DATETIME (YYYY-MM-DD hh:mm:ss). }\end{array}$ \\
\hline dd_tlt_time_unc & $\begin{array}{l}\text { Measurement time } \\
\text { uncertainty }\end{array}$ & $\begin{array}{l}\text { The uncertainty in the measurement time in } \\
\text { UTC stored as DATETIME (YYYY-MM- } \\
\text { DD hh:mm:ss). }\end{array}$ \\
\hline dd_tlt_srate & Sampling rate & $\begin{array}{l}\text { The sampling rate for these data in seconds } \\
\text { (xxxxxxx). }\end{array}$ \\
\hline dd_tlt1 & Tilt 1 & 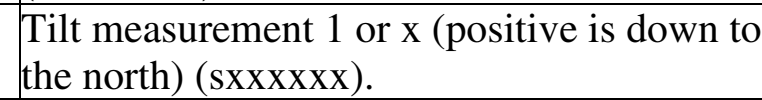 \\
\hline
\end{tabular}




\begin{tabular}{|c|c|c|}
\hline dd_tlt2 & Tilt 2 & $\begin{array}{l}\text { Tilt measurement } 2 \text { or } y \text { (positive is down to } \\
\text { the east) (sxxxxxx). }\end{array}$ \\
\hline dd_tlt_err1 & Tilt 1 error & $\begin{array}{l}\text { The error from all sources (instrument, rain, } \\
\text { diurnal heating, etc) for processed tilt } 1 \text { data } \\
\text { or error from environmental factors only if } \\
\text { the raw data are provided (xxx). }\end{array}$ \\
\hline dd_tlt_err2 & Tilt 2 error & $\begin{array}{l}\text { The error from all sources (instrument, rain, } \\
\text { diurnal heating, etc) for processed tilt } 2 \text { data } \\
\text { or error from environmental factors only if } \\
\text { the raw data are provided (xxx). }\end{array}$ \\
\hline dd_tlt_proc_flg & Processed data flag & $\begin{array}{l}\text { A single character field to indicate that these } \\
\text { data have already been processed and do not } \\
\text { require a link to the instrument table for } \\
\text { conversions. Use } \mathrm{P} \text { for processed data or } \mathrm{R} \\
\text { for raw data. }\end{array}$ \\
\hline cc_id & Collector ID & $\begin{array}{l}\text { An identifier for linking to contact } \\
\text { information for the data collector. }\end{array}$ \\
\hline dd_tlt_loaddate & Load date & The date this row was entered in UTC. \\
\hline dd_tlt_pubdate & Publish date & $\begin{array}{l}\text { The date this row can become public. This } \\
\text { date can be set up to two years in advance. }\end{array}$ \\
\hline cc_id_load & Data loader ID & $\begin{array}{l}\text { An identifier for linking to contact } \\
\text { information for the person who entered this } \\
\text { row of data. }\end{array}$ \\
\hline
\end{tabular}

The Electronic Tilt data table (dd_tlt for deformation data - tilt) contains tilt data that are either raw or processed. The primary ID is dd_tlt_id and there are several foreign IDs for linking to other tables. The Deformation Station table is linked by ds_id and provides location information including the datum, a list of installed instruments, and a conversion from local time to UTC (please see the Deformation Station table for more details). The Tilt/Strain Instrument table is linked by di_tlt_id and provides the necessary information for processing raw data and general instrument information (please see the Tilt/Strain Instrument table for more details). The collector ID (cc_id) links to contact information about the person or observatory that collected the data and the data loader ID, cc_id_load, links to the Contact table for more information about the person who loaded the data (ran the script or is in charge of running the script) into WOVOdat. The load date, dd_tlt_loaddate, is a TIMESTAMP and entered automatically in UTC. The date the data can become public is stored in dd_tlt_pubdate. The time of the tilt measurement, dd_tlt_time, along with the uncertainty, dd_tlt_time_unc, are stored as DATETIME in UTC (see time discussion under challenges). The data will be collected continuously and imported using scripts that will convert from local time to UTC. We decided to store the sampling rate (dd_tlt_srate) instead of computing it because in some cases the sampling rate will change, for example there are tiltmeters that are event triggered and will sample at a higher frequency during periods of greater unrest.

The actual tilt data will be stored in dd_tlt1 and dd_tlt2. Measurements should be recorded with a positive sign for down to the north. For processed tilt errors, dd_tlt_err1 and dd_tlt_err2, should include all sources of error including the instrument, temperature, and rainfall. If the data are in a raw $\mathrm{mV}$ form, then the analog to digital resolution and the electronic conversions are stored in the instrument tables. These values in the instrument tables should be used for the instrument error. The tilt errors stored in the data table should include environmental factors, such as rainfall and temperature. 
The processed data flag (dd_tlt_proc_flg) provides an easy way to determine if the data in dd_tlt1 and dd_tlt2 are raw and therefore require processing using the instrument (di_tlt_id) link or if the data do not require further processing for comparisons. The processed data flag is a single character text field and we request that $\mathrm{P}$ is used to indicate processed data and $\mathrm{R}$ is used to indicate raw data.

\section{Tilt Vector Data}

Table D2. Tilt Vector Data Table

\begin{tabular}{|c|c|c|}
\hline dd_tlv_id & Tilt vector data ID & An identifier for linking with other tables. \\
\hline ds_id & Deformation station ID & $\begin{array}{l}\text { An identifier for linking to the Deformation } \\
\text { Station information. }\end{array}$ \\
\hline di_tlt_id & Tilt/Strain Instrument ID & $\begin{array}{l}\text { An identifier for linking with the tilt/strain } \\
\text { instrument table. This table stores general } \\
\text { instrument details. }\end{array}$ \\
\hline dd_tlv_stime & Start time & $\begin{array}{l}\text { Start time of measurement in UTC stored as } \\
\text { DATETIME (YYYY-MM-DD hh:mm:ss). }\end{array}$ \\
\hline dd_tlv_stime_unc & Start time uncertainty & $\begin{array}{l}\text { The uncertainty of the start time of } \\
\text { measurement in UTC stored as DATETIME } \\
\text { (YYYY-MM-DD hh:mm:ss). }\end{array}$ \\
\hline dd_tlv_etime & End time & $\begin{array}{l}\text { End time of measurement in UTC stored as } \\
\text { DATETIME (YYYY-MM-DD hh:mm:ss). }\end{array}$ \\
\hline dd_tlv_etime_unc & End time uncertainty & $\begin{array}{l}\text { The uncertainty of the end time of } \\
\text { measurement in UTC stored as DATETIME } \\
\text { (YYYY-MM-DD hh:mm:ss). }\end{array}$ \\
\hline dd_tlv_mag & Tilt magnitude & $\begin{array}{l}\text { The magnitude of the tilt vector (the length) } \\
\text { in microradians (xxxx). }\end{array}$ \\
\hline dd_tlv_azi & Tilt azimuth & $\begin{array}{l}\text { The azimuth of downward tilt (the } \\
\text { direction) in degrees }(0-360)(\mathrm{xxx})\end{array}$ \\
\hline dd_tlv_magerr & Magnitude error & The magnitude error in microradians (xxx). \\
\hline dd_tlv_azierr & Azimuth error & The azimuth error in degrees (xx). \\
\hline dd_tlv_com & Comments & $\begin{array}{l}\text { Comments about possible artifacts and } \\
\text { instrument details if not available in the } \\
\text { Tilt/Strain Instrument table. }\end{array}$ \\
\hline cc_id & Collector ID & $\begin{array}{l}\text { An identifier for linking to contact } \\
\text { information for the data collector. }\end{array}$ \\
\hline dd_tlv_loaddate & Load date & The date this row was entered in UTC. \\
\hline dd_tlv_pubdate & Publish date & $\begin{array}{l}\text { The date this row can become public. This } \\
\text { date can be set up to two years in advance. }\end{array}$ \\
\hline cc_id_load & Data loader ID & $\begin{array}{l}\text { An identifier for linking to contact } \\
\text { information for the person who entered this } \\
\text { row of data. }\end{array}$ \\
\hline
\end{tabular}

The Tilt Vector Data table (dd_tlv) stores tilt information from sources where we do not have the raw or semi-processed data and only have access to tilt vectors. These data may need to be entered 
by hand. The primary ID is dd_tlv_id and there are several foreign IDs for linking to other tables. The Deformation Station table is linked by ds_id, if available, and provides location information including the datum, a list of installed instruments, and a conversion from local time to UTC (please see the Deformation Station table for more details). Information about the instrument used, if available, can be found in the Tilt/Strain Instrument table linked by di_tlv_id, which provides instrument specifics including resolution. The collector ID (cc_id) links to contact information about the person or observatory that collected the data and the data loader ID, cc_id_load, links to the Contact table for more information about the person who loaded the data into WOVOdat. The load date, dd_tlv_loaddate, is a TIMESTAMP and entered automatically in UTC. The date the data can become public is stored in dd_tlv_pubdate.

Tilt vectors show a change in tilt over a period of time. We store the start and end times in the fields dd_tlv_stime and dd_tlv_etime along with the uncertainties, dd_tlv_stime_unc and dd_tlv_etime_unc, as DATETIME (YYYY-MM-DD hh:mm:ss) in UTC (please see the time discussion under challenges for more information about time). The tilt magnitude or length of the vector (dd_tlv_mag) is stored in microradians and the tilt azimuth or direction of the vector (dd_tlv_azi) is stored in degrees from 0-360. Each of the measurements also has an associated total error, dd_tlv_magerr for tilt magnitude and dd_tlv_azierr for tilt azimuth. The Tilt Vector table includes a comments field, dd_tlv_com, for providing any additional information about the vector such as possible artifacts and instrument details if not available in the Tilt/Strain Instrument table.

\section{Strainmeter Data}

Table D3. Strainmeter Data Table

\begin{tabular}{|c|c|c|}
\hline dd_str_id & Strain Data ID & An identifier for linking with other tables. \\
\hline ds_id & Deformation Station ID & $\begin{array}{l}\text { An identifier for linking to the Deformation } \\
\text { Station information. The Deformation } \\
\text { Station table stores location information } \\
\text { including the datum, a list of any installed } \\
\text { instruments, and a conversion from local } \\
\text { time to UTC. }\end{array}$ \\
\hline di_tlt_id & Tilt/Strain Instrument ID & $\begin{array}{l}\text { An identifier for linking with the tilt/strain } \\
\text { instrument table. This table gives } \\
\text { conversion information for processing raw } \\
\text { data and general instrument details. }\end{array}$ \\
\hline dd_str_time & Measurement time & $\begin{array}{l}\text { The time of measurement in UTC stored as } \\
\text { DATETIME (YYYY-MM-DD hh:mm:ss). }\end{array}$ \\
\hline dd_str_time_unc & $\begin{array}{l}\text { Measurement time } \\
\text { uncertainty }\end{array}$ & $\begin{array}{l}\text { The uncertainty in the measurement time in } \\
\text { UTC stored as DATETIME (YYYY-MM- } \\
\text { DD hh:mm:ss). }\end{array}$ \\
\hline dd_str_comp1 & Component 1 & $\begin{array}{l}\text { The strainmeter data for component } 1 \text { in } \\
\text { microstrain where contraction is positive } \\
\text { and dilatation is negative (xxx.xxxx). }\end{array}$ \\
\hline dd_str_comp2 & Component 2 & $\begin{array}{l}\text { The strainmeter data for component } 2 \text { in } \\
\text { microstrain where contraction is positive } \\
\text { and dilatation is negative (xxx.xxxx). }\end{array}$ \\
\hline
\end{tabular}




\begin{tabular}{|c|c|c|}
\hline dd_str_comp3 & Component 3 & $\begin{array}{l}\text { The strainmeter data for component } 3 \text { in } \\
\text { microstrain where contraction is positive } \\
\text { and dilatation is negative (xxx.xxxx). }\end{array}$ \\
\hline dd_str_comp4 & Component 4 & $\begin{array}{l}\text { The strainmeter data for component } 4 \text { in } \\
\text { microstrain where contraction is positive } \\
\text { and dilatation is negative (xxx.xxx). }\end{array}$ \\
\hline dd_str_err1 & Error 1 & $\begin{array}{l}\text { The error in measurement of component } 1 \text {, } \\
\text { in microstrain (x.xxxx). }\end{array}$ \\
\hline dd_str_err2 & Error 2 & $\begin{array}{l}\text { The error in measurement of component } 2 \text {, } \\
\text { in microstrain (x.xxxx). }\end{array}$ \\
\hline dd_str_err3 & Error 3 & $\begin{array}{l}\text { The error in measurement of component } 3 \\
\text { in microstrain (x.xxxx). }\end{array}$ \\
\hline dd_str_err4 & Error 4 & $\begin{array}{l}\text { The error in measurement of component } 4 \text {, } \\
\text { in microstrain (x.xxxx). }\end{array}$ \\
\hline dd_str_vdstr & Volumetric Strain change & $\begin{array}{l}\text { The volumetric strain in microstrain } \\
\text { (contraction is positive and dilatation is } \\
\text { negative) (sxxxx.xxx). }\end{array}$ \\
\hline dd_str_vdstr_err & $\begin{array}{l}\text { Volumetric strain change } \\
\text { error }\end{array}$ & $\begin{array}{l}\text { The error associated with the volumetric } \\
\text { strain in microstrain (x.xxxx). }\end{array}$ \\
\hline dd_str_sstr_ax 1 & Shear strain, axis 1 & $\begin{array}{l}\text { The shear strain of axis } 1 \text { (gamma 1) in } \\
\text { microstrain (sxxxx.xxx). }\end{array}$ \\
\hline dd_str_azi_ax1 & Azimuth, axis 1 & $\begin{array}{l}\text { The azimuth of axis } 1 \text { (gamma } 1 \text { ) in degrees } \\
(0-360) \text { measuring with respect to North } \\
\text { with clockwise rotation as positive (xxx). }\end{array}$ \\
\hline dd_str_sstr_ax2 & Shear strain, axis 2 & $\begin{array}{l}\text { The shear strain of axis } 2 \text { (gamma 2) in } \\
\text { microstrain (sxxxx.xxx). }\end{array}$ \\
\hline dd_str_azi_ax2 & Azimuth, axis 2 & $\begin{array}{l}\text { The azimuth of axis } 2 \text { (gamma } 2 \text { ) in degrees } \\
(0-360) \text { ) measuring with respect to North } \\
\text { with clockwise rotation as positive (xxx). }\end{array}$ \\
\hline dd_str_sstr_ax3 & Shear strain, axis 3 & $\begin{array}{l}\text { The shear strain of axis } 3 \text { (gamma 3) in } \\
\text { microstrain, (for 3D strainmeters) } \\
\text { (sxxxx.xxx). }\end{array}$ \\
\hline dd_str_azi_ax3 & Azimuth, axis 3 & $\begin{array}{l}\text { The azimuth of axis } 3 \text { (gamma } 3 \text { ) in degrees } \\
(0-360) \text { measuring with respect to North } \\
\text { with clockwise rotation as positive (xxx). }\end{array}$ \\
\hline dd_str_stderr1 & Standard error 1 & $\begin{array}{l}\text { The uncertainty in the strain for axis } 1 \text { in } \\
\text { microstrain (xxx.xxx). }\end{array}$ \\
\hline dd_str_stderr2 & Standard error 2 & $\begin{array}{l}\text { The uncertainty in the strain for axis } 2 \text { in } \\
\text { microstrain (xxx.xxx). }\end{array}$ \\
\hline dd_str_stderr3 & Standard error 3 & $\begin{array}{l}\text { The uncertainty in the strain for axis } 3 \text { in } \\
\text { microstrain (xxx.xxx). }\end{array}$ \\
\hline dd_str_pmax & Max principal strain 1 & $\begin{array}{l}\text { The maximum principal strain in } \\
\text { microstrain (xxx.xxx). }\end{array}$ \\
\hline
\end{tabular}




\begin{tabular}{|l|l|l|}
\hline dd_str_pmaxerr & $\begin{array}{l}\text { Max principal strain 1 } \\
\text { standard error }\end{array}$ & $\begin{array}{l}\text { The uncertainty in the maximum principle } \\
\text { strain in microstrain (xxx.xxx). }\end{array}$ \\
\hline dd_str_pmin & Min principal strain 3 & $\begin{array}{l}\text { The minimum principal strain in microstrain } \\
\text { (xxx.xxx). }\end{array}$ \\
\hline dd_str_pminerr & $\begin{array}{l}\text { Min principal strain 3 } \\
\text { standard error }\end{array}$ & $\begin{array}{l}\text { The uncertainty in the minimum principle } \\
\text { strain in microstrain (xxx.xxx). }\end{array}$ \\
\hline dd_str_pmax_dir & Max principal strain direction & $\begin{array}{l}\text { The direction of the maximum principal } \\
\text { strain 1 in degrees (0-360) (xxx). }\end{array}$ \\
\hline dd_str_pmax_direrr & $\begin{array}{l}\text { Max principal strain direction } \\
\text { standard error }\end{array}$ & $\begin{array}{l}\text { The uncertainty in the maximum principal } \\
\text { strain direction in microstrain (xx). }\end{array}$ \\
\hline dd_str_pmin_dir & Min principal strain direction & $\begin{array}{l}\text { The direction of the minimum principal } \\
\text { strain 3 in degrees (0-360) (xxx). }\end{array}$ \\
\hline dd_str_pmin_direrr & $\begin{array}{l}\text { Min principal strain direction } \\
\text { standard error }\end{array}$ & $\begin{array}{l}\text { The uncertainty in the minimum principal } \\
\text { strain direction in microstrain (xx). }\end{array}$ \\
\hline cc_id & Collector ID & $\begin{array}{l}\text { An identifier for linking to contact } \\
\text { information for the data collector. }\end{array}$ \\
\hline dd_str_loaddate & Load date & The date this row was entered in UTC. \\
\hline dd_str_pubdate & Publish date & $\begin{array}{l}\text { The date this row can become public. This } \\
\text { date can be set up to two years in advance. }\end{array}$ \\
\hline & & $\begin{array}{l}\text { An identifier for linking to contact } \\
\text { information for the person who entered this } \\
\text { row of data. }\end{array}$ \\
\hline cc_id_load & Data loader ID &
\end{tabular}

The Strainmeter Data table (dd_str for deformation data - strain) stores both raw and processed strainmeter data. The primary ID is dd_str_id and there are several foreign IDs for linking to other tables. The Deformation Station table is linked by ds_id and provides location information including the datum, a list of installed instruments, and a conversion from local time to UTC (please see the Deformation Station table for more details). The Tilt/Strain Instrument ID di_tlt_id provides a link to the necessary information for processing raw data (please see the tilt/strain instrument table for more details). The collector ID (cc_id) links to contact information about the person or observatory that collected the data and the data loader ID, cc_id_load, links to the Contact table for more information about the person who loaded the data (ran the script or is in charge of running the script) into WOVOdat. The load date, dd_str_loaddate, is a TIMESTAMP and entered automatically in UTC. The date the data can become public is stored in dd_str_pubdate. The time of the strain measurement, dd_str_time, along with the uncertainty, dd_str_time_unc, is stored as DATETIME in UTC (see time discussion under challenges). In most cases the data will be collected continuously and imported using scripts that will convert from local time to UTC.

The strain data are stored by component, dd_str_comp1, dd_str_comp2, dd_str_comp3, and dd_str_comp4, as microstrain with a positive value for contraction and a negative value for dilatation. Each of the strain data values has an error, dd_str_err1, dd_str_err2, dd_str_err3, dd_str_err4, also in microstrain. We also store processed data in this table such as the volumetric strain, dd_str_vdstr, and the volumetric strain error, dd_str_vdstrerr in microstrain. The shear strains in microstrain and azimuths in degrees (0-360) are stored for each of three axes, dd_str_sstr_ax1, dd_str_azi_ax1, dd_str_sstr_ax2, dd_str_azi_ax2, dd_str_sstr_ax3, along with their errors, dd_str_stderr1, dd_str_stderr2, dd_str_stderr3, which are also in microstrain. The maximum principal strain, dd_str_pmax, minimum principle strain, dd_str_pmin, and their associated errors, dd_str_pmaxerr, and dd_str_pminerr are all stored in microstrain. The maximum principal strain direction, dd_str_pmax_dir, and minimum principal strain 
direction, dd_str_pmin_dir, are stored in degrees (0-360) whereas their associated errors, dd_str_pmax_direrr and dd_str_pmin_direrr are in microstrain.

Tilt/Strain Instrument

Table D4. Tilt/Strain Instrument Table

\begin{tabular}{|c|c|c|}
\hline di_tlt_id & Tilt/Strain Instrument ID & An identifier for linking with other tables. \\
\hline ds_id & Deformation Station ID & $\begin{array}{l}\text { An identifier for linking to the Deformation } \\
\text { Station information. The Deformation } \\
\text { Station table stores location information } \\
\text { including the datum, a list of installed } \\
\text { instruments, and a conversion from local } \\
\text { time to UTC. }\end{array}$ \\
\hline di_tlt_name & Name & $\begin{array}{l}\text { The name, model, and manufacturer of the } \\
\text { instrument. }\end{array}$ \\
\hline di_tlt_type & Type & The type of instrument. \\
\hline di_tlt_units & Measured units & The units the instrument measures. \\
\hline di_tlt_res & Resolution & $\begin{array}{l}\text { The analog to digitizer resolution. This is a } \\
\text { text field for describing the resolution (xxx). }\end{array}$ \\
\hline di_tlt_dir1 & Direction 1 & $\begin{array}{l}\text { The azimuth of direction } 1 \text { (or } \mathrm{x} \text { for } \\
\text { tiltmeters) using geographic north in degrees } \\
\text { from } 0 \text { to } 360 \text { (xxx). }\end{array}$ \\
\hline di_tlt_dir2 & Direction 2 & $\begin{array}{l}\text { The azimuth of direction } 2 \text { (or y for } \\
\text { tiltmeters) using geographic north in degrees } \\
\text { from } 0 \text { to } 360 \text { (xxx). }\end{array}$ \\
\hline di_tlt_dir3 & Direction 3 & $\begin{array}{l}\text { The azimuth of direction } 3 \text { using geographic } \\
\text { north in degrees from } 0 \text { to } 360 \text { (xxx). }\end{array}$ \\
\hline di_tlt_dir4 & Direction 4 & $\begin{array}{l}\text { The azimuth of direction } 4 \text { using geographic } \\
\text { north in degrees from } 0 \text { to } 360 \text { (xxx). }\end{array}$ \\
\hline di_tlt_econv1 & Electronic conversion 1 & $\begin{array}{l}\text { The electronic conversion (scale factor) for } \\
\text { component } 1 \text {. The tilt conversion will be } \\
\text { from } \mathrm{mV} \text { to microradians and the strain } \\
\text { conversion should be from } \mathrm{mV} \text { to } \\
\text { microstrain. If we do put the conversions in } \\
\text { the data input stage rather than into } \\
\text { WOVOdat storage, these fields would no } \\
\text { longer be necessary (xxx.xx). }\end{array}$ \\
\hline di_tlt_econv2 & Electronic conversion 2 & $\begin{array}{l}\text { The electronic conversion (scale factor) for } \\
\text { component } 2 \text {. The tilt conversion should be } \\
\text { from } m V \text { to microradian conversion and the } \\
\text { strain conversion should be from } \mathrm{mV} \text { to } \\
\text { microstrain (xxx.xx). }\end{array}$ \\
\hline di_tlt_econv3 & Electronic conversion 3 & $\begin{array}{l}\text { The electronic conversion (scale factor) for } \\
\text { component } 3 \text {, if applicable. The tilt } \\
\text { conversion should be from } \mathrm{mV} \text { to }\end{array}$ \\
\hline
\end{tabular}




\begin{tabular}{|c|c|c|}
\hline & & $\begin{array}{l}\text { microradian conversion and the strain } \\
\text { conversion should be from } \mathrm{mV} \text { to } \\
\text { microstrain (xxx.xx). }\end{array}$ \\
\hline di_tlt_econv4 & Electronic conversion 4 & $\begin{array}{l}\text { The electronic conversion (scale factor) for } \\
\text { component } 4 \text {, if applicable. The tilt } \\
\text { conversion should be from } \mathrm{mV} \text { to } \\
\text { microradian conversion and the strain } \\
\text { conversion should be from } \mathrm{mV} \text { to } \\
\text { microstrain (xxx.xx). }\end{array}$ \\
\hline di_tlt_stime & Start time & $\begin{array}{l}\text { The time the instrument information in this } \\
\text { table became valid in UTC stored as } \\
\text { DATETIME (YYYY-MM-DD hh:mm:ss). }\end{array}$ \\
\hline dd_tlt_stime_unc & Start time uncertainty & $\begin{array}{l}\text { The uncertainty of the time the instrument } \\
\text { information in this table became valid in } \\
\text { UTC stored as DATETIME (YYYY-MM- } \\
\text { DD hh:mm:ss). }\end{array}$ \\
\hline di_tlt_etime & End time & $\begin{array}{l}\text { The time the instrument information in this } \\
\text { table changed in UTC stored as DATETIME } \\
\text { (YYYY-MM-DD hh:mm:ss). This field will } \\
\text { be null if the original information is still } \\
\text { valid. }\end{array}$ \\
\hline dd_tlt_etime_unc & End time uncertainty & $\begin{array}{l}\text { The uncertainty of the time the instrument } \\
\text { information in this table changed in UTC } \\
\text { stored as DATETIME (YYYY-MM-DD } \\
\text { hh:mm:ss). This field will be null if the } \\
\text { original information is still valid. }\end{array}$ \\
\hline di_tlt_com & Comments & Comments about the instrument. \\
\hline cc_id & Contact ID & $\begin{array}{l}\text { An identifier for linking to contact } \\
\text { information for this instrument. }\end{array}$ \\
\hline di_tlt_loaddate & Load date & The date this row was entered in UTC. \\
\hline di_tlt_pubdate & Publish date & $\begin{array}{l}\text { The date this row can become public. This } \\
\text { date can be set up to two years in advance. }\end{array}$ \\
\hline cc_id_load & Data loader ID & $\begin{array}{l}\text { An identifier for linking to contact } \\
\text { information for the person who entered this } \\
\text { row of data. }\end{array}$ \\
\hline
\end{tabular}

The Tilt/Strain Instrument table (di_tlt for deformation instrument - tilt/strain) stores information about each individual instrument and provides the necessary data to process raw data from the tilt and strain data tables. The original thought was to have a common instrument table for the model number and a more specific instrument table for the resolution of the instrument at the specific station but we decided to limit the number of joins and combine the tables. The primary ID is di_tlt_id and there are only a few foreign IDs for linking to other tables. The contact ID (cc_id) links to contact information about the person or observatory that manages the station and the data loader ID, cc_id_load, links to the Contact table for more information about the person who loaded the data into WOVOdat. The load date, dd_tlv_loaddate, is a TIMESTAMP and entered automatically in UTC. The date the data can become public is stored in dd_tlv_pubdate. 
The Tilt/Strain Instrument table contains information about the instrument such as the name, model, and manufacturer in di_tlt_name, the type of instrument, di_tlt_type, and the units the instrument measures in di_tlt_units. These units may not be the units we are requesting for the data tables and conversions may be necessary (these should be part of the individual data loading scripts for each observatory). The resolution for converting from an analog signal to a digital signal is stored in di_tlt_res and gives the least count noise or how small of a change can be measured. The directions or azimuth for the tilt and strainmeter components are stored as di_tlt_dir1, di_tlt_dir2, di_tlt_dir3, and di_tlt_dir4. The tiltmeters will only use di_tlt_dir1 and di_tlt_dir2 as the $\mathrm{x}$ and $\mathrm{y}$ directions. All directions should be entered as degrees from 0 to 360 using geographic north. Most strainmeters have up to three components, however, there are new strainmeters that contain a fourth. To convert the raw data to processed data we also need to store the electronic conversions or scale factors for each of the components, di_tlt_econv1, di_tlt_econv2, di_tlt_econv3, di_tlt_econv4. The electronic conversions for the components are different than the analog to digital conversion for the entire instrument. For tiltmeters the conversion is from millivolts to microradians and for the strainmeters the converstion is from millivolts to microstrain.

The final attributes of the Tilt/Strain Instrument table are the valid from or start time, di_tlt_stime, and the valid to or end time, di_tlt_etime, along with their uncertainties, di_tlt_stime_unc and di_tlt_etime_unc. These fields are stored in DATETIME UTC (the information for converting to UTC is found in the Deformation Station table). The end time should be entered after an instrument has been pulled out of the ground for maintenance and then reset, if the resolution was changed, if the instrument was permanently removed, or if the instrument is no longer working. Information should then be entered for the new or modified instrument using a new di_tlt_id and a new start time. Comments or additional information about the instrument should be included in the field, di_tlt_com.

\section{EDM}

Table D5. EDM Data Table

\begin{tabular}{|l|l|l|}
\hline dd_edm_id & EDM data ID & Identifier for linking to other tables. \\
\hline di_gen_id & $\begin{array}{l}\text { An identifier for linking with the General } \\
\text { Deformation Instrument table. The General } \\
\text { Deformation Instrument table provides } \\
\text { specific information about the instrument } \\
\text { including the resolution, the type of } \\
\text { monitoring performed, and a link to the } \\
\text { Deformation Station table if the instrument } \\
\text { is permanently installed at a station. }\end{array}$ \\
\hline ds_id1 & $\begin{array}{l}\text { General Deformation } \\
\text { Instrument ID }\end{array}$ & $\begin{array}{l}\text { An identifier for linking to information } \\
\text { about the station where the EDM is being } \\
\text { operated }\end{array}$ \\
\hline & Instrument station ID & $\begin{array}{l}\text { An identifier for linking to information } \\
\text { about the Target or Reflector station, in the } \\
\text { Deformation Station table. The Deformation } \\
\text { Station table gives the station nominal } \\
\text { location, a list of installed instruments, the } \\
\text { conversion from local time to UTC, and a } \\
\text { reference datum. }\end{array}$ \\
\hline ds_id2 & Target station ID & \\
\hline
\end{tabular}




\begin{tabular}{|l|l|l|}
\hline dd_edm_cont & Continuous flag & $\begin{array}{l}\text { A single character field used to identify } \\
\text { continuous data. Use C for data that were } \\
\text { collected continuously or P for data that } \\
\text { were collected periodically. }\end{array}$ \\
\hline dd_edm_time & Measurement time & $\begin{array}{l}\text { The time of the measurement in UTC stored } \\
\text { as DATETIME (YYYY-MM-DD } \\
\text { hh:mm:ss). }\end{array}$ \\
\hline dd_edm_time_unc & Measurement time & $\begin{array}{l}\text { The uncertainty in the measurement time in } \\
\text { UTC stored as DATETIME (YYYY-MM- } \\
\text { DD hh:mm:ss). }\end{array}$ \\
\hline dd_edm_line & Line length & $\begin{array}{l}\text { The mark-to-mark line length in meters } \\
\text { (xxxxx.xxx). }\end{array}$ \\
\hline dd_edm_cerr & Constant error & $\begin{array}{l}\text { The constant error in meters, an indication } \\
\text { of the instrument and reflector error (x.xxx ) }\end{array}$ \\
\hline dd_edm_serr & Scale error & $\begin{array}{l}\text { The scale error in ppm, an indication of the } \\
\text { error in line length due to temperature, and } \\
\text { pressure (xxxx ). }\end{array}$ \\
\hline cc_id & Collector ID & $\begin{array}{l}\text { An identifier for linking to contact } \\
\text { information for the data collector. }\end{array}$ \\
\hline dd_edm_loaddate & Load date & The date this row was entered in UTC. \\
\hline dd_edm_pubdate & Publish date & $\begin{array}{l}\text { The date this row can become public. This } \\
\text { date can be set up to two years in advance. }\end{array}$ \\
\hline cc_id_load & & $\begin{array}{l}\text { An identifier for linking to contact } \\
\text { information for the person who entered this } \\
\text { row of data. }\end{array}$ \\
\hline
\end{tabular}

The EDM data table (dd_edm for deformation data - electronic distance meter) contains EDM data that were collected between two stations, an Instrument station and a Target or Reflector station. Information about both of these stations can be found in the Deformation Station table, linked from ds_id1 for the instrument station and ds_id2 for the target station. The Deformation Station table provides the nominal locations for each station or benchmark, a link to the Network table, a list of any installed instruments, a conversion from local time to UTC, and a link to the reference station information. Information about the instrument used to take campaign measurements is reached using the link di_gen_id. Contact information and information about the instruments that record continuous data can be found through links in the Deformation Station table. The primary ID for the EDM table is dd_edm_id. The collector ID, cc_id, links to contact information about the person or observatory that collected campaign data and the data loader ID, cc_id_load, links to the Contact table for more information about the person who loaded the data into WOVOdat. The load date, dd_edm_loaddate, is a TIMESTAMP and entered automatically in UTC. The date the data can become public is stored in dd_edm_pubdate.

EDM data is generally collected as part of a campaign but is collected continuously by at least one observatory. A flag, dd_edm_cont, is included to identify the continuous data. The attribute dd_edm_cont should store the letter C only if all data recorded at the measurement time was recorded continuously and the letter P for data collected as part of a campaign. The data attributes for the EDM table are the time of measurement, the line length, and the errors. The time of measurement, 
dd_edm_time, along with the uncertainty, dd_edm_unc, is stored in UTC DATETIME (YYYY-MMDD hh:mm:ss). The frequency of measurements varies greatly from one volcano to another or even on a single volcano. The line length, dd_edm_line, is the length of the measurement from the Instrument station to the Target station in meters. The constant error, dd_edm_cerr, is an indication of the instrument and reflector error recorded in meters. The scale error, dd_edm_serr, is an indication of the error in line length due to temperature and pressure recorded in ppm.

Angle Data table

Table D6. Angle Data Table

\begin{tabular}{|c|c|c|}
\hline dd_ang_id & Angle data ID & Identifier for linking to other tables. \\
\hline di_gen_id & $\begin{array}{l}\text { General Deformation } \\
\text { Instrument ID }\end{array}$ & $\begin{array}{l}\text { An identifier for linking with the General } \\
\text { Deformation Instrument table. The General } \\
\text { Deformation Instrument table provides } \\
\text { information about instruments and their } \\
\text { resolution. }\end{array}$ \\
\hline ds_id & Instrument station ID & $\begin{array}{l}\text { An identifier for linking to information } \\
\text { about the station from which the } \\
\text { measurements were taken, if available, in } \\
\text { the Deformation Station table. }\end{array}$ \\
\hline ds id1 & Target station ID 1 & $\begin{array}{l}\text { An identifier for linking with information } \\
\text { about Target station number } 1 \text {, if available, } \\
\text { in the Deformation Station table. }\end{array}$ \\
\hline ds_id2 & Target station ID 2 & $\begin{array}{l}\text { An identifier for linking with information } \\
\text { about Target station number } 2 \text {, if available, } \\
\text { in the Deformation Station table. }\end{array}$ \\
\hline dd_ang_time & Measurement time & $\begin{array}{l}\text { The time of the measurement in UTC stored } \\
\text { as DATETIME (YYYY-MM-DD } \\
\text { hh:mm:ss). }\end{array}$ \\
\hline dd_ang_time_unc & $\begin{array}{l}\text { Measurement time } \\
\text { uncertainty }\end{array}$ & $\begin{array}{l}\text { The uncertainty in the measurement time in } \\
\text { UTC stored as DATETIME (YYYY-MM- } \\
\text { DD hh:mm:ss). }\end{array}$ \\
\hline dd_ang_hort1 & Horizontal angle to target 1 & $\begin{array}{l}\text { The horizontal angle as measured by } \\
\text { theodolite or total station (in degrees, 0-360) } \\
\text { (xxx.xx) to target } 1 \text {. }\end{array}$ \\
\hline dd_ang_hort2 & Horizontal angle to target 2 & $\begin{array}{l}\text { The horizontal angle as measured by } \\
\text { theodolite or total station (in degrees, 0-360) } \\
\text { (xxx.xx) to target } 2 \text {. }\end{array}$ \\
\hline dd_ang_vert1 & Vertical angle to target 1 & $\begin{array}{l}\text { The vertical angle as measured by } \\
\text { theodolite or total station (in degrees }-90 \text { to } \\
+90)(\text { xxx.xx) to target } 1 \text {. }\end{array}$ \\
\hline dd_ang_vert2 & Vertical angle to target 2 & $\begin{array}{l}\text { The vertical angle as measured by } \\
\text { theodolite or total station (in degrees }-90 \text { to } \\
+90)(x \times x . x x) \text { to target } 2 \text {. }\end{array}$ \\
\hline dd_ang_h & Horizontal error on angle 1 & $\begin{array}{l}\text { The error on the horizontal angle (x.xx) to } \\
\text { target } 1 .\end{array}$ \\
\hline
\end{tabular}




\begin{tabular}{|c|c|c|}
\hline dd_ang_herr2 & Horizontal error on angle 2 & $\begin{array}{l}\text { The error on the horizontal angle (x.xx) to } \\
\text { target } 2 \text {. }\end{array}$ \\
\hline dd_ang_verr1 & Vertical error on angle 1 & $\begin{array}{l}\text { The error on the vertical angle (x.xx) to } \\
\text { target } 1 \text {. }\end{array}$ \\
\hline dd_ang_verr2 & Vertical error on angle 2 & $\begin{array}{l}\text { The error on the vertical angle (x.xx) to } \\
\text { target } 2 \text {. }\end{array}$ \\
\hline dd_ang_com & Comments & $\begin{array}{l}\text { Comments about the angle data including } \\
\text { any information that is not available in the } \\
\text { Deformation station and instruments tables, } \\
\text { and information on how well we know the } \\
\text { location and time of measurement. }\end{array}$ \\
\hline cc_id & Collector ID & $\begin{array}{l}\text { An identifier for linking to contact } \\
\text { information for the data collector. }\end{array}$ \\
\hline dd_ang_loaddate & Load date & The date this row was entered in UTC. \\
\hline dd_ang_pubdate & Publish date & $\begin{array}{l}\text { The date this row can become public. This } \\
\text { date can be set up to two years in advance. }\end{array}$ \\
\hline cc_id_load & Data loader ID & $\begin{array}{l}\text { An identifier for linking to contact } \\
\text { information for the person who entered this } \\
\text { row of data. }\end{array}$ \\
\hline
\end{tabular}

The Angle data table (dd_ang for deformation data - angle) contains a few angles from early geodetic surveys where someone would stand on a high point (on top of a mountain) and measure the horizontal and vertical angles to prominent features in the area. Today, angles are measured to describe dramatic vertical or horizontal deformation of points on which GPS receivers and other modern instruments cannot safely be installed (e.g., on growing lava domes). We include a comments field, dd_ang_com, for additional information about the locations (see below for more information on the comments field). More specific information about the Instrument and two Target stations, if available, can be found in the Deformation Station table and is linked from ds_id1 for the Instrument station, ds_id2 for the first Target station, and ds_id3 for the second Target station. The Deformation Station table provides the nominal locations for each station or benchmark, a link to the Network table, a list of any installed instruments, and a conversion from local time to UTC. Information about the instrument used to take the measurements, if available, is linked by di_gen_id, to the General Deformation Instrument table. The General Deformation Instrument table provides specific information about the instrument including the resolution and the type of monitoring performed. If a link to the General Deformation Instrument table is not available, the comments field provides an alternative place for more general instrument information. The primary ID for the Angle table is dd_ang_id. The collector ID, cc_id, and data loader ID, cc_id_load, both link to contact information in the Contact table. The load date, dd_ang_loaddate, is a TIMESTAMP and entered automatically in UTC. The date the data can become public is stored in dd_ang_pubdate.

The data attributes for the Angle table are the time of measurement, the angles, and the errors on the angles. The time of measurement, dd_ang_time, may be an approximate time when the data was collected and the uncertainty is stored in dd_ang_time_unc. The two angles are stored in dd_ang_hort1 and dd_ang_hort2 for the hortizontal angle (0-360 degrees) to target 1 and 2 and dd_ang_vert 1 and dd_ang_vert2 for the vertical angle (+90 to -90 degrees) to target 1 and 2 . The errors on the angles, dd_ang_herr1 and dd_ang_herr2 for the horizontal and dd_ang_verr1 and dd_ang_verr2 for the vertical 
angle errors, are both also in degrees. It was unclear during the discussions if fields were needed for the for horizontal and vertical angles to target station 2. In addition to providing location information, the comments field, dd_ang_com, should include information about how well the location and time of measurement are known and instrument information.

\section{GPS Data}

Table D7. GPS Data Table

\begin{tabular}{|c|c|c|}
\hline dd_gps_id & GPS data ID & An identifier for linking with other tables. \\
\hline di_gen_id & $\begin{array}{l}\text { General Deformation } \\
\text { Instrument ID }\end{array}$ & $\begin{array}{l}\text { An identifier for linking with the General } \\
\text { Deformation Instrument table. The General } \\
\text { Deformation Instrument table provides } \\
\text { information about non-tilt/strain instruments } \\
\text { and their resolution, and a link to the } \\
\text { Deformation Station table if the instrument } \\
\text { is permanently installed at a station. } \\
\end{array}$ \\
\hline ds_id & GPS station ID & $\begin{array}{l}\text { An identifier for linking with the } \\
\text { Deformation Station table. }\end{array}$ \\
\hline ds_id_ref1 & Reference station 1 & The first reference (fixed) station. \\
\hline ds_id_ref2 & Reference station 2 & The second reference (fixed) station, if any. \\
\hline dd_gps_cont & Continuous flag & $\begin{array}{l}\text { A single character field used to identify } \\
\text { continuous data. Use C for data that were } \\
\text { collected continuously or P for data that } \\
\text { were collected periodically. }\end{array}$ \\
\hline dd_gps_time & Time of measurement & $\begin{array}{l}\text { The time of the measurement in UTC stored } \\
\text { as DATETIME (YYYY-MM-DD } \\
\text { hh:mm:ss). }\end{array}$ \\
\hline dd_gps_time_unc & $\begin{array}{l}\text { Measurement time } \\
\text { uncertainty }\end{array}$ & $\begin{array}{l}\text { The uncertainty in the measurement time in } \\
\text { UTC stored as DATETIME (YYYY-MM- } \\
\text { DD hh:mm:ss). }\end{array}$ \\
\hline dd_gps_lat & Latitude & $\begin{array}{l}\text { The measured latitude in decimal degrees } \\
(\text { (sxx.xxxxxxxxx). }\end{array}$ \\
\hline dd_gps_lon & Longitude & $\begin{array}{l}\text { The measured longitude in decimal degrees } \\
(\text { (sxxx.Xxxxxxxxx). }\end{array}$ \\
\hline dd_gps_elev & Elevation & $\begin{array}{l}\text { The measured elevation in meters (asl) } \\
(\text { (sxxxx.xxx). }\end{array}$ \\
\hline dd_gps_datum & Datum & $\begin{array}{l}\text { The datum used for the longitude and } \\
\text { latitude and the original datum if different. }\end{array}$ \\
\hline dd_gps_nserr & N-S Error & $\begin{array}{l}\text { The north-south error in degrees } \\
(x . x x x x x x x x)\end{array}$ \\
\hline dd_gps_ewerr & E-W Error & $\begin{array}{l}\text { The east-west error in degrees } \\
\text { (x.xxxxxxxxx). }\end{array}$ \\
\hline dd_gps_verr & Vertical Error & The vertical error in meters (x.xxx ). \\
\hline
\end{tabular}




\begin{tabular}{|c|c|c|}
\hline dd_gps_software & $\begin{array}{l}\text { Position-determining } \\
\text { software }\end{array}$ & $\begin{array}{l}\text { The software used to determine the } \\
\text { positions, e.g., GIPSY, BERNESE, other. }\end{array}$ \\
\hline dd_gps_orbits & Orbits used & $\begin{array}{l}\text { The orbits used to determine the positions } \\
\text { (source, and corrections applied). Please } \\
\text { provide whose orbits and which ones. }\end{array}$ \\
\hline dd_gps_dur & Duration of the solution & $\begin{array}{l}\text { The duration of the solution in minutes. For } \\
\text { continuous data, please give the frequency } \\
\text { of measurement and the duration of time } \\
\text { used to calculate each position, e.g., For } \\
\text { example, data collected every } 10 \text { seconds } \\
\text { and each position computed from } 24 \text { hours } \\
\text { of data. For periodic (campaign) data, } \\
\text { please give the duration of dataused to } \\
\text { calculate this position. }\end{array}$ \\
\hline dd_gps_qual & Quality marker & $\begin{array}{l}\text { An indicator of the quality for this } \\
\text { measurement (use E for excellent, G for } \\
\text { good, P for poor, and U for unknown). }\end{array}$ \\
\hline cc_id & Collector ID & $\begin{array}{l}\text { An identifier for linking to contact } \\
\text { information for the data collector. }\end{array}$ \\
\hline dd_gps_loaddate & Load date & The date this row was entered in UTC. \\
\hline dd_gps_pubdate & Publish date & $\begin{array}{l}\text { The date this row can become public. This } \\
\text { date can be set up to two years in advance. }\end{array}$ \\
\hline cc_id_load & Data loader ID & $\begin{array}{l}\text { An identifier for linking to contact } \\
\text { information for the person who entered this } \\
\text { row of data. }\end{array}$ \\
\hline
\end{tabular}

The GPS data table (dd_gps for deformation data - Global Positioning System) contains continuous and periodic data collected at a single station and referenced to two reference stations. These data are collected either by a temporary GPS instrument for a period of time or by an instrument that records the position continuously. The periodic data may require a web form for data entry. The primary ID for the GPS table is dd_gps_id and the station from which the measurement was made is linked using the Deformation Station table ID, ds_id. Fields for two reference stations, ds_id_ref1 and ds_id_ref2, are included and should also link to the Deformation Station table. The Deformation Station table provides the nominal locations for each station or benchmark, a link to the Network table, a list of any installed instruments, a conversion from local time to UTC, and a link to the reference station information. Information about the instrument used to take the measurements is linked by di_gen_id, to the General Deformation Instrument table. The General Deformation Instrument table provides specific information about the instrument including the resolution, and a link to the Deformation Station table if the instrument is permanently installed at a station. The collector ID, cc_id, and data loader ID, cc_id_load, both link to contact information in the Contact table. The load date, dd_gps_loaddate, is a TIMESTAMP and entered automatically in UTC. The date the data can become public is stored in dd_gps_pubdate.

The time of the measurement is stored in, dd_gps_time, along with an uncertainty, dd_gps_time_unc, in UTC DATETIME. GPS data can be collected either continuously or as part of a campaign so a flag, dd_gps_cont, is included to identify the continuous data. The abbreviation (C) 
should be used for continuous data and (P) should be used for campaign or periodic data collection. The frequency time frame should be exact for the continuous data and approximate for the periodic data.

The measured location is stored in dd_gps_lat, dd_gps_lon, and dd_gps_elev for the latitude, longitude, and elevation. The datum used for the measurements is stored in dd_gps_datum. All data should be converted to WGS 84 prior to entering WOVOdat. If conversion is not possible during data loading, the original datum must be entered into the datum field, dd_gps_datum. In addition to the measured location, we also request errors associated with each direction of the location, dd_gps_nserr for the North-South error, dd_gps_ewerr for the East-West error, and dd_gps_verr for the vertical error. The North-South and East-West errors are stored in degrees whereas the vertical error is stored in meters. The software used to determine the location should be stored in dd_gps_software and information about the orbits used should be stored in dd_gps_orbits. Both the software and orbits attributes are text fields that should include any information that would be helpful for understanding how the locations were calculated. The duration of the solution, dd_gps_dur, depends on whether the data were collected continuously or periodically and should include an uncertainty. If the data were collected continuously, the frequency of data collection should be included along with the length of time the data were averaged over. For example, "data collected every 10 seconds, plus or minus one half second. one value computed for each 24 hour period.” If the data were collected periodically (by hand) please indicate the period of time during which the measurement was taken in minutes. The GPS data table also includes a quality marker, dd_gps_qual, for defining the data. The quality marker is a single character text field for the following characters; E for excellent, G for good, P for poor, and U for unknown.

\section{GPS Vectors}

Table D8. GPS Vectors Table

\begin{tabular}{|l|l|l|}
\hline dd_gpv_id & GPS data ID & Identifier for linking to other tables \\
\hline di_gen_id & $\begin{array}{l}\text { An identifier for linking with the General } \\
\text { Deformation Instrument table. The General } \\
\text { Deformation Instrument table provides } \\
\text { specific information about the non-tilt/strain } \\
\text { instruments and their resolution. }\end{array}$ \\
\hline ds_id & $\begin{array}{l}\text { General Deformation } \\
\text { Instrument ID }\end{array}$ & $\begin{array}{l}\text { An identifier for linking with the } \\
\text { Deformation Station table. }\end{array}$ \\
\hline dd_gpv_stime & GPS BM ID & $\begin{array}{l}\text { Start time of measuring interval in UTC } \\
\text { stored as DATETIME (YYYY-MM-DD } \\
\text { hh:mm:ss). }\end{array}$ \\
\hline dd_gpv_stime_unc & Start time uncertainty & $\begin{array}{l}\text { The uncertainty of the start time of } \\
\text { measurement in UTC stored as DATETIME } \\
\text { (YYYY-MM-DD hh:mm:ss). }\end{array}$ \\
\hline dd_gpv_etime & & $\begin{array}{l}\text { End time of measuring interval in UTC } \\
\text { stored as DATETIME (YYYY-MM-DD } \\
\text { hh:mm:ss). }\end{array}$ \\
\hline End time & $\begin{array}{l}\text { The uncertainty of the end time of } \\
\text { measurement in UTC stored as DATETIME } \\
\text { (YYYY-MM-DD hh:mm:ss). }\end{array}$ \\
\hline dd_gpv_etime_unc & End time uncertainty &
\end{tabular}




\begin{tabular}{|c|c|c|}
\hline dd_gpv_dmag & Displacement magnitude & $\begin{array}{l}\text { The magnitude of the displacement in } \mathrm{mm} \text {, } \\
\text { if vector is described by displacement } \\
\text { magnitude, azimuth, and vector inclination } \\
\text { (xxxxx). }\end{array}$ \\
\hline dd_gpv_daz & Displacement azimuth & $\begin{array}{l}\text { The displacement azimuth in degrees (0- } \\
360 \text { ), if vector is so described (xxx.x). }\end{array}$ \\
\hline dd_gpv_vincl & Vector inclination & $\begin{array}{l}\text { The inclination of displacement vector in } \\
\text { degrees (0-90), if vector is so described } \\
\text { (xx.x). }\end{array}$ \\
\hline dd_gpv_N & North displacement & $\begin{array}{l}\text { The displacement to the north in } \mathrm{mm} \text {, if } \\
\text { vector is described in terms of North, East, } \\
\text { and Vertical displacement (xxxxx). }\end{array}$ \\
\hline dd_gpv_E & East displacement & $\begin{array}{l}\text { The displacement to the east in } \mathrm{mm} \text {, if } \\
\text { vector is so described (xxxx). }\end{array}$ \\
\hline dd_gpv_vert & Vertical displacement & $\begin{array}{l}\text { The vertical displacement in } \mathrm{mm} \text {, if vector } \\
\text { is so described (xxxxx). }\end{array}$ \\
\hline dd_gpv_dherr & $\begin{array}{l}\text { Magnitude horizontal } \\
\text { uncertainty }\end{array}$ & $\begin{array}{l}\text { The uncertainty in horizontal displacement } \\
\text { magnitude in } \mathrm{mm}(\mathrm{xxx}) \text {. }\end{array}$ \\
\hline dd_gpv_dverr & $\begin{array}{l}\text { Magnitude vertical } \\
\text { uncertainty }\end{array}$ & $\begin{array}{l}\text { The uncertainty in vertical displacement } \\
\text { magnitude in } \mathrm{mm} \text { (xxx). }\end{array}$ \\
\hline dd_gpv_com & Comments & $\begin{array}{l}\text { Comments about the vector data including } \\
\text { locations of the instrument and target } \\
\text { stations (if the specifics are not available in } \\
\text { the Deformation Station Table), information } \\
\text { about the instruments used (if not available } \\
\text { in the General Deformation Instrument } \\
\text { table), and information on how well we } \\
\text { know the location and time of measurement. }\end{array}$ \\
\hline cc_id & Contact ID & $\begin{array}{l}\text { An identifier for linking to contact } \\
\text { information for the person or observatory } \\
\text { who collected or provided the data. }\end{array}$ \\
\hline dd_gpv_loaddate & Load date & The date this row was entered in UTC. \\
\hline dd_gpv_pubdate & Publish date & $\begin{array}{l}\text { The date this row can become public. This } \\
\text { date can be set up to two years in advance. }\end{array}$ \\
\hline cc_id_load & Data loader ID & $\begin{array}{l}\text { An identifier for linking to contact } \\
\text { information for the person who entered this } \\
\text { row of data. }\end{array}$ \\
\hline
\end{tabular}

The GPS Vectors table (dd_gpv for deformation data - Global Positioning System vectors) contains vectors that were computed from GPS data where the actual positions are not available. These data will need to be entered by hand and will require a web script. The primary ID for the GPS Vectors table is dd_gpv_id and information about the station from which the data was collected is linked using 
the Deformation station ID, ds_id, if available. If these data are not available, then a comments field (see below) has been created to store more general location information. The Deformation Station table provides the nominal locations for each station or benchmark, a link to the Network table, a list of any installed instruments, a conversion from local time to UTC, and a link to the reference station information. Information about the instrument used, if available, can be found in the General Deformation Instrument table, which stores general information about the instrument including resolution. If a link to the General Deformation Instrument table is not available, the comments field (see below) provides an alternative place for more general instrument information. The contact ID (cc_id) links to contact information about the person or observatory that provided the data and the data loader ID, cc_id_load, links to the Contact table for more information about the person who loaded the data into WOVOdat. The load date, dd_gpv_loaddate, is a TIMESTAMP and entered automatically in UTC. The date the data can become public is stored in dd_gpv_pubdate.

The GPS vectors record changes of position from time 1 to time 2. The attribute dd_gpv_stime stores the start time of the interval and dd_gpv_etime stores the end time of the interval, all in UTC DATETIME. The uncertainties for the times, dd_gpv_stime_unc and dd_gpv_etime_unc, are also stored in UTC DATETIME. The conversion to UTC can be found in the Deformation Station table. The values for the angles can be given as either displacement magnitudes and azimuths, or as north, east, and vertical displacements. Data can be entered for either but not both. The displacement magnitudes and azimuths are stored in dd_gpv_dmag as mm and dd_gpv_daz as degrees from 0-360. The vector inclination is stored in dd_gpv_vincl as degrees from 0-90. The alternative method for storing the angle data, by north, east, and vertical displacement is stored in dd_gpv_n, dd_gpv_e, and dd_gpv_vert all in $\mathrm{mm}$. We also request a magnitude uncertainty, dd_gpv_derr, in mm. A comments field, dd_gpv_com, is included for information about the station if specifics are not available in the Deformation Station Table, information about the instrument used, if not available in the General Deformation Instrument table, and information on how well we know the location and time of measurement.

\section{Leveling Data}

Table D9. Leveling Data Table

\begin{tabular}{|l|l|l|}
\hline dd_lev_id & Leveling ID & An identifier for linking with other tables. \\
\hline ds_id_ref & Reference BM ID & $\begin{array}{l}\text { An identifier for linking with the reference } \\
\text { benchmark in the Deformation Station table. }\end{array}$ \\
\hline di_gen_id & $\begin{array}{l}\text { General Deformation } \\
\text { Instrument ID }\end{array}$ & $\begin{array}{l}\text { An identifier for linking with the General } \\
\text { Deformation Instrument table. }\end{array}$ \\
\hline dd_lev_ord & Order & The order of the survey. \\
\hline dd_lev_class & Class & The class of the survey. \\
\hline dd_lev_time & & $\begin{array}{l}\text { The date of the survey in UTC stored as } \\
\text { DATETIME (YYYY-MM-DD hh:mm:ss). }\end{array}$ \\
\hline & Survey date & $\begin{array}{l}\text { The uncertainty in the date of the survey in } \\
\text { UTC stored as DATETIME (YYYY-MM- } \\
\text { DD hh:mm:ss). }\end{array}$ \\
\hline dd_lev_time_unc & Survey date uncertainty &
\end{tabular}




\begin{tabular}{|c|c|c|}
\hline ds_id1 & $\mathrm{BM}(\mathrm{n}) \mathrm{ID}$ & $\begin{array}{l}\text { An identifier for linking to the first } \\
\text { benchmark (n) in the Deformation Station } \\
\text { table. }\end{array}$ \\
\hline ds_id2 & $\mathrm{BM}(\mathrm{n}+1) \mathrm{ID}$ & $\begin{array}{l}\text { An identifier for linking to the second } \\
\text { benchmark }(n+1) \text { in the Deformation } \\
\text { Station table. }\end{array}$ \\
\hline dd_lev_delev & Elevation change & $\begin{array}{l}\text { The elevation change in } m m \text { from the first } \\
\text { benchmark (n) to the second benchmark } \\
(\mathrm{n}+1)(\mathrm{xxx} . \mathrm{x}) \text {. }\end{array}$ \\
\hline dd_lev_herr & Estimated error in delta $h$ & $\begin{array}{l}\text { The estimated error in the elevation change } \\
\text { in mm from the first benchmark (n) to the } \\
\text { second benchmark ( } \mathrm{n}+1)(\mathrm{xx} . \mathrm{x}) \text {. }\end{array}$ \\
\hline dd_lev_com & Comments & $\begin{array}{l}\text { Comments about the data including the } \\
\text { original level of detail for the survey date } \\
\text { (the year, the month, or the day). }\end{array}$ \\
\hline cc_id & Collector ID & $\begin{array}{l}\text { An identifier for linking to contact } \\
\text { information for the data collector. }\end{array}$ \\
\hline dd_lev_loaddate & Load date & The date this row was entered in UTC. \\
\hline dd_lev_pubdate & Publish date & $\begin{array}{l}\text { The date this row can become public. This } \\
\text { date can be set up to two years in advance. }\end{array}$ \\
\hline cc_id_load & Data loader ID & $\begin{array}{l}\text { An identifier for linking to contact } \\
\text { information for the person who entered this } \\
\text { row of data. }\end{array}$ \\
\hline
\end{tabular}

The Leveling data table (dd_lev for deformation data - leveling) contains elevation changes between successive benchmarks of a leveling line. The primary ID for the Leveling table is dd_lev_id and information about the reference station for the measurements is linked using the Deformation Station table ID, ds_id_ref. Information about the first benchmark or station (n) in the measurement is linked to the Deformation Station table using ds_id1 and the second benchmark or station $(n+1)$ is linked using ds_id2. The Deformation Station table provides the nominal locations for each station or benchmark, a link to the Network table, a list of any installed instruments, and a conversion from local time to UTC. Information about the instrument used to take the measurements is linked by di_gen_id, to the General Deformation Instrument table. The General Deformation Instrument table provides specific information about the instrument including the resolution and the type of monitoring performed. The collector ID, cc_id, and data loader ID, cc_id_load, both link to contact information in the Contact table. The load date, dd_lev_loaddate, is a TIMESTAMP and entered automatically in UTC. The date the data can become public is stored in dd_lev_pubdate.

Leveling data are collected in time-consuming but precise campaigns. The survey date is stored in dd_lev_time, along with an uncertainty, dd_lev_time_unc, as DATETIME for consistency with the other WOVOdat data, although many leveling data are identified only by year and month. If only the day is known, use a time of 12:00:00 and if only the month is known, use the $15^{\text {th }}$ for the day. Information about the known level of detail should be included in the comments field, dd_lev_com (see below). The order of the survey is stored as dd_lev_order and the class of the survey is stored as dd_lev_class. Both are small text fields. The measured elevation change from the first benchmark (n) to 
the second benchmark $(\mathrm{n}+1)$ in $\mathrm{mm}$ is stored in dd_lev_delev and an estimated error on the elevation change is stored in dd_lev_herr. The comments field, dd_lev_com, stores comments about the data including the original level of detail for the date of the survey.

InSAR Image

Table D10. InSAR Image Table

\begin{tabular}{|c|c|c|}
\hline dd_sar_id & InSAR ID & An identifier for linking with other tables. \\
\hline vd_id & Volcano ID & $\begin{array}{l}\text { The identifier for linking to the Volcano } \\
\text { table. The Volcano table stores the volcano } \\
\text { name and time zone. It is used to connect to } \\
\text { all other data. }\end{array}$ \\
\hline di_gen_id & $\begin{array}{l}\text { General Deformation } \\
\text { Instrument ID }\end{array}$ & $\begin{array}{l}\text { An identifier for linking with the General } \\
\text { Deformation Instrument table. }\end{array}$ \\
\hline dd_sar_slat & Starting latitude & $\begin{array}{l}\text { The latitude in the starting corner } \\
(\text { (sxx.xxxxxxx). }\end{array}$ \\
\hline dd_sar_slon & Starting longitude & $\begin{array}{l}\text { The longitude in the starting corner } \\
\text { (sxxx.Xxxxxxx). }\end{array}$ \\
\hline dd_sar_datum & Datum & $\begin{array}{l}\text { The datum used for the latitude and } \\
\text { longitude. }\end{array}$ \\
\hline dd_sar_spos & Starting position & $\begin{array}{l}\text { The starting position. Use BLC for bottom } \\
\text { left corner or TLC for top left corner. }\end{array}$ \\
\hline dd_sar_rord & Row order & $\begin{array}{l}\text { The order of the rows for example, left to } \\
\text { right. }\end{array}$ \\
\hline dd_sar_nrows & Number of rows & The number of rows in the image. \\
\hline dd_sar_ncols & Number of columns & The number of columns in the image. \\
\hline dd_sar_units & Units & The units used in the image (e.g., mm). \\
\hline dd_sar_ndata & Null data value & The number used for fields without data. \\
\hline dd_sar_loc & Location & $\begin{array}{l}\text { The location of the image (e.g., This is } \\
\text { Yellowstone). }\end{array}$ \\
\hline dd_sar_pair & Pair flag & $\begin{array}{l}\text { A flag indicating if the image is composed } \\
\text { of a pair }(\mathrm{P}) \text { of data, stacked data }(\mathrm{S}) \text {, or } \\
\text { unknown }(\mathrm{U}) \text {. }\end{array}$ \\
\hline dd_sar_desc & Description of image & $\begin{array}{l}\text { A description of the image including a set of } \\
\text { standard features, the number of satellite } \\
\text { passes, and the time frame covered by the } \\
\text { image (e.g., Norris uplift anomaly includes } \\
3 \text { images, one from Sept. } 1996 \text { to Sept } 2000 \text {, } \\
\text { one from Aug. } 2000 \text { to Aug } 2001 \text {, and one } \\
\text { from July } 2001 \text { to July 2002). }\end{array}$ \\
\hline dd_sar_dem & DEM & The DEM used (e.g., 30m NED or SRTM). \\
\hline
\end{tabular}




\begin{tabular}{|c|c|c|}
\hline dd_sar_dord & Data order & $\begin{array}{l}\text { The order in which the bytes are stored and } \\
\text { which bytes are most significant in multi- } \\
\text { byte data types (e.g., big endian or little } \\
\text { endian). }\end{array}$ \\
\hline dd_sar_img1_time & Date, image 1 & $\begin{array}{l}\text { The date of image } 1 \text { in UTC stored as } \\
\text { DATETIME (YYYY-MM-DD hh:mm:ss). }\end{array}$ \\
\hline $\begin{array}{l}\text { dd_sar_img1_time_un } \\
\text { c }\end{array}$ & Date, image 1 uncertainty & $\begin{array}{l}\text { The uncertainty in the date of image } 1 \text { in } \\
\text { UTC stored as DATETIME (YYYY-MM- } \\
\text { DD hh:mm:ss). }\end{array}$ \\
\hline dd_sar_img2_time & Date, image 2 & $\begin{array}{l}\text { The date of image } 2 \text { in UTC stored as } \\
\text { DATETIME (YYYY-MM-DD hh:mm:ss). }\end{array}$ \\
\hline $\begin{array}{l}\text { dd_sar_img2_time_un } \\
\text { c }\end{array}$ & Date, image 2 uncertainty & $\begin{array}{l}\text { The uncertainty in the date of image } 2 \text { in } \\
\text { UTC stored as DATETIME (YYYY-MM- } \\
\text { DD hh:mm:ss). }\end{array}$ \\
\hline dd_sar_pixsiz & Pixel size & The pixel size in meters $(\mathrm{xxxxx})$ \\
\hline dd_sar_spacing & Spacing of rows and columns & $\begin{array}{l}\text { Same information as pixel size, but in units } \\
\text { of decimal degrees (one can be calculated } \\
\text { from the other). }\end{array}$ \\
\hline dd_sar_lookang & Look angle & The look angle (xx). \\
\hline dd_sar_limb & Limb & $\begin{array}{l}\text { The limb, Use ASC for ascending or DES } \\
\text { for descending. }\end{array}$ \\
\hline dd_sar_jpg & JPG of interferogram & A JPG of interferogram. \\
\hline dd_sar_geotiff & Geotiff of Interferogram & $\begin{array}{l}\text { A Geotiff of the interferograms ( } 24 \text { bit color } \\
\text { and includes the encoded projection types, } \\
\text { coordinate systems, datums, ellipsoids, etc. }\end{array}$ \\
\hline dd_sar_prometh & Processing method & The processing method. \\
\hline dd_sar_softwr & Software & The software used. \\
\hline dd_sar_dem_qual & DEM quality & $\begin{array}{l}\text { The DEM quality, Use excellent }(\mathrm{E}) \text { for } 1 \mathrm{~m} \text {, } \\
\text { good }(\mathrm{G}) \text { for } 10 \mathrm{~m} \text {, fair }(\mathrm{F}) \text { for } 100 \mathrm{~m} \text {, or } \\
\text { unknown }(\mathrm{U}) \text {. }\end{array}$ \\
\hline cc_id & Collector ID & $\begin{array}{l}\text { An identifier for linking to contact } \\
\text { information for the data collector. }\end{array}$ \\
\hline dd_sar_loaddate & Load date & The date this row was entered in UTC. \\
\hline dd_sar_pubdate & Publish date & $\begin{array}{l}\text { The date this row can become public. This } \\
\text { date can be set up to two years in advance. }\end{array}$ \\
\hline cc_id_load & Data loader ID & $\begin{array}{l}\text { An identifier for linking to contact } \\
\text { information for the person who entered this } \\
\text { row of data. }\end{array}$ \\
\hline
\end{tabular}


The InSAR image table (dd_sar for deformation data - InSAR) contains information about radar interferograms that show deformation of volcanoes. The original data are pairs of radar images, currently from a satellite such as ERS1, ERS2, Envisat, JERS, Radarsat, or (soon) PalSAR. Only select, processed interferograms are included in WOVOdat. At present, most interferograms use only data from a single satellite because all of the current radar satellites (except ERS1 and ERS2) have different orbits, radar sources, and formats, however, data from multiple satellites may be used for interferograms in the future. A separate InSAR-Satellite relationship table is available for cases where different satellites were used. Alternatively, a satellite ID could be included in this table along with a flag to let users know if the relationship table is needed for their query.

The data used to create the interferogram are stored in the InSAR data table and linked to the image table using the InSAR image table primary ID, dd_sar_id. Information about the volcano that is being imaged can be found using the volcano id link, vd_id. Information about the instrument used to take the measurements is linked by di_gen_id, to the General Deformation Instrument table. The General Deformation Instrument table provides specific information about the instrument including the resolution and the type of monitoring performed. The collector ID, cc_id, and data loader ID, cc_id_load, both link to contact information in the Contact table. The load date, dd_sar_loaddate, is a TIMESTAMP and entered automatically in UTC. The date the data can become public is stored in dd_sar_pubdate.

The data contained in the InSAR image table describes the InSAR image. The location the image covers is described by a starting latitude, dd_sar_slat; a starting longitude, dd_sar_slon; the datum for the latitude and longitude, dd_sar_datum; and the starting position of the image, dd_sar_spos. The starting position is a small text field and can be either the bottom left corner (BLC) or the top left corner (TLC). If a different starting position is used, a brief description of the starting position should be included in dd_sar_spos. The units used in the image, such as mm, are stored in the text field dd_sar_units. The value used for fields without data are stored in the text field dd_sar_ndata. Two short descriptive text fields are included for information about the image. The location attribute, dd_sar_loc, should contain a brief description of where the image was taken, for example, Yellowstone National Park. The pair flag, dd_sar_pair, stores a flag that indicates if the image is composed of a pair (P) of data, stacked data (S), or if it is unknown (U). A description of the image, stored in dd_sar_desc, should include a set of standard features, the number of satellite passes, and the time frame covered by the image (e.g., Norris uplift anomaly includes 3 images, one from Sept. 1996 to Sept 2000, one from Aug. 2000 to Aug 2001, and one from July 2001 to July 2002).

The DEM used should be stored in dd_sar_dem and the quality of the DEM should be stored in dd_sar_dem_qual, where excellent (E) is for $1 \mathrm{~m}$, good $(\mathrm{G})$ is for $10 \mathrm{~m}$, fair $(\mathrm{F})$ is for $100 \mathrm{~m}$, and (U) is for unknown. The data order (big endian or little endian) should be stored in dd_sar_dord. The image date attributes are dd_sar_time1 and dd_sar_time2 for the first and second passes by the satellite, along with their uncertainties, dd_sar_time1_unc and dd_sar_time2_unc. These dates are stored in UTC in DATETIME. The pixel size, dd_sar_pixsiz, is in $\mathrm{mm}$ and the look angle, dd_sar_lookang, is in degrees. The limb, dd_sar_limb is a text field, use ASC for ascending and DES is for descending. The information about the processing method for creating the image should be stored in the text field, dd_sar_prometh and information about the software used should be stored in dd_sar_softwr. Sample images should be stored as a jpeg in dd_sar_jpg and/or as a geotiff in dd_sar_geotiff. 


\section{InSAR Satellite Junction Table}

Table D11. InSAR Satellite Junction Table

\begin{tabular}{|l|l|l|}
\hline j_sarsat_id & $\begin{array}{l}\text { InSAR Satellite junction } \\
\text { ID }\end{array}$ & $\begin{array}{l}\text { An identifier for linking with other } \\
\text { tables }\end{array}$ \\
\hline Ad_sar_id & $\begin{array}{l}\text { An identifier for linking with the } \\
\text { INSAR table for details about the full } \\
\text { image such as the location, size, } \\
\text { processing method, dates, and a } \\
\text { sample image. }\end{array}$ \\
\hline cs_id & InSAR ID & $\begin{array}{l}\text { An identifier for linking with the } \\
\text { Satellite table. The Satellite table gives } \\
\text { the name of the satellite and a } \\
\text { description. }\end{array}$ \\
\hline j_sarsat_loaddate & Satellite ID & The date this row was entered. \\
\hline j_sarsat_pubdate & Load date & $\begin{array}{l}\text { The date this row can become public. } \\
\text { This date can be set up to two years in } \\
\text { advance. }\end{array}$ \\
\hline cc_id_load & Publish date & $\begin{array}{l}\text { The ID linking to the person who } \\
\text { entered this row of data. }\end{array}$ \\
\hline
\end{tabular}

The InSAR Satellite Relationship table, j_sarsat, is the junction table for the many-to-many relationship between the satellite data and the InSAR data. This table is necessary because InSAR images can be created by different satellite passes over an area. Also, different satellites collect data over multiple areas. Alternatively, a satellite ID could be included in the InSAR image table along with a flag to let users know if this relationship table is needed for their query. The table contains an ID, j_sarsat_id, for joining with other tables in separate databases, the InSAR ID, dd_sar_id, the Satellite ID, cs_id, a load date, j_sarsat_loaddate, the date the data can become public, j_sarsat_pubdate, and a data loader ID, cc_id_load for linking with contact information about the person who loaded that row of information.

InSAR data

Table D12. InSAR Data Table

\begin{tabular}{|l|l|l|}
\hline dd_srd_ID & InSAR data ID & An identifier for linking with other tables. \\
\hline dd_sar_id & $\begin{array}{l}\text { An identifier for linking with the InSAR } \\
\text { table for details about the full image such as } \\
\text { the location, size, processing method, dates, } \\
\text { and a .jpg or geotiff image. }\end{array}$ \\
\hline dd_srd_dchange & Range of change & $\begin{array}{l}\text { The range of change for each pixel in mm } \\
\text { (xx.x). }\end{array}$ \\
\hline dd_srd_loaddate & Load date & The date this row was entered in UTC. \\
\hline
\end{tabular}




\begin{tabular}{|l|l|l|}
\hline dd_srd_pubdate & Publish date & $\begin{array}{l}\text { The date this row can become public. This } \\
\text { date can be set up to two years in advance. }\end{array}$ \\
\hline cc_id_load & Data loader ID & $\begin{array}{l}\text { An identifier for linking to contact } \\
\text { information for the person who entered this } \\
\text { row of data. }\end{array}$ \\
\hline
\end{tabular}

The InSAR data table (dd_srd for deformation data - InSAR data) contains the data collected by two satellites to create an InSAR image. Information about the InSAR image is stored in the InSAR image table and linked using the INSAR image table primary ID, dd_sar_id. The InSAR data primary ID is dd_srd_id. The data loader ID, cc_id_load, links to the contact table and provides information about the person who loaded the data into WOVOdat. The load date, dd_sar_loaddate, is a TIMESTAMP and entered automatically in UTC. The date the data can become public is stored in dd_sar_pubdate. The only data attribute in the InSAR data table is dd_srd_dchange, which is the rate of change for each pixel in mm.

\section{Deformation Station}

Table D13. Deformation Station Table

\begin{tabular}{|c|c|c|}
\hline ds_id & Deformation Station ID & An identifier for linking with other tables. \\
\hline ds_nam & Station Name & $\begin{array}{l}\text { The name of the benchmark or station given } \\
\text { by the observatory. }\end{array}$ \\
\hline ds_code & Station Code & The station code given by the observatory. \\
\hline cn_id & Network ID & $\begin{array}{l}\text { An identifier for linking with information } \\
\text { about the network in the Common Network } \\
\text { table. The Common Network table gives a } \\
\text { description of this network and a link to the } \\
\text { volcano. }\end{array}$ \\
\hline ds_perm & Instrument & $\begin{array}{l}\text { A list of any permanent instruments } \\
\text { installed at this site. The instrument tables } \\
\text { will link to the Deformation Station table } \\
\text { and will provide details and allow for their } \\
\text { to be several permanent and periodic } \\
\text { instruments at each station. }\end{array}$ \\
\hline ds_freq & Frequency of measurement & $\begin{array}{l}\text { The frequency of measurements. For } \\
\text { continuous measurements Use a C followed } \\
\text { by a time frame such as every } 10 \text { sec. or } \\
3 x / \text { week. For periodic measurements Use a } \\
\text { P followed by a time frame such as yearly, } \\
\text { every } 5 \text { years, or whenever possible. Please } \\
\text { include both if this station is used for both } \\
\text { continuous and campaign measurements. }\end{array}$ \\
\hline ds_nlat & Nominal latitude & $\begin{array}{l}\text { The nominal latitude of the station in } \\
\text { decimal degrees (sxx.xxxxxxx). }\end{array}$ \\
\hline
\end{tabular}




\begin{tabular}{|c|c|c|}
\hline ds_nlon & Nominal longitude & $\begin{array}{l}\text { The nominal longitude of the station in } \\
\text { decimal degrees (sxxx.xxxxxxx). }\end{array}$ \\
\hline ds_nelev & Nominal elevation & $\begin{array}{l}\text { The nominal elevation of the station in } \\
\text { meters (sxxxx). }\end{array}$ \\
\hline ds_datum & Datum & $\begin{array}{l}\text { The datum used for the longitude and } \\
\text { latitude. }\end{array}$ \\
\hline ds_herr_loc & Horizontal precision location & $\begin{array}{l}\text { The horizontal precision of nominal location } \\
\text { for GPS. }\end{array}$ \\
\hline ds_stime & Start date & $\begin{array}{l}\text { The date (UTC) the station was set up and } \\
\text { activated or the time new information in this } \\
\text { table became valid. The date is stored in } \\
\text { DATETIME (YYYY-MM-DD hh:mm:ss). }\end{array}$ \\
\hline ds_stime_unc & Start date uncertainty & $\begin{array}{l}\text { The uncertainty in the date (UTC) the } \\
\text { station was set up and activated or the time } \\
\text { new information in this table became valid. } \\
\text { The date is stored in DATETIME (YYYY- } \\
\text { MM-DD hh:mm:ss). }\end{array}$ \\
\hline ds_etime & End date & $\begin{array}{l}\text { The date (UTC) the station was permanently } \\
\text { decommissioned or the time the information } \\
\text { in this table became invalid. The date is } \\
\text { stored in DATETIME (YYYY-MM-DD } \\
\text { hh:mm:ss). See observatory for station } \\
\text { operation history. }\end{array}$ \\
\hline ds_etime_unc & End date uncertainty & $\begin{array}{l}\text { The uncertainty in the date (UTC) the } \\
\text { station was permanently decommissioned or } \\
\text { the time the information in this table } \\
\text { became invalid. The date is stored in } \\
\text { DATETIME (YYYY-MM-DD hh:mm:ss). }\end{array}$ \\
\hline ds_utc & Difference from UTC & $\begin{array}{l}\text { The time zone relative to UTC. Please enter } \\
\text { the number of hours from GMT, using a } \\
\text { negative sign (-) for hours before GMT and } \\
\text { no sign for positive numbers (sxx.x). }\end{array}$ \\
\hline ds_rflag & Reference station flag & $\begin{array}{l}\text { A flag indicating that this station is used as } \\
\text { a reference station (Y for yes). }\end{array}$ \\
\hline ds_desc & Station description & $\begin{array}{l}\text { A description of the station or any } \\
\text { comments. }\end{array}$ \\
\hline cc_id & Contact ID & $\begin{array}{l}\text { An identifier for linking to contact } \\
\text { information. }\end{array}$ \\
\hline ds_loaddate & Load date & The date this row was entered in UTC. \\
\hline
\end{tabular}




\begin{tabular}{|l|l|l|}
\hline ds_pubdate & Publish date & $\begin{array}{l}\text { The date this row can become public. This } \\
\text { date can be set up to two years in advance. }\end{array}$ \\
\hline cc_id_load & Data loader ID & $\begin{array}{l}\text { An identifier for linking to contact } \\
\text { information for the person who entered this } \\
\text { row of data. }\end{array}$ \\
\hline
\end{tabular}

The Deformation Station table (ds_ for Deformation Station) stores information such as a location, name, and description for stations where deformation or geodetic data are collected. Originally there were going to be two station tables, a tilt/strain station table and a general deformation station table, each with a link to the appropriate instrument table for linking with vector and angle data. It was later decided to have one station table and allow for multiple instruments at a station by having the link go from the instrument table to the station table for permanent stations. For instruments used periodically, there was an instrument/station junction table but it was decided to treat the instrument like data, since it could change so often, and store the instrument link in the data tables.

The primary ID for the Deformation Station table is ds_id and there are several foreign IDs for linking to other tables. The Deformation Station table links to the Common Network table by the network ID, cn_id. It is through the network table that data collected at a station can be linked to the volcano. Information about tiltmeters or strainmeters installed or used at this station can be found in the Tilt/Strain Instrument table using the station table ID, ds_id. The Tilt/Strain Instrument table provides the necessary information for processing raw data along with general instrument information (please see the Tilt/Strain Instrument table for more details). The link to the instrument table can also be found in some of the tilt/strain data tables. Information about other types of instruments used and their resolution can be found in the General Deformation Instrument table, which is linked to the Deformation Station table using the station primary ID, ds_id. The contact ID (cc_id) links to contact information about the person or observatory that manages the station and the data loader ID, cc_id_load, links to the Contact table for more information about the person who loaded the data into WOVOdat. The load date, ds_loaddate, is a TIMESTAMP and entered automatically in UTC. The date the data can become public is stored in ds_pubdate.

Each station has a name, ds_name, given by the observatory and if applicable, a separate station code, ds_code. The station name and code are both text fields. The field ds_inst records any permanent instruments installed at the station. Additional information about the instruments can be found in either the General Deformation Instrument table or the Tilt/Strain Instrument table; both contain links to the station table. For cases where an instrument is part of a campaign and is used at multiple stations, the instrument is linked from the data tables. The frequency of measurement field, ds_def_freq, is a text field that should contain an abbreviation for continuous $(\mathrm{C})$ or periodic $(\mathrm{P})$ in addition to a time frame for the frequency. The frequency time frame should be exact for the continuous data and approximate for the periodic data.

The Deformation Station table stores all of the information for determining the station location including the latitude, ds_lat, longitude, ds_lon, elevation, ds_elev, and datum, ds_datum. All data should be converted to WGS 84 prior to entering WOVOdat. If conversion is not possible during data loading, the original datum must be entered into the datum field, ds_datum. The Deformation Station table also includes start and end dates, ds_stime and ds_etime, along with their uncertainties, ds_stime_unc and ds_etime_unc, in DATETIME UTC. These dates provide information on when the station information in the table is valid. The instrument table also contains a date range. New instruments at the station should be recorded in the instrument table instead of the station table unless the location of the new instrument changes the location of the station. The Deformation Station table also contains a description field, ds_desc. The description field should include information about the 
setting, for example, "very close to a steep cliff," in addition to any information that could help explain future data and site selection. The difference from local time to UTC is stored as ds_utc. The UTC field allows for the conversion back to UTC whenever needed as discussed in the Time Section.

\section{General Deformation Instrument}

Table D14. General Deformation Instrument Table

\begin{tabular}{|c|c|c|}
\hline di_gen_id & $\begin{array}{l}\text { General Deformation } \\
\text { Instrument ID }\end{array}$ & An identifier for linking with other tables \\
\hline ds_id & Deformation Station ID & $\begin{array}{l}\text { An identifier for linking with the } \\
\text { Deformation Station table. This link } \\
\text { requires the station type as well. }\end{array}$ \\
\hline di_gen_perm & Permanent & $\begin{array}{l}\text { A single character field to let the user } \\
\text { know if the instrument is part of a } \\
\text { permanent installation (use P for } \\
\text { permanent) or part of a campaign (use C } \\
\text { for campaign). }\end{array}$ \\
\hline di_gen_name & Name & $\begin{array}{l}\text { The name, model, and manufacturer of } \\
\text { the instrument. }\end{array}$ \\
\hline di_gen_type & Type & $\begin{array}{l}\text { The type of instrument chosen from a } \\
\text { standard set of instruments. This field } \\
\text { will be used along with the Deformation } \\
\text { Station ID to uniquely link installed } \\
\text { instruments to their stations. }\end{array}$ \\
\hline di_gen_units & Measured units & The units the instrument measures. \\
\hline di_gen_res & Resolution & $\begin{array}{l}\text { Typical instrumental measuring } \\
\text { precision. }\end{array}$ \\
\hline di_gen_stn & Signal to noise & $\begin{array}{l}\text { An instrument specific signal to noise } \\
\text { ratio. }\end{array}$ \\
\hline di_gen_stime & Start date & $\begin{array}{l}\text { The date (UTC) the instrument was set } \\
\text { up and activated or the time new } \\
\text { information in this table became valid. } \\
\text { The date is stored in DATETIME } \\
\text { (YYYY-MM-DD hh:mm:ss). }\end{array}$ \\
\hline di_gen_stime_unc & Start date uncertainty & $\begin{array}{l}\text { The uncertainty in the date (UTC) the } \\
\text { instrument was set up and activated or } \\
\text { the time new information in this table } \\
\text { became valid. The date is stored in } \\
\text { DATETIME (YYYY-MM-DD } \\
\text { hh:mm:ss). }\end{array}$ \\
\hline
\end{tabular}




\begin{tabular}{|c|c|c|}
\hline di_gen_etime & End date & $\begin{array}{l}\text { The date (UTC) the instrument was } \\
\text { permanently decommissioned or the time } \\
\text { the information in this table became } \\
\text { invalid. The date is stored in } \\
\text { DATETIME (YYYY-MM-DD } \\
\text { hh:mm:ss). See observatory for station } \\
\text { operation history. }\end{array}$ \\
\hline di_gen_etime_unc & End date uncertainty & $\begin{array}{l}\text { The uncertainty in the date (UTC) the } \\
\text { instrument was permanently } \\
\text { decommissioned or the time the } \\
\text { information in this table became invalid. } \\
\text { The date is stored in DATETIME } \\
\text { (YYYY-MM-DD hh:mm:ss). See } \\
\text { observatory for station operation history. }\end{array}$ \\
\hline di_gen_com & Comments & $\begin{array}{l}\text { Comments on the instrument including } \\
\text { anything unusual, for example, } \\
\text { modifications. }\end{array}$ \\
\hline CC_id & Contact ID & $\begin{array}{l}\text { An identifier for linking with the person } \\
\text { or group of people responsible for this } \\
\text { instrument. }\end{array}$ \\
\hline di_gen_loaddate & Load date & The date this row was entered in UTC. \\
\hline di_gen_pubdate & Publish date & $\begin{array}{l}\text { The date this row can become public. } \\
\text { This date can be set up to two years in } \\
\text { advance. }\end{array}$ \\
\hline CC_id_load & Data loader ID & $\begin{array}{l}\text { An identifier for linking to contact } \\
\text { information for the person who entered } \\
\text { this row of data. }\end{array}$ \\
\hline
\end{tabular}

The General Deformation Instrument table (di_gen for deformation instrument - general) stores information about each individual instrument along with a flag, di_gen_perm, to indicate if the instrument is installed permanently or is used periodically as part of a campaign. The permanently installed instruments are linked to the stations at which they are installed by the station ID, ds_id, and the instrument type, di_gen_type, which gives information on the type of instrument. Having two fields allows for searches of all instruments at a station and also for instruments of a certain type at all stations. The periodic instrument data are linked to the General Deformation Instrument table using the instrument table's primary ID, di_gen_id, which has been placed in the data tables. An instrument/station junction table was originally created to handle periodic data recorded by multiple instruments that could be used at multiple stations. We decided to put the instrument link with the data, along with the station link, because the instruments can change often. The contact ID (cc_id) links to contact information about the person or observatory that manages the station and the data loader ID, cc_id_load, links to the Contact table for more information about the person who loaded the data into WOVOdat. The load date, di_gen_loaddate, is a TIMESTAMP and entered automatically in UTC. The date the data can become public is stored in di_gen _pubdate.

The name of the instrument is stored in di_gen_name, the manufacturer is stored in di_gen_man, and the model is stored in di_gen_mod. All of these fields are text fields. The units the instrument 
measures are stored in the text field di_gen_units and the resolution or measuring precision for those units is stored in di_gen_res. The instrument specific signal to noise ratio is stored in di_gen_stn. The General Deformation Instrument table also includes start and end dates, di_gen_stime and di_gen_etime, along with their uncertainties, di_gen_stime_unc and di_gen_etime_unc, in DATETIME UTC. These dates provide information for determing which set of instrument information is valid. The data are considered invalid if the resolution or signal to noise ratio changes or if an installed instrument is removed from a station. A comments attribute, di_gen_com, is included for information about how this instrument has been modified or is used in a non-standard way.

\section{Create table statements for deformation tables}

DROP TABLE IF EXISTS dd_tlt;

create table dd_tlt (

dd_tlt_id mediumint not null auto_increment,

ds_id mediumint,

di_tlt_id mediumint,

dd_tlt_time datetime,

dd_tlt_time_unc datetime,

dd_tlt_srate float,

dd_tlt1 float,

dd_tlt2 float,

dd_tlt_err1 float,

dd_tlt_err2 float,

dd_tlt_proc_flg char(1),

cc_id mediumint,

dd_tlt_loaddate datetime,

dd_tlt_pubdate datetime,

cc_id_load mediumint,

primary key (dd_tlt_id));

DROP TABLE IF EXISTS dd_tlv;

create table dd_tlv (

dd_tlv_id mediumint not null auto_increment,

ds_id mediumint,

di_tlt_id mediumint,

dd_tlv_stime datetime,

dd_tlv_stime_unc datetime,

dd_tlv_etime datetime,

dd_tlv_etime_unc datetime,

dd_tlv_mag float,

dd_tlv_azi float,

dd_tlv_magerr float,

dd_tlv_azierr float,

dd_tlv_com varchar(255),

cc_id mediumint,

dd_tlv_loaddate datetime,

dd_tlv_pubdate datetime,

cc_id_load mediumint,

primary key (dd_tlv_id)); 


\section{DROP TABLE IF EXISTS dd_str;}

create table dd_str (

dd_str_id mediumint not null auto_increment, ds_id mediumint,

di_tlt_id mediumint,

dd_str_time datetime,

dd_str_time_unc datetime,

dd_str_comp1 float,

dd_str_comp2 float,

dd_str_comp3 float,

dd_str_comp4 float,

dd_str_err1 float,

dd_str_err2 float,

dd_str_err3 float,

dd_str_err4 float,

dd_str_vdstr float,

dd_str_vdstr_err float,

dd_str_sstr_ax1 float,

dd_str_azi_ax1 float,

dd_str_sstr_ax2 float, dd_str_azi_ax2 float,

dd_str_sstr_ax3 float, dd_str_azi_ax3 float,

dd_str_stderr1 float, dd_str_stderr2 float, dd_str_stderr3 float, dd_str_pmax float, dd_str_pmaxerr float, dd_str_pmin float, dd_str_pminerr float, dd_str_pmax_dir float, dd_str_pmax_direrr float, dd_str_pmin_dir float, dd_str_pmin_direrr float, cc_id mediumint,

dd_str_loaddate datetime, dd_str_pubdate datetime, cc_id_load mediumint, primary key (dd_str_id));

DROP TABLE IF EXISTS dd_edm;

create table dd_edm (

dd_edm_id mediumint not null auto_increment, di_gen_id mediumint,

ds_id1 mediumint,

ds_id2 mediumint,

dd_edm_cont char(1),

dd_edm_time datetime,

dd_edm_time_unc datetime,

dd_edm_line float,

dd_edm_cerr float,

dd_edm_serr float,

cc_id mediumint,

dd_edm_loaddate datetime, dd_edm_pubdate datetime,

cc_id_load mediumint, 
primary key (dd_edm_id));

DROP TABLE IF EXISTS dd_ang;

create table dd_ang (

dd_ang_id mediumint not null auto_increment,

di_gen_id mediumint,

ds_id mediumint,

ds_id1 mediumint,

ds_id2 mediumint,

dd_ang_time datetime,

dd_ang_time_unc datetime,

dd_ang_hort1 float,

dd_ang_hort2 float,

dd_ang_vert1 float,

dd_ang_vert2 float,

dd_ang_herr1 float,

dd_ang_herr2 float,

dd_ang_verr1 float,

dd_ang_verr2 float,

dd_ang_com varchar(255),

cc_id mediumint,

dd_ang_loaddate datetime,

dd_ang_pubdate datetime,

cc_id_load mediumint,

primary key (dd_ang_id));

DROP TABLE IF EXISTS dd_gps;

create table dd_gps (

dd_gps_id mediumint not null auto_increment,

di_gen_id mediumint,

ds_id mediumint,

ds_id_ref1 mediumint,

ds_id_ref2 mediumint,

dd_gps_cont char(1),

dd_gps_time datetime,

dd_gps_time_unc datetime,

dd_gps_lat float,

dd_gps_lon float,

dd_gps_elev float,

dd_gps_datum varchar(30),

dd_gps_nserr float,

dd_gps_ewerr float,

dd_gps_verr float,

dd_gps_software varchar(50),

dd_gps_orbits varchar(255),

dd_gps_dur varchar(255),

dd_gps_qual varchar(30),

cc_id mediumint,

dd_gps_loaddate datetime,

dd_gps_pubdate datetime,

cc_id_load mediumint,

primary key (dd_gps_id));

DROP TABLE IF EXISTS dd_gpv;

create table dd_gpv ( 
dd_gpv_id mediumint not null auto_increment, di_gen_id mediumint,

ds_id mediumint,

dd_gpv_stime datetime,

dd_gpv_stime_unc datetime,

dd_gpv_etime datetime,

dd_gpv_etime_unc datetime,

dd_gpv_dmag float,

dd_gpv_daz float,

dd_gpv_vincl float,

dd_gpv_N float,

dd_gpv_E float,

dd_gpv_vert float,

dd_gpv_dherr float,

dd_gpv_dverr float,

dd_gpv_com varchar(255),

cc_id mediumint,

dd_gpv_loaddate datetime,

dd_gpv_pubdate datetime,

cc_id_load mediumint,

primary key (dd_gpv_id));

DROP TABLE IF EXISTS dd_lev;

create table dd_lev (

dd_lev_id mediumint not null auto_increment, ds_id_ref mediumint,

di_gen_id mediumint,

dd_lev_ord mediumint,

dd_lev_class varchar(30),

dd_lev_time datetime,

dd_lev_time_unc datetime,

ds_id1 mediumint,

ds_id2 mediumint,

dd_lev_delev float,

dd_lev_herr float,

dd_lev_com varchar(255),

cc_id mediumint,

dd_lev_loaddate datetime,

dd_lev_pubdate datetime,

cc_id_load mediumint,

primary key (dd_lev_id));

DROP TABLE IF EXISTS dd_sar;

create table dd_sar (

dd_sar_id mediumint not null auto_increment,

vd_id mediumint,

di_gen_id mediumint,

dd_sar_slat float,

dd_sar_slon float,

dd_sar_datum varchar(30),

dd_sar_spos char(3),

dd_sar_rord varchar(30),

dd_sar_nrows float,

dd_sar_ncols float,

dd_sar_units varchar(30),

dd_sar_ndata varchar(30), 
dd_sar_loc varchar(255),

dd_sar_pair char(1),

dd_sar_desc varchar(255),

dd_sar_dem varchar(50),

dd_sar_dord varchar(30),

dd_sar_img1_time datetime,

dd_sar_img1_time_unc datetime,

dd_sar_img2_time datetime,

dd_sar_img2_time_unc datetime,

dd_sar_pixsiz float,

dd_sar_spacing float,

dd_sar_lookang float,

dd_sar_limb char(3),

dd_sar_jpg varchar(255),

dd_sar_geotiff varchar(255),

dd_sar_prometh varchar(255),

dd_sar_softwr varchar(255),

dd_sar_dem_qual varchar(30),

cc_id mediumint,

dd_sar_loaddate datetime,

dd_sar_pubdate datetime,

cc_id_load mediumint,

primary key (dd_sar_id));

DROP TABLE IF EXISTS j_sarsat;

create table j_sarsat (

j_sarsat_id mediumint not null auto_increment, dd_sar_id mediumint,

cs_id mediumint,

j_sarsat_loaddate datetime,

j_sarsat_pubdate datetime,

cc_id_load mediumint,

primary key (j_sarsat_id));

DROP TABLE IF EXISTS dd_srd;

create table dd_srd (

dd_srd_ID mediumint not null auto_increment,

dd_sar_id mediumint,

dd_srd_dchange float,

dd_srd_loaddate datetime,

dd_srd_pubdate datetime,

cc_id_load mediumint,

primary key (dd_srd_id));

DROP TABLE IF EXISTS di_tlt;

create table di_tlt (

di_tlt_id mediumint not null auto_increment,

ds_id mediumint,

di_tlt_name varchar(255),

di_tlt_type varchar(50),

di_tlt_units varchar(30),

di_tlt_res float,

di_tlt_dir1 float,

di_tlt_dir2 float,

di_tlt_dir3 float, 


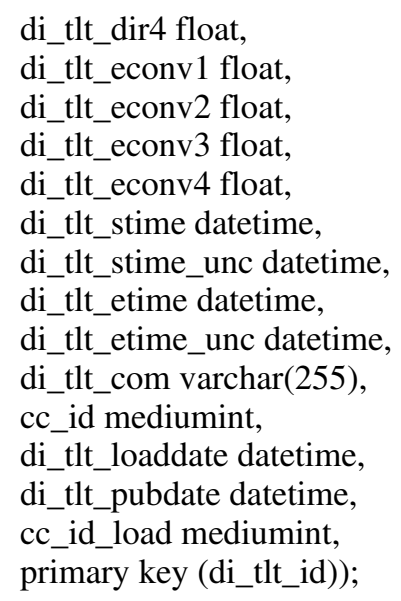

DROP TABLE IF EXISTS ds;

create table ds (

ds_id mediumint not null auto_increment,

ds_nam varchar(30),

ds_code varchar(30),

cn_id mediumint,

ds_perm varchar(255),

ds_freq varchar(255),

ds_nlat float,

ds_nlon float,

ds_nelev float,

ds_datum varchar(30),

ds_herr_loc float,

ds_stime datetime,

ds_stime_unc datetime,

ds_etime datetime,

ds_etime_unc datetime,

ds_utc float,

ds_rflag char(1),

ds_desc varchar(255),

cc_id mediumint,

ds_loaddate datetime,

ds_pubdate datetime,

cc_id_load mediumint,

primary key (ds_id));

DROP TABLE IF EXISTS di_gen;

create table di_gen (

di_gen_id mediumint not null auto_increment,

ds_id mediumint,

di_gen_perm char(1),

di_gen_name varchar(255),

di_gen_type varchar(50),

di_gen_units varchar(30),

di_gen_res float,

di_gen_stn float,

di_gen_stime datetime,

di_gen_stime_unc datetime,

di_gen_etime datetime,

di_gen_etime_unc datetime, 
di_gen_com varchar(255),

cc_id mediumint,

di_gen_loaddate datetime,

di_gen_pubdate datetime,

cc_id_load mediumint,

primary key (di_gen_id));

\section{Gas}

The gas tables contain data about fumaroles, plumes, or diffuse soil degassing. Both direct sampling (fumarole and diffuse soil degassing) and remote plume measurements can be continuous or periodic. These tables include a flag to note if the data are continuous or periodic. A link to the collector ID and instrument ID are included for the periodic data whereas those links can be found through the station table for the continuous data. There are five main gas tables:

- The Directly Sampled table, gd, contains gas concentrations collected from a point source. The type of point source is included in the station table. The recorded data units are entered in this table to solve the issue of multiple measurement types. If the recorded units do not solve the issue, the measurement types should be stored in a separate table.

- The Soil Efflux Data table, gd_sol, contains the total flux value per day and the number of points sampled for a single measured species. $\mathrm{CO}_{2}$ is the most common species measured using this technique but it is possible to measure other species. The Soil Efflux table was created to provide the flexibility for future measurements.

- The Plume Data table, gd_plu, contains plume data including the emission rates of several gases, the plume height, vent location, and weather information. The plume data are collected remotely, either from an instrument that is moving or fixed in space.

- The Gas Station table contains information about the location of the station and permanently installed instruments. It is linked to the Common Network table, which contains information about the monitoring network and a link to the Volcano table.

- The Gas Instrument table contains the instrument model, its resolution, and the units it measures. The permanently installed instruments are linked to their stations and the periodically used instruments are linked through the data tables.

\section{Directly Sampled Gas}

Table G1. Directly Sampled Gas Table

\begin{tabular}{|l|l|l|}
\hline gd_id & Directly sampled ID & $\begin{array}{l}\text { An identifier for linking with other } \\
\text { tables. }\end{array}$ \\
\hline gs_id & $\begin{array}{l}\text { The identifier for linking with the Gas } \\
\text { Station table. The Gas Station table } \\
\text { contains the station name, location, and } \\
\text { description. }\end{array}$ \\
\hline gd_continuous & $\begin{array}{l}\text { A single character field used to identify } \\
\text { continuous data. Use C for data that were } \\
\text { collected continuously or P for data that } \\
\text { were collected periodically. If the data } \\
\text { were from a periodic collection, please }\end{array}$ \\
\hline
\end{tabular}




\begin{tabular}{|c|c|c|}
\hline & & $\begin{array}{l}\text { include the collector ID in cc_id and the } \\
\text { instrument ID in gi_id. }\end{array}$ \\
\hline gd_time & Sampling/measurement time & $\begin{array}{l}\text { Sampling/measurement time in UTC } \\
\text { stored as DATETIME (YYYY-MM-DD } \\
\text { hh:mm:ss). }\end{array}$ \\
\hline gd_time_unc & $\begin{array}{l}\text { Sampling/measurement time } \\
\text { uncertainty }\end{array}$ & $\begin{array}{l}\text { The uncertainty in the } \\
\text { sampling/measurement time in UTC } \\
\text { stored as DATETIME (YYYY-MM-DD } \\
\text { hh:mm:ss). }\end{array}$ \\
\hline gd_gtemp & Gas temperature & $\begin{array}{l}\text { The gas temperature in degrees Celsius } \\
\text { (xxx.x). }\end{array}$ \\
\hline gd_bp & Barometric pressure & $\begin{array}{l}\text { The atmospheric pressure in millibars at } \\
\text { the time of measurement (xxxx.x ). }\end{array}$ \\
\hline gd_flow & Gas emission rate & The measured gas emission rate. \\
\hline gd_units & Reported units & $\begin{array}{l}\text { The units reported for the species below, } \\
\text { e.g., vol } \% \text { or wt } \% \text {. }\end{array}$ \\
\hline gd_co2 & $\mathrm{CO}_{2}$ & The measured $\mathrm{CO}_{2}$. \\
\hline gd_co2_err & Estimated uncertainty $\mathrm{CO}_{2}$ & The estimated uncertainty in $\mathrm{CO}_{2}$. \\
\hline gd_so2 & $\mathrm{SO} 2$ & The measured $\mathrm{SO}_{2}$. \\
\hline gd_so2_err & Estimated uncertainty $\mathrm{SO}_{2}$ & The estimated uncertainty in $\mathrm{SO}_{2}$. \\
\hline gd_h2s & $\mathrm{H}_{2} \mathrm{~S}$ & The measured $\mathrm{H}_{2} \mathrm{~S}$. \\
\hline gd_h2s_err & Estimated uncertainty $\mathrm{H}_{2} \mathrm{~S}$ & The estimated uncertainty in $\mathrm{H}_{2} \mathrm{~S}$. \\
\hline gd_hcl & $\mathrm{HCl}$ & The measured $\mathrm{HCl}$. \\
\hline gd_hcl_err & Estimated uncertainty $\mathrm{HCl}$ & The estimated uncertainty in $\mathrm{HCl}$. \\
\hline gd_hf & HF & The measured HF. \\
\hline gd_hf_err & Estimated uncertainty HF & The estimated uncertainty in HF. \\
\hline gd_ch4 & $\mathrm{CH} 4$ & The measured CH4. \\
\hline gd_ch4_err & Estimated uncertainty $\mathrm{CH} 4$ & The estimated uncertainty in $\mathrm{CH} 4$. \\
\hline gd_h2 & $\mathrm{H}_{2}$ & The measured $\mathrm{H}_{2}$. \\
\hline gd_h2_err & Estimated uncertainty $\mathrm{H}_{2}$ & The estimated uncertainty in $\mathrm{H}_{2}$. \\
\hline gd_co & $\mathrm{CO}$ & The measured CO. \\
\hline gd_co_err & Estimated uncertainty $\mathrm{CO}$ & The estimated uncertainty in CO. \\
\hline gd_co2_h20free & $\mathrm{CO}_{2}$ (water-free) & The calculated $\mathrm{CO}_{2}$ water-free. \\
\hline gd_so2_h20free & $\mathrm{SO}_{2}$ (water free) & The calculated $\mathrm{SO}_{2}$ water-free. \\
\hline gd_h2s_h20free & H2S (water free) & The calculated $\mathrm{H}_{2} \mathrm{~S}$ water-free. \\
\hline gd_hcl_h20free & $\mathrm{HCl}$ (water free) & The calculated $\mathrm{HCl}$ water-free. \\
\hline gd_hf_h20free & HF (water free) & The calculated HF water-free. \\
\hline
\end{tabular}




\begin{tabular}{|c|c|c|}
\hline gd_ch4_h20free & CH4 (water free) & The calculated $\mathrm{CH} 4$ water free. \\
\hline gd_h2_h20free & $\mathrm{H}_{2}$ (water free) & The calculated $\mathrm{H}_{2}$ water free. \\
\hline gd_co_h20free & $\mathrm{CO}$ (water free) & The calculated CO water free. \\
\hline gd_3he4he & $3 \mathrm{He} / 4 \mathrm{He}$ & The measured $3 \mathrm{He} / 4 \mathrm{He}$ ratio. \\
\hline gd_d13c & delta 13C & The measured delta $13 \mathrm{C}$ in per mil. \\
\hline gd_d34s & delta 34S & The measured delta $34 \mathrm{~S}$ in per mil. \\
\hline gd_d18o & delta 180 & The measured delta $18 \mathrm{O}$ in per mil. \\
\hline gd_dd & delta D & The measured delta $\mathrm{D}$ in per mil. \\
\hline gd_envir & Environmental factors & $\begin{array}{l}\text { Comments on environmental factors, } \\
\text { e.g., snowpack, groundwater masking }\end{array}$ \\
\hline gd_submin & Sublimate minerals & Information on sublimate minerals \\
\hline gd_com & Other comments & $\begin{array}{l}\text { Additional comments, e.g., tree kill, dead } \\
\text { animals, etc. }\end{array}$ \\
\hline gi_id & Gas Instrument ID & $\begin{array}{l}\text { An identifier for linking to information } \\
\text { in the Gas Instrument table. The Gas } \\
\text { Instrument table contains the instrument } \\
\text { model, its resolution, and the units it } \\
\text { measures. }\end{array}$ \\
\hline cc_id & Collector ID & $\begin{array}{l}\text { An identifier for linking to contact } \\
\text { information for the data collector for } \\
\text { periodically collected data. }\end{array}$ \\
\hline gd_loaddate & Load date & The date this row was entered in UTC. \\
\hline gd_pubdate & Publish date & $\begin{array}{l}\text { The date this row can become public. } \\
\text { This date can be set up to two years in } \\
\text { advance. }\end{array}$ \\
\hline cc_id_load & Data loader ID & $\begin{array}{l}\text { An identifier for linking to contact } \\
\text { information for the person who entered } \\
\text { this row of data. }\end{array}$ \\
\hline
\end{tabular}

The Directly Sampled Gas table (gd for gas data - ground-based) stores gas data collected at ground sites. Data include the gas temperature, concentrations, and environmental factors. The primary ID is gd_id and the main foreign keys are the station ID, gs_id, for linking to station information, such as the type of gas feature (bubbling pool gas, fumerole, ambient air, lava gas, hornito or skylight, submarine vent, etc.) and its location, the gas instrument ID, gi_id, for linking to information about the instrument that collected periodic data, and the collector ID (cc_id) links to contact information for the person or observatory that collected the periodic data. The instrument and contact information for continuous data can be found through the station ID. The data loader ID, cc_id_load, links to the Contact table for more information about the person who loaded the data into WOVOdat. The load date, gd_loaddate, is a TIMESTAMP and entered automatically in UTC. The date the data can become public is stored in gd_pubdate.

Directly sampled gas data can be collected either continuously or periodically so a flag, gd_continuous, is included to identify the continuous data. The attribute gd_continuous should store the 
letter P for data collected periodically and $\mathrm{C}$ for data collected continuously. If the data are collected periodically, please also include the collector ID in cc_id and the instrument ID in gi_id. The time of the measurement along with an uncertainty is stored in, gd_time and gd_time_unc, in UTC DATETIME. The gas temperature, gd_temp, is stored in Celsius. The barometric pressure, gd_bp, is the atmospheric pressure in millibars at the time of measurement and the gas emission rate is stored in gd_flow. Because there are several methods for collecting directly sampled gas data the units used for the concentrations in the field should be stored in, gd_units. The field gd_units is a 255-character text field allowing space for information about all units included in the table. The gas concentrations, stored in the units recorded in gd_units, include; $\mathrm{CO}_{2}$ in $\mathrm{gd} \_c o 2, \mathrm{SO}_{2}$ in $\mathrm{gd} \_s o 2, \mathrm{H}_{2} \mathrm{~S}$ in $\mathrm{gd} \_\mathrm{h} 2 \mathrm{~s}, \mathrm{HCl}, \mathrm{gd}$ hcl, $\mathrm{HF}$ in gd_hf, $\mathrm{CH}_{4}$ in gd_ch4, $\mathrm{H}_{2}$ in gd_h2, and CO in gd_co. The estimated uncertainty for each of these measurements, in the same units recorded in gd_units, should be stored as follows: $\mathrm{CO}_{2}$ in gd_co2_err, $\mathrm{SO}_{2}$ in gd_so2_err, $\mathrm{H}_{2} \mathrm{~S}$ in gd_h2s_err, $\mathrm{HCl}$, gd_hcl_err, $\mathrm{HF}$ in $\mathrm{gd}$ _hf_err, $\mathrm{CH}_{4}$ in gd_ch4_err, $\mathrm{H}_{2}$ in gd_h2_err, and $\mathrm{CO}$ in gd_co_err. A field for calculated water-free values in the reported units is included as follows: $\mathrm{CO}_{2}$ in gd_co2_noh2o, $\mathrm{SO}_{2}$ in gd_so2_noh2o, $\mathrm{H}_{2} \mathrm{~S}$ in $\mathrm{gd}$ _h2s_noh2o, $\mathrm{HCl}, \mathrm{gd} \_h c l \_n o h 2 o, \mathrm{HF}$ in gd_hf_noh2o, $\mathrm{CH}_{4}$ in gd_ch4_noh2o, $\mathrm{H}_{2}$ in gd_h2_noh2o, and $\mathrm{CO}$ in gd_co_noh2o. The measured Helium 3/4 ratio $(3 \mathrm{He} / 4 \mathrm{He})$ is stored in $\mathrm{gd}$ _3he4he. There are also several ratios referred to by the measured delta per mil such as ${ }^{13} \mathrm{C}$ in $\mathrm{gd} \_\mathrm{d} 13 \mathrm{c}, \delta^{34} \mathrm{~S}$ in $\mathrm{gd} \_\mathrm{d} 34 \mathrm{~s}, \delta \mathrm{D}$ in $\mathrm{gd} \_\mathrm{d}$, and $\delta^{18} \mathrm{O}$ in $\mathrm{gd} \_\mathrm{d} 18 \mathrm{o}$.

Three additional comments fields are included to describe the sample site. The environmental factors field, gd_envir, should include comments on environmental factors such as a snow pack and the weather for that day. The sublimate minerals field, gd_submin, is for comments on any sublimate minerals seen during the measurements. And the general comments field, gd_com, stores additional information about the measurements or observations including tree kill and dead animals.

\section{Soil Efflux Data}

Table G3. Soil Efflux Data Table

\begin{tabular}{|l|l|l|}
\hline gd_sol_id & Soil Efflux Data ID & An identifier for linking with other tables. \\
\hline gs_id & Gas Station ID & $\begin{array}{l}\text { The identifier for linking with the Gas } \\
\text { Station table. The Gas Station table contains } \\
\text { the station name, location, and description. }\end{array}$ \\
\hline gd_sol_time & Measurement time & $\begin{array}{l}\text { The measurement time in UTC stored as } \\
\text { DATETIME (YYYY-MM-DD hh:mm:ss). }\end{array}$ \\
\hline & Measurement time & $\begin{array}{l}\text { The uncertainty in the measurement time in } \\
\text { UTC stored as DATETIME (YYYY-MM- } \\
\text { DD hh:mm:ss). }\end{array}$ \\
\hline gd_sol_species & Measured species & $\begin{array}{l}\text { The type of gas measured }\left(C_{2}, \text { Radon, }\right. \\
\text { etc.). }\end{array}$ \\
\hline gd_sol_tflux & Total flux & The total flux value in t/d. \\
\hline gd_sol_flux_err & Flux value uncertainty & The uncertainty in the flux value in t/d. \\
\hline gd_sol_pts & Number of points & The number of points measured. \\
\hline gd_sol_area & Area & The area measured in m2. \\
\hline gd_sol_high & Highest individual flux & $\begin{array}{l}\text { The highest individual flux for the measured } \\
\text { species in g/m2/d. }\end{array}$ \\
\hline gd_sol_htemp & Highest temperature & The highest measured temperature in \\
\hline
\end{tabular}




\begin{tabular}{|l|l|l|}
\hline & & $\begin{array}{l}\text { degrees Celsius if the measurement was } \\
\text { from a geothermal area. }\end{array}$ \\
\hline gd_sol_com & Comments & $\begin{array}{l}\text { Comments about the measurement } \\
\text { including information about the weather } \\
\text { such as snow on the ground. }\end{array}$ \\
\hline gi_id & Gas Instrument ID & $\begin{array}{l}\text { An identifier for linking to information in } \\
\text { the Gas Instrument table. The Gas } \\
\text { Instrument table contains the instrument } \\
\text { model, its resolution, and the units it } \\
\text { measures. }\end{array}$ \\
\hline cc_id & Collector ID & $\begin{array}{l}\text { An identifier for linking to contact } \\
\text { information for the data collector. }\end{array}$ \\
\hline gd_sol_loaddate & Load date & The date this row was entered in UTC. \\
\hline gd_sol_pubdate & Publish date & $\begin{array}{l}\text { The date this row can become public. This } \\
\text { date can be set up to two years in advance. }\end{array}$ \\
\hline & & $\begin{array}{l}\text { An identifier for linking to contact } \\
\text { information for the person who entered this } \\
\text { row of data. }\end{array}$ \\
\hline cc_id_load & Data loader ID &
\end{tabular}

The Soil Efflux Data table (gd_sol for gas data - soil efflux) stores a daily total flux value for an individual gas species. The primary ID is gd_sol_id and the main foreign keys are the station ID, gs_id for linking to the Gas Station table, for the name of the site, its location, and a link to the network, and gi_id, the gas instrument ID for linking to information about the instrument. The collector ID, cc_id, and data loader ID, cc_id_load, both link to contact information in the Contact table. The load date, gd_sol_loaddate, is a TIMESTAMP and entered automatically in UTC. The date the data can become public is stored in ed_pubdate.

The time of the measurement along with an uncertainty is stored in, gd_sol_time and gd_sol_time_unc, in UTC DATETIME. The measured species, gd_sol_species, contains the gas species measured at the site, for example radon or $\mathrm{CO}_{2}$. The total flux of the gas species is stored in gd_sol_tflux and the total flux value uncertainty is stored in gd_sol_tflux_err, both as t/d. The number of points measured is stored in gd_sol_pts and the area measured is stored in gd_sol_area in meters squared. The highest individual efflux in $\mathrm{g} / \mathrm{m} 2 / \mathrm{d}$ is stored in gd_sol_high and the highest soil temperature is stored in degrees Celsius in gd_sol_htemp if the area measured is a geothermal area. The comments field, gd_sol_com, provides a field for comments about the weather, the site, and the measurement.

\section{Plume Data}

Table G4. Plume Data Table

\begin{tabular}{|l|l|l|}
\hline gd_plu_id & Plume ID & An identifier for linking with other tables \\
\hline vd_id & Volcano ID & $\begin{array}{l}\text { An identifier for linking with the volcano } \\
\text { tables }\end{array}$ \\
\hline gs_id & Gas Station ID & The identifier for linking with the Gas \\
\hline
\end{tabular}




\begin{tabular}{|c|c|c|}
\hline & & $\begin{array}{l}\text { Station table. The Gas Station table contains } \\
\text { the station name, location, and description. }\end{array}$ \\
\hline gd_continuous & Continuous flag & $\begin{array}{l}\text { A single character field used to identify } \\
\text { continuous data. Use } \mathrm{C} \text { for data that were } \\
\text { collected continuously or P for data that } \\
\text { were collected periodically. If the data were } \\
\text { from a periodic collection, please include } \\
\text { the collector ID in cc_id. }\end{array}$ \\
\hline gd_plu_units & Reported units & $\begin{array}{l}\text { The units reported for the emission rates } \\
\text { below, e.g., } \mathrm{t} / \mathrm{d} \text { or } \mathrm{kg} / \mathrm{s} \text {. }\end{array}$ \\
\hline gd_plu_lat & Latitude & $\begin{array}{l}\text { The latitude of the vent in decimal degrees } \\
\text { (sxx.xxxxxxx). }\end{array}$ \\
\hline gd_plu_lon & Longitude & $\begin{array}{l}\text { The longitude of the vent in decimal degrees } \\
\text { (sxxx.xxxxxxx). }\end{array}$ \\
\hline gd_plu_datum & Datum & $\begin{array}{l}\text { The datum used for the longitude and } \\
\text { latitude. Latitudes and longitudes should be } \\
\text { converted to WGS } 84 \text {. . }\end{array}$ \\
\hline gd_plu_height & Height & The height of the plume in $\mathrm{km}$. \\
\hline gd_plu_hdet & Plume height determination & $\begin{array}{l}\text { The method used to determine the height of } \\
\text { the plume. }\end{array}$ \\
\hline gd_plu_iddesc & Instrument description & $\begin{array}{l}\text { A description of the type of instrument and } \\
\text { its location, for example on a moving object } \\
\text { like a vehicle, airplane, or satellite or on a } \\
\text { stationary object like a tripod. }\end{array}$ \\
\hline gd_plu_time & Measure & $\begin{array}{l}\text { The measurement time in UTC stored as } \\
\text { DATETIME (YYYY-MM-DD hh:mm:ss). }\end{array}$ \\
\hline gd_plu_time_unc & $\begin{array}{l}\text { Measurement time } \\
\text { uncertainty }\end{array}$ & $\begin{array}{l}\text { The uncertainty in the measurement time in } \\
\text { UTC stored as DATETIME (YYYY-MM- } \\
\text { DD hh:mm:ss). }\end{array}$ \\
\hline gd_plu_co2 & $\mathrm{CO}_{2}$ emission rate & $\begin{array}{l}\text { The } \mathrm{CO}_{2} \text { emission rate in the plume in the } \\
\text { units reported in gd_plu_units. }\end{array}$ \\
\hline gd_plu_co2_err & $\mathrm{CO}_{2}$ emission standard error & $\begin{array}{l}\text { The } \mathrm{CO}_{2} \text { standard error in the units reported } \\
\text { in gd_plu_units. }\end{array}$ \\
\hline gd_plu_so2 & $\mathrm{SO}_{2}$ emission rate & $\begin{array}{l}\text { The } \mathrm{SO}_{2} \text { emission rate the plume in the units } \\
\text { reported in gd_plu_units. }\end{array}$ \\
\hline gd_plu_so2_err & $\mathrm{SO}_{2}$ emission standard error & $\begin{array}{l}\text { The } \mathrm{SO}_{2} \text { standard error in the units reported } \\
\text { in gd_plu_units. }\end{array}$ \\
\hline gd_plu_h2s & $\mathrm{H}_{2} \mathrm{~S}$ emission rate & $\begin{array}{l}\text { The } \mathrm{H}_{2} \mathrm{~S} \text { emission rate in the plume in the } \\
\text { units reported in gd_plu_units. }\end{array}$ \\
\hline gd_plu_h2s_err & $\mathrm{H}_{2} \mathrm{~S}$ emission standard error & $\begin{array}{l}\text { The } \mathrm{H}_{2} \mathrm{~S} \text { standard error in the units reported } \\
\text { in gd_plu_units. }\end{array}$ \\
\hline gd_plu_hcl & $\mathrm{HCl}$ emission rate & $\begin{array}{l}\text { The } \mathrm{HCl} \text { emission rate, in the units reported } \\
\text { in gd_plu_units. }\end{array}$ \\
\hline gd_plu_hcl_err & $\mathrm{HCl}$ emission standard error & $\begin{array}{l}\text { The } \mathrm{HCl} \text { standard error in the units reported } \\
\text { in gd_plu_units. }\end{array}$ \\
\hline gd_plu_hf & HF emission rate & The HF emission rate measured in metric \\
\hline
\end{tabular}




\begin{tabular}{|l|l|l|}
\hline & & tonnes/day. \\
\hline gd_plu_hf_err & HF emission standard error & $\begin{array}{l}\text { The HF standard error in the units reported } \\
\text { in gd_plu_units. }\end{array}$ \\
\hline gd_plu_co & CO emission rate & $\begin{array}{l}\text { The CO emission rate measured in the } \\
\text { plume in the units reported in gd_plu_units. }\end{array}$ \\
\hline gd_plu_co_err & CO emission standard error & $\begin{array}{l}\text { The CO standard deviation in the units } \\
\text { reported in gd_plu_units. }\end{array}$ \\
\hline gd_plu_wind & Wind speed & $\begin{array}{l}\text { The estimated wind speed at plume height } \\
\text { in m/s (xx.x). }\end{array}$ \\
\hline gd_plu_weth & Weather notes & $\begin{array}{l}\text { Notes on the weather for example } \\
\text { information on cloud cover, rain, ambient } \\
\text { temperature, etc. }\end{array}$ \\
\hline gd_plu_com & Additional comments & $\begin{array}{l}\text { Additional comments about the plume such } \\
\text { as the shape and size, and how the plume } \\
\text { data was collected. }\end{array}$ \\
\hline gi_id & & $\begin{array}{l}\text { An identifier for linking to information in } \\
\text { the Gas Instrument table. The Gas } \\
\text { Instrument table contains the instrument } \\
\text { model, its resolution, and the units it } \\
\text { measures. }\end{array}$ \\
\hline cc_id & Gas Instrument ID & $\begin{array}{l}\text { An identifier for linking to contact } \\
\text { information for the data collector. }\end{array}$ \\
\hline gd_plu_loaddate & Load date & The date this row was entered in UTC. \\
\hline gd_plu_pubdate & Publish date & $\begin{array}{l}\text { The date this row can become public. This } \\
\text { date can be set up to two years in advance. }\end{array}$ \\
\hline cc_id_load & Data loader ID & $\begin{array}{l}\text { An identifier for linking to contact } \\
\text { information for the person who entered this } \\
\text { row of data. }\end{array}$ \\
\hline
\end{tabular}

The Plume Data table (gd_plu for gas data - plume) stores gas data collected from a plume including the location of the vent, the height of the plume, and the gas emission rates. The primary ID is gd_plu_id. The main foreign keys are the volcano ID, vd_id, for linking periodic data collected from space to the Volcano table and the station ID, gs_id, to link to the station, instrument, and contact information for continuous ground-based emission-rates. Data collected periodically by a satellite or airplane are linked to instrument information by the instrument ID, gi_id, and collector information by the collector ID, cc_id. The data loader ID, cc_id_load, links to contact information about the person who loaded the data into WOVOdat. The load date, gd_plu_loaddate, is a TIMESTAMP and entered automatically in UTC. The date the data can become public is stored in gd_plu_pubdate.

Plume data can be collected either continuously or periodically so a flag, gd_plu_continuous, is included to identify the continuous data. The attribute gd_plu_continuous should store the letter P for data collected periodically and $\mathrm{C}$ for data collected continuously. If the data are collected periodically, include the collector ID in cc_id and the instrument ID in gi_id. Because continuous and periodic data are often reported differently, the units for the emission rates, e.g., $\mathrm{t} / \mathrm{d}$ or $\mathrm{kg} / \mathrm{s}$. are stored in gd_plu_units. The location of the plume, including the latitude and longitude of its source vent in decimal degrees, is stored in gd_plu_lat and gd_plu_lon, and the datum, gd_plu_datum. All data should 
be converted to WGS 84 prior to entering WOVOdat. If conversion is not possible during data loading, the original datum must be entered into the datum field, gd_plu_datum. The height of the plume in kilometers above sea level is stored in, gd_plu_height, and the method for determining the height is stored in gd_plu_hdet. The time of the measurement along with an uncertainty is stored in, gd_plu_time and gd_plu_time_unc, in UTC DATETIME.

The Plume Data table stores several emission rates and their standard deviations in metric tonnes per day: $\mathrm{CO}_{2}$ in $\mathrm{gd} \_p l u \_c o 2$ and $\mathrm{gd} \_p l u \_c o 2 \_e r r, \mathrm{SO}_{2}$ in $\mathrm{gd} \_p l u \_s o 2$ and gd_plu_so2_err, $\mathrm{H}_{2} \mathrm{~S}$ in gd_plu_h2s and gd_plu_h2s_err, $\mathrm{HCl}$ in gd_plu_hcl and gd_plu_hcl_err, HF in gd_plu_hf and gd_plu_hf_err, and CO in gd_plu_co and gd_plu_co_err. The measurement platform,gd_plu_plat, should contain information about how the instrument was mounted for a measurement for example, on a tripod, vehicle, plane or satellite. Three comments fields are included for additional information about the data. The estimated wind speed field, gd_plu_wind, is for information about the wind speed at the plume height. The weather field, gd_plu_weth, is for comments about the weather such as cloud cover, rain, and ambient temperature. The general comments field, gd_plu_com, is for additional information about the plume, for example shape and size, and how the measurements were taken.

\section{Gas Station}

Table G5. Gas Station Table

\begin{tabular}{|l|l|l|}
\hline gs_id & Gas Station ID & An identifier for linking with other tables \\
\hline gs_name & Station name or code & The name of the station. \\
\hline cn_id & Network ID & $\begin{array}{l}\text { An identifier for linking with the Common } \\
\text { Network table, if applicable. The Common } \\
\text { Network table contains information about } \\
\text { the monitoring network and links to the } \\
\text { Volcano table. }\end{array}$ \\
\hline gs_lat & Latitude & $\begin{array}{l}\text { The latitude of the station in decimal } \\
\text { degrees (sxx.xxxxxxx). }\end{array}$ \\
\hline gs_lon & Longitude & $\begin{array}{l}\text { The longitude of the station in decimal } \\
\text { degrees (sxxx.xxxxxx). }\end{array}$ \\
\hline gs_elev & Elevation & $\begin{array}{l}\text { The elevation of the land surface in meters } \\
\text { above sea level (asl) (sxxxx). }\end{array}$ \\
\hline gs_datum & Datum & $\begin{array}{l}\text { The datum used for the longitude and } \\
\text { latitude. Please also include the original } \\
\text { datum. }\end{array}$ \\
\hline gs_freq & Frequency of measurement & $\begin{array}{l}\text { A list of permanent instruments, if } \\
\text { applicable, installed at this site. The Gas } \\
\text { Instrument table links to the Gas Station } \\
\text { table for permanent instruments and } \\
\text { provides details about the permanent and } \\
\text { campaign instruments. }\end{array}$ \\
\hline gs_inst & Instrument & $\begin{array}{l}\text { The frequency of measurements. For } \\
\text { continuous measurements Use a C followed } \\
\text { by a time frame such as every 10 min. For } \\
\text { periodic measurements Use a P followed by }\end{array}$ \\
\hline & & \\
\hline & &
\end{tabular}




\begin{tabular}{|c|c|c|}
\hline & & $\begin{array}{l}\text { a time frame such as yearly, every } 5 \text { years, } \\
\text { or whenever possible. Please include both if } \\
\text { this station is used for both continuous and } \\
\text { campaign measurements. }\end{array}$ \\
\hline gs_type & Type & $\begin{array}{l}\text { The type of gas body found at the station, } \\
\text { for example fumarole or diffuse soil } \\
\text { degassing or if the station is used to collect } \\
\text { remote plume data. }\end{array}$ \\
\hline gs_utc & Difference from UTC & $\begin{array}{l}\text { The time zone relative to UTC. Please enter } \\
\text { the number of hours from GMT, using a } \\
\text { negative sign (-) for hours before GMT and } \\
\text { no sign for positive numbers. }\end{array}$ \\
\hline gs_stime & Start date & $\begin{array}{l}\text { The date (UTC) the station was set up and } \\
\text { activated or the time new information in this } \\
\text { table became valid. The date is stored in } \\
\text { DATETIME (YYYY-MM-DD hh:mm:ss). }\end{array}$ \\
\hline gs_stime_unc & Start date uncertainty & $\begin{array}{l}\text { The uncertainty in the date (UTC) the } \\
\text { station was set up and activated or the time } \\
\text { new information in this table became valid. } \\
\text { The date is stored in DATETIME (YYYY- } \\
\text { MM-DD hh:mm:ss). }\end{array}$ \\
\hline gs_etime & Stop date & $\begin{array}{l}\text { The date (UTC) the station was permanently } \\
\text { decommissioned or the time the information } \\
\text { in this table became invalid. The date is } \\
\text { stored in DATETIME (YYYY-MM-DD } \\
\text { hh:mm:ss). See observatory for station } \\
\text { operation history. }\end{array}$ \\
\hline gs_etime_unc & End date uncertainty & $\begin{array}{l}\text { The uncertainty in the date the station was } \\
\text { decommissioned or the time this set of } \\
\text { information is no longer valid in UTC } \\
\text { stored as DATETIME (YYYY-MM-DD } \\
\text { hh:mm:ss). }\end{array}$ \\
\hline gs_desc & Station description & $\begin{array}{l}\text { A description of the station and any } \\
\text { comments. }\end{array}$ \\
\hline cc_id & Contact ID & $\begin{array}{l}\text { An identifier for linking to contact } \\
\text { information for the person or observatory in } \\
\text { charge of this station. }\end{array}$ \\
\hline gs_loaddate & Load date & The date this row was entered in UTC. \\
\hline gs_pubdate & Publish date & $\begin{array}{l}\text { The date this row can become public. This } \\
\text { date can be set up to two years in advance. }\end{array}$ \\
\hline cc_id_load & Data loader ID & $\begin{array}{l}\text { An identifier for linking to contact } \\
\text { information for the person who entered this } \\
\text { row of data. }\end{array}$ \\
\hline
\end{tabular}


The Gas Station table (gs_ for Gas Station) stores information such as a location, type of gas body monitored, and a description of the stations where gas data are collected. A Gas network is defined as a set of stations that collect Gas data on either a single volcano or over a series of nearby volcanoes. The primary ID for the Gas Station table is gs_id. The Gas Station table links to the Common Network table by the network ID, cn_id. The network table provides the link to the volcano table. A junction table connects the network and volcano for instances where the network covers more than one volcano. The contact ID (cc_id) links to contact information about the person or observatory that manages the station and the data loader ID, cc_id_load, links to the Contact table for more information about the person who loaded the data into WOVOdat. The load date, gs_loaddate, is a TIMESTAMP and entered automatically in UTC. The date the data can become public is stored in gs_pubdate.

The Gas Station table stores the station location including the latitude and longitude in decimal degrees, gs_lat and gs_lon, the elevation in meters, gs_elev, and the datum, gs_datum. All data should be converted to WGS 84 prior to entering WOVOdat. If conversion is not possible during data loading, the original datum must be entered into the datum field, gs_datum. The names of any instruments installed at the station should be stored in the text field, gs_inst. Additional information about these instruments can be found in the Gas Instrument table by searching on the gas station ID (the instrument is linked to the station because there can be multiple instruments at a station). The frequency of measurement field, gs_freq, should contain an abbreviation for continuous $(\mathrm{C})$ or periodic $(\mathrm{P})$ in addition to a time frame for the frequency. The frequency time frame should be exact for the continuous data and approximate for the periodic data.

The station name or code, created by the observatory, is stored in gs_name. The type of body monitored at the station is stored in gs_type and should include a brief description of the feature at the site, e.g., $1 \mathrm{~m}$ wide fumarole or a remote feature, e.g., a plume. The difference from local time to UTC is stored in gs_utc. This information allows for the conversion back to UTC whenever needed as discussed in the Time Section.

The Gas Station table also includes start and end dates, gs_stime and gs_etime, along with uncertainties for those times, gs_stime_unc and gs_etime_unc, in DATETIME UTC. These dates provide information on when the station information in the table is valid. The instrument table also contains a date range. New station instruments should be recorded in the instrument table instead of the station table unless the location of the new instrument changes the screen location or the location of the station. The description of the station, gs_desc, is stored in a 255-character text field. The description should include any additional information about the station such as the activity level of the site and comments on why there is gas to monitor.

\section{Gas Instrument}

Table T5. Gas Instrument Table

\begin{tabular}{|l|l|l|}
\hline gi_id & Sensor ID & An identifier for linking with other tables. \\
\hline cs_id & $\begin{array}{l}\text { An identifier for linking with the Satellite } \\
\text { table, if the instrument is mounted on a } \\
\text { satellite or airplane. The Satellite table gives } \\
\text { the name of the satellite and a description. }\end{array}$ \\
\hline ts_id & $\begin{array}{l}\text { An identifier for linking with the Gas } \\
\text { Station table for instruments installed at a } \\
\text { station. The Gas Station table includes the } \\
\text { station location, the type of gas feature, and }\end{array}$ \\
\hline
\end{tabular}




\begin{tabular}{|l|l|l|}
\hline & & $\begin{array}{l}\text { links to the Gas Network and Gas } \\
\text { Instrument tables (for permanently installed } \\
\text { instruments). }\end{array}$ \\
\hline gi_perm & $\begin{array}{l}\text { A single character field to let the user know } \\
\text { if the instrument is part of a permanent } \\
\text { installation (use P for permanent) or part of } \\
\text { a campaign (use C for campaign). }\end{array}$ \\
\hline gi_type & The type of instrument. \\
\hline gi_name & Type & $\begin{array}{l}\text { The name, manufacturer, and model of the } \\
\text { instrument. }\end{array}$ \\
\hline gi_units & Name & The units the instrument measures. \\
\hline gi_pres & Resolution & Typical instrumental measuring precision. \\
\hline gi_stn & Signal to noise & An instrument specific signal to noise ratio. \\
\hline gi_calib & Calibration & The calibration method. \\
\hline gi_stime & & $\begin{array}{l}\text { The date (UTC) the instrument was set up } \\
\text { and activated or the time new information in } \\
\text { this table became valid. The date is stored in }\end{array}$ \\
\hline DATETIME (YYYY-MM-DD hh:mm:ss).
\end{tabular}

The Gas Instrument table (gi for gas instrument) was created to store information about the instruments used to collect ground-based and remote gas data along with a flag, gi_perm, to indicate if the instrument is installed permanently or is used periodically as part of a campaign. The permanently 
installed instruments are linked to the stations at which they are installed by the station ID, gs_id. The periodic instrument data are linked to the Gas Instrument table using the instrument table's primary ID, gi_id, which has been placed in the data tables.

The contact ID (cc_id) links to contact information about the person or observatory that manages the instrument and the data loader ID, cc_id_load, links to the Contact table for more information about the person who loaded the data into WOVOdat. The load date, gi_loaddate, is a TIMESTAMP and entered automatically in UTC. The date the data can become public is stored in gi_pubdate.

The name, model, and manufacturer of the instrument are stored in the text field gi_name, and the type of instrument is stored in the text field gi_type. The units the instrument measures are stored in the text field gi_units and the resolution or measuring precision in those units is stored in gi_res. The instrument specific signal to noise ratio is stored in gi_stn. The Gas Instrument table also includes start and end dates, gi_stime and gi_etime, along with uncertainties, gi_stime_unc and gi_etime_unc, in DATETIME UTC. These dates provide information on when the instrument information in the table is valid. The data are considered invalid if the resolution or signal to noise ratio changes or if an installed instrument is removed from a station. A comments attribute, gi_com, is included for comments about the instrument and its uses.

\section{Create table statements for gas tables}

DROP TABLE IF EXISTS gd;

create table gd (

gd_id mediumint not null auto_increment, gs_id mediumint,

gd_continuous char(1), gd_time datetime, gd_time_unc datetime, gd_gtemp float, gd_flow float, gd_bp float, gd_units varchar(30), gd_co2 float, gd_co2_err float, gd_so2 float, gd_so2_err float, gd_h2s float, gd_h2s_err float, gd_hcl float, gd_hcl_err float, gd_hf float, gd_hf_err float, gd_ch4 float, gd_ch4_err float, gd_h2 float, gd_h2_err float, gd_co float, gd_co_err float, gd_co2_h20free float, gd_so2_h20free float, gd_h2s_h20free float, gd_hcl_h20free float, gd_hf_h20free float, gd_ch4_h20free float, 
gd_h2_h20free float, gd_co_h20free float, gd_3he4he float, gd_d13c float, gd_d34s float, gd_d18o float, gd_dd float,

gd_envir varchar(255),

gd_submin varchar(255),

gd_com varchar(255),

gi_id mediumint,

cc_id mediumint,

gd_loaddate datetime, gd_pubdate datetime, cc_id_load mediumint, primary key (gd_id));

DROP TABLE IF EXISTS gd_sol;

create table gd_sol (

gd_sol_id mediumint not null auto_increment, gs_id mediumint,

gd_sol_time datetime,

gd_sol_time_unc datetime,

gd_sol_species varchar(30),

gd_sol_tflux float,

gd_sol_flux_err float,

gd_sol_pts float,

gd_sol_area float,

gd_sol_high float,

gd_sol_htemp float,

gd_sol_com varchar(255),

gi_id mediumint,

cc_id mediumint,

gd_sol_loaddate datetime,

gd_sol_pubdate datetime,

cc_id_load mediumint,

primary key (gd_sol_id));

DROP TABLE IF EXISTS gd_plu;

create table gd_plu (

gd_plu_id mediumint not null auto_increment, vd_id mediumint,

gs_id mediumint,

gd_continuous char(1),

gd_plu_units varchar(30),

gd_plu_lat float,

gd_plu_lon float,

gd_plu_datum varchar(50),

gd_plu_height float,

gd_plu_hdet varchar(255),

gd_plu_iddesc varchar(255),

gd_plu_time datetime,

gd_plu_time_unc datetime,

gd_plu_co2 float,

gd_plu_co2_err float, 
gd_plu_so2 float,

gd_plu_so2_err float, gd_plu_h2s float,

gd_plu_h2s_err float, gd_plu_hcl float,

gd_plu_hcl_err float, gd_plu_hf float,

gd_plu_hf_err float, gd_plu_co float, gd_plu_co_err float, gd_plu_wind float, gd_plu_weth varchar(255), gd_plu_com varchar(255), gi_id mediumint, cc_id mediumint, gd_plu_loaddate datetime, gd_plu_pubdate datetime, cc_id_load mediumint, primary key (gd_plu_id));

DROP TABLE IF EXISTS gs;

create table gs (

gs_id mediumint not null auto_increment,

gs_name varchar(50),

cn_id mediumint,

gs_lat float,

gs_lon float,

gs_elev float,

gs_datum varchar(50),

gs_inst varchar(255),

gs_freq varchar(255),

gs_type varchar(255),

gs_utc float,

gs_stime datetime,

gs_stime_unc datetime,

gs_etime datetime,

gs_etime_unc datetime,

gs_desc varchar(255),

cc_id mediumint,

gd_loaddate datetime,

gd_pubdate datetime,

cc_id_load mediumint,

primary key (gs_id));

\section{DROP TABLE IF EXISTS gi;}

create table gi (

gi_id mediumint not null auto_increment, cs_id mediumint,

ts_id mediumint,

gi_perm char(1),

gi_type varchar(255),

gi_name varchar(255),

gi_units varchar(50),

gi_pres float,

gi_stn float,

gi_calib varchar(255), 
gi_stime datetime,

gi_stime_unc datetime,

gi_etime datetime,

gi_etime_unc datetime,

gi_com varchar(255),

cc_id mediumint,

gi_loaddate datetime,

gi_pubdate datetime,

cc_id_load mediumint,

primary key (gi_id));

\section{Hydrologic}

The hydrology section of WOVOdat contains water monitoring data that are collected from water wells, springs, or crater lakes, all broadly indicative of groundwater conditions and the possible role of groundwater in volcanic unrest. WOVOdat's hydrology tables do not contain data on surface water hydrology that is unrelated to unrest at the volcano, e.g., normal variations in stream discharge or chemistry. There are three hydrology tables:

- The Hydrologic Data table, hd, contains all of the water data including temperature, water depth, and chemical composition. The data are collected either continuously or periodically as part of a campaign. The most commonly collected campaign data are water levels, temperature, $\mathrm{pH}$, and conductance but concentrations can also be included. As WOVOdat and collecting methods evolve, separate tables may be useful if there is a clear distinction between the frequency of data collection. The Hydrologic Data table is linked to the Hydrologic Station table, hs.

- The Hydrologic Station table contains information about the location of the station, the type of water body, and a list of any permanently installed instruments. The Hydrologic Station table is linked to the Common Network table, which contains information about the monitoring network and a link to the Volcano table.

- The Hydrologic Instrument table contains information about permanent and campaign instruments including the pressure measurement type, the units measured, and the resolution. Permanent instruments are linked to the Hydrologic Station table, whereas campaign instruments are linked to the Hydrologic Instrument table through the Hydrologic Data table.

Hydrologic Data

Table H1. Hydrologic Data Table

\begin{tabular}{|l|l|l|}
\hline hd_id & Hydrologic data ID & An identifier for linking with other tables \\
\hline hs_id & $\begin{array}{l}\text { An identifier for linking with the } \\
\text { Hydrologic Station table. The Hydrologic } \\
\text { Station table contains information about the } \\
\text { type of water body and location. }\end{array}$ \\
\hline & Hydrologic Station ID & $\begin{array}{l}\text { An identifier for linking with the } \\
\text { Hydrologic Instrument table for non- } \\
\text { permanent instruments. The Hydrologic } \\
\text { Instrument table contains instrument } \\
\text { information including the pressure } \\
\text { measurement type, the units measured, and }\end{array}$ \\
\hline hi_id & Hydrologic Instrument ID &
\end{tabular}




\begin{tabular}{|c|c|c|}
\hline & & the resolution \\
\hline hd_continuous & Continuous flag & $\begin{array}{l}\text { A single character field used to identify } \\
\text { continuous data. Use C for data that were } \\
\text { collected continuously or P for data that } \\
\text { were collected periodically. }\end{array}$ \\
\hline hd_time & Measurement time & $\begin{array}{l}\text { The measurement time (UTC) stored as } \\
\text { DATETIME (YYYY-MM-DD hh:mm:s). }\end{array}$ \\
\hline hd_time_unc & $\begin{array}{l}\text { Measurement time } \\
\text { uncertainty }\end{array}$ & $\begin{array}{l}\text { The uncertainty in the measurement time in } \\
\text { UTC stored as DATETIME (YYYY-MM- } \\
\text { DD hh:mm:ss). }\end{array}$ \\
\hline hd_temp & Temperature & $\begin{array}{l}\text { The temperature of the water in degrees } \\
\text { Celsius (xxx.xx). }\end{array}$ \\
\hline hd_welev & Water elevation & $\begin{array}{l}\text { The elevation of the water level in meters } \\
\text { above sea level, if available (sxxxx.xxx). }\end{array}$ \\
\hline hd_wdepth & Water depth & $\begin{array}{l}\text { The water depth in meters below the ground } \\
\text { surface, if available (xxxx.xxx). }\end{array}$ \\
\hline hd_dwlev & Change in water level & $\begin{array}{l}\text { The change in water level in meters if the } \\
\text { water depth and water elevation are not } \\
\text { available (xxx.xxx). }\end{array}$ \\
\hline hd_bp & Barometric Pressure & $\begin{array}{l}\text { The atmospheric pressure in millibars at the } \\
\text { time of measurement (xxxx.x ). }\end{array}$ \\
\hline hd_sdisc & Spring discharge rate & $\begin{array}{l}\text { The measured spring discharge rate in liters } \\
\text { per second (xxxx.xx). }\end{array}$ \\
\hline hd_prec & Precipitation & $\begin{array}{l}\text { The amount of precipitation in millimeters } \\
\text { for this measurement. Use the number } 0 \text { for } \\
\text { no rain and leave the field blank for } \\
\text { unknown. The frequency of the } \\
\text { precipitation measurement may be different } \\
\text { than the frequency of the other data, please } \\
\text { check in the Hydrologic Station table for the } \\
\text { measurement frequencies. (xxx.x) }\end{array}$ \\
\hline hd_dprec & Daily precipitation & $\begin{array}{l}\text { The precipitation in millimeters for the } \\
\text { preceding day. Use the number } 0 \text { for no rain } \\
\text { because a null value will stand for no data } \\
\text { measured. This information should be } \\
\text { included only if the precipitation is not } \\
\text { recorded continuously. }\end{array}$ \\
\hline hd_tprec & Type of precipitation & $\begin{array}{l}\text { The precipitation type. Use R for rain, FR } \\
\text { for freezing rain or sleet, } \mathrm{S} \text { for snow, H for } \\
\text { hail, or any combination of the above. }\end{array}$ \\
\hline hd_ph & $\mathrm{pH}$ & The $\mathrm{pH}$ of the water $(\mathrm{xx} \cdot \mathrm{x})$ \\
\hline hd_ph_err & pH standard error & $\begin{array}{l}\text { The standard error in the measured } \mathrm{pH} \text { of } \\
\text { the water (x.x). }\end{array}$ \\
\hline
\end{tabular}




\begin{tabular}{|c|c|c|}
\hline hd_cond & Conductivity & $\begin{array}{l}\text { The measured conductivity in } \\
\text { micromhos/cm (microSiemens/cm) (xxx.x). }\end{array}$ \\
\hline hd_cond_err & Conductivity standard error & $\begin{array}{l}\text { The standard error in measured conductivity } \\
\text { in micromhos/cm (microSiemens/cm) } \\
\text { (xx.x). }\end{array}$ \\
\hline hd_so4 & SO4= content & $\begin{array}{l}\text { The measured SO4= content in mg/L } \\
(x x x x) \text {. }\end{array}$ \\
\hline hd_so4_err & SO4= content standard error & $\begin{array}{l}\text { The standard error in measured SO4= } \\
\text { content in } \mathrm{mg} / \mathrm{L} \text { (xxx). }\end{array}$ \\
\hline hd_h2s & H2S content (total sulfide) & The total sulfide as H2S in mg/L ( $\mathrm{xxxx}$ ). \\
\hline hd_h2s_err & $\begin{array}{l}\text { H2S content (total sulfide) } \\
\text { standard error }\end{array}$ & $\begin{array}{l}\text { The standard error in measured H2S content } \\
\text { (total sulfide) in mg/L (xxx). }\end{array}$ \\
\hline hd_cl_en & Cl- content & The measured $\mathrm{Cl}$ - content in $\mathrm{mg} / \mathrm{L}$ ( $\mathrm{xxxxx}$ ). \\
\hline hd_cl_err & Cl- content standard error & $\begin{array}{l}\text { The standard error in measured } \mathrm{Cl} \text { - content } \\
\text { in } \mathrm{mg} / \mathrm{L} \text { (xxxx). }\end{array}$ \\
\hline hd_f & F- content & The measured F- content in mg/L (xxxx). \\
\hline hd_f_err & F- content standard error & $\begin{array}{l}\text { The standard error in measured F- content in } \\
\mathrm{mg} / \mathrm{L}(\mathrm{xxx}) \text {. }\end{array}$ \\
\hline hd_hco3 & HCO3- content & $\begin{array}{l}\text { The measured } \mathrm{HCO}_{3} \text { - content in } \mathrm{mg} / \mathrm{L} \\
\text { (xxxx). }\end{array}$ \\
\hline hd_hco3_err & HCO3- content standard error & $\begin{array}{l}\text { The standard error in measured } \mathrm{HCO}_{3^{-}} \\
\text {content in } \mathrm{mg} / \mathrm{L}(\mathrm{xxx}) \text {. }\end{array}$ \\
\hline hd_mg & $\mathrm{Mg}$ & The measured Mg content in mg/L (xxxx). \\
\hline hd_mg_err & Mg standard error & $\begin{array}{l}\text { The standard error in measured Mg content } \\
\text { in } \mathrm{mg} / \mathrm{L}(\mathrm{xxx}) \text {. }\end{array}$ \\
\hline hd_fe & $\mathrm{Fe}$ & The measured Fe content in mg/L (xxxx). \\
\hline hd_fe_err & Fe standard error & $\begin{array}{l}\text { The standard error in measured Fe content } \\
\text { in } \mathrm{mg} / \mathrm{L}(\mathrm{xxx}) \text {. }\end{array}$ \\
\hline hd_ca & $\mathrm{Ca}$ & The measured Ca content in mg/L (xxxx). \\
\hline hd_ca_err & Ca standard error & $\begin{array}{l}\text { The standard error in measured Ca content } \\
\text { in } \mathrm{mg} / \mathrm{L}(\mathrm{xxx}) \text {. }\end{array}$ \\
\hline hd_na & $\mathrm{Na}$ & The measured Na content in $\mathrm{mg} / \mathrm{L}$ (xxxxx). \\
\hline hd_na_err & Na standard error & $\begin{array}{l}\text { The standard error in measured Na content } \\
\text { in } \mathrm{mg} / \mathrm{L} \text { (xxxx). }\end{array}$ \\
\hline hd_k & K & The measured K content in mg/L (xxxx). \\
\hline hd_k_err & K standard error & $\begin{array}{l}\text { The standard error in measured } \mathrm{K} \text { content in } \\
\mathrm{mg} / \mathrm{L} \text { (xxx). }\end{array}$ \\
\hline hd_3he4he & $3 \mathrm{He} / 4 \mathrm{He}$ & The measured ${ }^{3} \mathrm{He} /{ }^{4} \mathrm{He}$ ratio (xx.x). \\
\hline hd_3he4he_err & 3He/4He standard error & $\begin{array}{l}\text { The standard error in measured }{ }^{3} \mathrm{He} /{ }^{4} \mathrm{He} \\
\text { ratio (x.x). }\end{array}$ \\
\hline hd_c3he4he & Corrected $3 \mathrm{He} / 4 \mathrm{He}$ & $\begin{array}{l}\text { The measured }{ }^{3} \mathrm{He} /{ }^{4} \mathrm{He} \text { ratio corrected for } \\
\text { air contamination (xx.x). }\end{array}$ \\
\hline hd_c3he4he_err & $\begin{array}{l}\text { Corrected 3He/4He standard } \\
\text { error }\end{array}$ & $\begin{array}{l}\text { The standard error in measured }{ }^{3} \mathrm{He} /{ }^{4} \mathrm{He} \\
\text { ratio (x.x). }\end{array}$ \\
\hline hd_d13c & delta 13C & The measured delta ${ }^{13} \mathrm{C}$ per mil (xx.xx). \\
\hline
\end{tabular}




\begin{tabular}{|l|l|l|}
\hline hd_d13c_err & delta 13C standard error & $\begin{array}{l}\text { The standard error in measured delta }{ }^{13} \mathrm{C} \text { per } \\
\text { mil (x.xx). }\end{array}$ \\
\hline hd_d34s & delta 34S & The measured delta ${ }^{34}$ S per mil (xx.xx). \\
\hline hd_d34s_err & delta 34S standard error & $\begin{array}{l}\text { The standard error in measured delta }{ }^{34} \mathrm{~S} \text { per } \\
\text { mil (x.xx). }\end{array}$ \\
\hline hd_dd & delta D & The measured delta D per mil (xxx.xx). \\
\hline hd_dd_err & delta D standard error & $\begin{array}{l}\text { The standard error in measured delta D per } \\
\text { mil (xx.xx). }\end{array}$ \\
\hline hd_d180 & delta 18O & The measured delta ${ }^{18}$ O per mil (xx.xx). \\
\hline hd_d18o_err & delta 18O standard error & $\begin{array}{l}\text { The standard error in measured delta }{ }^{18} \text { O per } \\
\text { mil (x.xx). }\end{array}$ \\
\hline hd_com & Comments & $\begin{array}{l}\text { Comments about the measurement and } \\
\text { about precipitation over the past month. }\end{array}$ \\
\hline CC_id & $\begin{array}{l}\text { An identifier for linking to contact } \\
\text { information for the data collector. The } \\
\text { collector ID is for campaign data only, the } \\
\text { Hydrologic Station table includes contact } \\
\text { information for the continuous data. }\end{array}$ \\
\hline hd_loaddate & Load date & The date this row was entered in UTC. \\
\hline hd_pubdate & Publish date & $\begin{array}{l}\text { The date this row can become public. This } \\
\text { date can be set up to two years in advance. }\end{array}$ \\
\hline & & $\begin{array}{l}\text { An identifier for linking to contact } \\
\text { information for the person who entered this } \\
\text { row of data. }\end{array}$ \\
\hline cc_id_load & Data loader ID &
\end{tabular}

The Hydrologic Data table (hd for hydrologic data) stores all of the water data including temperature, water depth, and concentrations. The primary ID is hd_id and the main foreign keys are the station ID, hs_id for linking to the station information, which includes the type of water body, its location and a link for information about permanent instruments, and hi_id, the hydrologic instrument ID, for linking to instrument information for campaign data. The instrument link for the continuous data can be found in the Hydrologic Station table. The collector ID (cc_id) links to contact information about the person or observatory that collected the data. The collector ID is for campaign data only, the Hydrologic Station table includes contact information for the continuous data. The data loader ID, cc_id_load, links to the Contact table for more information about the person who loaded the data into WOVOdat. The load date, hd_loaddate, is a TIMESTAMP and entered automatically in UTC. The date the data can become public is stored in hd_pubdate.

The time of the measurement is stored in, hd_time, along with an uncertainty, hd_time_unc, in UTC DATETIME. The hydrologic data can be collected either continuously or periodically. A flag, hd_continuous, is included to identify the continuous data. If some of the data are collected as part of a campaign and others are collected at the same time continuously, then Use, P, for periodic in hd_continuous. The attribute hd_continuous should store the letter $\mathrm{C}$ for continuous data only if all data recorded at the measurement time were recorded continuously. The temperature, hd_temp, is stored in Celsius. The depth of the water is stored in three different parameters depending on the original data. The water elevation, hd_welev, is the elevation of the water surface in meters above sea level. The water depth, hd_wdepth, is the water depth in meters below the ground surface, and the change in water level, hd_dwlev, is the change in water level in meters for cases where the water depth and water elevation are 
not known. The barometric pressure, hd_bp, is the atmospheric pressure in millibars at the time of measurement. The spring discharge rate, hd_sdisc, is the measured spring discharge rate in liters per second, where applicable. Information about precipitation is stored in three parameters, the precipitation rate at the time of measurement, hd_prec, for continuous measurements, the daily precipitation rate, hd_dprec, for campaign measurements, and the type of precipitation, hd_tprec. The precipitation rates are stored in millimeters, use the number 0 for no rain and a null value for no data measured. The precipitation type should contain single letters for each type of precipitation, such as, $\mathrm{R}$ for rain, FR for freezing rain or sleet, $\mathrm{S}$ for snow, $\mathrm{H}$ for hail, or any combination of the above. The $\mathrm{pH}$ of the water is stored in hd_ph, and the conductivity is stored in hd_cond as micromhos/cm (or microSeimans/cm). Standard errors or resolutions for the $\mathrm{pH}$ and conductivity are stored in hd_ph_err and hd_cond_err.

The Hydrologic Data table stores several concentrations of common ions in units of mg/L; $\mathrm{SO}_{4}{ }^{=}$ in hd_so4, $\mathrm{H}_{2} \mathrm{~S}$ (reduced S) in hd_h2s, $\mathrm{Cl}^{-}$in hd_cl in $\mathrm{F}^{-}$, hd_f, $\mathrm{HCO}_{3}{ }^{-}$in hd_hco3, Mg in hd_mg, Fe in hd_fe, Ca in hd_ca, Na in hd_na, and $\mathrm{K}$ in hd_k. The measured Helium 3/4 ratio $\left({ }^{3} \mathrm{He} /{ }^{4} \mathrm{He}\right)$ is stored in hd_3he4he and the ${ }^{3} \mathrm{He} /{ }^{4} \mathrm{He}$ ratio corrected for air contamination is stored in hd_c3he4he. There are also several ratios referred to by the measured delta per milliliter such as $\delta^{13} \mathrm{C}$ in hd_d13c, $\delta^{34} \mathrm{~S}$ in hd_d34s, $\delta \mathrm{D}$ in hd_dd, and $\delta^{18} \mathrm{O}$ in hd_d18o. Each of these concentrations has an associated standard error or resolution: hd_so4_err, hd_h2s_err, hd_cl_err, hd_f_err, hd_hco3_err, hd_mg_err, hd_fe_err, hd_ca_err, hd_na_err, hd_k_err, hd_3he4he_err, hd_c3he4he_err, hd_d13c_err, hd_d34s_err, hd_dd_err, and hd_d18o_err. A comments field, hd_com, is included to store additional information about the measurements or observations that day including the current weather.

\section{Hydrologic Station}

Table H2. Hydrologic Station Table

\begin{tabular}{|l|l|l|}
\hline hs_id & Hydrologic station ID & An identifier for linking with other tables \\
\hline cn_id & Common Network ID & $\begin{array}{l}\text { An identifier for linking with the Common } \\
\text { Network table, if applicable. The Common } \\
\text { Network table contains information about } \\
\text { the monitoring network and links to the } \\
\text { Volcano table. }\end{array}$ \\
\hline hs_lat & Latitude & $\begin{array}{l}\text { The latitude of the station in decimal } \\
\text { degrees (xx.xxxxxx). }\end{array}$ \\
\hline hs_lon & Longitude & $\begin{array}{l}\text { The longitude of the station in decimal } \\
\text { degrees (xxx.xxxxxx). }\end{array}$ \\
\hline hs_elev & Elevation & $\begin{array}{l}\text { The elevation of the land surface in meters } \\
\text { (xxxx). }\end{array}$ \\
\hline hs_datum & & $\begin{array}{l}\text { The datum used for the longitude and } \\
\text { latitude. Please also include the original } \\
\text { datum. }\end{array}$ \\
\hline Datum & $\begin{array}{l}\text { A list of permanent instruments, if } \\
\text { applicable, installed at this site. The } \\
\text { Hydrologic Instrument table links to the } \\
\text { Hydrologic Station table for details of these } \\
\text { permanent instruments. and provides details } \\
\text { about the permanent and campaign } \\
\text { instruments. }\end{array}$ \\
\hline hs_perm & & \\
\hline
\end{tabular}




\begin{tabular}{|c|c|c|}
\hline ds_freq & Frequency of measurement & $\begin{array}{l}\text { The frequency of measurements. For } \\
\text { continuous measurements Use a C followed } \\
\text { by a sampling or reporting rate such as } \\
\text { every } 10 \text { mins. For periodic (=campaign) } \\
\text { measurements Use a P followed by an } \\
\text { approximate frequency of repeat } \\
\text { measurements e.g., yearly, every } 5 \text { years, or } \\
\text { whenever possible. Please include both if } \\
\text { this station is used for both continuous and } \\
\text { campaign measurements. }\end{array}$ \\
\hline hs_name & Well name or code & The name or code of the station. \\
\hline hs_type & Type of water body & $\begin{array}{l}\text { The type of water body (well, lake, spring, } \\
\text { etc.) }\end{array}$ \\
\hline hs_utc & Difference from UTC & $\begin{array}{l}\text { The time zone relative to UTC. Please enter } \\
\text { the number of hours from GMT, using a } \\
\text { negative sign (-) for hours before GMT and } \\
\text { no sign for positive numbers (xx.x). }\end{array}$ \\
\hline hs_tscr & Top of screen & $\begin{array}{l}\text { The top of the interval open to inflow in } \\
\text { meters below the surface (xxx.xx). }\end{array}$ \\
\hline hs_bscr & Bottom of screen & $\begin{array}{l}\text { The bottom of the interval open to inflow in } \\
\text { meters below the surface (xxx.xx). }\end{array}$ \\
\hline hs_tdepth & Total depth of well & $\begin{array}{l}\text { The total depth of well in meters below the } \\
\text { surface (xxxx.xx). }\end{array}$ \\
\hline hs_stime & Start date & $\begin{array}{l}\text { The date (UTC) the station was set up and } \\
\text { activated or the time new information in this } \\
\text { table became valid. The date is stored in } \\
\text { DATETIME (YYYY-MM-DD hh:mm:ss). }\end{array}$ \\
\hline hs_stime_unc & Start date uncertainty & $\begin{array}{l}\text { The uncertainty in the date (UTC) the } \\
\text { station was set up and activated or the time } \\
\text { new information in this table became valid. } \\
\text { The date is stored in DATETIME (YYYY- } \\
\text { MM-DD hh:mm:ss). }\end{array}$ \\
\hline hs_etime & Stop date & $\begin{array}{l}\text { The date (UTC) the station was permanently } \\
\text { decommissioned or the time the information } \\
\text { in this table became invalid. The date is } \\
\text { stored in DATETIME (YYYY-MM-DD } \\
\text { hh:mm:ss). See observatory for station } \\
\text { operation history. }\end{array}$ \\
\hline hs_etime_unc & End date uncertainty & $\begin{array}{l}\text { The uncertainty in the date the station was } \\
\text { decommissioned or the time this set of } \\
\text { information is no longer valid in UTC } \\
\text { stored as DATETIME (YYYY-MM-DD } \\
\text { hh:mm:ss). }\end{array}$ \\
\hline hs_desc & Station description & $\begin{array}{l}\text { A description of the station, please include } \\
\text { information about environmental factors, } \\
\text { e.g., nearby pumping, ocean tides, or }\end{array}$ \\
\hline
\end{tabular}




\begin{tabular}{|l|l|l|}
\hline & & $\begin{array}{l}\text { anything else that might affect the water } \\
\text { measurements. }\end{array}$ \\
\hline cc_id & Contact ID & $\begin{array}{l}\text { An identifier for linking to contact } \\
\text { information about the person or observatory } \\
\text { that manages this station. }\end{array}$ \\
\hline hs_loaddate & Load date & The date this row was entered in UTC. \\
\hline hs_pubdate & Publish date & $\begin{array}{l}\text { The date this row can become public. This } \\
\text { date can be set up to two years in advance. }\end{array}$ \\
\hline cc_id_load & $\begin{array}{l}\text { An identifier for linking to contact } \\
\text { information for the person who entered this } \\
\text { row of data. }\end{array}$ \\
\hline
\end{tabular}

The Hydrologic Station table (hs_for Hydrologic Station) stores information such as location, type of water body, and descriptions for stations where hydrologic data are collected. There are often multiple instruments at a station and some observatories may use an instrument at multiple stations. Multiple permanent instruments at a station are recorded by a link to the Hydrologic Station table in the Hydrologic Instrument. For instruments used periodically, the link to the instrument is included in the Hydrologic Data table. Originally, an instrument/station junction table was used for the periodic instruments but it was decided to treat the instrument like data, since it could change so often, and store the instrument link in the data tables.

The primary ID for the Hydrologic Station table is hs_id. The Hydrologic Station table links to the Common Network table by the network ID, cn_id. The data can be linked to the volcano through the Common Network table. A hydrologic network is defined as a set of stations that collect hydrologic data either on a single volcano or over a series of nearby volcanoes. The contact ID (cc_id) links to contact information about the person or observatory that manages the station and the data loader ID, cc_id_load, links to the Contact table for more information about the person who loaded the data into WOVOdat. The load date, hs_loaddate, is a TIMESTAMP and entered automatically in UTC. The date the data can become public is stored in hs_pubdate.

The station name or code, given by the observatory, is stored in hs_name and the type of body monitored is stored in hs_type. The Hydrologic Station table stores the station location including the latitude and longitude in decimal degrees, hs_lat and hs_lon, the elevation in meters, hs_elev, and the datum, hs_datum. All data should be converted to WGS 84 prior to entering WOVOdat. If conversion is not possible during data loading, the original datum must be entered into the datum field, hs_datum.

A list of any instruments permanently installed at the station should be stored in the text field, hs_perm. Additional information about these instruments can be found in the Hydrologic Instrument table by searching on the hydrologic station ID (the instrument is linked to the station because there can be multiple instruments at a station). The frequency of measurement field, hs_freq, is a text field that should contain an abbreviation for continuous $(\mathrm{C})$ or periodic $(\mathrm{P})$ in addition to a time frame for the frequency. The frequency time frame will be exact for the continuous data and approximate for the periodic data. The difference from local time to UTC is stored in hs_utc. This information allows for the conversion back to UTC whenever needed as discussed in the Time Section.

The top of the interval open to inflow or the top of the screen, hs_tscr, is stored in meters below the surface and the bottom of the interval open to inflow, hs_bscr, is stored in meters below the surface. The total depth of the well, hs_tdepth, is stored in meters below the surface. The Hydrologic Station table also includes start and end dates, hs_stime and hs_etime, along with uncertainties, hs_stime_unc and hs_etime_unc, in DATETIME UTC. These dates provide information on when the station information in the table is valid. The instrument table also contains a date range. New station instruments should be recorded in the instrument table instead of the station table unless the location of 
the new instrument changes the screen location or the location of the station. A 255-character field, hd_desc, is available for storing a description of the station. The description should include any additional information about the station such as information about nearby pumping, ocean tides, or anything else that might affect the water measurements.

Hydrologic Instrument

Table H3. Hydrologic Instrument Table

\begin{tabular}{|c|c|c|}
\hline hi_id & Hydrologic instrument ID & An identifier for linking with other tables. \\
\hline hs_id & Hydrologic Station ID & $\begin{array}{l}\text { An identifier for linking with the } \\
\text { Hydrologic Station table. The Hydrologic } \\
\text { Station table contains information about the } \\
\text { type of water body and location. }\end{array}$ \\
\hline hi_perm & Permanent & $\begin{array}{l}\text { A single character field to let the user know } \\
\text { if the instrument is part of a permanent } \\
\text { installation. Use } C \text { for continuous } \\
\text { (permanent) and } P \text { for periodic (campaign). }\end{array}$ \\
\hline hi_name & Name & $\begin{array}{l}\text { The name of the instrument including the } \\
\text { model and manufacturer. }\end{array}$ \\
\hline hi_type & Type & $\begin{array}{l}\text { The type of instrument (float, pressure } \\
\text { transducer, bubbler, rain gage, barometer, } \\
\text { flow meter, pH or conductivity meter) }\end{array}$ \\
\hline hs_meas & Pressure measurement type & $\begin{array}{l}\text { A single character text field (A or V) that } \\
\text { stores whether the pressure transducer } \\
\text { measurement is absolute (non-vented) or } \\
\text { vented (gauge). }\end{array}$ \\
\hline hi_units & Measured units & The units the instrument measures. \\
\hline hi_res & Resolution & The measurement resolution or precision. \\
\hline hi_stime & Installation date & $\begin{array}{l}\text { The date (UTC) the instrument was set up } \\
\text { and activated or the time new information in } \\
\text { this table became valid. The date is stored in } \\
\text { DATETIME (YYYY-MM-DD hh:mm:ss). }\end{array}$ \\
\hline hi_stime_unc & Start date uncertainty & $\begin{array}{l}\text { The uncertainty in the date (UTC) the } \\
\text { instrument was set up and activated or the } \\
\text { time new information in this table became } \\
\text { valid. The date is stored in DATETIME } \\
\text { (YYYY-MM-DD hh:mm:ss). }\end{array}$ \\
\hline hi_etime & End date & $\begin{array}{l}\text { The date (UTC) the instrument was } \\
\text { permanently decommissioned or the time } \\
\text { the information in this table became invalid. } \\
\text { The date is stored in DATETIME (YYYY- } \\
\text { MM-DD hh:mm:ss). See observatory for } \\
\text { station operation history. }\end{array}$ \\
\hline
\end{tabular}




\begin{tabular}{|l|l|l|}
\hline & & $\begin{array}{l}\text { The uncertainty in the date the instrument } \\
\text { was decommissioned or the time this set of } \\
\text { information is no longer valid in UTC } \\
\text { stored as DATETIME (YYYY-MM-DD } \\
\text { hh:mm:ss). }\end{array}$ \\
\hline hi_etime_unc & End date uncertainty & $\begin{array}{l}\text { A description of or comments about the } \\
\text { instrument. }\end{array}$ \\
\hline hi_desc & Description & $\begin{array}{l}\text { An identifier for linking to contact } \\
\text { information for the person or observatory } \\
\text { responsible for this instrument. }\end{array}$ \\
\hline cc_id & Contact ID & The date this row was entered in UTC. \\
\hline hi_loaddate & Load date & $\begin{array}{l}\text { The date this row can become public. This } \\
\text { date can be set up to two years in advance. }\end{array}$ \\
\hline hi_pubdate & Publish date & $\begin{array}{l}\text { An identifier for linking to contact } \\
\text { information for the person who entered this } \\
\text { row of data. }\end{array}$ \\
\hline cc_id_load & & Data loader ID
\end{tabular}

The Hydrologic Instrument table (hi for hydrologic instrument) stores information about each individual instrument along with a flag, hi_perm, to indicate if the instrument is installed permanently or is used periodically as part of a campaign. Hydrologic stations will often have multiple permanently installed instruments and these can be identified for each station using the hydrologic station ID link, hs_id. The periodic instrument data are linked to the Hydrologic Instrument table using the instrument table's primary ID, hi _id, which has been placed in the Hydrologic Data table. An instrument/station junction table was originally created to handle the periodic data from a non-permanent instrument but because the instruments can change often, it was decided to put the instrument link with the data, along with the station link. The contact ID (cc_id) links to contact information about the person or observatory responsible for the instrument and the data loader ID, cc_id_load, links to the Contact table for more information about the person who loaded the data into WOVOdat. The load date, hi_loaddate, is a TIMESTAMP and entered automatically in UTC. The date the data can become public is stored in hi_pubdate.

The name of the instrument is stored in the text field hi_name. The instrument type, di_type, provides the type of instrument including what it measures. The field, hi_meas, is a single character text field (A or V) that stores information about whether the pressure transducer measurement is absolute (non-vented) or vented (gauge). The units the instrument measures are stored in the text field hi_units and the resolution or measuring precision in those units is stored in hi_res. The Hydrologic Instrument table also includes start and end dates, hi_stime and hi_etime, in DATETIME UTC. These dates provide information on when the instrument information in the table is valid. The data are considered invalid if the resolution changes or if an installed instrument is removed from a station. A description attribute, hi_desc, is included for a description of the type of instrument and its uses.

\section{Create table statements for hydrology tables}

DROP TABLE IF EXISTS hd;

create table hd (

hd_id mediumint not null auto_increment,

hs_id mediumint,

hi_id mediumint, 
hd_continuous char(1),

hd_time datetime,

hd_time_unc datetime,

hd_temp float,

hd_welev float,

hd_wdepth float,

hd_dwlev float,

hd_bp float,

hd_sdisc float,

hd_prec float,

hd_dprec float,

hd_tprec varchar(30),

hd_ph float,

hd_ph_err float,

hd_cond float,

hd_cond_err float,

hd_so4 float,

hd_so4_err float,

hd_h2s float,

hd_h2s_err float,

hd_cl float,

hd_cl_err float,

hd_f float,

hd_f_err float,

hd_hco3 float,

hd_hco3_err float,

hd_mg float,

hd_mg_err float,

hd_fe float,

hd_fe_err float,

hd_ca float,

hd_ca_err float,

hd_na float,

hd_na_err float,

hd_k float,

hd_k_err float,

hd_3he4he float,

hd_3he4he_err float,

hd_c3he4he float,

hd_c3he4he_err float,

hd_d13c float,

hd_d13c_err float,

hd_d34s float,

hd_d34s_err float,

hd_dd float,

hd_dd_err float,

hd_d18o float,

hd_d18o_err float,

hd_com varchar(255),

cc_id mediumint,

hd_loaddate datetime, hd_pubdate datetime,

cc_id_load mediumint,

primary key (hd_id));

DROP TABLE IF EXISTS hs;

create table hs ( 
hs_id mediumint, cn_id mediumint, hs_lat float, hs_lon float, hs_elev float, hs_datum varchar(30), hs_perm varchar(255), ds_freq varchar(255), hs_name varchar(30), hs_type varchar(255), hs_utc float, hs_tscr float, hs_bscr float, hs_tdepth float, hs_stime datetime, hs_stime_unc datetime, hs_etime datetime,

hs_etime_unc datetime, hs_desc varchar(255),

cc_id mediumint, hs_loaddate datetime, hs_pubdate datetime, cc_id_load mediumint, primary key (hs_id));

DROP TABLE IF EXISTS hi;

create table hi (

hi_id mediumint, hs_id mediumint, hi_perm char(1),

hi_name varchar(255),

hi_type varchar(50),

hs_meas char(1),

hi_units float,

hi_res float,

hi_stime datetime,

hi_stime_unc datetime,

hi_etime datetime,

hi_etime_unc datetime, hi_desc varchar(255),

cc_id mediumint, hi_loaddate datetime, hi_pubdate datetime, cc_id_load mediumint, primary key (hi_id));

\section{Potential Fields}

The potential fields tables contain data on magnetic, gravity, and electrical changes at volcanoes. These measurements can be continuous or periodic and the data tables include a flag to note the frequency of measurement. A link to the collector ID and instrument ID are included for the periodic data whereas those links can be found through the station table for the continuous data. There are six potential fields tables: 
- The Magnetic Field Strength data table stores the total field strength and the frequency range of measurement.

- The Magnetic Vector Data table stores the vector declination and inclination.

- The Electric Data table stores the electric field, frequency range for the measurement, the self potential, and resistivities.

- The Gravity Data table stores the field strength and information about associated vertical displacement and ground water levels, if known.

- The Fields Station table contains the station location, a conversion from local time to UTC, and links to the instrument and network tables. The instrument links in the Fields Station table are for permanent stations only, data collected as part of a campaign are stored in the data tables with links to the instruments.

- The Fields Instrument table contains the instrument type, resolution, sampling rate, filter type, and orientation.

Magnetic Fields

Table F1. Magnetic Fields Data Table

\begin{tabular}{|c|c|c|}
\hline fd_mag_id & Magnetic field strength ID & An identifier for linking with other tables. \\
\hline fs_id & Fields station ID & $\begin{array}{l}\text { The identifier for linking to the Fields } \\
\text { Station table. The Fields Station table } \\
\text { contains the station location, a conversion } \\
\text { from local time to UTC, and links to the } \\
\text { Fields Instrument and Common Network } \\
\text { tables. }\end{array}$ \\
\hline fs_id_ref & Reference station ID & $\begin{array}{l}\text { A link to information about the reference } \\
\text { station in the Fields Station table. The } \\
\text { Fields Station table contains the station } \\
\text { location, a conversion from local time to } \\
\text { UTC, and links to the Fields Instrument and } \\
\text { Common Network tables. }\end{array}$ \\
\hline fi_id & Fields Instrument ID & $\begin{array}{l}\text { An identifier for linking with the Fields } \\
\text { Instrument table for non-permanent } \\
\text { (campaign) instruments. }\end{array}$ \\
\hline fd_mag_continuous & Continuous flag & $\begin{array}{l}\text { A single character field used to identify } \\
\text { continuous data. Use C for data that were } \\
\text { collected continuously or P for data that } \\
\text { were collected periodically. }\end{array}$ \\
\hline fd_mag_time & Measurement time & $\begin{array}{l}\text { The measurement time in UTC stored as } \\
\text { DATETIME (YYYY-MM-DD hh:mm:ss). }\end{array}$ \\
\hline fd_mag_time_unc & $\begin{array}{l}\text { Measurement time } \\
\text { uncertainty }\end{array}$ & $\begin{array}{l}\text { The uncertainty in the measurement time in } \\
\text { UTC stored as DATETIME (YYYY-MM- } \\
\text { DD hh:mm:ss). }\end{array}$ \\
\hline fd_mag_f & 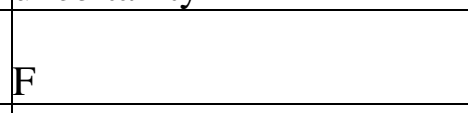 & $\begin{array}{l}\text { The total field strength in nanoteslas } \\
\text { (xxxxx.xx). }\end{array}$ \\
\hline fd_mag_compx & $\mathrm{X}$ & The X component in nanoteslas (xxxxx.Xx). \\
\hline
\end{tabular}




\begin{tabular}{|c|c|c|}
\hline fd_mag_compy & $\mathrm{Y}$ & The Y component in nanoteslas (xxxxx.xx). \\
\hline fd_mag_compz & $\mathrm{Z}$ & The $\mathrm{Z}$ component in nanoteslas (xxxxx.xx). \\
\hline fd_mag_ferr & $\begin{array}{l}\text { Tot field strength uncertainty } \\
\text { (F) }\end{array}$ & $\begin{array}{l}\text { The total field strength uncertainty in } \\
\text { nanoteslas (xx.xx). }\end{array}$ \\
\hline fd_mag_errx & Component X uncertainty & $\begin{array}{l}\text { The uncertainty in the } \mathrm{x} \text { component } \\
\text { measurement in nanoteslas (xx.xx). }\end{array}$ \\
\hline fd_mag_erry & Component Y uncertainty & $\begin{array}{l}\text { The uncertainty in the y component } \\
\text { measurement in nanoteslas (xx.xx). }\end{array}$ \\
\hline fd_mag_errz & Component $\mathrm{Z}$ uncertainty & $\begin{array}{l}\text { The uncertainty in the } \mathrm{z} \text { component } \\
\text { measurement in nanoteslas (xx.xx). }\end{array}$ \\
\hline fd_mag_highpass & Highpass & $\begin{array}{l}\text { The high pass filter frequency value in } \mathrm{Hz} \\
\text { above which signals are used (passed) } \\
\text { (xx.x). }\end{array}$ \\
\hline fd_mag_lowpass & Lowpass & $\begin{array}{l}\text { The low pass filter frequency value in } \mathrm{Hz} \\
\text { below which signals are used (passed) } \\
\text { (xx.x). }\end{array}$ \\
\hline fd_mag_com & Comments & Comments on the magnetic measurements. \\
\hline cc_id & Collector ID & $\begin{array}{l}\text { An identifier for linking to contact } \\
\text { information for the data collector. }\end{array}$ \\
\hline fd_mag_loaddate & Load date & The date this row was entered in UTC. \\
\hline fd_mag_pubdate & Publish date & $\begin{array}{l}\text { The date this row can become public. This } \\
\text { date can be set up to two years in advance. }\end{array}$ \\
\hline cc_id_load & Data loader ID & $\begin{array}{l}\text { An identifier for linking to contact } \\
\text { information for the person who entered this } \\
\text { row of data. }\end{array}$ \\
\hline
\end{tabular}

The Magnetic Fields Data table (fd_mag for fields data - magnetic) contains magnetic data that were collected digitally. The primary ID is fd_mag_id and there are several foreign IDs for linking to other tables. The Fields Station table is linked by fs_id and provides the station location, a conversion from local time to UTC, and links to the Fields Instrument and Common Network tables. The reference station ID is stored in fs_id_ref and links to the Fields Station table. The instrument ID, fi_id, is included for linking to the Fields Instrument table for information about instruments that collected campaign data. The collector ID, cc_id, links to contact information about the person or observatory that collected the data and the data loader ID, cc_id_load, links to the Contact table for more information about the person who loaded the data (ran the script or is in charge of running the script) into WOVOdat. The load date, fd_mag_loaddate,, is a TIMESTAMP and entered automatically in UTC. The date the data can become public is stored in fd_mag_pubdate.

Magnetic fields data can be collected either continuously or periodically so a flag, fd_mag_continuous, is included to identify the continuous data. The attribute fd_mag_continuous should store the letter $\mathrm{C}$ only if all data recorded at the measurement time was recorded continuously and the letter $\mathrm{P}$ if any data were collected as part of a campaign. The time of the measurement is stored in, fd_mag_time, along with an uncertainty, fd_mag_time_unc in UTC DATETIME. The total field strength is stored in, fd_mag_f, in nanoteslas and the total field strength uncertainty is stored in fd_mag_ferr, also in nanoteslas. The $\mathrm{x}, \mathrm{y}$, and $\mathrm{z}$ components are stored in fd_mag_x, fd_mag_y, and 
fd_mag_z, in nanoteslas as are the uncertainties in $\mathrm{x}, \mathrm{y}$, and $\mathrm{z}$ (fd_mag_xerr, fd_mag_yerr, and fd_mag_zerr).

If there is a high pass filter, the frequency above which signal is being used is stored in fd_mag_hpass. If there is a lowpass filter, the frequency below which signal is being used is stored in fd_mag_lpass. If a bandpass filter range is used, please enter the high value of the range in fd_mag_lpass and the low value of the range in fd_mag_hpass. Additional comments about the measurements should be stored in fd_mag_com.

Magnetic Vector

Table F2. Magnetic Vector Data Table

\begin{tabular}{|l|l|l|}
\hline fd_mgv_id & Magnetic vector ID & An identifier for linking with other tables. \\
\hline fs_id & Fields station ID & $\begin{array}{l}\text { The identifier for linking to the Fields } \\
\text { Station table. The Fields Station table } \\
\text { contains the station location, a conversion } \\
\text { from local time to UTC, and links to the } \\
\text { Fields Instrument and Common Network } \\
\text { tables. }\end{array}$ \\
\hline fi_id & Fields Instrument ID & $\begin{array}{l}\text { An identifier for linking with the Fields } \\
\text { Instrument table for non-permanent } \\
\text { (campaign) instruments. }\end{array}$ \\
\hline fd_mgv_time & Measurement time & $\begin{array}{l}\text { The measurement time in UTC stored as } \\
\text { DATETIME (YYYY-MM-DD hh:mm:ss). }\end{array}$ \\
\hline fd_mgv_time_unc & $\begin{array}{l}\text { Measurement time } \\
\text { uncertainty }\end{array}$ & $\begin{array}{l}\text { The uncertainty in the measurement time in } \\
\text { UTC stored as DATETIME (YYYY-MM- } \\
\text { DD hh:mm:ss). }\end{array}$ \\
\hline fd_mgv_dec & Declination & $\begin{array}{l}\text { The declination in degrees from 0 to 360 } \\
\text { (xxx). }\end{array}$ \\
\hline fd_mgv_incl & Inclination & $\begin{array}{l}\text { The inclination in degrees from 0 to 90 } \\
\text { (sxx). }\end{array}$ \\
\hline fd_mgv_com & Comments & Comments \\
\hline cc_id & Collector ID & $\begin{array}{l}\text { An identifier for linking to contact } \\
\text { information for the data collector. }\end{array}$ \\
\hline fd_mgv_loaddate & Load date & The date this row was entered in UTC. \\
\hline fd_mgv_pubdate & Publish date & $\begin{array}{l}\text { The date this row can become public. This } \\
\text { date can be set up to two years in advance. }\end{array}$ \\
\hline & & $\begin{array}{l}\text { An identifier for linking to contact } \\
\text { information for the person who entered this } \\
\text { row of data. }\end{array}$ \\
\hline cc_id_load & Data loader ID & \\
\hline & &
\end{tabular}

The Magnetic Vector Data table (fd_mgv for fields data - magnetic vector) contains magnetic vector data for which the data for the individual components is unavailable. The primary ID is fd_mgv_id and there are several foreign IDs for linking to other tables. The Fields Station table is linked 
by fs_id and provides the station location, a conversion from local time to UTC, and links to the Fields Instrument and Common Network tables. The Fields Instrument table is linked by fi_id and contains instrument information for data collected as part of a campaign. The collector ID, cc_id, links to contact information about the person or observatory that collected the data and the data loader ID, cc_id_load, links to the Contact table for more information about the person who loaded the data (ran the script or is in charge of running the script) into WOVOdat. The load date, fd_mgv_loaddate, is a TIMESTAMP and entered automatically in UTC. The date the data can become public is stored in fd_mgv_pubdate.

The time of the measurement is stored in, fd_mgv_time, along with an uncertainty, fd_mgv_time_unc, in UTC DATETIME. The declination of the vector in degrees from 0 to 360 is stored in fd_mgv_dec and the inclination of the vector in degrees from 0 to 90 is stored in fd_mgv_incl. Additional comments about the measurements can be stored in fd_mgv_com.

\section{Electric Fields}

Table F3. Electric Fields Data Table

\begin{tabular}{|c|c|c|}
\hline fd_ele_id & Electric data ID & An identifier for linking with other tables \\
\hline fs_id1 & Ref station 1 ID & $\begin{array}{l}\text { The identifier for linking to the electric } \\
\text { fields station information from which the } \\
\text { electrode is subtracted (station A in the } \\
\text { equation A - B). The Fields Station table } \\
\text { contains the station location, a conversion } \\
\text { from local time to UTC, and links to the } \\
\text { Fields Instrument and Common Network } \\
\text { tables. }\end{array}$ \\
\hline fs_id2 & Ref station 2 ID & $\begin{array}{l}\text { The identifier for linking to the electric } \\
\text { fields station information for the electrode } \\
\text { that's being subtracted (station B in the } \\
\text { equation A - B). The Fields Station table } \\
\text { contains the station location, a conversion } \\
\text { from local time to UTC, and links to the } \\
\text { Fields Instrument and Common Network } \\
\text { tables. }\end{array}$ \\
\hline fi_id & Fields Instrument ID & $\begin{array}{l}\text { An identifier for linking with the Fields } \\
\text { Instrument table for non-permanent } \\
\text { (campaign) instruments. }\end{array}$ \\
\hline fd_ele_continuous & Continuous flag & $\begin{array}{l}\text { A single character field used to identify } \\
\text { continuous data. Use C for data that were } \\
\text { collected continuously or P for data that } \\
\text { were collected periodically. }\end{array}$ \\
\hline fd_ele_time & Measurement time & $\begin{array}{l}\text { The measurement time in UTC stored as } \\
\text { DATETIME (YYYY-MM-DD hh:mm:ss). }\end{array}$ \\
\hline fd_ele_time_unc & $\begin{array}{l}\text { Measurement time } \\
\text { uncertainty }\end{array}$ & $\begin{array}{l}\text { The uncertainty in the measurement time in } \\
\text { UTC stored as DATETIME (YYYY-MM- } \\
\text { DD hh:mm:ss). }\end{array}$ \\
\hline fd_ele_field & Electric field & The electric field in $\mathrm{mV}$ \\
\hline
\end{tabular}




\begin{tabular}{|c|c|c|}
\hline & & (difference/distance) (sxxxx). \\
\hline fd_ele_ferr & Electric field uncertainty & Electric field uncertainty in $\mathrm{mV}(\mathrm{xxx})$. \\
\hline fd_ele_dir & Direction & $\begin{array}{l}\text { The direction from station } 1 \text { to station } 2 \text { in } \\
\text { degrees from } 0 \text { to } 360 \text { with respect to } \\
\text { geodetic north (xxx). }\end{array}$ \\
\hline fd_ele_hpass & High pass & $\begin{array}{l}\text { The high pass filter frequency value in } \mathrm{Hz} \\
\text { above which signals are used (passed) } \\
\text { (xx.x). }\end{array}$ \\
\hline fd_ele_lpass & Low pass & $\begin{array}{l}\text { The low pass filter frequency value in } \mathrm{Hz} \\
\text { below which signals are used (passed) } \\
\text { (xx.x). }\end{array}$ \\
\hline fd_ele_spot & Self Potential & $\begin{array}{l}\text { The self potential in } \mathrm{mV} \text { between station } 1 \\
\text { (A) and station } 2 \text { (B) (i.e., 1-2, or A-B) } \\
\text { ( } \text { (sxxxx). }\end{array}$ \\
\hline fd_ele_spot_err & Self potential uncertainty & The self potential uncertainty in $\mathrm{mV}(\mathrm{xxx})$. \\
\hline fd_ele_ares & Apparent Resistivity & The apparent resistivity in ohm-m (xxxx). \\
\hline fd_ele_ares_err & $\begin{array}{l}\text { Apparent Resistivity } \\
\text { uncertainty }\end{array}$ & $\begin{array}{l}\text { The uncertainty in apparent resistivity in } \\
\text { ohm-m (xxx). }\end{array}$ \\
\hline fd_ele_dres & Direct Resistivity & The direct resistivity in ohm-m (xxxx). \\
\hline fd_ele_dres_err & Direct Resistivity uncertainty & $\begin{array}{l}\text { The uncertainty in direct resistivity in ohm- } \\
m(x x x x) \text {. }\end{array}$ \\
\hline fd_ele_com & Comments & Any comments about the measurements. \\
\hline cc_id & Collector ID & $\begin{array}{l}\text { An identifier for linking to contact } \\
\text { information for the data collector. }\end{array}$ \\
\hline fd_ele_loaddate & Load date & The date this row was entered in UTC. \\
\hline fd_ele_pubdate & Publish date & $\begin{array}{l}\text { The date this row can become public. This } \\
\text { date can be set up to two years in advance. }\end{array}$ \\
\hline cc_id_load & Data loader ID & $\begin{array}{l}\text { An identifier for linking to contact } \\
\text { information for the person who entered this } \\
\text { row of data. }\end{array}$ \\
\hline
\end{tabular}

The Electric Fields Data table (fd_ele for fields data - electric) contains electric data in digital form. The primary ID is fd_ele_id and there are several foreign IDs for linking to other tables. There are two reference tables, fs_id1 and fs_id2. Both reference stations link to the Fields Station table, which contains the station location, a conversion from local time to UTC, and links to the Fields Instrument and Common Network tables. A link to the Fields Instrument table, fi_id, is included in this table for all campaign data. The collector ID, cc_id, links to contact information about the person or observatory that collected the data and the data loader ID, cc_id_load, links to the Contact table for more information about the person who loaded the data (ran the script or is in charge of running the script) into WOVOdat. The load date, fd_ele_loaddate,, is a TIMESTAMP and entered automatically in UTC. The date the data can become public is stored in fd_ele_pubdate.

Some observatories collect electric fields data continuously so a flag, fd_ele_continuous, is included to identify those data. The attribute fd_ele_continuous should store the letter $\mathrm{C}$ for continuous 
data only if all data recorded at the measurement time was recorded continuously and the letter $\mathrm{P}$ if any data were collected as part of a campaign. The time of the measurement is stored in, fd_ele_time, along with an uncertainty, fd_ele_time_unc, in UTC DATETIME. The electric field is stored in,fd_ele_field, in milliVolts and the electric field uncertainty is stored in fd_ele_ferr, also in milliVolts. If there is a high pass filter, the frequency above which signal is being used is stored in fd_ele_hpass. If there is a lowpass filter, the frequency below which signal is being used is stored in fd_ele_lpass. If a bandpass filter range is used, please enter the high value of the range in fd_ele_lpass and the low value of the range in fd_ele_hpass. The self potential is stored in fd_ele_spot in milliVolts and the self potential uncertainty, fd_ele_spot_err, is also stored in milliVolts. The direction from station 1 to station 2 is stored in fd_ele_dir, in degrees from 0 to 360 with respect to North. The apparent resistivity, fd_ele_ares, and direct resistivity, fd_ele_dres, are stored in ohm-m as are their uncertainities, fd_ele_ares_err and fd_dres_err. Additional comments about the measurements should be stored in fd_ele_com.

\section{Gravity}

Table F4. Gravity Data Table

\begin{tabular}{|c|c|c|}
\hline fd_gra_id & Gravity data ID & An identifier for linking with other tables \\
\hline fs_id & Fields station ID & $\begin{array}{l}\text { The identifier for linking to the Fields } \\
\text { Station table. The Fields Station table } \\
\text { contains the station location, a conversion } \\
\text { from local time to UTC, and links to the } \\
\text { Fields Instrument and Common Network } \\
\text { tables. }\end{array}$ \\
\hline fs_id_ref & Reference station ID & $\begin{array}{l}\text { A link to information about the reference } \\
\text { station in the Fields Station table. The } \\
\text { Fields Station table contains the station } \\
\text { location, a conversion from local time to } \\
\text { UTC, and links to the Fields Instrument and } \\
\text { Common Network tables. }\end{array}$ \\
\hline fi_id & Fields Instrument ID & $\begin{array}{l}\text { An identifier for linking with the Fields } \\
\text { Instrument table for non-permanent } \\
\text { (campaign) instruments. }\end{array}$ \\
\hline fd_gra_continuous & Continuous flag & $\begin{array}{l}\text { A single character field used to identify } \\
\text { continuous data. Use } \mathrm{C} \text { for data that were } \\
\text { collected continuously or P for data that } \\
\text { were collected periodically. }\end{array}$ \\
\hline fd_gra_time & Measurement time & $\begin{array}{l}\text { The measurement time in UTC stored as } \\
\text { DATETIME (YYYY-MM-DD hh:mm:ss). }\end{array}$ \\
\hline fd_gra_time_unc & $\begin{array}{l}\text { Measurement time } \\
\text { uncertainty }\end{array}$ & $\begin{array}{l}\text { The uncertainty in the measurement time in } \\
\text { UTC stored as DATETIME (YYYY-MM- } \\
\text { DD hh:mm:ss). }\end{array}$ \\
\hline fd_gra_fstr & Field strength & $\begin{array}{l}\text { The field strength in Gal corrected for tides } \\
\text { (xxxx.xxx). }\end{array}$ \\
\hline
\end{tabular}




\begin{tabular}{|l|l|l|}
\hline fd_gra_ferr & Field strength uncertainty & $\begin{array}{l}\text { The field strength uncertainty in Gal } \\
\text { (xxxx.x). }\end{array}$ \\
\hline fd_gra_vdisp & $\begin{array}{l}\text { A field for comments on associated vertical } \\
\text { displacement. Use the letters Y for yes, U } \\
\text { for unknown and N for none in front of the } \\
\text { comments. }\end{array}$ \\
\hline Assoc vertical displacement & $\begin{array}{l}\text { A field for comments on associated change } \\
\text { in groundwater level. Use the letters Y for } \\
\text { yes, U for unknown and N for none in front } \\
\text { of the comments. }\end{array}$ \\
\hline fd_gra_com & Assoc gwater level & Comments about the measurements. \\
\hline cc_id & Collector ID & $\begin{array}{l}\text { An identifier for linking to contact } \\
\text { information for the data collector. }\end{array}$ \\
\hline fd_gra_loaddate & Load date & The date this row was entered in UTC. \\
\hline fd_gra_pubdate & Publish date & $\begin{array}{l}\text { The date this row can become public. This } \\
\text { date can be set up to two years in advance. }\end{array}$ \\
\hline de & & $\begin{array}{l}\text { An identifier for linking to contact } \\
\text { information for the person who entered this } \\
\text { row of data. }\end{array}$ \\
\hline cc_id_load & Data loader ID &
\end{tabular}

The Gravity Data table (fd_gra for fields data - gravity) contains gravity data such as field strength and associated vertical displacement. The primary ID is fd_gra_id and there are several foreign IDs for linking to other tables. The Fields Station table is linked by fs_id and provides the station location, a conversion from local time to UTC, and links to the Fields Instrument and Common Network tables. The reference station ID is stored in fs_id_ref and contains the same station information. A link to the Fields Instrument table, fi_id, is included for all campaign data. The collector ID, cc_id, links to contact information about the person or observatory that collected the data and the data loader ID, cc_id_load, links to the Contact table for more information about the person who loaded the data (ran the script or is in charge of running the script) into WOVOdat. The load date, fd_gra_loaddate, is a TIMESTAMP and entered automatically in UTC. The date the data can become public is stored in fd_gra_pubdate.

Some observatories collect gravity data continuously so a flag, fd_gra_continuous, is included to identify those data. The attribute fd_gra_continuous should store the letter $\mathrm{C}$ for continuous data only if all data recorded at the measurement time was recorded continuously and the letter $\mathrm{P}$ if any data were recorded as part of a campaign. The time of the measurement is stored in, fd_gra_time, along with an uncertainty, fd_gra_time_unc, in UTC DATETIME. The field strength is stored in, fd_gra_fstr, in Gal and the field strength uncertainty is stored in fd_gra_ferr, also in Gals. Three text fields are included for comments. The field for comments on associated vertical displacement, if applicable, is gd_gra_vdisp and the field for comments on associated groundwater level, if applicable, is gd_gra_gwater. Use the letters $\mathrm{Y}$ for yes, $\mathrm{U}$ for unknown and $\mathrm{N}$ for none. In addition, a general comments field, fd_gra_com, is included for any additional comments on the measurement. 


\section{Fields Station}

Table F5. Fields Station Table

\begin{tabular}{|c|c|c|}
\hline fs_id & Fields station table ID & An identifier for linking with other tables. \\
\hline cn_id & Network ID & $\begin{array}{l}\text { An identifier for linking with information } \\
\text { about the network in the Common Network } \\
\text { table. The Common Network table gives a } \\
\text { description of the network and a link to the } \\
\text { volcano. }\end{array}$ \\
\hline fs_code & Station Code & The station code given by the observatory. \\
\hline fs_nam & Station Name & $\begin{array}{l}\text { The name of the benchmark or station given } \\
\text { by the observatory. }\end{array}$ \\
\hline fs_lat & Latitude & $\begin{array}{l}\text { The latitude of the station in decimal } \\
\text { degrees (sxx.xxxxxxx). }\end{array}$ \\
\hline fs_lon & Longitude & $\begin{array}{l}\text { The longitude of the station in decimal } \\
\text { degrees (sxxx.xxxxxxx). }\end{array}$ \\
\hline fs_elev & Elevation & $\begin{array}{l}\text { The elevation of the land surface in meters } \\
\text { (sxxxx). }\end{array}$ \\
\hline fs_datum & Datum & $\begin{array}{l}\text { The datum used for the longitude and } \\
\text { latitude. Please also include the original } \\
\text { datum in parentheses. }\end{array}$ \\
\hline fs_inst & Instrument List & $\begin{array}{l}\text { A list of permanent instruments, if } \\
\text { applicable, installed at this site. The } \\
\text { Common Instrument table links to the } \\
\text { Fields Station table for permanent } \\
\text { instruments and provides details about the } \\
\text { permanent and campaign instruments. }\end{array}$ \\
\hline fs_freq & Frequency of measurement & $\begin{array}{l}\text { The frequency of measurements. For } \\
\text { continuous measurements Use a C followed } \\
\text { by a time frame such as every } 10 \text { min. For } \\
\text { periodic measurements Use a P followed by } \\
\text { a time frame such as yearly, every } 5 \text { years, } \\
\text { or whenever possible. Please include both if } \\
\text { this station is used for both continuous and } \\
\text { campaign measurements. }\end{array}$ \\
\hline fs_utc & Difference from UTC & $\begin{array}{l}\text { The time zone relative to UTC. Please enter } \\
\text { the number of hours from GMT, using a } \\
\text { negative sign (-) for hours before GMT and } \\
\text { no sign for positive numbers (sxx.x). }\end{array}$ \\
\hline fs_stime & Start date & $\begin{array}{l}\text { The date (UTC) the station was set up and } \\
\text { activated or the time new information in this } \\
\text { table became valid. The date is stored in } \\
\text { DATETIME (YYYY-MM-DD hh:mm:ss). }\end{array}$ \\
\hline
\end{tabular}




\begin{tabular}{|c|c|c|}
\hline fs_stime_unc & Start date uncertainty & $\begin{array}{l}\text { The uncertainty in the date (UTC) the } \\
\text { station was set up and activated or the time } \\
\text { new information in this table became valid. } \\
\text { The date is stored in DATETIME (YYYY- } \\
\text { MM-DD hh:mm:ss). }\end{array}$ \\
\hline fs_etime & Stop date & $\begin{array}{l}\text { The date (UTC) the station was permanently } \\
\text { decommissioned or the time the information } \\
\text { in this table became invalid. The date is } \\
\text { stored in DATETIME (YYYY-MM-DD } \\
\text { hh:mm:ss). See observatory for station } \\
\text { operation history. }\end{array}$ \\
\hline fs_etime_unc & End date uncertainty & $\begin{array}{l}\text { The uncertainty in the date the station was } \\
\text { decommissioned or the time this set of } \\
\text { information is no longer valid in UTC } \\
\text { stored as DATETIME (YYYY-MM-DD } \\
\text { hh:mm:ss). }\end{array}$ \\
\hline fs_desc & Station description & $\begin{array}{l}\text { A description of the station or any } \\
\text { comments }\end{array}$ \\
\hline cc_id & Contact ID & $\begin{array}{l}\text { An identifier for linking to contact } \\
\text { information for the person or observatory in } \\
\text { charge of this station. }\end{array}$ \\
\hline fs_loaddate & Load date & The date this row was entered in UTC. \\
\hline fs_pubdate & Publish date & $\begin{array}{l}\text { The date this row can become public. This } \\
\text { date can be set up to two years in advance. }\end{array}$ \\
\hline cc_id_load & Data loader ID & $\begin{array}{l}\text { An identifier for linking to contact } \\
\text { information for the person who entered this } \\
\text { row of data. }\end{array}$ \\
\hline
\end{tabular}

The Fields Station table (fs_for fields station) stores information such as a location, conversion from local time to UTC, and a description of the stations where fields data are collected. The primary ID for the Fields Station table is fs_id. The Fields Station table links to the Common Network table by the network ID, cn_id. It is through the network table that the data can be linked to the volcano. A fields network is defined as a set of stations that collect fields data either on a single volcano or over a series of nearby volcanoes. The contact ID (cc_id) links to contact information about the person or observatory that manages the station and the data loader ID, cc_id_load, links to the Contact table for more information about the person who loaded the data into WOVOdat. The load date, fs_loaddate, is a TIMESTAMP and entered automatically in UTC. The date the data can become public is stored in fs_pubdate.

The Fields Station table stores the station location including the latitude and longitude in decimal degrees, fs_lat and fs_lon, the elevation in meters, fs_elev, and the datum, fs_datum. All data should be converted to WGS 84 prior to entering WOVOdat. If conversion is not possible during data loading, the original datum must be entered into the datum field, fs_datum.

The name and code for the station, given by the observatory, are stored in fs_name and fs_code. A list of instruments permanently installed at the station should be stored in the text field, fs_perm. 
Additional information about these instruments can be found in the Fields Instrument table by searching on the fields station ID (the instrument is linked to the station because there can be multiple instruments at a station). The frequency of measurement, fs_freq, is a text field that should contain an abbreviation for continuous, $\mathrm{C}$, or periodic, $\mathrm{P}$, in addition to the exact or approximate measurement frequency (or reporting rate), e.g., "every $10 \mathrm{~min}$, or $1 \mathrm{x} /$ year." The frequency time frame will be exact for the continuous data and approximate for the periodic data. The instrument link for periodic data is stored within the fields data tables. The difference from local time to UTC is stored in fs_utc. This information allows for the conversion back to UTC whenever needed as discussed in the Time Section.

The Fields Station table also includes start and end dates, fs_stime and fs_etime, along with uncertainties, fs_stime_unc and fs_etime_unc, in DATETIME UTC. These dates provide information on when the station information in the table is valid. The instrument table also contains a date range and new station instruments should be recorded in the instrument table instead of the station table unless the location of the new instrument changes the location of the station. The description of the station, fs_desc, should include any additional information about the station such as the site environment and why the site was chosen for the type of measurement.

Fields Instrument

Table F6. Fields Instrument Table

\begin{tabular}{|c|c|c|}
\hline fi_id & Fields Instrument ID & An identifier for linking with other tables. \\
\hline fs_id & Fields Station ID & $\begin{array}{l}\text { A link to the Fields Station table for the } \\
\text { permanent installations. The Fields Station } \\
\text { table contains the station location, a } \\
\text { conversion from local time to UTC, and } \\
\text { links to the Fields Instrument and Common } \\
\text { Network tables. This link requires the } \\
\text { station type as well. }\end{array}$ \\
\hline fi_perm & Permanent & $\begin{array}{l}\text { A single character field to let the user know } \\
\text { if the instrument is part of a permanent } \\
\text { installation (use P for permanent) or part of } \\
\text { a campaign (use C for campaign). }\end{array}$ \\
\hline fi_st_type & Station Type & $\begin{array}{l}\text { The type of station at which the instrument } \\
\text { is permanently installed. This field and the } \\
\text { Station ID field will be used for linking with } \\
\text { the station information. }\end{array}$ \\
\hline fi_name & Name & $\begin{array}{l}\text { The name, model, and manufacturer of the } \\
\text { instrument or instrument package, for } \\
\text { example magnetometers may consist of one } \\
\text { instrument for gathering vectorial data and } \\
\text { another for total intensity of the field. }\end{array}$ \\
\hline fi_type & Type & $\begin{array}{l}\text { The type of instrument(s) and the units each } \\
\text { instrument measures. }\end{array}$ \\
\hline fi_res & Resolution & $\begin{array}{l}\text { The resolution of each individual instrument } \\
\text { in the instrument package. Please give the } \\
\text { instrument name and then the resolution. }\end{array}$ \\
\hline
\end{tabular}




\begin{tabular}{|c|c|c|}
\hline fi_rate & Sampling Rate & The sampling rate for the instrument(s). \\
\hline fi_filter & Filter type & The filter type, if applicable. \\
\hline fi_orient & Orientation & $\begin{array}{l}\text { The orientation of the instrument, if } \\
\text { applicable (for permanent stations only). }\end{array}$ \\
\hline fi_calc & Calculation & $\begin{array}{l}\text { Any processing used to convert and clean or } \\
\text { correct the raw data collected by this } \\
\text { instrument to the data stored in the fields } \\
\text { data tables. Please note corrections made for } \\
\text { atmospheric conditions, ground } \\
\text { deformation, noise, thermal stability, and/or } \\
\text { long term instability of the instrument(s). }\end{array}$ \\
\hline fi_stime & Start date & $\begin{array}{l}\text { The date (UTC) the instrument was set up } \\
\text { and activated or the time new information in } \\
\text { this table became valid. The date is stored in } \\
\text { DATETIME (YYYY-MM-DD hh:mm:ss). }\end{array}$ \\
\hline fi_stime_unc & Start date uncertainty & $\begin{array}{l}\text { The uncertainty in the date (UTC) the } \\
\text { instrument was set up and activated or the } \\
\text { time new information in this table became } \\
\text { valid. The date is stored in DATETIME } \\
\text { (YYYY-MM-DD hh:mm:ss). }\end{array}$ \\
\hline fi_etime & End date & $\begin{array}{l}\text { The date (UTC) the instrument was } \\
\text { permanently decommissioned or the time } \\
\text { the information in this table became invalid. } \\
\text { The date is stored in DATETIME (YYYY- } \\
\text { MM-DD hh:mm:ss). See observatory for } \\
\text { station operation history. }\end{array}$ \\
\hline fi_etime_unc & End date uncertainty & $\begin{array}{l}\text { The uncertainty in the date the instrument } \\
\text { was decommissioned or the time this set of } \\
\text { information is no longer valid in UTC } \\
\text { stored as DATETIME (YYYY-MM-DD } \\
\text { hh:mm:ss). }\end{array}$ \\
\hline fi_com & Comments & Comments on the instrument(s). \\
\hline cc_id & Contact ID & $\begin{array}{l}\text { An identifier for linking with the person or } \\
\text { group of people who use this instrument. }\end{array}$ \\
\hline fi_loaddate & Load date & The date this row was entered in UTC. \\
\hline fi_pubdate & Publish date & $\begin{array}{l}\text { The date this row can become public. This } \\
\text { date can be set up to two years in advance. }\end{array}$ \\
\hline cc_id_load & Data loader ID & $\begin{array}{l}\text { An identifier for linking to contact } \\
\text { information for the person who entered this } \\
\text { row of data. }\end{array}$ \\
\hline fi_id & Fields Instrument ID & An identifier for linking with other tables. \\
\hline
\end{tabular}


The Fields Instrument table (fi_for fields instruments) stores information about the instruments used to collect magnetic, electric, and gravity data along with a flag, fi_perm, to indicate if the instrument is installed permanently or is used periodically as part of a campaign. The permanently installed instruments are linked to the stations at which they are installed by the station ID, fs_id, and the instrument type, fi_type, which gives information on the type of potential field monitoring for which the instrument is used. Having two fields allows for searches of all instruments at a station and also for instruments of a certain type. The periodic instrument data are linked to the Fields Instrument table using the instrument table's primary ID, fi_id, which has been placed in the data tables. In some cases several instruments will be used together to collect the data, such as with measuring magnetic data where one instrument will be used for gathering vectorial data $(\mathrm{H}, \mathrm{D}, \mathrm{Z})$ and another for total intensity of the field $(\mathrm{F})$.

The Fields Instrument table also includes a contact ID, cc_id, which links to contact information about the person or observatory that manages the station and a data loader ID, cc_id_load, which links to information about the person who loaded the data into WOVOdat. The load date, fi_loaddate, is a TIMESTAMP and entered automatically in UTC. The date the data can become public is stored in fi_pubdate.

Basic instrument information such as the name, model, and manufacturer should be stored in the text field fi_name whereas the instrument type should be stored in fi_type. The units the instrument(s) measures and the resolution or measuring precision in those units should be stored in the text fields fi_units and fi_res. The sampling rate is stored in fi_srate and the filter type is stored in fi_filter. The orientation of the instrument, for electric measurements in particular, is stored in fi_orient. Any standard calculations used to convert, clean and correct the raw data into WOVOdat data should be stored in fi_calc along with a list of potential artifacts and instabilities of the instrument. The Fields Instrument table also includes start and end dates, fi_stime and fi_etime, along with uncertainties, fi_stime_unc and fi_etime_unc, in DATETIME UTC. These dates provide information on when the instrument information in the table is valid. The data are considered invalid if the resolution changes or if an installed instrument is removed from a station. A description attribute, fi_desc, is included for more information about the type of instrument and its uses. The comments attribute, fi_com, is included for any information on how this instrument might be used in a non-standard way, for example, changes in precision.

\section{Create Table Statements for potential fields tables}

DROP TABLE IF EXISTS fd_mag;

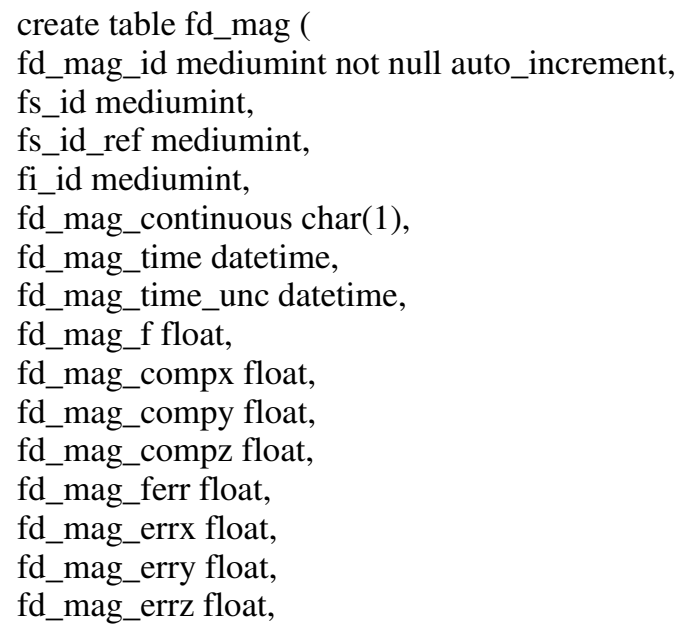


fd_mag_highpass float,

fd_mag_lowpass float,

fd_mag_com varchar(255),

cc_id mediumint,

fd_mag_loaddate datetime,

fd_mag_pubdate datetime,

cc_id_load mediumint,

primary key (fd_mag_id));

DROP TABLE IF EXISTS fd_mgv;

create table fd_mgv (

fd_mgv_id mediumint not null auto_increment,

fs_id mediumint,

fi_id mediumint,

fd_mgv_time datetime,

fd_mgv_time_unc datetime,

fd_mgv_dec float,

fd_mgv_incl float,

fd_mgv_com varchar(255),

cc_id mediumint,

fd_mgv_loaddate datetime,

fd_mgv_pubdate datetime,

cc_id_load mediumint,

primary key (fd_mgv_id));

DROP TABLE IF EXISTS fd_ele;

create table fd_ele (

fd_ele_id mediumint not null auto_increment,

fs_id1 mediumint,

fs_id2 mediumint,

fi_id mediumint,

fd_ele_continuous char(1),

fd_ele_time datetime,

fd_ele_time_unc datetime,

fd_ele_field float,

fd_ele_ferr float,

fd_ele_dir float,

fd_ele_hpass float,

fd_ele_lpass float,

fd_ele_spot float,

fd_ele_spot_err float,

fd_ele_ares float,

fd_ele_ares_err float,

fd_ele_dres float,

fd_ele_dres_err float,

fd_ele_com varchar(255),

cc_id mediumint,

fd_ele_loaddate datetime,

fd_ele_pubdate datetime,

cc_id_load mediumint,

primary key (fd_ele_id));

DROP TABLE IF EXISTS fd_gra;

create table fd_gra (

fd_gra_id mediumint not null auto_increment, 
fs_id mediumint,

fs_id_ref mediumint,

fi_id mediumint,

fd_gra_continuous char(1),

fd_gra_time datetime,

fd_gra_time_unc datetime,

fd_gra_fstr float,

fd_gra_ferr float,

fd_gra_vdisp varchar(255),

fd_gra_gwater varchar(255),

fd_gra_com varchar(255),

cc_id mediumint,

fd_gra_loaddate datetime,

fd_gra_pubdate datetime,

cc_id_load mediumint,

primary key (fd_gra_id));

DROP TABLE IF EXISTS fs;

create table fs (

fs_id mediumint not null auto_increment, cn_id mediumint,

fs_code varchar(50),

fs_nam varchar(50),

fs_lat float,

fs_lon float,

fs_elev float,

fs_datum varchar(30),

fs_inst varchar(255),

fs_freq varchar(255),

fs_utc float,

fs_stime datetime,

fs_stime_unc datetime,

fs_etime datetime,

fs_etime_unc datetime,

fs_desc varchar(255),

cc_id mediumint,

fs_loaddate datetime,

fs_pubdate datetime,

cc_id_load mediumint,

primary key (fs_id));

\section{DROP TABLE IF EXISTS fi;}

create table fi (

fi_id mediumint not null auto_increment,

fs_id mediumint,

fi_perm char(1),

fi_st_type varchar(255),

fi_name varchar(255),

fi_type $\operatorname{varchar}(255)$,

fi_res $\operatorname{varchar}(255)$,

fi_units varchar(255),

fi_rate $\operatorname{varchar}(255)$,

fi_filter varchar(255),

fi_orient varchar(255),

fi_calc varchar(255),

fi_stime datetime, 
fi_stime_unc datetime,

fi_etime datetime,

fi_etime_unc datetime,

fi_com varchar(255),

cc_id mediumint,

fi_loaddate datetime,

fi_pubdate datetime,

cc_id_load mediumint,

primary key (fi_id));

\section{Thermal}

The thermal tables contain ground-based data collected at the thermal site or image data collected remotely. Thermal image data are often the only method for examining remote volcanoes where seismic and other monitoring instruments are not available. These data can be collected continuously or periodically. Temperature measurements of fumaroles, springs, and crater lakes that are made primarily for the purpose of tracking temperature change are included in this section, even though there will be slight overlap with data in the Gas and Hydrologic unrest tables. The main challenge of organizing the thermal data is that the image data can be collected from an instrument mounted to a moving object, like a satellite or aiplane, or it can be collected from an instrument mounted to a stationary object, like a caldera rim or observatory roof. Sites that contain stationary instruments should be included in the Thermal Station table along with comments about the instrument recording image data. Instruments mounted on a moving object are linked through the Thermal Image table. There are five thermal tables:

- The Ground-based Thermal Data table, td, contains non-image thermal data collected on the ground. These data can be collected continuously or periodically. The Ground-based Thermal Data table is linked to the Thermal Station table, ts.

- The Thermal Image table, td_img, contains information about images created from remote instruments that are either moving or fixed. Information about each pixel in the thermal image is stored in the Thermal Image Data table, td_pix.

- The Thermal Image Data table links to the Thermal Image table.

- The Thermal Station table contains information about the location of the ground-based stations and is linked to the Common Network table, which contains information about the monitoring network and a link to the Volcano table.

- The Thermal Instrument table contains information about imaging and non-imaging instruments. Periodic instruments are linked to the Thermal Instrument table through the thermal data tables.

Ground-Based Thermal

Table T1. Ground-Based Thermal Data Table

\begin{tabular}{|l|l|l|}
\hline td_id & Ground-based thermal ID & An identifier for linking with other tables. \\
\hline & & $\begin{array}{l}\text { An identifier for linking with the Thermal } \\
\text { Station table. The Thermal Station table } \\
\text { includes the station location, the type of } \\
\text { thermal feature, and links to the Thermal } \\
\text { ts_id }\end{array}$ \\
\cline { 2 - 2 } & Thermal Station ID &
\end{tabular}




\begin{tabular}{|c|c|c|}
\hline ti_id & Instrument ID & $\begin{array}{l}\text { An identifier for linking with the Instrument } \\
\text { table. The Instrument table provides } \\
\text { information about the instrument model, its } \\
\text { resolution, and the units it measures. }\end{array}$ \\
\hline td_mtype & Type of measurement & $\begin{array}{l}\text { The type of measurement, for example, } \\
\text { thermocouple or thermal IR. }\end{array}$ \\
\hline td_continuous & Continuous flag & $\begin{array}{l}\text { A single character field used to identify } \\
\text { continuous data. Use } \mathrm{C} \text { for data that were } \\
\text { collected continuously or P for data that } \\
\text { were collected periodically. If the data were } \\
\text { from a periodic collection, please include } \\
\text { the collector ID in cc_id. }\end{array}$ \\
\hline td_time & Time of measurement & $\begin{array}{l}\text { The measurement time (UTC) stored as } \\
\text { DATETIME (YYYY-MM-DD hh:mm:s). }\end{array}$ \\
\hline td_time_unc & $\begin{array}{l}\text { Time of measurement } \\
\text { uncertainty }\end{array}$ & $\begin{array}{l}\text { The uncertainty in the measurement time } \\
\text { (UTC) stored as DATETIME (YYYY-MM- } \\
\text { DD hh:mm:s). }\end{array}$ \\
\hline td_depth & Depth of measurement & $\begin{array}{l}\text { The depth of the measurement in meters } \\
\text { below the ground surface. Depths are used } \\
\text { to derive geothermal gradients and/or heat } \\
\text { flux. }\end{array}$ \\
\hline td_temp & Temperature & $\begin{array}{l}\text { The measured temperature in degrees } \\
\text { Celsius. }\end{array}$ \\
\hline td_terr & Standard error & $\begin{array}{l}\text { The standard error or precision of the } \\
\text { temperature in degrees Celsius. }\end{array}$ \\
\hline td_dtemp & Delta T & $\begin{array}{l}\text { The change in temperature from a previous } \\
\text { measurement. Use this field only when the } \\
\text { actual temperatures are not available. The } \\
\text { previous measurement time must be } \\
\text { supplied in td_ptime. }\end{array}$ \\
\hline td_ptime & Previous measurement time & $\begin{array}{l}\text { The time of the previous measurement } \\
\text { (UTC) stored as DATETIME (YYYY-MM- } \\
\text { DD hh:mm:s). Use this field only when a } \\
\text { delta temperature has been reported. }\end{array}$ \\
\hline td_ptime_unc & $\begin{array}{l}\text { Previous measurement time } \\
\text { uncertainty }\end{array}$ & $\begin{array}{l}\text { The uncertainty in the previouw } \\
\text { measurement time (UTC) stored as } \\
\text { DATETIME (YYYY-MM-DD hh:mm:s). }\end{array}$ \\
\hline td_aarea & Approximate area & $\begin{array}{l}\text { The approximate area of of the body } \\
\text { measured in meters squared. }\end{array}$ \\
\hline td_flux & Heat Flux & The heat flux in W/m2. \\
\hline td_ferr & Standard error & $\begin{array}{l}\text { The standard error or precision of flux in } \\
\mathrm{W} / \mathrm{m} 2 \text {. }\end{array}$ \\
\hline td_bkgg & $\begin{array}{l}\text { Background geothermal } \\
\text { gradient }\end{array}$ & $\begin{array}{l}\text { The regional background geothermal } \\
\text { gradient in } \mathrm{deg} \text { Celsius } / \mathrm{km} \text {. }\end{array}$ \\
\hline
\end{tabular}




\begin{tabular}{|c|c|c|}
\hline td_tcond & Thermal conductivity & $\begin{array}{l}\text { The thermal conductivity at the station or } \\
\text { measurement point, in } \mathrm{W} /(\mathrm{m} 2 \mathrm{degC}) \text {. This } \\
\text { value is either inferred from the soil type or } \\
\text { measured intrinsically, and used to derive } \\
\text { heat flux with the help of Fick's law. }\end{array}$ \\
\hline td_com & Comments & $\begin{array}{l}\text { Additional comments on the heat flux and } \\
\text { thermal conductivity including if they } \\
\text { inferred or measured. }\end{array}$ \\
\hline cc_id & Collector ID & $\begin{array}{l}\text { An identifier for linking to contact } \\
\text { information for the data collector. To be } \\
\text { entered only if data are not continuous. }\end{array}$ \\
\hline td_loaddate & Load date & The date this row was entered in UTC. \\
\hline td_pubdate & Publish date & $\begin{array}{l}\text { The date this row can become public. This } \\
\text { date can be set up to two years in advance. }\end{array}$ \\
\hline cc_id_load & Data loader ID & $\begin{array}{l}\text { An identifier for linking to contact } \\
\text { information for the person who entered this } \\
\text { row of data. }\end{array}$ \\
\hline
\end{tabular}

The Ground-based Thermal Data table (td for thermal data) stores all of the thermal data collected on the ground. The primary ID is td_id. The thermal station ID, ts_id, links to station information including the type of thermal feature, the soil or ground type, and its location; the thermal instrument ID, ti_id, links to information about the instrument including its model, resolution, and the units it measures for periodic measurements. The collector ID (cc_id) links to contact information about the person or observatory that collected the data, if it was collected periodically. Contact information for data that are collected continuously can be found in the Thermal Station table along with a link to the instrument information. The data loader ID, cc_id_load, also links to Contact table and provides contact information about the person who loaded the data into WOVOdat. The load date, td_loaddate, is a TIMESTAMP and entered automatically in UTC; the publish date, td_pubdate, is the date the data will become accessible by the public.

The type of measurement is stored in the text field td_mtype. Thermal data can be collected either continuously or periodically. A flag, td_continuous, is used to identify the continuous data. The attribute td_continuous should store the letter P for data collected periodically and C for data collected continuously. If the data are collected periodically, please also include the collector ID in cc_id and the instrument ID in ti_id. The time of the measurement is stored in, td_time, in UTC DATETIME, along with an uncertainty in the time, td_time_unc, and the depth of the measurement, td_depth, is stored in meters. The measurement temperature is stored in degrees Celsius in td_temp and the standard error or precision in the temperature measurement is stored in td_terr, also in degrees Celsius. If the data are only available as a change in temperature from a previous measurement (delta $\mathrm{T}$ ), then the change in temperature is stored in degrees Celsius in td_dtemp and the previous measurement time is stored in UTC DATETIME in td_ptime along with an uncertainty in the time, td_ptime_unc. The approximate area of the body measured is stored in td_aarea in meters squared. The measured or derived heat flux is stored in td_flux in $\mathrm{W} / \mathrm{m}^{2}$ and the standard error on the flux is stored in td_ferr, also as $\mathrm{W} / \mathrm{m}^{2}$. Whether the flux was measured or derived should be stored in the comments field, td_com (see below). The regional background geothermal gradient is stored in td_bkgg as degrees Celsius per kilometer and the thermal conductivity is stored in td_tcond as $\mathrm{W} /\left(\mathrm{m}^{2}\right.$ degrees Celsius $)$. 
Comments on the measurement including if the heat flux and thermal conductivity were inferred or measured should be stored in td_com. If sampling occurred at a new site, for which station information has yet to be entered, for example a new hot spot or fumarole, please include the location and any additional information about the site that would help explain why data were collected in the comments field.

Thermal Image

Table T2. Thermal Image Table

\begin{tabular}{|c|c|c|}
\hline td_img_id & Thermal image ID & An identifier for linking with other tables. \\
\hline vd_id & Volcano ID & $\begin{array}{l}\text { The identifier for linking to the Volcano } \\
\text { table for data that is collected by an } \\
\text { instrument mounted on a moving object. } \\
\text { The Volcano table stores the volcano name } \\
\text { and time zone. It is used to connect to all } \\
\text { other data. }\end{array}$ \\
\hline cs_id & Satellite ID & $\begin{array}{l}\text { An identifier for linking with the Satellite } \\
\text { table which gives the name of the satellite } \\
\text { and a description. }\end{array}$ \\
\hline ts_id & Thermal Station ID & $\begin{array}{l}\text { An identifier for linking with the Thermal } \\
\text { Station table. The Thermal Station table } \\
\text { includes the station location, the type of } \\
\text { thermal feature, and links to the Thermal } \\
\text { Network and Instrument tables. }\end{array}$ \\
\hline ti_id & Instrument ID & $\begin{array}{l}\text { An identifier for linking with the Thermal } \\
\text { Instrument table. The Thermal Instrument } \\
\text { table provides information about the } \\
\text { instrument model, its resolution, and the } \\
\text { units it measures. }\end{array}$ \\
\hline td_img_iplat & Instrument platform & $\begin{array}{l}\text { A description of the instrument platform, for } \\
\text { example on an airplane or satellite, or on a } \\
\text { crater rim or roof of a hut. }\end{array}$ \\
\hline td_img_ialt & Instrument altitude & $\begin{array}{l}\text { The altitude of the instrument during } \\
\text { recording of image in meters above sea } \\
\text { level. Please enter the location information } \\
\text { for instruments on moving objects only. } \\
\text { Stationary instrument locations are provided } \\
\text { in the Thermal Station table. }\end{array}$ \\
\hline td_img_ilat & Instrument latitude & $\begin{array}{l}\text { The latitude of the instrument during } \\
\text { recording of image in decimal degrees. } \\
\text { Please enter the location information for } \\
\text { instruments on moving objects only. } \\
\text { Stationary instrument locations are provided } \\
\text { in the Thermal Station table. }\end{array}$ \\
\hline
\end{tabular}




\begin{tabular}{|c|c|c|}
\hline td_img_ilon & Instrument longitude & $\begin{array}{l}\text { The longitude of the instrument during } \\
\text { recording of image in decimal degrees. } \\
\text { Please enter the location information for } \\
\text { instruments on moving objects only. } \\
\text { Stationary instrument locations are provided } \\
\text { in the Thermal Station table. }\end{array}$ \\
\hline td_img_idatum & Datum & $\begin{array}{l}\text { The datum used for the latitude and } \\
\text { longitude. Please enter the datum } \\
\text { information for instruments on moving } \\
\text { objects only. Stationary instrument locations } \\
\text { are provided in the Thermal Station table. }\end{array}$ \\
\hline td_img_desc & Description of image & $\begin{array}{l}\text { A description of the thermal image, for } \\
\text { example a hot spot at summit that has } \\
\text { increased in temperature over the past week. }\end{array}$ \\
\hline td_img_time & Time of image & $\begin{array}{l}\text { The time the image was taken in UTC } \\
\text { stored as DATETIME (YYYY-MM-DD } \\
\text { hh:mm:ss). }\end{array}$ \\
\hline td_img_time_unc & Time of image uncertainty & $\begin{array}{l}\text { The uncertainty in the time the image was } \\
\text { taken in UTC stored as DATETIME } \\
\text { (YYYY-MM-DD hh:mm:ss). }\end{array}$ \\
\hline td_img_bname & Band name & $\begin{array}{l}\text { The band name where each band is } \\
\text { separated by a comma. }\end{array}$ \\
\hline td_img_hbwave & High band wavelength & $\begin{array}{l}\text { The high value of the band wavelength } \\
\text { range in microns. }\end{array}$ \\
\hline td_img_lbwave & Low band wavelength & $\begin{array}{l}\text { The low value of the band wavelength range } \\
\text { in microns. }\end{array}$ \\
\hline td_img_jpg & Image & The image stored as a jpg. \\
\hline td_img_psize & Pixel size & The pixel size in meters. \\
\hline td_img_maxrad & Maximum radiance & $\begin{array}{l}\text { The maximum radiance of any pixel in the } \\
\text { frame in } \mathrm{W} /\left(\mathrm{m}^{2}-\mathrm{m}\right) \times 10^{7} \text {. }\end{array}$ \\
\hline td_img_maxrrad & Maximum relative radiance & $\begin{array}{l}\text { The maximum relative radiance of any pixel } \\
\text { in the frame in } \mathrm{W} /\left(\mathrm{m}^{2}-\mathrm{m} \times \mathrm{sr}\right) \times 10^{7} \text { where } \\
\text { sr is spectral radiance, which is wavelength } \\
\text { dependent. }\end{array}$ \\
\hline td_img_maxtemp & T of hottest pixel & $\begin{array}{l}\text { The temperature of the hottest pixel (if } \\
\text { calibrated) in degrees Celsius. }\end{array}$ \\
\hline td_img_maxflux & Maximum Heat flux & The heat flux of the hottest pixel in $\mathrm{W} / \mathrm{m}^{2}$. \\
\hline td_img_ntres & Nominal T resolution & $\begin{array}{l}\text { The nominal temperature resolution (per } \\
\text { pixel) in degrees Celsius. }\end{array}$ \\
\hline td_img_atmcorr & Atmospheric correction & $\begin{array}{l}\text { The type of atmospheric correction } \\
\text { procedure / method applied. }\end{array}$ \\
\hline td_img_thmcorr & Thermal correction & $\begin{array}{l}\text { The type of thermal correction procedure / } \\
\text { method applied using ground truth points. }\end{array}$ \\
\hline
\end{tabular}




\begin{tabular}{|l|l|l|}
\hline td_img_ortho & Orthorectification procedure & $\begin{array}{l}\text { The type of orthorectification procedure } \\
\text { used, for example ESRI tool, rubber } \\
\text { sheeting, etc. }\end{array}$ \\
\hline td_img_com & Comments & $\begin{array}{l}\text { Additional cmments on the measurement, } \\
\text { instrument, etc. }\end{array}$ \\
\hline cc_id & Collector ID & $\begin{array}{l}\text { An identifier for linking to contact } \\
\text { information for the data collector. }\end{array}$ \\
\hline td_img_loaddate & Load date & The date this row was entered in UTC. \\
\hline td_img_pubdate & Publish date & $\begin{array}{l}\text { The date this row can become public. This } \\
\text { date can be set up to two years in advance. }\end{array}$ \\
\hline cc_id_load & Data loader ID & $\begin{array}{l}\text { An identifier for linking to contact } \\
\text { information for the person who entered this } \\
\text { row of data. }\end{array}$ \\
\hline
\end{tabular}

The Thermal Image table (td_img for thermal data - image) contains data collected from space, the air, or the ground that are used to create thermal images. The actual pixel-by-pixel data of the image are stored in the Thermal Image Data table, which is linked to the Thermal Image table. The Thermal Image table primary ID is td_img_id and there are several foreign keys for linking to additional information. The volcano ID, vd_id, links the data collected from space to the volcano that is being observed. The sensor ID, ti_id, links to the Thermal Instrument table, which contains information about the instrument including the type and precision. The Thermal Station ID is included for linking to station information about stationary sites, such as a caldera rim. The stationary thermal image sites are a little different from other sites in that they include information about a measuring station and not about the point on the ground that is being measured. This distinction is made in the Thermal Station table. The satellite ID, cs_id, links to information about the satellite or airplane. The collector ID (cc_id) links to contact information about the person or observatory that collected the image data, if collected periodically. Contact information for data that are collected continuously can be found in the Thermal Station table. The data loader ID, cc_id_load, also links to Contact table and provides contact information about the person who loaded the data into WOVOdat. The load date, td_img_loaddate, is a TIMESTAMP and entered automatically in UTC. The publish date, td_img_pubdate, is the date the data becomes public.

A description of the imaging sensor or instrument's platform and its relative location, for example, from an airplane, satellite, crater rim, roof of a hut, or observatory, is stored in td_img_iplat. The exact location of the instrument, given by td_img_ilat, td_img_ilon, td_img_ielev, and td_img_idatum, should be used only if the instrument recording the information is non-permanent where future measurements will not necessarily occur from the same place. For example, if the instrument is in the air on a satellite or airplane. The latitudes and longitudes are stored in decimal degrees and the elevation is stored in meters. All data should be converted to WGS 84 prior to entering WOVOdat. If conversion is not possible during data loading, the original datum must be entered into the datum field, ds_datum. The locations of the permanent instruments can be found in the Thermal Station table, and are linked using the station ID ts_id.

A description of the anomaly being imaged is stored in td_img_desc as a text field. The text field is currently 255 characters but the may need to be increased in the future. The time the image was taken is stored in td_img_time in UTC DATETIME. A conversion to UTC can be made using information in the Volcano table. The band name is stored in the text field td_img_bname. Individual bands should be separated by a semicolon. The band wavelength range is stored in td_img_hbwave and 
td_img_lbwave, for the high value and low value of the range, both in microns. A copy of the image is stored as a .jpg in td_img_jpg. The pixel size for the image is stored in td_img_psize in meters. The maximum radiance in any frame is stored in td_img_maxrad in $\mathrm{W} /\left(\mathrm{m}^{2}-\mathrm{m}\right) \times 10^{7}$. The maximum relative radiance of any pixel in the frame is stored in td_img_maxrrad in $\mathrm{W} /\left(\mathrm{m}^{2}-\mathrm{m} \mathrm{x} \mathrm{sr}\right) \times 10^{7}$ where $\mathrm{sr}$ is spectral radiance. The spectral radiance is wavelength dependent. The temperature of the hottest pixel, td_img_maxtemp, is stored in degrees Celsius if the temperature is calibrated. The maximum heat flux of the hottest pixel, td_img_maxflux, is stored as $\mathrm{W} / \mathrm{m}^{2}$ and the nominal temperature resolution per pixel, td_img_ntres, is stored in degrees Celsius.

The type of atmospheric correction applied, td_img_atmcorr, the type of thermal correction applied using ground truth points, td_img_thmcorr, and the orthorectification procedure used, td_img_ortho, are stored as text fields. These text fields are all 255 characters in length. Additional information about the image or methods used should be stored in the comments, td_img_com, field.

Thermal Image

Table T3. Thermal Image Data Table

\begin{tabular}{|c|c|c|}
\hline td_pix_id & Image data ID & An identifier for linking with other tables \\
\hline td_img_id & Thermal Image ID & $\begin{array}{l}\text { An identifier for linking with the Thermal } \\
\text { Image table (td_img). The Thermal Image } \\
\text { table contains information about the image } \\
\text { these data create including a description of } \\
\text { the anomaly, corrections applied, and a jpg } \\
\text { of the image. }\end{array}$ \\
\hline td_pix_elev & Pixel center elevation & The elevation at the pixel center in meters. \\
\hline td_pix_lat & Pixel center latitude & $\begin{array}{l}\text { The latitude at the pixel center in decimal } \\
\text { degrees. }\end{array}$ \\
\hline td_pix_lon & Pixel center longitude & $\begin{array}{l}\text { The longitude at the pixel center in decimal } \\
\text { degrees. }\end{array}$ \\
\hline td_pix_datum & Datum & $\begin{array}{l}\text { The datum used for the latitude and } \\
\text { longitude. }\end{array}$ \\
\hline td_pix_rad & Pixel center radiance & $\begin{array}{l}\text { The radiance of the pixel center in } \mathrm{W} /\left(\mathrm{m}^{2}-\right. \\
\mathrm{m}) \times 10^{7} \text {. }\end{array}$ \\
\hline td_pix_flux & Pixel center heat flux & The heat flux at the pixel center in $\mathrm{W} / \mathrm{m}^{2}$. \\
\hline td_pix_temp & Pixel center temperature & $\begin{array}{l}\text { The temperature at the pixel center in } \\
\text { degrees Celsius. }\end{array}$ \\
\hline td_pix_loaddate & Load date & The date this row was entered in UTC. \\
\hline td_pix_pubdate & Publish date & $\begin{array}{l}\text { The date this row can become public. This } \\
\text { date can be set up to two years in advance. }\end{array}$ \\
\hline cc_id_load & Data loader ID & $\begin{array}{l}\text { An identifier for linking to contact } \\
\text { information for the person who entered this } \\
\text { row of data. }\end{array}$ \\
\hline
\end{tabular}


The Thermal Image Data table (td_pix for thermal data - pixels) contains data for each pixel of a thermal image. Information about the thermal image is stored in the Thermal Image table and linked using the thermal image data ID, td_img_id. The Thermal Image table contains information about the image these data create including a description of the anomaly, corrections applied, and a jpg of the image. The thermal image data primary ID is td_pix_id. The data loader ID, cc_id_load, links to the contact table and provides information about the person who loaded the data into WOVOdat. The load date, td_pix_loaddate, is a TIMESTAMP and entered automatically in UTC. The publish date, td_pix_pubdate, is the date the data becomes public.

The location of each pixel is stored as the center elevation, td_pix_elev, in meters and the pixel center longitude, td_pix_lon, and pixel center latitude,td_pix_lat in decimal degrees. All data should be converted to WGS 84 prior to entering WOVOdat. If conversion is not possible during data loading, the original datum must be entered into the datum field, td_pix_datum. The datum, td_pix_datum, should contain the original and stored datum if available. The radiance of the pixel center, td_pix_rad, is stored in $\mathrm{W} /\left(\mathrm{m}^{2}-\mathrm{m}\right) \times 10^{7}$ and the heat flux at the pixel center, td_pix_flux, is stored in $\mathrm{W} / \mathrm{m}^{2}$. The temperature at the pixel center, td_pix_temp, is stored in degrees Celsius.

\section{Thermal Station}

Table T4. Thermal Station Table

\begin{tabular}{|c|c|c|}
\hline ts_id & Thermal Station ID & An identifier for linking with other tables \\
\hline cn_id & Network ID & $\begin{array}{l}\text { An identifier for linking with information } \\
\text { about the network in the Common Network } \\
\text { table, if applicable. The Common Network } \\
\text { table gives a description of the network and } \\
\text { a link to the volcano. }\end{array}$ \\
\hline ts_nam & Benchmark name & The name of the benchmark or station \\
\hline ts_type & Type of thermal feature & $\begin{array}{l}\text { The type of thermal feature at the site (soil, } \\
\text { fumarole, surface or crack in a dome, } \\
\text { spring, crater lake, etc.) or if the station is } \\
\text { used to collect remote image data. }\end{array}$ \\
\hline ts_ground & The soil or ground type & The soil or ground type. \\
\hline ts_lat & Latitude & $\begin{array}{l}\text { The latitude of the station in decimal } \\
\text { degrees. }\end{array}$ \\
\hline ts_lon & Longitude & $\begin{array}{l}\text { The longitude of the station in decimal } \\
\text { degrees. }\end{array}$ \\
\hline ts_elev & Elevation & $\begin{array}{l}\text { The nominal elevation of the station in } \\
\text { meters. }\end{array}$ \\
\hline ts_datum & Datum & $\begin{array}{l}\text { The datum used for the longitude and } \\
\text { latitude. Please include the original datum } \\
\text { as well. }\end{array}$ \\
\hline ts_perm & Instruments & $\begin{array}{l}\text { A list of any permanent instruments } \\
\text { installed at this site. The instrument tables } \\
\text { will link to the Thermal Station table and } \\
\text { will provide details and allow for their to be }\end{array}$ \\
\hline
\end{tabular}




\begin{tabular}{|c|c|c|}
\hline & & $\begin{array}{l}\text { several permanent and periodic instruments } \\
\text { at each station, if applicable. }\end{array}$ \\
\hline ts_freq & Frequency of measurement & $\begin{array}{l}\text { The frequency of measurement, ts_freq, is a } \\
\text { text field that should contain an } \\
\text { abbreviation for continuous (C) or periodic } \\
\text { (P) in addition to a time frame for the } \\
\text { frequency. The frequency time frame should } \\
\text { be exact for the continuous data and } \\
\text { approximate for the periodic data. }\end{array}$ \\
\hline ts_utc & Difference from UTC & $\begin{array}{l}\text { The time zone relative to UTC. Please enter } \\
\text { the number of hours from GMT, using a } \\
\text { negative sign (-) for hours before GMT and } \\
\text { no sign for positive numbers. }\end{array}$ \\
\hline ts_stime & Date established & $\begin{array}{l}\text { The date the station was set up in UTC } \\
\text { stored as DATETIME (YYYY-MM-DD } \\
\text { hh:mm:ss). }\end{array}$ \\
\hline ts_stime_unc & Date established uncertainty & $\begin{array}{l}\text { The uncertainty in the date the station was } \\
\text { set up in UTC stored as DATETIME } \\
\text { (YYYY-MM-DD hh:mm:ss). }\end{array}$ \\
\hline ts_etime & End date & $\begin{array}{l}\text { The date (UTC) the station was permanently } \\
\text { decommissioned or the time this set of } \\
\text { information is no longer valid. The date is } \\
\text { stored in DATETIME (YYYY-MM-DD } \\
\text { hh:mm:ss). See observatory for station } \\
\text { operation history. }\end{array}$ \\
\hline ts_etime_unc & End date uncertainty & $\begin{array}{l}\text { The uncertainty in the date the station was } \\
\text { decommissioned or the time this set of } \\
\text { information is no longer valid in UTC } \\
\text { stored as DATETIME (YYYY-MM-DD } \\
\text { hh:mm:ss). }\end{array}$ \\
\hline ts_desc & Station description & A description of the station or comments \\
\hline cc_id & Contact ID & $\begin{array}{l}\text { An identifier for linking to contact } \\
\text { information. }\end{array}$ \\
\hline ts_loaddate & Load date & The date this row was entered in UTC. \\
\hline ts_pubdate & Publish date & $\begin{array}{l}\text { The date this row can become public. This } \\
\text { date can be set up to two years in advance. }\end{array}$ \\
\hline cc_id_load & Data loader ID & $\begin{array}{l}\text { An identifier for linking to contact } \\
\text { information for the person who entered this } \\
\text { row of data. }\end{array}$ \\
\hline
\end{tabular}

The Thermal Station table (ts for thermal station) stores information such as a location, name, and a description for stations where thermal data are collected. The primary ID for the Thermal Station table is ts_id and there are several foreign IDs for linking to other tables. Permanently installed instruments are linked to the Thermal Station table from the Thermal Instrument table using the thermal station ID, ts_id. Periodically used instrument information are linked from the data tables. The Thermal 
Station table links to the Common Network table by the network ID, cn_id, which contains the volcano ID. The contact ID (cc_id) links to contact information about the person or observatory that manages the station and the data loader ID, cc_id_load, links to the Contact table for more information about the person who loaded the data into WOVOdat. The load date, ts_loaddate, is a TIMESTAMP and entered automatically in UTC. The publish date, td_img_pubdate, is the date the data becomes public.

The station location information includes the latitude, ts_lat, longitude, ts_lon, elevation, ts_elev, and datum, ts_datum. The latitudes and longitudes are stored in decimal degrees and the elevation is stored in meters. All data should be converted to WGS 84 prior to entering WOVOdat. If conversion is not possible during data loading, the original datum must be entered into the datum field, ds_datum.

The station name, given by the observatory, is stored in ts_name and the type of thermal feature found at the station is stored in ts_type. The ts_type field should also be used to indicate if the station is used to collect remote image data. A list of the instruments installed at the station, if applicable, is stored in ts_perm. The frequency of measurement field, ts_freq, is a text field that should contain an abbreviation for continuous $(\mathrm{C})$ or periodic $(\mathrm{P})$ in addition to a time frame for the frequency. The frequency time frame should be exact for the continuous data and approximate for the periodic data. The difference from local time to UTC is stored as ts_utc. This information allows for the conversion back to UTC whenever needed as discussed in the Time Section.

The Thermal Station table also includes start and end dates, ts_stime and ts_etime, along with their uncertainties, ts_stime_unc and ts_etime_unc, in DATETIME UTC. These dates provide information on when the information in the station table is valid. The instrument table also contains a date range. New station instruments should be recorded in the instrument table instead of the station table unless the location of the new instrument changes the location of the station. The Thermal Station table also contains a description field, ts_desc, which should be used for additional information that could help explain the data and the selection of the site.

\section{Thermal Instrument}

Table T5. Thermal Instrument Table

\begin{tabular}{|l|l|l|}
\hline \multicolumn{1}{|l}{} & & \\
ti_id & Sensor ID & An identifier for linking with other tables. \\
\hline cs_id & Satellite ID & $\begin{array}{l}\text { An identifier for linking with the Satellite } \\
\text { table, if the instrument is mounted on a } \\
\text { satellite or airplane. The Satellite table gives } \\
\text { the name of the satellite and a description. }\end{array}$ \\
\hline ts_id & $\begin{array}{l}\text { An identifier for linking with the Thermal } \\
\text { Station table for instruments installed at a } \\
\text { station. The Thermal Station table includes } \\
\text { the station location, the type of thermal } \\
\text { feature, and links to the Thermal Network } \\
\text { and Instrument tables. }\end{array}$ \\
\hline ti_perm & $\begin{array}{l}\text { A single character field to let the user know } \\
\text { if the instrument is part of a permanent } \\
\text { installation (use P for permanent) or part of }\end{array}$ \\
\hline
\end{tabular}




\begin{tabular}{|l|l|l|}
\hline & & a campaign (use C for campaign). \\
\hline ti_type & Type & The type of instrument. \\
\hline ti_name & Name & $\begin{array}{l}\text { The name, manufacturer, and model of the } \\
\text { instrument. }\end{array}$ \\
\hline ti_units & Measured units & The units the instrument measures. \\
\hline ti_pres & Resolution & Typical instrumental measuring precision. \\
\hline ti_stn & Signal to noise & An instrument specific signal to noise ratio. \\
\hline ti_stime & & $\begin{array}{l}\text { The date (UTC) the instrument was set up } \\
\text { and activated or the time new information in } \\
\text { this table became valid. The date is stored in }\end{array}$ \\
\hline DATETIME (YYYY-MM-DD hh:mm:ss).
\end{tabular}

The Thermal Instrument table (ti for thermal instrument) was created to store information about the instruments used to collect ground-based and remote thermal data. The flag, ti_perm, should be used to indicate if the instrument is installed permanently or is used periodically as part of a campaign. The letter should be used only if all of the data were collected continuously and the letter P should be used if any of the data were collected as part of a campaign. The permanently installed instruments are linked to the stations at which they are installed by the station ID, ts_id. The periodic instrument data are linked to the Thermal Instrument table using the instrument table's primary ID, ti_id, which has been placed in the data tables. Links to information about instruments on moving platforms have been kept in 
the data tables to avoid the creation of an additional junction table because the instruments are more likely to change than the permanently installed instruments. For cases where an instrument is permanently installed on a satellite, there is a link from the Thermal Instrument table to the Satellite table, cs_id. The satellite information can also be accessed through a link in the Thermal Image table.

The contact ID (cc_id) links to contact information about the person or observatory that manages the instrument and the data loader ID, cc_id_load, links to the Contact table for more information about the person who loaded the data into WOVOdat. The load date, ti_loaddate, is a TIMESTAMP and entered automatically in UTC. The publish date,td_img_pubdate, is the date the data becomes public.

The name, model, and manufacturer of the instrument are stored in the text field ti_name, and the type of instrument is stored in the text field ti_type. The units the instrument measures are stored in the text field ti_units and the resolution or measuring precision in those units is stored in ti_res. The instrument specific signal to noise ratio is stored in ti_stn. The Thermal Instrument table also includes start and end dates, ti_stime and ti_etime, along with their uncertainties, ti_stime_unc and ti_etime_unc, in DATETIME UTC. These dates provide information on when the instrument information in the table is valid. The data are considered invalid if the resolution or signal to noise ratio changes or if an installed instrument is removed from a station. A comments attribute, ti_com, is included for comments about the type of instrument and its uses.

\section{Create table statements for thermal tables}

\section{DROP TABLE IF EXISTS td;}

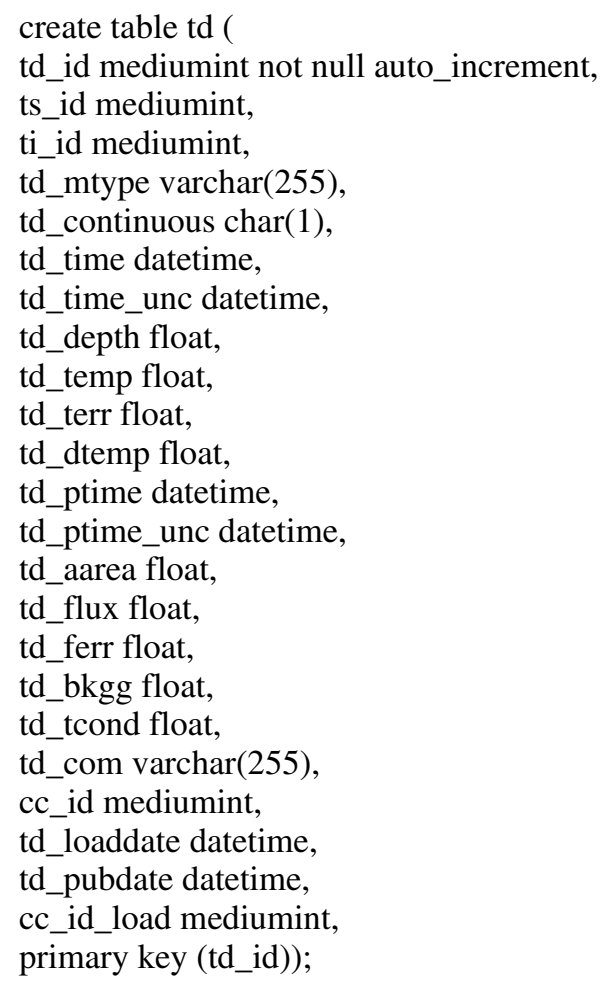

DROP TABLE IF EXISTS td_img;

create table td_img (

td_img_id mediumint not null auto_increment, 
vd_id mediumint, cs_id mediumint,

ts_id mediumint,

ti_id mediumint,

td_img_iplat varchar(255),

td_img_ialt float,

td_img_ilat float,

td_img_ilon float,

td_img_idatum varchar(255),

td_img_desc varchar(255),

td_img_time datetime,

td_img_time_unc datetime,

td_img_bname varchar(255),

td_img_hbwave float,

td_img_lbwave float,

td_img_jpg varchar(255),

td_img_psize float,

td_img_maxrad float,

td_img_maxrrad float,

td_img_maxtemp float,

td_img_maxflux float,

td_img_ntres float,

td_img_atmcorr varchar(255),

td_img_thmcorr varchar(255),

td_img_ortho varchar(255),

td_img_com varchar(255),

cc_id mediumint,

td_img_loaddate datetime,

td_img_pubdate datetime,

cc_id_load mediumint,

primary key (td_img_id));

DROP TABLE IF EXISTS td_pix;

create table td_pix (

td_pix_id mediumint not null auto_increment,

td_img_id mediumint,

td_pix_elev float,

td_pix_lat float,

td_pix_lon float,

td_pix_datum varchar(255),

td_pix_rad float,

td_pix_flux float,

td_pix_temp float,

td_pix_loaddate datetime,

td_pix_pubdate datetime,

cc_id_load mediumint,

primary key (td_pix_id));

DROP TABLE IF EXISTS ts;

create table ts (

ts_id mediumint not null auto_increment,

cn_id mediumint,

ts_nam varchar(30),

ts_type varchar(255),

ts_ground varchar(255),

ts_lat float, 
ts_lon float,

ts_elev float,

ts_datum varchar(30),

ts_perm varchar(255),

ts_freq varchar(255),

ts_utc float,

ts_stime datetime,

ts_stime_unc datetime,

ts_etime datetime,

ts_etime_unc datetime,

ts_desc varchar(255),

cc_id mediumint,

ts_loaddate datetime,

ts_pubdate datetime,

cc_id_load mediumint,

primary key (ts_id));

DROP TABLE IF EXISTS ti;

create table ti (

ti_id mediumint not null auto_increment,

cs_id mediumint,

ts_id mediumint,

ti_perm char(1),

ti_type varchar(255),

ti_name varchar(255),

ti_units varchar(50),

ti_pres float,

ti_stn float,

ti_stime datetime,

ti_stime_unc datetime,

ti_etime datetime,

ti_etime_unc datetime,

ti_com varchar(255),

cc_id mediumint,

ti_loaddate datetime,

ti_pubdate datetime,

cc_id_load mediumint,

primary key (ti_id));

\section{Inferred Processes}

The Inferred Processes tables were created to store historical (in most cases, published) inferences about processes causing volcanic unrest. These tables link to the volcano, date/time of unrest, and pertinent references or contact persons. The inferred process tables include a table on magma movement, a table on volatile saturation, a table on the buildup of magma pressure, a table on interactions with a hydrothermal system, and a table on the interaction of the magma/hydrothermal system with regional tectonics. The inferred process fields store a single character, $\mathrm{Y}$ for yes, $\mathrm{N}$ for No, $\mathrm{M}$ for maybe, and $\mathrm{U}$ for unknown or no information, with a table-wide comments field for additional information. Please note the information stored in these tables is based on interpretations. WOVOdat includes these processes as they were reported, but makes no judgment about the validity of the inferences. References are linked using keywords in the bibliographic table. 
Magma Movement

Table IP1. Magma Movement Table

\begin{tabular}{|c|c|c|}
\hline ip_mag_id & Magma movement ID & An identifier for linking with other tables. \\
\hline vd_id & Volcano ID & $\begin{array}{l}\text { An identifier for linking to the Volcano } \\
\text { table. The Volcano table stores the volcano } \\
\text { name and time zone. It is used to connect to } \\
\text { all other data. }\end{array}$ \\
\hline ip_mag_time & Inference time & $\begin{array}{l}\text { The date and time of the inference in UTC } \\
\text { stored as DATETIME (YYYY-MM-DD } \\
\text { hh:mm:ss). Will often be a year of } \\
\text { publication. }\end{array}$ \\
\hline ip_mag_time_unc & Inference time & $\begin{array}{l}\text { The uncertainty in the date and time of the } \\
\text { inference in UTC stored as DATETIME } \\
\text { (YYYY-MM-DD hh:mm:ss). Will often be } \\
\text { a year of publication. }\end{array}$ \\
\hline ip_mag_start & Start time of inferred process & $\begin{array}{l}\text { The date and time at which this inferred } \\
\text { process started. In UTC as DATETIME } \\
\text { (YYYY-MM-DD hh:mm:ss). If no specific } \\
\text { times or dates are available, give the year of } \\
\text { eruption. }\end{array}$ \\
\hline ip_mag_start_unc & $\begin{array}{l}\text { Start time of inferred process } \\
\text { uncertainty }\end{array}$ & $\begin{array}{l}\text { The uncertainty in the date and time at } \\
\text { which this inferred process started. In UTC } \\
\text { as DATETIME (YYYY-MM-DD } \\
\text { hh:mm:ss). If no specific times or dates are } \\
\text { available, give the year of eruption. }\end{array}$ \\
\hline ip_mag_end & $\begin{array}{l}\text { Ending time of inferred } \\
\text { process }\end{array}$ & $\begin{array}{l}\text { The date and time at which (or by which) } \\
\text { this inferred process stopped. In UTC as } \\
\text { DATETIME (YYYY-MM-DD hh:mm:ss) }\end{array}$ \\
\hline ip_mag_end_unc & $\begin{array}{l}\text { End time of inferred process } \\
\text { uncertainty }\end{array}$ & $\begin{array}{l}\text { The uncertainty in the date and time at } \\
\text { which this inferred process ended. In UTC } \\
\text { as DATETIME (YYYY-MM-DD } \\
\text { hh:mm:ss). If no specific times or dates are } \\
\text { available, give the year of eruption. }\end{array}$ \\
\hline ip_mag_deepsupp & Deep Supply & $\begin{array}{l}\text { New or renewed supply of magma from } \\
\text { depth. Use Y for yes, N for No, M for } \\
\text { maybe, and U for unknown or no } \\
\text { information. }\end{array}$ \\
\hline ip_mag_asc & Ascent & $\begin{array}{l}\text { Magma ascent, up from reservoir. Use } \mathrm{Y} \text { for } \\
\text { yes, } \mathrm{N} \text { for No, M for maybe, and U for } \\
\text { unknown or no information. }\end{array}$ \\
\hline ip_mag_convb & Convection Below & $\begin{array}{l}\text { Magma convection/overturn induced from } \\
\text { below by an intrusion at the base. The } \\
\text { magma convection can be within the }\end{array}$ \\
\hline
\end{tabular}




\begin{tabular}{|c|c|c|}
\hline & & $\begin{array}{l}\text { conduit and/or in underlying reservoir. If } \\
\text { magma in a conduit convects to shallow } \\
\text { depth, it may foam and release a substantial } \\
\text { part of its gas. Use Y for yes, N for No, M } \\
\text { for maybe, and U for unknown or no } \\
\text { information. }\end{array}$ \\
\hline ip_mag_conva & Convection Above & $\begin{array}{l}\text { Magma convection/overturn induced from } \\
\text { above, by settling of a dense crystal-rich } \\
\text { mass. In conduit and/or reservoir, with } \\
\text { potential foaming, as above. Use Y for yes, } \\
\mathrm{N} \text { for No, M for maybe, and U for unknown } \\
\text { or no information. }\end{array}$ \\
\hline ip_mag_mix & Magma Mixing & $\begin{array}{l}\text { Magma mixing. Use } \mathrm{Y} \text { for yes, } \mathrm{N} \text { for } \mathrm{No}, \mathrm{M} \\
\text { for maybe, and } \mathrm{U} \text { for unknown or no } \\
\text { information. }\end{array}$ \\
\hline ip_mag_dike & Dike & $\begin{array}{l}\text { Dike intrusion. In many cases this will be } \\
\text { new intrusion through country rock; in } \\
\text { some instances, magmas will flow anew } \\
\text { through existing dikes. Use Y for yes, N for } \\
\text { No, M for maybe, and U for unknown or no } \\
\text { information. }\end{array}$ \\
\hline ip_mag_pipe & Pipe & $\begin{array}{l}\text { Intrusion through a pipe-like cylindrical } \\
\text { conduit. As above, may be a new intrusion } \\
\text { through country rock or renewed flow in an } \\
\text { existing conduit. Use Y for yes, } \mathrm{N} \text { for No, } \\
\text { M for maybe, and U for unknown or no } \\
\text { information. }\end{array}$ \\
\hline ip_mag_sill & Sill & $\begin{array}{l}\text { Sill intrusion. Use } \mathrm{Y} \text { for yes, } \mathrm{N} \text { for No, } \mathrm{M} \\
\text { for maybe, and U for unknown or no } \\
\text { information. }\end{array}$ \\
\hline ip_mag_com & Comments & Added comments on magma movement. \\
\hline cc_id & Interpreter ID & $\begin{array}{l}\text { An identifier for linking to contact } \\
\text { information for the person who interpreted } \\
\text { this process. }\end{array}$ \\
\hline ip_mag_loaddate & Load date & The date this row was entered in UTC. \\
\hline ip_mag_pubdate & Publish date & $\begin{array}{l}\text { The date this row can become public. This } \\
\text { date can be set up to two years in advance. }\end{array}$ \\
\hline cc_ip_load & Data loader ID & $\begin{array}{l}\text { An identifier for linking to contact } \\
\text { information for the person who entered this } \\
\text { row of data. }\end{array}$ \\
\hline
\end{tabular}

The Magma Movement table stores information about processes related to the movement of magma. The primary ID is ip_mag_id, the link to the Volcano table is vd_id, and the link to the person making the inference is cc_id. The date the information was entered is stored in ip_mag_loaddate, the date the information can become public is stored in ip_mag_pubdate, and a link to information about the person who loaded the data is stored in cc_ip_load. The time the inference was made is stored in 
ip_mag_time in UTC as DATETIME and the uncertainty for the time is stored in ip_mag_time_unc. The times at which the inferred process began and ended are stored in ip_mag_start and ip_mag_end. The uncertainties in the times the process began and ended are stored in ip_mag_start_unc and ip_mag_end_unc.

The inferred processes in the Magma Movement table are deep magma supply, ip_mag_deepsupply, magma ascent from a reservoir, ip_mag_asc, magma convection induced from below, ip_mag_convb, magma convection induced from above, ip_mag_conva, magma mixing, ip_mag_mix, a dike intrusion, ip_mag_dike, a pipe intrusion, ip_mag_pipe, and a sill intrusion, ip_mag_sill. The magma movement inferred process fields should store a single character, $\mathrm{Y}$ for yes, $\mathrm{N}$ for No, $\mathrm{M}$ for maybe, and $\mathrm{U}$ for unknown or no information. The comments field, ip_mag_com, is included for storing additional information.

\section{Volatile Saturation}

Table IP3. Volatile Saturation Table

\begin{tabular}{|c|c|c|}
\hline ip_sat_id & Volatile saturation ID & An identifier for linking with other tables \\
\hline vd_id & Volcano ID & $\begin{array}{l}\text { An identifier for linking to the Volcano } \\
\text { table. The Volcano table stores the volcano } \\
\text { name and time zone. It is used to connect to } \\
\text { all other data. }\end{array}$ \\
\hline ip_sat_time & Inference time & $\begin{array}{l}\text { The date and time of the inference in UTC } \\
\text { stored as DATETIME (YYYY-MM-DD } \\
\text { hh:mm:ss). }\end{array}$ \\
\hline ip_sat_time_unc & Inference time & $\begin{array}{l}\text { The uncertainty in the date and time of the } \\
\text { inference in UTC stored as DATETIME } \\
\text { (YYYY-MM-DD hh:mm:ss). Will often be } \\
\text { a year of publication. }\end{array}$ \\
\hline ip_sat_start & Start time of inferred process & $\begin{array}{l}\text { The date and time at which this inferred } \\
\text { process started. In UTC as DATETIME } \\
\text { (YYYY-MM-DD hh:mm:ss). If no specific } \\
\text { times or dates are available, give the year of } \\
\text { eruption. }\end{array}$ \\
\hline ip_sat_start_unc & $\begin{array}{l}\text { Start time of inferred process } \\
\text { uncertainty }\end{array}$ & $\begin{array}{l}\text { The uncertainty in the date and time at } \\
\text { which this inferred process started. In UTC } \\
\text { as DATETIME (YYYY-MM-DD } \\
\text { hh:mm:ss). If no specific times or dates are } \\
\text { available, give the year of eruption. }\end{array}$ \\
\hline ip_sat_end & $\begin{array}{l}\text { Ending time of inferred } \\
\text { process }\end{array}$ & $\begin{array}{l}\text { The date and time at which (or by which) } \\
\text { this inferred process stopped. In UTC as } \\
\text { DATETIME (YYYY-MM-DD hh:mm:ss) }\end{array}$ \\
\hline ip_sat_end_unc & $\begin{array}{l}\text { End time of inferred process } \\
\text { uncertainty }\end{array}$ & $\begin{array}{l}\text { The uncertainty in the date and time at } \\
\text { which this inferred process ended. In UTC } \\
\text { as DATETIME (YYYY-MM-DD } \\
\text { hh:mm:ss). If no specific times or dates are } \\
\text { available, give the year of eruption. }\end{array}$ \\
\hline
\end{tabular}




\begin{tabular}{|c|c|c|}
\hline ip_sat_co2 & $\mathrm{CO}_{2}$ saturation & $\begin{array}{l}\text { Magma became saturated with } \mathrm{CO}_{2} \text { before } \\
\text { an eruption and contributed to preeruption } \\
\text { unrest. Saturation induced by any cause. } \\
\text { Use Y for yes, } \mathrm{N} \text { for No, M for maybe, and } \\
\text { U for unknown or no information. }\end{array}$ \\
\hline ip_sat_h2o & $\mathrm{H}_{2} \mathrm{O}$ saturation & $\begin{array}{l}\text { Magma became saturated with } \mathrm{H}_{2} \mathrm{O} \text { before } \\
\text { an eruption and contributed to preeruption } \\
\text { unrest. Saturation induced by any cause. } \\
\text { Use Y for yes, } \mathrm{N} \text { for No, M for maybe, and } \\
\text { U for unknown or no information. }\end{array}$ \\
\hline ip_sat_decomp & Decompress & $\begin{array}{l}\text { Volatile saturation by decompression. Use } \\
\text { Y for yes, } \mathrm{N} \text { for No, } \mathrm{M} \text { for maybe, and } \mathrm{U} \\
\text { for unknown or no information. }\end{array}$ \\
\hline ip_sat_dfo2 & Fugacity & $\begin{array}{l}\text { Volatile saturation by change in } \mathrm{fO}_{2} \text {. Use } \mathrm{Y} \\
\text { for yes, } \mathrm{N} \text { for No, } \mathrm{M} \text { for maybe, and U for } \\
\text { unknown or no information. }\end{array}$ \\
\hline ip_sat_add & Volatile Addition & $\begin{array}{l}\text { Volatile saturation by volatile addition. Use } \\
\text { Y for yes, } \mathrm{N} \text { for No, } \mathrm{M} \text { for maybe, and } \mathrm{U} \\
\text { for unknown or no information. }\end{array}$ \\
\hline ip_sat_xtl & $2^{\text {nd }}$ Boil & $\begin{array}{l}\text { Volatile saturation by crystallization or } \\
\text { second boiling. Use Y for yes, } \mathrm{N} \text { for No, M } \\
\text { for maybe, and U for unknown or no } \\
\text { information. }\end{array}$ \\
\hline ip_sat_ves & Vesiculation & $\begin{array}{l}\text { Subsurface, preeruptive increases in } \\
\text { vesiculation, thereby decreasing density. } \\
\text { This would include extreme vesiculation to } \\
\text { permeable foam. Use Y for yes, } \mathrm{N} \text { for No, } \\
\text { M for maybe, and U for unknown or no } \\
\text { information. }\end{array}$ \\
\hline ip_sat_deves & Devesiculation & $\begin{array}{l}\text { Subsurface, preeruptive decreases in } \\
\text { vesiculation, thereby increasing density. } \\
\text { This would include collapse of newly- } \\
\text { degassed foam. Use Y for yes, N for No, M } \\
\text { for maybe, and U for unknown or no } \\
\text { information. }\end{array}$ \\
\hline ip_sat_degas & Degassing & $\begin{array}{l}\text { Deep and near-surface degassing including } \\
\text { gas explosion events. Use Y for yes, } \mathrm{N} \text { for } \\
\text { No, M for maybe, and U for unknown or no } \\
\text { information. Use Y for yes, } \mathrm{N} \text { for No, } \mathrm{M} \text { for } \\
\text { maybe, and U for unknown or no } \\
\text { information. }\end{array}$ \\
\hline ip_sat_com & Comments & Additional comments on volatile saturation. \\
\hline cc_id & Interpreter ID & $\begin{array}{l}\text { An identifier for linking to contact } \\
\text { information for the person who interpreted } \\
\text { this process. }\end{array}$ \\
\hline
\end{tabular}




\begin{tabular}{|l|l|l|}
\hline ip_sat_loaddate & Load date & The date this row was entered in UTC. \\
\hline ip_sat_pubdate & Publish date & $\begin{array}{l}\text { The date this row can become public. This } \\
\text { date can be set up to two years in advance. }\end{array}$ \\
\hline cc_ip_load & $\begin{array}{l}\text { An identifier for linking to contact } \\
\text { information for the person who entered this } \\
\text { row of data. }\end{array}$ \\
\hline
\end{tabular}

The Volatile Saturation table stores information about processes related to volatiles in the magma. The primary ID is ip_sat_id, the link to the Volcano table is vd_id, and the link to the person making the inference is cc_id. The date the information was entered is stored in ip_sat_loaddate, the date the information can become public is stored in ip_sat_pubdate, and a link to information about the person who loaded the data is stored in cc_ip_load. The time the inference was made is stored in ip_sat_time in UTC as DATETIME and the uncertainty for the time is stored in ip_sat_time_unc. The times at which the inferred process began and ended are stored in ip_sat_start and ip_sat_end. The uncertainties in the times the process began and ended are stored in ip_sat_start_unc and ip_sat_end_unc.

The initial processes correspond to the presence of volatile saturation and include magma saturated with $\mathrm{CO}_{2}$, ip_sat_co2, and magma saturated with $\mathrm{H} 2 \mathrm{O}$, ip_sat_h2o. The next set of inferred processes are about how the magma became volatile saturated and include by decompression, ip_sat_decomp, by change in $\mathrm{fO}_{2}$, ip_sat_dfo2, by volatile addition, ip_sat_add, by crystallization or second boiling, ip_sat_xtl, by increases in vesiculation or decreasing density, ip_sat_ves, by decreases in vesiculation or increasing density, ip_sat_deves, or by deep and near-surface degassing, ip_sat_degas. The volatile saturation inferred process fields should store a single character, $\mathrm{Y}$ for yes, $\mathrm{N}$ for No, $\mathrm{M}$ for maybe, and $\mathrm{U}$ for unknown or no information. The comments field, ip_sat_com, is included for additional information.

\section{Buildup of Magma Pressure}

Table IP5. Buildup of Magma Pressure Table

\begin{tabular}{|l|l|l|}
\hline ip_pres_id & Magma pressure ID & An identifier for linking with other tables \\
\hline vd_id & Volcano ID & $\begin{array}{l}\text { An identifier for linking to the Volcano } \\
\text { table. The Volcano table stores the volcano } \\
\text { name and time zone. It is used to connect to } \\
\text { all other data. }\end{array}$ \\
\hline ip_pres_time & Inference time & $\begin{array}{l}\text { The date and time of the inference in UTC } \\
\text { stored as DATETIME (YYYY-MM-DD } \\
\text { hh:mm:ss). }\end{array}$ \\
\hline ip_pres_time_unc & Inference time & $\begin{array}{l}\text { The uncertainty in the date and time of the } \\
\text { inference in UTC stored as DATETIME } \\
\text { (YYYY-MM-DD hh:mm:ss). Will often be } \\
\text { a year of publication. }\end{array}$ \\
\hline ip_pres_start & Start time of inferred process & $\begin{array}{l}\text { The date and time at which this inferred } \\
\text { process started. In UTC as DATETIME }\end{array}$ \\
\hline
\end{tabular}




\begin{tabular}{|c|c|c|}
\hline & & $\begin{array}{l}\text { (YYYY-MM-DD hh:mm:ss). If no specific } \\
\text { times or dates are available, give the year of } \\
\text { eruption. }\end{array}$ \\
\hline ip_pres_start_unc & $\begin{array}{l}\text { Start time of inferred process } \\
\text { uncertainty }\end{array}$ & $\begin{array}{l}\text { The uncertainty in the date and time at } \\
\text { which this inferred process started. In UTC } \\
\text { as DATETIME (YYYY-MM-DD } \\
\text { hh:mm:ss). If no specific times or dates are } \\
\text { available, give the year of eruption. }\end{array}$ \\
\hline ip_pres_end & End time of inferred process & $\begin{array}{l}\text { The date and time at which (or by which) } \\
\text { this inferred process stopped. In UTC as } \\
\text { DATETIME (YYYY-MM-DD hh:mm:ss) }\end{array}$ \\
\hline ip_pres_end_unc & $\begin{array}{l}\text { End time of inferred process } \\
\text { uncertainty }\end{array}$ & $\begin{array}{l}\text { The uncertainty in the date and time at } \\
\text { which this inferred process ended. In UTC } \\
\text { as DATETIME (YYYY-MM-DD } \\
\text { hh:mm:ss). If no specific times or dates are } \\
\text { available, give the year of eruption. }\end{array}$ \\
\hline ip_pres_gas & Gas Overpressure & $\begin{array}{l}\text { Gas-induced overpressure. Use } \mathrm{Y} \text { for yes, } \mathrm{N} \\
\text { for No, } \mathrm{M} \text { for maybe, and } \mathrm{U} \text { for unknown or } \\
\text { no information. }\end{array}$ \\
\hline ip_pres_tec & Tectonic Overpressure & $\begin{array}{l}\text { Magma or tectonically induced } \\
\text { overpressures. Use Y for yes, N for No, M } \\
\text { for maybe, and U for unknown or no } \\
\text { information. }\end{array}$ \\
\hline ip_pres_com & Comments & $\begin{array}{l}\text { Comments on the buildup of magma } \\
\text { pressure }\end{array}$ \\
\hline cc_id & Interpreter ID & $\begin{array}{l}\text { An identifier for linking to contact } \\
\text { information for the person who interpreted } \\
\text { this process. }\end{array}$ \\
\hline ip_pres_loaddate & Load date & The date this row was entered in UTC. \\
\hline ip_pres_pubdate & Publish date & $\begin{array}{l}\text { The date this row can become public. This } \\
\text { date can be set up to two years in advance. }\end{array}$ \\
\hline cc_ip_load & Data loader ID & $\begin{array}{l}\text { An identifier for linking to contact } \\
\text { information for the person who entered this } \\
\text { row of data. }\end{array}$ \\
\hline
\end{tabular}

The Buildup of Magma Pressure table stores information about processes related to an increase in magmatic pressure. The primary ID is ip_pres_id, the link to the Volcano table is vd_id, and the link to the person making the inference is cc_id. The date the information was entered is stored in ip_pres_loaddate, the date the information can become public is stored in ip_pres_pubdate, and a link to information about the person who loaded the data is stored in cc_ip_load. The time the inference was made is stored in ip_pres_time in UTC as DATETIME and the uncertainty for the time is stored in ip_pres_time_unc. The times at which the inferred process began and ended are stored in ip_pres_start and ip_pres_end. The uncertainties in the times the process began and ended are stored in ip_ pres_start_unc and ip_pres_end_unc. 
The inferred processes in the Buildup of Magma Pressure table are gas-induced overpressure, ip_pres_gas, and magma or tectonically induced overpressures, ip_pres_tec. The buildup of magma pressure inferred process fields should store a single character, $\mathrm{Y}$ for yes, $\mathrm{N}$ for $\mathrm{No}, \mathrm{M}$ for maybe, and $\mathrm{U}$ for unknown or no information. The comments field, ip_pres_com, is included for additional information.

Hydrothermal System Interaction

Table IP7. Hydrothermal System Interaction Table

\begin{tabular}{|l|l|l|}
\hline ip_hyd_id & Hydrothermal ID & An identifier for linking with other tables \\
\hline vd_id & Volcano ID & $\begin{array}{l}\text { An identifier for linking to the Volcano } \\
\text { table. The Volcano table stores the volcano } \\
\text { name and time zone. It is used to connect to } \\
\text { all other data. }\end{array}$ \\
\hline ip_hyd_time & $\begin{array}{l}\text { The date and time of the inference in UTC } \\
\text { stored as DATETIME (YYYY-MM-DD } \\
\text { hh:mm:ss). }\end{array}$ \\
\hline ip_hyd_time_unc & Inference time & $\begin{array}{l}\text { The uncertainty in the date and time of the } \\
\text { inference in UTC stored as DATETIME } \\
\text { (YYYY-MM-DD hh:mm:ss). Will often be } \\
\text { a year of publication. }\end{array}$ \\
\hline ip_hyd_start & Inference time & $\begin{array}{l}\text { The date and time at which this inferred } \\
\text { process started. In UTC as DATETIME } \\
\text { (YYYY-MM-DD hh:mm:ss). If no specific } \\
\text { times or dates are available, give the year of }\end{array}$ \\
\hline eruption.
\end{tabular}




\begin{tabular}{|c|c|c|}
\hline & & information. \\
\hline ip_hyd_edef & Pore Deformation & $\begin{array}{l}\text { Elastic deformation induced by pore } \\
\text { pressure change. Use Y for yes, N for No, } \\
\text { M for maybe, and U for unknown or no } \\
\text { information. }\end{array}$ \\
\hline ip_hyd_hfrac & Hydrofracturing & $\begin{array}{l}\text { Hydrofracturing. Use } \mathrm{Y} \text { for yes, } \mathrm{N} \text { for No, } \\
\text { M for maybe, and U for unknown or no } \\
\text { information. }\end{array}$ \\
\hline ip_hyd_btrem & Boiling induced tremor & $\begin{array}{l}\text { Boiling-induced tremor. Use Y for yes, } \mathrm{N} \\
\text { for No, M for maybe, and U for unknown or } \\
\text { no information. }\end{array}$ \\
\hline ip_hyd_abgas & Soluble Gases & $\begin{array}{l}\text { Absorption of soluble gases. Use } \mathrm{Y} \text { for yes, } \\
\mathrm{N} \text { for No, } \mathrm{M} \text { for maybe, and } \mathrm{U} \text { for unknown } \\
\text { or no information. }\end{array}$ \\
\hline ip_hyd_species & Equilibrium Change & $\begin{array}{l}\text { Changing the equilibrium species. Use } \mathrm{Y} \\
\text { for yes, } \mathrm{N} \text { for No, } \mathrm{M} \text { for maybe, and } \mathrm{U} \text { for } \\
\text { unknown or no information. }\end{array}$ \\
\hline ip_hyd_chim & Boiling until Dry & $\begin{array}{l}\text { Boiling until dry chimneys are formed. Use } \\
Y \text { for yes, } \mathrm{N} \text { for No, } \mathrm{M} \text { for maybe, and } \mathrm{U} \\
\text { for unknown or no information. }\end{array}$ \\
\hline ip_hyd_com & Comments & $\begin{array}{l}\text { Comments on interaction with the } \\
\text { hydrothermal system. }\end{array}$ \\
\hline cc_id & Interpreter ID & $\begin{array}{l}\text { An identifier for linking to contact } \\
\text { information for the person who interpreted } \\
\text { this process. }\end{array}$ \\
\hline ip_hyd_loaddate & Load date & The date this row was entered in UTC. \\
\hline ip_hyd_pubdate & Publish date & $\begin{array}{l}\text { The date this row can become public. This } \\
\text { date can be set up to two years in advance. }\end{array}$ \\
\hline cc_ip_load & Data loader ID & $\begin{array}{l}\text { An identifier for linking to contact } \\
\text { information for the person who entered this } \\
\text { row of data. }\end{array}$ \\
\hline
\end{tabular}

The Hydrothermal System Interaction table stores information about magmatic interactions with the hydrothermal system. The primary ID is ip_hyd_id, the link to the Volcano table is vd_id, and the link to the person making the inference is cc_id. The date the information was entered is stored in ip_hyd_loaddate, the date the information can become public is stored in ip_hyd_pubdate, and a link to information about the person who loaded the data is stored in cc_ip_load. The time the inference was made is stored in ip_hyd_time in UTC as DATETIME and the uncertainty for the time is stored in ip_mag_hyd_unc. The times at which the inferred process began and ended are stored in ip_ hyd _start and ip_ hyd_end. The uncertainties in the times the process began and ended are stored in ip_ hyd_start_unc and ip_hyd_end_unc.

The inferred processes in the Hydrothermal System Interaction table are convective heating of the groundwater, ip_hyd_gwater, destabilization of the edifice due to increased pore pressure, ip_hyd_ipor, elastic deformation induced by a change in pore pressure, ip_hyd_edef, hydrofracturing, 
ip_hyd_hfrac, boiling-induced tremor, ip_hyd_btrem, absorption of a soluble gas, ip_hyd_abgas, changing the equilibrium species, ip_hyd_species, and boiling until dry chimneys form, ip_hyd_chim. Each of the inferred processes fields should store a one-character flag ( $\mathrm{Y}$ for yes, $\mathrm{N}$ for No, $\mathrm{M}$ for maybe, and U for unknown or no information). The comments field, ip_hyd_com, is included for additional information on the hydrothermal interaction.

Regional Tectonics Interactions

Table IP9. Regional Tectonics Interactions Table

\begin{tabular}{|c|c|c|}
\hline ip_tec_id & Regional tectonics ID & An identifier for linking with other tables \\
\hline vd_id & Volcano ID & $\begin{array}{l}\text { An identifier for linking to the Volcano } \\
\text { table. The Volcano table stores the volcano } \\
\text { name and time zone. It is used to connect to } \\
\text { all other data. }\end{array}$ \\
\hline ip_tec_time & Inference time & $\begin{array}{l}\text { The date and time of the inference in UTC } \\
\text { stored as DATETIME (YYYY-MM-DD } \\
\text { hh:mm:ss). Will often be a year of } \\
\text { publication. }\end{array}$ \\
\hline ip_tec_time_unc & Inference time uncertainty & $\begin{array}{l}\text { The uncertainty in the date and time of the } \\
\text { inference in UTC stored as DATETIME } \\
\text { (YYYY-MM-DD hh:mm:ss). Will often be } \\
\text { a year of publication. }\end{array}$ \\
\hline ip_tec_start & Start time of inferred process & $\begin{array}{l}\text { The date and time at which this inferred } \\
\text { process started. In UTC as DATETIME } \\
\text { (YYYY-MM-DD hh:mm:ss). If no specific } \\
\text { times or dates are available, give the year of } \\
\text { eruption. }\end{array}$ \\
\hline ip_tec_start_unc & $\begin{array}{l}\text { Start time of inferred process } \\
\text { uncertainty }\end{array}$ & $\begin{array}{l}\text { The uncertainty in the date and time at } \\
\text { which this inferred process started. In UTC } \\
\text { as DATETIME (YYYY-MM-DD } \\
\text { hh:mm:ss). If no specific times or dates are } \\
\text { available, give the year of eruption. }\end{array}$ \\
\hline ip_tec_end & $\begin{array}{l}\text { Ending time of inferred } \\
\text { process }\end{array}$ & $\begin{array}{l}\text { The date and time at which (or by which) } \\
\text { this inferred process stopped. In UTC as } \\
\text { DATETIME (YYYY-MM-DD hh:mm:ss) }\end{array}$ \\
\hline ip_tec_end_unc & $\begin{array}{l}\text { End time of inferred process } \\
\text { uncertainty }\end{array}$ & $\begin{array}{l}\text { The uncertainty in the date and time at } \\
\text { which this inferred process ended. In UTC } \\
\text { as DATETIME (YYYY-MM-DD } \\
\text { hh:mm:ss). If no specific times or dates are } \\
\text { available, give the year of eruption. }\end{array}$ \\
\hline ip_tec_change & Tectonic Changes & $\begin{array}{l}\text { Tectonically induced changes in } \\
\text { magma/hydrothermal system (any } \\
\text { mechanism). Use Y for yes, N for No, M } \\
\text { for maybe, and U for unknown or no } \\
\text { information. }\end{array}$ \\
\hline
\end{tabular}




\begin{tabular}{|l|l|l|}
\hline & & $\begin{array}{l}\text { Changes induced by changes in static stress } \\
\text { after large regional earthquakes (incl. } \\
\text { Viscoelastic processes). Use Y for yes, N } \\
\text { for No, M for maybe, and U for unknown or } \\
\text { no information. }\end{array}$ \\
\hline ip_tec_sstress & Static Stress & $\begin{array}{l}\text { Changes induced by dynamic strain, } \\
\text { associated with passage of earthquake } \\
\text { waves from distal sources. Use Y for yes, N } \\
\text { for No, M for maybe, and U for unknown or } \\
\text { no information. }\end{array}$ \\
\hline ip_tec_dstrain & Dynamic Strain & $\begin{array}{l}\text { Changes induced by local fault shear or } \\
\text { other deformation of the cone. Use Y for } \\
\text { yes, N for No, M for maybe, and U for }\end{array}$ \\
inknown or no information.
\end{tabular}




\begin{tabular}{|l|l|l|}
\hline & information. \\
\hline ip_tec_com & Comments & $\begin{array}{l}\text { Comments on interaction between the } \\
\text { magma/hydrothermal system and regional } \\
\text { tectonics }\end{array}$ \\
\hline cc_id & Interpreter ID & $\begin{array}{l}\text { An identifier for linking to contact } \\
\text { information for the person who interpreted } \\
\text { this process. }\end{array}$ \\
\hline ip_tec_loaddate & Load date & The date this row was entered in UTC. \\
\hline ip_tec_pubdate & Publish date & $\begin{array}{l}\text { The date this row can become public. This } \\
\text { date can be set up to two years in advance. }\end{array}$ \\
\hline cc_ip_load & Data loader ID & $\begin{array}{l}\text { An identifier for linking to contact } \\
\text { information for the person who entered this } \\
\text { row of data. }\end{array}$ \\
\hline
\end{tabular}

The Regional Tectonics Interactions table stores information about processes related to regional tectonic events. The primary ID is ip_tec_id, the link to the Volcano table is vd_id, and the link to the person making the inference is cc_id. The date the information was entered is stored in ip_tec_loaddate, the date the information can become public is stored in ip_tec_pubdate, and a link to information about the person who loaded the data is stored in cc_ip_load. The time the inference was made is stored in ip_tec_time in UTC as DATETIME and the uncertainty for the time is stored in ip_tec_time_unc. The times at which the inferred process began and ended are stored in ip_tec_start and ip_tec_end. The uncertainties in the times the process began and ended are stored in ip_tec_start_unc and ip_tec_end_unc.

The inferred processes in the Regional Tectonics Interactions table include a basic field for tectonically induced changes, ip_tec_change. There are also seven inferred processes to record changes induced by changes in static stress, ip_tec_sstress, dynamic strain, ip_tec_dstrain, local fault shear or other deformation of the cone, ip_tec_fault, slow earthquakes, ip_tec_seq, pressurization of magma or hydrothermal reservoir, ip_tec_press, depressurization of the magma or hydrothermal reservoir, ip_tec_depress, and increased hydrothermal pore pressures, ip_tec_hppress. The final three inferred processes are magmatically or hydrothermally induced release of tectonic strain, ip_tec_tstrain, earthtide interactions, ip_tec_etide, and interactions with changes in atmospheric pressure, rainfall, or wind, ip_tec_atmp. The regional tectonics interactions inferred process fields should store a single character, $\mathrm{Y}$ for yes, $\mathrm{N}$ for No, $\mathrm{M}$ for maybe, and $\mathrm{U}$ for unknown or no information. The comments field, ip_tec_com, is included for additional information.

\section{Create table statements for the inferred tables}

DROP TABLE IF EXISTS ip_mag;

create table ip_mag (

ip_mag_id mediumint not null auto_increment,

vd_id mediumint,

ip_mag_time datetime,

ip_mag_time_unc datetime,

ip_mag_start datetime, 
ip_mag_start_unc datetime, ip_mag_end datetime,

ip_mag_end_unc datetime

ip_mag_deepsupp char(1),

ip_mag_asc char(1),

ip_mag_convb char(1),

ip_mag_conva char(1),

ip_mag_mix char(1),

ip_mag_dike char(1),

ip_mag_pipe char(1),

ip_mag_sill char(1),

ip_mag_com varchar(255),

cc_id mediumint,

ip_mag_loaddate datetime,

ip_mag_pubdate datetime,

cc_ip_load mediumint,

primary key (ip_mag_id));

DROP TABLE IF EXISTS ip_sat;

create table ip_sat (

ip_sat_id mediumint not null auto_increment,

vd_id mediumint,

ip_sat_time datetime,

ip_sat_time_unc datetime,

ip_sat_start datetime,

ip_sat_start_unc datetime,

ip_sat_end datetime,

ip_sat_end_unc datetime,

ip_sat_co2 char(1),

ip_sat_h2o char(1),

ip_sat_decomp char(1),

ip_sat_dfo2 char(1),

ip_sat_add char(1),

ip_sat_xtl char(1),

ip_sat_ves char(1),

ip_sat_deves char(1),

ip_sat_degas char(1),

ip_sat_com varchar(255),

cc_id mediumint,

ip_sat_loaddate datetime,

ip_sat_pubdate datetime,

cc_ip_load mediumint,

primary key (ip_sat_id));

\section{DROP TABLE IF EXISTS ip_pres;}

create table ip_pres (

ip_pres_id mediumint not null auto_increment, vd_id mediumint,

ip_pres_time datetime,

ip_pres_time_unc datetime,

ip_pres_start datetime,

ip_pres_start_unc datetime,

ip_pres_end datetime,

ip_pres_end_unc datetime,

ip_pres_gas char(1),

ip_pres_tec char(1), 
ip_pres_com varchar(255),

cc_id mediumint,

ip_pres_loaddate datetime,

ip_pres_pubdate datetime,

cc_ip_load mediumint,

primary key (ip_pres_id));

DROP TABLE IF EXISTS ip_hyd;

create table ip_hyd (

ip_hyd_id mediumint not null auto_increment, vd_id mediumint,

ip_hyd_time datetime,

ip_hyd_time_unc datetime,

ip_hyd_start datetime,

ip_hyd_start_unc datetime,

ip_hyd_end datetime,

ip_hyd_end_unc datetime,

ip_hyd_gwater char(1),

ip_hyd_ipor char(1),

ip_hyd_edef char(1),

ip_hyd_hfrac char(1),

ip_hyd_btrem char(1),

ip_hyd_abgas char(1),

ip_hyd_species char(1),

ip_hyd_chim char(1),

ip_hyd_com varchar(255),

cc_id mediumint,

ip_hyd_loaddate datetime,

ip_hyd_pubdate datetime,

cc_ip_load mediumint,

primary key (ip_hyd_id));

DROP TABLE IF EXISTS ip_tec;

create table ip_tec (

ip_tec_id mediumint not null auto_increment, vd_id mediumint,

ip_tec_time datetime,

ip_tec_time_unc datetime,

ip_tec_start datetime,

ip_tec_start_unc datetime,

ip_tec_end datetime,

ip_tec_end_unc datetime,

ip_tec_change char(1),

ip_tec_sstress char(1),

ip_tec_dstrain char(1),

ip_tec_fault char(1),

ip_tec_seq char(1),

ip_tec_press char(1),

ip_tec_depress char(1),

ip_tec_hppress char(1),

ip_tec_etide char(1),

ip_tec_atmp char(1),

ip_tec_com char(255),

cc_id mediumint,

ip_tec_loaddate datetime,

ip_tec_pubdate datetime, 
cc_ip_load mediumint, primary key (ip_tec_id));

\section{Common or Shared}

The common or shared tables store data from within the Volcano $>$ Network $>$ Station $>$ Instrument hierarchy that are used by almost all of the monitoring data tables. The common tables include:

- The Bibliographic table, which stores reference information.

- The Contact table, which stores contact information.

- The Registry table, which stores usernames and passwords for users requiring both read and write privileges.

- The Permissions table, which stores the permissions for each user level.

- The Images table, which stores images associated with WOVOdat data.

- The Images Junction table for storing links between the Images table and other tables.

- The Common Network table, which stores network information from non-seismic or geodetic networks.

- The Satellite table, which stores satellite or airplane information.

- A Volcano-Network Junction table for storing links between the Volcano and Network tables for instances where the relationship is many-to-many instead of one-to-many.

- A Maps table for storing information about maps that that cover areas where WOVOdat data is collected.

- A Changes table for storing information about any changes made to WOVOdat.

- An Observations table for storing observations about volcanic activity.

Bibliographic Table

Table C1. Bibliographic Table

\begin{tabular}{|l|l|l|}
\hline cb_id & Reference ID & An identifier for linking with other tables \\
\hline cb_auth & Authors/Editors & $\begin{array}{l}\text { The authors or editors of the paper or } \\
\text { article. }\end{array}$ \\
\hline cb_year & Publication yr & The publication year stored as YEAR. \\
\hline cb_title & Title & The title of the paper or book. \\
\hline cb_journ & Journal & The name of the journal. \\
\hline cb_vol & Volume & The journal volume. \\
\hline cb_pub & Publisher & The name of the publisher (book only). \\
\hline cb_page & Pages & The page numbers. \\
\hline & & \\
cb_doi & Digital object identifier & The digital object identifier. \\
\hline & $\begin{array}{l}\text { International standard book } \\
\text { number }\end{array}$ & \\
\hline cb_isbn & The international standard book number. \\
\hline
\end{tabular}




\begin{tabular}{|l|l|l|}
\hline & Leb info & $\begin{array}{l}\text { Information about where to find the article } \\
\text { if it was published on the web including the } \\
\text { URL. This field can also store an address } \\
\text { for a web site that contains additional } \\
\text { information about data in WOVOdat or } \\
\text { interpretations of data in WOVOdat. }\end{array}$ \\
\hline cb_keywords & Keywords & $\begin{array}{l}\text { A list of keywords separated by commas to } \\
\text { describe the article. The keywords should } \\
\text { include the name of the volcano, the type of } \\
\text { monitoring data discussed, and an eruption } \\
\text { if applicable. }\end{array}$ \\
\hline cb_loaddate & Load date & $\begin{array}{l}\text { The date this bibliographic reference was } \\
\text { entered in UTC. }\end{array}$ \\
\hline cb_pubdate & Publish date & $\begin{array}{l}\text { The date this row can become public. This } \\
\text { date can be set up to two years in advance. }\end{array}$ \\
\hline cc_id_load & Data loader ID & $\begin{array}{l}\text { An identifier for linking to contact } \\
\text { information for the person who entered the } \\
\text { bibliographic data. }\end{array}$ \\
\hline
\end{tabular}

The Bibliographic table store information about articles, papers, books, and web sites, hereafter referred to as articles, with information that is related to the data in WOVOdat. Originally, the information in the Bibliographic table was going to be linked directly to the data tables using multiple junction tables. We instead decided to include keywords for linking bibliographic information to the data and to create junction tables for the inferred processes only. Junction tables for the rest of the data can be easily created in the future, if necessary. The primary ID for the Bibliographic table is cb_id. The date the data was loaded into the table is stored in cb_loaddate in UTC and the date the information can become public is stored in cb_pubdate. The link to the contact information for the data loader is stored in cc_id_load.

The general bibliographic information in this table includes text fields for the authors or editors, cb_auth, the title, cb_title, the journal name, cb_journ, the journal volumn, cb_vol, the publisher for books only, cb_pub, and the page numbers, cb_page. The publication year, cb_year, is stored as YEAR. If known, the digital object identifier and the international standard book number should be entered in cb_doi and cb_isbn. If the article was published on the web or if the reference is to a website then the web address or URL should be stored in cb_url. The keywords that will be used for finding the article should be stored in cb_keywords and separated by commas. The keywords should include the name of the volcano, the type of monitoring data discussed, and an eruption if applicable.

\section{Contact Table}

Table C2. Contact Table

\begin{tabular}{|l|l|l|}
\hline cc_id & $\begin{array}{l}\text { Contact, Collector, or } \\
\text { Dataloader ID }\end{array}$ & An identifier for linking with other tables. \\
\hline cc_fname & First name & $\begin{array}{l}\text { The first name of the person who can be } \\
\text { contacted using the information in this row } \\
\text { of the Contact table. }\end{array}$ \\
\hline
\end{tabular}




\begin{tabular}{|l|l|l|}
\hline cc_lname & Last name & $\begin{array}{l}\text { The last name of the person who can be } \\
\text { contacted using the information in this row } \\
\text { of the Contact table. }\end{array}$ \\
\hline cc_obs & $\begin{array}{l}\text { The name of the observatory, university, or } \\
\text { company with which the contact person is } \\
\text { associated. If the first and last name fields } \\
\text { are null then this row of data contains only } \\
\text { the contact information for the institution. }\end{array}$ \\
\hline cc_add1 & Observatory & The first line of the contact address. \\
\hline cc_add2 & Address1 & The second line of the contact address. \\
\hline cc_city & Address2 & The city of the contact address. \\
\hline cc_state & State, province, or prefecture & $\begin{array}{l}\text { The state, province, or prefecture of the } \\
\text { contact address. }\end{array}$ \\
\hline cc_country & Country & The country of the contact address. \\
\hline cc_post & Postal code & The postal code of the contact address. \\
\hline cc_url & Web address & $\begin{array}{l}\text { The web address for the person or } \\
\text { institution, if applicable. }\end{array}$ \\
\hline cc_email & email & $\begin{array}{l}\text { The email address of the contact person or } \\
\text { institution. }\end{array}$ \\
\hline cc_phone & Phone & $\begin{array}{l}\text { The primary phone number for contacting } \\
\text { the person or institution. }\end{array}$ \\
\hline cc_phone2 & Phone 2 & $\begin{array}{l}\text { The secondary phone number for contacting } \\
\text { the person or institution. }\end{array}$ \\
\hline cc_fax & Fax & $\begin{array}{l}\text { The fax number for contacting the person or } \\
\text { institution. }\end{array}$ \\
\hline cc_com & Comments & $\begin{array}{l}\text { A text field for comments about contacting } \\
\text { the person or institution. }\end{array}$ \\
\hline cc_loaddate & Data loader ID & The date this row was entered in UTC. \\
\hline cc_pubdate & $\begin{array}{l}\text { The date this row can become public. This } \\
\text { date can be set up to two years in advance. }\end{array}$ \\
\hline & $\begin{array}{l}\text { An identifier for linking to contact } \\
\text { information for the person who entered this } \\
\text { row of data in case the data was not entered } \\
\text { by the person being described. }\end{array}$ \\
\hline
\end{tabular}

The Contact table provides all of the contact information for a person, observatory, or institution. The primary ID is cc_id and is included in most of the WOVOdat tables as a contact ID, collector ID, or data loader ID. The date the data was loaded into the table is stored in cc_loaddate in UTC and the date the information can become public is stored in cc_pubdate. The link to contact information for the data loader is stored in cc_id_load.

If the contact is for a person then the first name is stored in cc_fname and the last name is stored in cc_lname. The observatory or institution is stored in cc_obs. If the first and last name fields are null 
then data associated with this cc_id contains the contact information for the institution only. The address is stored in separate text fields and includes the first line of the contact address, cc_add1, the second line of the address, cc_add2, the city, cc_city, state, cc_state, country, cc_country, and postal code, cc_post. A web address, if applicable, is stored in cc_url and a contact email address is stored in cc_email. The phone and fax numbers are also stored in text fields and include a primary phone number, cc_phone, a secondary phone number, cc_phone2, and a fax number, cc_fax. A comments field is also included to record any additional information about the contact including the best method of contact.

Registry

Table C3. Registry Table

\begin{tabular}{|c|c|c|}
\hline cr_id & Registry ID & An identifier for linking with other tables \\
\hline cc_id & Contact ID & $\begin{array}{l}\text { An identifier for linking with the Contact } \\
\text { table. The Contact table contains the name, } \\
\text { address, phone, and email address for the } \\
\text { person or observatory. }\end{array}$ \\
\hline cr_uame & Username & A username for logging into the system. \\
\hline cr_pwd & Password & $\begin{array}{l}\text { A password for logging into the system with } \\
\text { read and write privileges. }\end{array}$ \\
\hline cr_type & User type & $\begin{array}{l}\text { The type of user for the system and need for } \\
\text { writing privileges. For example, } \\
\text { Deformation data loader for LVO. This } \\
\text { information is used to determine which } \\
\text { tables should be read/write accessible. }\end{array}$ \\
\hline cr_regdate & Register date & $\begin{array}{l}\text { The date the information was originally } \\
\text { entered. }\end{array}$ \\
\hline cr_update & Update & $\begin{array}{l}\text { The most recent date the information in this } \\
\text { table was updated. }\end{array}$ \\
\hline cr_com & Comments & $\begin{array}{l}\text { A text field for comments about the user } \\
\text { being granted additional privileges. }\end{array}$ \\
\hline
\end{tabular}

The Registry table (cr for common registry) provides username and password information for people who need both read and write privileges to WOVOdat. The primary ID is cr_id and the foreign key is the contact ID, cc_id, for linking with contact information for the user. The user's database privileges are stored in the Privileges table that is linked to the Registry table using the registry ID. The date the data was originally entered into the Registry table is stored in cr_regdate in UTC and the most recent update time is stored in cr_update. Superusers, those with write access to data for more than one observatory, should be requested to change their passwords periodically.

The username is stored in cr_uname and the password is encrypted in cr_pwd. The user type, cr_type, provides information about the responsibility of the user, for example, loading deformation data for LVO. There is also a comments field, cr_com, for any additional information about the user. 


\section{Permissions}

Table C4. Permissions Table

\begin{tabular}{|l|l|l|}
\hline cp_id & Permissions ID & An identifier for linking with other tables \\
\hline cr_id & Registry ID & $\begin{array}{l}\text { An identifier for linking with the Registry } \\
\text { table. The Registry table contains the user's } \\
\text { username and password. }\end{array}$ \\
\hline cp_access & The access level & The name of the privilege level for the user. \\
cp_description & Access description & $\begin{array}{l}\text { A description of the access level. For } \\
\text { example, editor with read, write, execute } \\
\text { access. }\end{array}$ \\
\hline cp_tables & Tables & $\begin{array}{l}\text { The table name or prefix for the set of tables } \\
\text { the access applies to. }\end{array}$ \\
\hline cp_com & Comments & $\begin{array}{l}\text { A text field for comments about the access } \\
\text { level. }\end{array}$ \\
\hline cc_id_load & Data loader ID & $\begin{array}{l}\text { An identifier for linking to contact } \\
\text { information for the person who entered this } \\
\text { row of data. }\end{array}$ \\
\hline
\end{tabular}

The Permissions table (cp for common permissions) provides the access information for each user. The primary ID is cp_id and the foreign key is the registry ID, cr_id, and data loader, cc_id_load. The name of the access level is stored in, cp_access, and a description of the access level is stored in cp_description. The access levels would include administrators, editors, data entry/correction, data entry, participating/contributing scientists and administrators, scientist power users, educators, and the public. The tables for which the access applies would be stored in cp_tables either as a table or prefix for a set of tables. The comments field, cp_com, provides space for additional information about the privilege.

Images

Table C5. Images Table

\begin{tabular}{|l|l|l|}
\hline cm_id & Images ID & An identifier for linking with other tables \\
\hline vd_id & Volcano ID & $\begin{array}{l}\text { An identifier for linking with the volcano } \\
\text { table. The Volcano table stores the volcano } \\
\text { name and time zone. It is used to connect to } \\
\text { all other data. }\end{array}$ \\
\hline cm_lat & Latitude & $\begin{array}{l}\text { The latitude of the image location in } \\
\text { decimal degrees (sxx.xxxxxx). }\end{array}$ \\
\hline cm_lon & Longitude & $\begin{array}{l}\text { The longitude of the image location in } \\
\text { decimal degrees (sxxx.xxxxxxx). }\end{array}$ \\
\hline
\end{tabular}




\begin{tabular}{|l|l|l|}
\hline cm_datum & Datum & $\begin{array}{l}\text { The datum used for the longitude and } \\
\text { latitude. WGS } 84 \text { is the official WOVOdat } \\
\text { datum and locations should be converted } \\
\text { wherever possible. }\end{array}$ \\
\hline cm_location & Location of image & $\begin{array}{l}\text { The location where the image was taken } \\
\text { including the direction the image was taken, } \\
\text { if known. }\end{array}$ \\
\hline cm_description & Image description & $\begin{array}{l}\text { A description of the image including the } \\
\text { scale. }\end{array}$ \\
\hline cm_format & Image format & The image format. \\
\hline cm_date & Image date & The date the image was taken. \\
\hline cm_date_unc & Image date uncertainty & $\begin{array}{l}\text { The uncertainty of date the image was } \\
\text { taken. }\end{array}$ \\
\hline cm_image & Image & The image. \\
\hline cm_keywords & Keywords & $\begin{array}{l}\text { Keywords to describe the image that will be } \\
\text { used for searches. }\end{array}$ \\
\hline cm_usage & Image usage & $\begin{array}{l}\text { Comments about use of the image include } \\
\text { copyright information. }\end{array}$ \\
\hline cm_loaddate & Load date & The date this row was entered in UTC. \\
\hline cm_pubdate & Publish date & $\begin{array}{l}\text { The date this row can become public. This } \\
\text { date can be set up to two years in advance. }\end{array}$ \\
\hline & & $\begin{array}{l}\text { An identifier for linking to contact } \\
\text { information for the data collector. To be } \\
\text { entered only if data are not continuous. }\end{array}$ \\
\hline cc_id & Collector ID & $\begin{array}{l}\text { An identifier for linking to contact } \\
\text { information for the person who entered this } \\
\text { row of data. }\end{array}$ \\
\hline & &
\end{tabular}

The Images table ( $\mathrm{cm}$ for common images) stores images that support other WOVOdat data. The primary ID is cm_id and the volcano ID, vd_id, is included for connecting to the volcano at which the image was taken, if applicable. Other methods for connecting the image to other WOVOdat data include the keywords field, cm_keywords and the Images Junction table. The collector ID, cc_id, links to contact information for the person who took or owns the image and the data loader ID, cn_id_load links to contact information for the person who loaded the data. The date the image information was loaded into the table is stored in $\mathrm{cm} \_$loaddate in UTC and the date the information can become public is stored in $\mathrm{cm} \_$pubdate.

The location information for the image includes the latitude, $\mathrm{cm} \_$lat, longitude, $\mathrm{cm} \_$lon, datum, cm_datum, and a description of the location, cm_location. All data should be converted to WGS 84 prior to entering WOVOdat. If conversion is not possible during data loading, the original datum must be entered into the datum field, cm_datum. A description of the image is stored in, cm_description, the image format is stored in $\mathrm{cm} \_$format, the date the image was taken is stored in $\mathrm{cm} \_$date, the uncertainty in the image date is stored in $\mathrm{cm} \_$date_unc, and the image is stored in, $\mathrm{cm} \_$image. The image usage field, $\mathrm{cm}$ _usage, should store information about use of the image including copyright information. Keywords, used for searching, should be entered into the field cm_keywords. A standard set of keywords should be created to help with searches. 
Images Junction

Table C6. Images Junction Table

\begin{tabular}{|c|c|c|}
\hline jj_imgx_id & Image Junction ID & An identifier for linking with other tables. \\
\hline $\mathrm{cm} \_\mathrm{id}$ & Image ID & $\begin{array}{l}\text { The identifier for linking to the Image table. } \\
\text { The Image table stores a description of the } \\
\text { image, the location, and the image. }\end{array}$ \\
\hline jj_idname & Name of linking table ID & The name of the other table ID of interest. \\
\hline jj_x_id & Linking table ID & $\begin{array}{l}\text { The identifier for linking to another table of } \\
\text { interest. }\end{array}$ \\
\hline ji_imgx_loaddate & Load date & The date this row was entered in UTC. \\
\hline cc_id_load & Data loader ID & $\begin{array}{l}\text { An identifier for linking to contact } \\
\text { information for the person who entered this } \\
\text { row of data. }\end{array}$ \\
\hline
\end{tabular}

The Images Junction table was created to link images to other known data. The Images Junction table contains a primary ID, jj_img_id, the image ID, cm_id, and the linking table ID name, jj_idname, and ID, jj_x_id. If images are taken during data collection then the Images Junction table should be used to link the images to the data. For example, if an image is taken of an area where gas emissions are being sampled then the ID name for the Directly Sampled Gas table, gd_id, would be stored in ji_idname, and the ID for the data collected would be stored in jj_x_id. Alternatively, the image could be linked to the appropriate station table. The image taken during gas sampling would then link to the Gas Station table, gs_ID, such that gs_ID would be entered into jj_idname and the ID number for the station where the picture was taken would be entered into $\mathrm{jj} \_\mathrm{x} \_\mathrm{id}$. The date the picture was taken would be found through the images table. If there are types of data that consistently include images then the image ID should be included in the data table. The load date is stored in UTC in jj_volnet_loaddate and the data loader ID is stored in cc_id_load.

Common Network

Table C7. Common Network Table

\begin{tabular}{|l|l|l|}
\hline cn_id & Network ID & An identifier for linking with other tables \\
\hline vd_id & Volcano ID & $\begin{array}{l}\text { An identifier for linking with the volcano } \\
\text { table. The Volcano table stores the volcano } \\
\text { name and time zone. It is used to connect to } \\
\text { all other data. }\end{array}$ \\
\hline cn_name & Name & The name of the network. \\
\hline cn_type & $\begin{array}{l}\text { The network type, for example seismic, } \\
\text { gravity, or GPS. These types should come } \\
\text { from a standard WOVOdat list and match } \\
\text { the station types. }\end{array}$ \\
\hline
\end{tabular}




\begin{tabular}{|c|c|c|}
\hline cn_area & Area & $\begin{array}{l}\text { The volcano and approximate area in } \mathrm{km}^{3} \\
\text { covered by the network. }\end{array}$ \\
\hline cn_map & Map & A map of the network from the observatory. \\
\hline cn_stime & Start date & $\begin{array}{l}\text { The date (UTC) the network was set up and } \\
\text { activated. The date is stored in DATETIME } \\
\text { (YYYY-MM-DD hh:mm:ss). }\end{array}$ \\
\hline cn_stime_unc & Start date uncertainty & $\begin{array}{l}\text { The uncertainty in the date (UTC) the } \\
\text { network was set up and activated. The date } \\
\text { is stored in DATETIME (YYYY-MM-DD } \\
\text { hh:mm:ss). }\end{array}$ \\
\hline cn_etime & Stop date & $\begin{array}{l}\text { The date (UTC) the network was } \\
\text { permanently decommissioned or the time } \\
\text { this set of information became invalid. The } \\
\text { date is stored in DATETIME (YYYY-MM- } \\
\text { DD hh:mm:ss). See observatory for network } \\
\text { and station operation history. }\end{array}$ \\
\hline cn_etime_unc & End date uncertainty & $\begin{array}{l}\text { The uncertainty in the date (UTC) the } \\
\text { network was decommissioned or the time } \\
\text { this set of information became invalid. The } \\
\text { date is stored in DATETIME (YYYY-MM- } \\
\text { DD hh:mm:ss). }\end{array}$ \\
\hline cn_desc & Description & $\begin{array}{l}\text { A description of the network including } \\
\text { permanent stations and types of instruments. }\end{array}$ \\
\hline cn_com & Comments & $\begin{array}{l}\text { Comments about the network including } \\
\text { minor updates to the network over time and } \\
\text { future plans. }\end{array}$ \\
\hline cc_id & Contact ID & $\begin{array}{l}\text { An identifier for linking to contact } \\
\text { information for the person responsible for } \\
\text { the station. }\end{array}$ \\
\hline cn_loaddate & Load date & The date this row was entered in UTC. \\
\hline cn_pubdate & Publish date & $\begin{array}{l}\text { The date this row can become public. This } \\
\text { date can be set up to two years in advance. }\end{array}$ \\
\hline cn_id_load & Data loader ID & $\begin{array}{l}\text { An identifier for linking to contact } \\
\text { information for the person who entered this } \\
\text { row of data. }\end{array}$ \\
\hline
\end{tabular}

The Common Network table contains information about the network of stations that collect data at a particular site, in general at one volcano. The primary ID is cn_id and a link to the volcano ID, vd_id, is included. If the network covers more than one volcano then the Volcano-Network Junction table is needed to connect the network to the multiple volcanoes. A contact ID, cc_id, links to contact information about the person or observatory responsible for the network and the data loader ID, cn_id_load links to the Contact table for more information about the person who loaded the data into WOVOdat. The load date cn_loaddate is a TIMESTAMP and entered automatically in UTC, the date the data becomes public is stored in cn_pubdate. 
The name of the network is stored in cn_name and the type of network is stored in cn_type. The area the network covers in cubic kilometers should be store in cn_area and an image of the network including the station locations should be included in cn_map. The Network table also includes start and end dates, cn_stime and cn_etime, and start and end time uncertainties, cn_stime_unc and cn_etime_unc, in DATETIME UTC. These dates provide information on when the network information in the table is valid. Modifications to the network such as the addition of a new instrument or station, or if a network has been deactivated, should be recorded in the comments field, cn_com (see below). A description of the network including permanent stations and types of instruments should be included in cn_desc and additional comments about the network should be stored in cn_com.

\section{Satellite Table}

Table C8. Satellite Table

\begin{tabular}{|c|c|c|}
\hline cs_id & Satellite ID & An identifier for linking with other tables \\
\hline cs_type & Satellite or airplane flag & $\begin{array}{l}\text { A flag for indicating if the information is } \\
\text { about a satellite }(\mathrm{S}) \text { or airplane }(\mathrm{A}) \text {. }\end{array}$ \\
\hline cs_name & Name & The name of the satellite or airplane. \\
\hline cs_desc & Description & $\begin{array}{l}\text { A description of the satellite or airplane } \\
\text { including where to find additional } \\
\text { information. For satellites, include } \\
\text { information about orbit (geostationary, } \\
\text { polar-orbiting, etc), the standard repeat time } \\
\text { for images taken from directly overhead, } \\
\text { and the package of onboard instruments that } \\
\text { are pertinent to volcano observations (e.g., } \\
\text { TOMS, ASTER, MODIS, etc) and anything } \\
\text { that makes the vehicle special or more } \\
\text { useful for collecting data. }\end{array}$ \\
\hline cs_stime & Start date & $\begin{array}{l}\text { The date (UTC) the satellite or airplane was } \\
\text { first used. The date is stored in DATETIME } \\
\text { (YYYY-MM-DD hh:mm:ss). }\end{array}$ \\
\hline cs_stime_unc & Start date uncertainty & $\begin{array}{l}\text { The uncertainty in the date (UTC) the date } \\
\text { satellite or airplane was first used. The date } \\
\text { is stored in DATETIME (YYYY-MM-DD } \\
\text { hh:mm:ss). }\end{array}$ \\
\hline cs_etime & Stop date & $\begin{array}{l}\text { The date (UTC) the satellite or airplane was } \\
\text { was permanently decommissioned or the } \\
\text { time this set of information became invalid. } \\
\text { The date is stored in DATETIME (YYYY- } \\
\text { MM-DD hh:mm:ss). See observatory for } \\
\text { network and station operation history. }\end{array}$ \\
\hline cs_etime_unc & End date uncertainty & $\begin{array}{l}\text { The uncertainty in the date (UTC) the } \\
\text { satellite or airplane was first used was } \\
\text { decommissioned or the time this set of }\end{array}$ \\
\hline
\end{tabular}




\begin{tabular}{|c|c|c|}
\hline & & $\begin{array}{l}\text { information became invalid. The date is } \\
\text { stored in DATETIME (YYYY-MM-DD } \\
\text { hh:mm:ss). }\end{array}$ \\
\hline cs_com & Comments & $\begin{array}{l}\text { Comments about the satellite or airplane } \\
\text { including where to find more information. }\end{array}$ \\
\hline cs_loaddate & Load date & The date this row was entered in UTC. \\
\hline cs_pubdate & Publish date & $\begin{array}{l}\text { The date this row can become public. This } \\
\text { date can be set up to two years in advance. }\end{array}$ \\
\hline cc_id_load & Data loader ID & $\begin{array}{l}\text { An identifier for linking to contact } \\
\text { information for the person who entered this } \\
\text { row of data. }\end{array}$ \\
\hline
\end{tabular}

The Satellite table stores information about satellites and airplanes that are used for collecting data from above the surface of the earth. The primary ID is cs_id. The type of aircraft, S for satellite or A for airplane, should be stored in the type flag and the name of the satellite or airplane should be stored in cs_name. The Satellite table also includes start and end dates, cn_stime and cn_etime, and start and end time uncertainties, cn_stime_unc and cn_etime_unc, in DATETIME UTC. These dates provide information on when the satellite information in the table is valid. The description field, cs_desc, should contain a description of the satellite or airplane including where to find additional information. The comments field, cs_com, should contain comments about the satellite or airplane including anything that makes the vehicle special or more useful for collecting data. The data loader ID, cn_id_load, links to the contact table and provides information about the person who loaded the data into WOVOdat. The load date, cn_loaddate, is a TIMESTAMP and entered automatically in UTC, the date the data become public is stored in cn_pubdate.

\section{Volcano-Network Junction}

Table C9. Volcano-Network Junction Table

\begin{tabular}{|l|l|l|}
\hline jj_volnet_id & Volcano-Network ID & An identifier for linking with other tables. \\
\hline vd_id & Volcano ID & $\begin{array}{l}\text { The identifier for linking to the Volcano } \\
\text { table. The Volcano table stores the volcano } \\
\text { name and time zone. It is used to connect to } \\
\text { all other data. }\end{array}$ \\
\hline cn_id & $\begin{array}{l}\text { An identifier for linking with information } \\
\text { about the network in the Common Network } \\
\text { table. The Common Network table gives a } \\
\text { description of the network and a link to the } \\
\text { volcano. }\end{array}$ \\
\hline Sn_net_id & Network ID & $\begin{array}{l}\text { An identifier for linking with the Seismic } \\
\text { Network table. The Seismic Network table } \\
\text { provides information on the velocity model } \\
\text { used and a link to the volcano information. }\end{array}$ \\
\hline
\end{tabular}




\begin{tabular}{|l|l|l|}
\hline jj_volnet_loaddate & Load date & The date this row was entered in UTC. \\
\hline jj_volnet_pubdate & Publish date & $\begin{array}{l}\text { The date this row can become public. This } \\
\text { date can be set up to two years in advance. }\end{array}$ \\
\hline cc_id_load & Data loader ID & $\begin{array}{l}\text { An identifier for linking to contact } \\
\text { information for the person who entered this } \\
\text { row of data. }\end{array}$ \\
\hline
\end{tabular}

The Volcano-Network Junction table was created to handle cases where a network covers more than one volcano, such as the Northern California Seismological Network, which covers multiple volcanoes in Northern California. The Volcano-Network Junction table contains a primary volcanonetwork ID, jj_volnet_id, and three foreign IDs, the volcano ID, vd_id, the common network ID, cn_id, and the seismic network ID, sn_net_id. The load date is stored in UTC in jj_volnet_loaddate and the data loader ID is stored in cc_id_load.

Maps

Table C10. Maps Table

\begin{tabular}{|l|l|l|}
\hline md_id & Map ID & An identifier for linking with other tables. \\
\hline md_name & Map name & $\begin{array}{l}\text { The name of the map including a title, quad } \\
\text { sheet name, or a description of the contents, } \\
\text { e.g., SRTM of Mt. St. Helens. }\end{array}$ \\
\hline md_type & Map type & The type of map (topo, DEM, etc.). \\
\hline md_srtm & SRTM data & $\begin{array}{l}\text { A link to the SRTM ARC file stored on the } \\
\text { WOVOdat server. Additional file types can } \\
\text { be found at } \\
\text { http://srtm.usgs.gov/data/obtainingdata.php }\end{array}$ \\
\hline md_scale & Scale & The scale of the map (1:xxxxxxx). \\
\hline md_contour & Contour interval & $\begin{array}{l}\text { For topographic maps, contour interval (in } \\
\text { m). }\end{array}$ \\
\hline md_date & Date of publication & $\begin{array}{l}\text { The date the map was published in DATE } \\
\text { (YYYY-MM-DD). }\end{array}$ \\
\hline md_date_unc & $\begin{array}{l}\text { Date of publication } \\
\text { uncertainty }\end{array}$ & $\begin{array}{l}\text { The uncertainty in the date the map was } \\
\text { published in DATE (YYYY-MM-DD). }\end{array}$ \\
\hline md_proj & Projection & \begin{tabular}{l} 
The map projection. \\
\hline mp_map_datum
\end{tabular} \\
\hline md_west & Geodetic model & $\begin{array}{l}\text { The horizontal datum, ellipsoid name, semi- } \\
\text { major axis, and denominator of flattening } \\
\text { ratio. }\end{array}$ \\
\hline md_east & West bounding coordinate & $\begin{array}{l}\text { The west bounding coordinate in decimal } \\
\text { degrees. }\end{array}$ \\
\hline md_north & East bounding coordinate & $\begin{array}{l}\text { The east bounding coordinate in decimal } \\
\text { degrees. }\end{array}$ \\
\hline & North bounding coordinate & $\begin{array}{l}\text { The north bounding coordinate in decimal } \\
\text { degrees. }\end{array}$ \\
\hline
\end{tabular}




\begin{tabular}{|c|c|c|}
\hline md_south & South bounding coordinate & $\begin{array}{l}\text { The south bounding coordinate in decimal } \\
\text { degrees. }\end{array}$ \\
\hline md_elev_max & Maximum elevation & $\begin{array}{l}\text { The maximum elevation on the map in } \\
\text { meteres where positive values are above sea } \\
\text { level (sxxxx). }\end{array}$ \\
\hline md_elev_min & Minimum elevation & $\begin{array}{l}\text { The minimum elevation on the map in } \\
\text { meteres where positive values are above sea } \\
\text { level (sxxxx). }\end{array}$ \\
\hline md_use & Intended use & The intended use for the map. \\
\hline md_restrictions & Restrictions & Restrictions on the use of the map. \\
\hline md_quality & Quality & The quality of the map. \\
\hline md_image & Image & $\begin{array}{l}\text { An image of the map or link to an image of } \\
\text { the map. }\end{array}$ \\
\hline md_desc & Description & $\begin{array}{l}\text { A description of the map including an } \\
\text { overview of what the map covers and } \\
\text { indicates. }\end{array}$ \\
\hline cc_id & Contact ID & $\begin{array}{l}\text { An identifier for linking to contact } \\
\text { information. }\end{array}$ \\
\hline mp_loaddate & Load date & The date this row was entered in UTC. \\
\hline mp_pubdate & Publish date & $\begin{array}{l}\text { The date this row can become public. This } \\
\text { date can be set up to two years in advance. }\end{array}$ \\
\hline cc_id_load & Data loader ID & $\begin{array}{l}\text { An identifier for linking to contact } \\
\text { information for the person who entered this } \\
\text { row of data. }\end{array}$ \\
\hline
\end{tabular}

The Maps table stores information about maps that cover areas where WOVOdat data is collected. The primary ID is md_id. A contact ID, cc_id, links to contact information about the person or observatory who is responsible for the map and the data loader ID, cc_id_load links to the Contact table for more information about the person who loaded the data into WOVOdat. The load date mp_loaddate is a TIMESTAMP and entered automatically in UTC. The date the information can become public is stored in mp_pubdate.

The map name including a title, quad sheet name, and a description of the contents, e.g., "SRTM of Mt. St. Helens," is stored in md_name. The map type is stored in md_type. WOVOdat will store SRTM data and basic vector data such as roads, major towns in an ARC file along with its metadata that is linked to the Maps table by md_srtm. SRTM data in other formats can be retrieved from the USGS Seamless Archive (http://srtm.usgs.gov/data/obtainingdata.php). There may also need to be another table to store digital map data. The scale of the map is stored in md_scale as text and the date the map was published is stored in md_date in DATE format, along with an uncertainty for the date, md_date_unc. The projection for the map is stored in md_proj and the horizontal datum is stored in md_datum. All data, including maps, should be converted to WGS 84 prior to being stored in WOVOdat. The original datum must be included if the map has been converted. The locations of the four corners of the map are stored for registering future data and include the west bounding coordinate, md_west, the east bounding coordinate, md_east, the north bounding coordinate, md_north, and the south bounding coordinate, md_south. All of the latitudes and longitudes are stored in decimal degrees. 
The maximum and minimum elevation are stored in md_elev_max and md_elev_min in meters. The intended use of the map should be stored in md_use and any restrictions on the use of the map should be stored in md_restrictions. The quality of the map should be stored in md_quality and guidelines for the quality qualifications will be needed. An image of the map or a link to an image of the map is stored in md_image and a description of the map is stored in md_desc.

\section{Changes}

Table C11. Changes Table

\begin{tabular}{|l|l|l|}
\hline ch_id & Changes ID & An identifier for linking with other tables \\
\hline ch_linkname & Link Name & $\begin{array}{l}\text { The name of the identifier (primary ID) for } \\
\text { the table where the change has been made. }\end{array}$ \\
\hline ch_atname & Link ID & $\begin{array}{l}\text { The ID (number) for the set of data (row) } \\
\text { where the change has been made. }\end{array}$ \\
\hline ch_desc & Attribute name & $\begin{array}{l}\text { The the name of the attribute where a } \\
\text { change has been made. }\end{array}$ \\
\hline ch_loaddate & Description of change & $\begin{array}{l}\text { A description of the change that has been } \\
\text { made. Include why the change was made } \\
\text { and both values. }\end{array}$ \\
\hline & Load date & The date this row was entered in UTC. \\
\hline cc_id_load & & $\begin{array}{l}\text { An identifier for linking to contact } \\
\text { information for the person who entered this } \\
\text { row of data. }\end{array}$ \\
\hline
\end{tabular}

The Changes table (ch for common changes) stores information about any changes that have been made in the database. The primary ID is ch_id. The name of the attribute where a change has been made is stored in, ch_atname, and the name of the ID for the data is stored in ch_linkname along with the actual ID for linking, ch_linkid. The load date ch_loaddate is a TIMESTAMP and entered automatically in UTC. The data loader, cc_id_load, contains the ID of the person making the change. All information about the change should be stored in ch_desc. For example, if a temperature was incorrectly entered into the Ground-based Thermal Data table then the attribute name, ch_atname would be td_temp, the ch_linkname would be td_id, and the actual id for linking to the changed data would be a number, such as 10034 . The description of the change might be, "decimal point entered incorrectly, T is 101.5 not $10.15 . "$

\section{Observations}

Table C12. Observations Table

\begin{tabular}{|c|c|c|}
\hline co_id & Observations ID & An identifier for linking with other tables \\
\hline vd_id & Volcano ID & $\begin{array}{l}\text { An identifier for linking with the Volcano } \\
\text { table. The volcano table stores the volcano } \\
\text { name and time zone. It is used to connect to } \\
\text { all other data. }\end{array}$ \\
\hline co_observe & Observation & A description of the observation. \\
\hline
\end{tabular}




\begin{tabular}{|c|c|c|}
\hline co_stime & Start time of observation & The time the observation was made. \\
\hline co_stime_unc & $\begin{array}{l}\text { Start time of observation } \\
\text { uncertainty }\end{array}$ & $\begin{array}{l}\text { The uncertainty in the time the observation } \\
\text { was made. }\end{array}$ \\
\hline co_etime & End time of observation & The end time the observation was made. \\
\hline co_etime_unc & $\begin{array}{l}\text { End time of observation } \\
\text { uncertainty }\end{array}$ & $\begin{array}{l}\text { The uncertainty in the end time the } \\
\text { observation was made. }\end{array}$ \\
\hline cc_id & Observer ID & $\begin{array}{l}\text { An identifier for linking to contact } \\
\text { information for the person who made this } \\
\text { observation. }\end{array}$ \\
\hline co_loaddate & Load date & The date this row was entered in UTC. \\
\hline co_pubdate & Publish date & $\begin{array}{l}\text { The date this row can become public. This } \\
\text { date can be set up to two years in advance. }\end{array}$ \\
\hline cc_id_load & Data loader ID & $\begin{array}{l}\text { An identifier for linking to contact } \\
\text { information for the person who entered this } \\
\text { row of data. }\end{array}$ \\
\hline
\end{tabular}

The Observations table (co for common observations) provides storage for observations about volcanic activity. The primary ID is co_id and the foreign keys include the volcano ID, vd_id, for linking to other information about the volcano, the observer ID, cc_id, for linking to contact information for the observer, and the data loader ID, for linking to contact information for the person who loaded the data. The load date co_loaddate is a TIMESTAMP and entered automatically in UTC. The date the information can become public is stored in co_pubdate.

The actual observations are stored in co_observe along with a start time the observation was made, co_stime, the end time of the observation, co_etime, and uncertainties for the times, co_stime_unc, and co_etime_unc.

\section{Create table statements for the common tables}

\section{DROP TABLE IF EXISTS cb;}

create table cb (

cb_id mediumint not null auto_increment,

cb_auth varchar(255),

cb_year year,

cb_title varchar(255),

cb_journ varchar(255),

cb_vol varchar(20),

cb_pub varchar(50),

cb_page varchar(30),

cb_doi varchar(20),

cb_isbn varchar(13),

cb_url varchar(255),

cb_keywords varchar(255),

cb_loaddate datetime,

cb_pubdate datetime,

cc_id_load mediumint,

primary key (cb_id)); 


\section{DROP TABLE IF EXISTS cC;}

create table cc (

cc_id mediumint not null auto_increment, cc_fname varchar(30),

cc_lname varchar(30),

cc_obs varchar(100),

cc_add1 varchar(50),

cc_add2 varchar(50),

cc_city varchar(50),

cc_state varchar(30),

cc_country varchar(30),

cc_post varchar(30),

cc_url varchar(255),

cc_email varchar(255),

cc_phone varchar(30),

cc_phone2 varchar(30),

cc_fax varchar(30),

cc_com varchar(255),

cc_loaddate datetime,

cc_pubdate datetime,

cc_id_load mediumint,

primary key (cc_id));

DROP TABLE IF EXISTS cr;

create table cr (

cr_id mediumint not null auto_increment, cc_id mediumint,

cr_uame varchar(30),

cr_pwd varchar(30),

cr_type varchar(255),

cr_regdate datetime,

cr_update datetime,

cr_com varchar(255),

primary key (cr_id));

DROP TABLE IF EXISTS cp;

create table cp (

cp_id mediumint not null auto_increment, cr_id mediumint,

cp_access varchar(60),

cr_description varchar(60),

cr_tables varchar(60),

cr_com varchar(255),

cc_id_load mediumint,

primary key (cp_id));

DROP TABLE IF EXISTS cm;

create table $\mathrm{cm}$ (

cm_id mediumint not null auto_increment, vd_id mediumint,

cm_lat float,

cm_lon float, 
cm_datum varchar(30),

cm_location varchar(255),

cm_description varchar(255),

cm_format varchar(10),

cm_date datetime,

cm_date_unc datetime,

cm_image text,

cm_usage varchar(255),

cm_keywords varchar(255),

cm_loaddate datetime,

cm_pubdate datetime,

cm_id_load mediumint,

primary key (cm_id));

DROP TABLE IF EXISTS jj_imgx;

create table jj_imgx (

jj_imgx_id mediumint not null auto_increment, cm_id mediumint,

jj_idname varchar(20),

jj_x_id mediumint,

jj_imgx_loaddate datetime,

cc_id_load mediumint,

primary key (jj_volnet_id));

DROP TABLE IF EXISTS cn;

create table cn (

cn_id mediumint not null auto_increment,

vd_id mediumint,

cn_name varchar(255),

cn_type varchar(255),

cn_area varchar(255),

cn_map varchar(255),

cn_stime datetime,

cn_stime_unc datetime,

cn_etime datetime,

cn_etime_unc datetime,

cn_desc varchar(255),

cn_com varchar(255),

cc_id mediumint,

cn_loaddate datetime,

cn_pubdate datetime,

cn_id_load mediumint,

primary key (cn_id));

DROP TABLE IF EXISTS cs;

create table cs (

cs_id mediumint not null auto_increment,

cs_type char(1),

cs_name varchar(50),

cs_stime datetime,

cs_stime_unc datetime,

cs_etime datetime,

cs_etime_unc datetime, 
Cs_desc varchar(255),

cs_com varchar(255),

cs_loaddate datetime,

cs_pubdate datetime,

cc_id_load mediumint,

primary key (cs_id));

DROP TABLE IF EXISTS jj_volnet;

create table jj_volnet (

jj_volnet_id mediumint not null auto_increment, vd_id mediumint,

cn_id mediumint,

sn_net_id mediumint,

jj_volnet_loaddate datetime,

cc_id_load mediumint,

primary key (jj_volnet_id));

DROP TABLE IF EXISTS md;

create table md (

md_id mediumint not null auto_increment, md_name varchar(255),

md_type varchar(30),

md_srtm varchar(255),

md_scale varchar(30),

md_contour varchar(30),

md_date date,

md_date_unc date,

md_proj varchar(255),

mp_map_datum varchar(255),

md_west float,

md_east float,

md_north float,

md_south float,

md_elev_max float,

md_elev_min_float,

md_use varchar(255),

md_restrictions varchar(255),

md_quality varchar(255),

md_image text,

md_desc varchar(255),

cc_id mediumint,

mp_loaddate datetime,

mp _pubdate datetime,

cc_id_load mediumint,

primary key (md_id));

DROP TABLE IF EXISTS ch;

create table ch (

ch_id mediumint not null auto_increment,

ch_linkname varchar(30),

ch_linkid mediumint,

ch_atname varchar(30),

ch_desc varchar(255), 


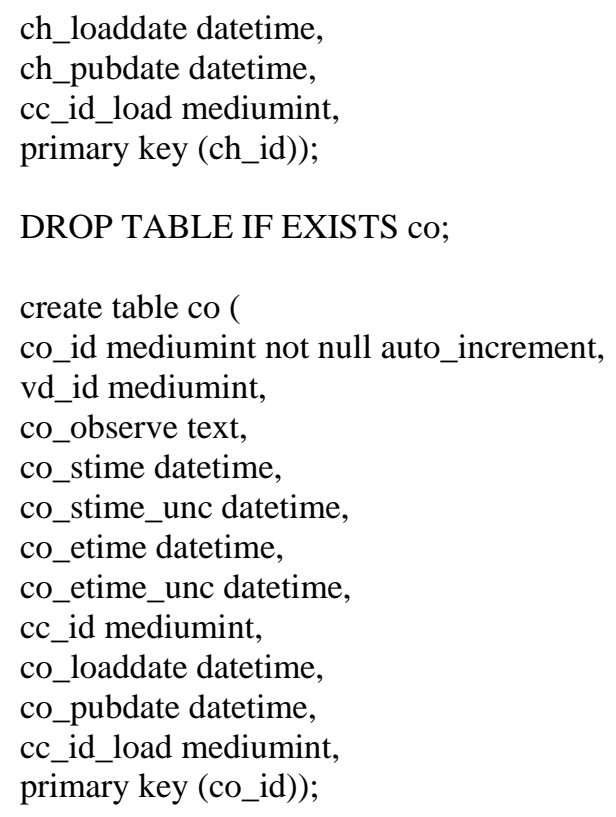

\section{Acknowledgements}

Creating WOVOdat has been a group effort and we would like to thank all of the WOVO observatories for their help and we hope for continued participation in this project. There are a few people who we would like to thank individually for their continued support and input. Florian Schwandner, Steve Malone, Manny Nathenson, Mike Lisowski, Mike Poland, Chuck Wicks, Evelyn Roeloffs, Bill Evans, Chris McGee, Malcolm Johnston, Ed Venzke, Peter Cervelli, Dan Cervelli, Joel Robinson, David Ramsey, Steve McNutt, Dave Hill, Chuck Meertens, Randy White, Maurizio Battaglia, David Oppenheimer, Phil Dawson, Jake Lowenstern, Jeff Wynn, Terry Keith, Bob Tilling, Stephen Hahn, Steve Schilling, Eisuke Fujita, Hideki Ueda, Jacopo Selva, Dan Cervelli, Bruce Weertman, Kelly Stroker, and Kenneth Masarie.

\section{Comments and Conclusions}

WOVOdat is an important project for bringing together data of worldwide volcanic unrest and this first version is a necessary step towards making the database a reality. There were multiple challenges involved with determining which parameters to use and how to organize them into tables that would allow for rapid querying. The main use of WOVOdat will be accessing data. Many decisions were made to make the access easier at the expense of the data loading process. Of course, due to the large number of raw data formats, the data loading process was always going to require scripts for individual observatories. The next challenge is to write the scripts to load the tables. Given more time we would have made some of the data types require specific input (ENUM). In time it will also become more apparent how many characters are required for the VARCHAR fields. We tried to create standards for names, VARCHAR(30), and long text, VARCHAR(255). There will be cases where longer text fields (TEXT) are required. There are also muliple unresolved questions that are mentioned in the documentation. Again, the data loaders will need to make decisions about these. We've enjoyed creating this pilot database and hope this document helps others understand the decisions we made so new and better versions of WOVOdat can be created. 